University of Louisville

ThinkIR: The University of Louisville's Institutional Repository

8-2008

\title{
Predictors of critical thinking as a component of an outcomes assessment in a graduate level school of social work.
}

Tonya Michelle Tucker

University of Louisville

Follow this and additional works at: https://ir.library.louisville.edu/etd

\section{Recommended Citation}

Tucker, Tonya Michelle, "Predictors of critical thinking as a component of an outcomes assessment in a graduate level school of social work." (2008). Electronic Theses and Dissertations. Paper 1466.

https://doi.org/10.18297/etd/1466

This Doctoral Dissertation is brought to you for free and open access by ThinkIR: The University of Louisville's Institutional Repository. It has been accepted for inclusion in Electronic Theses and Dissertations by an authorized administrator of ThinkIR: The University of Louisville's Institutional Repository. This title appears here courtesy of the author, who has retained all other copyrights. For more information, please contact thinkir@louisville.edu. 


\title{
PREDICTORS OF CRITICAL THINKING AS A COMPONENT OF AN OUTCOMES ASSESSMENT IN A GRADUATE LEVEL SCHOOL OF SOCIAL WORK
}

\author{
by \\ Tonya Michelle Tucker \\ BSW, Campbellsville University, 1998 \\ MSSW, University of Louisville, 2004
}

\author{
A Dissertation \\ Submitted to the Faculty of the \\ Graduate School of the University of Louisville \\ in Partial Fulfillment of the Requirements \\ for the degree of
}

Doctor of Philosophy

Kent School of Social Work

University of Louisville

Louisville, Kentucky

August 2008 
Copyright 2008 by Tonya Michelle Tucker

All rights reserved 


\section{PREDICTORS OF CRITICAL THINKING AS A COMPONENT OF AN OUTCOMES ASSESSMENT IN A GRADUATE LEVEL SCHOOL OF SOCIAL WORK}

by

Tonya Michelle Tucker

BSW, Campbellsville University, 1998

MSSW, University of Louisville, 2004

A Dissertation Approved on

July 31, 2008

By the following Dissertation Committee:

Anna C. Faul, Ph.D., Chair

Pam Yankeelov, Ph.D.

Seana Golder, Ph.D.

Ruth Huber, Ph.D.

Karen Badger, Ph.D. 


\section{DEDICATION}

I want to dedicate this dissertation to Jesus Christ, my personal Lord and Savior. This journey has been not only an educational process, but a spiritual journey as well. $\mathrm{He}$ has provided for me at each juncture of this process and has carried me when I thought I could not go any further. I am so humbled at his interest and love in my well being and in the development of my professional career. I stand eager to follow his will for my life. I thank him for all that he has done and continues to do daily as he leads me in this journey.

To my precious loving husband whose unwavering support and devotion during this process just leaves me in awe of his ability to give and love so deeply. I am so thankful for your support throughout this process.

To my mother who courageously made sacrifices to give me life and thus the chance to pursue my dreams. And to all my family and friends who provided words of encouragement, prayers and support throughout this process. 


\section{ACKNOWLEDGEMENTS}

I want to acknowledge my grandfather Reed Wilson, who was the first social worker I ever knew. Although he was only given the opportunity to attend school through the eighth grade, he served our community and those in need tirelessly. It was his selfless generosity and willingness to give of himself that laid the foundation for my interest to help others.

I would also like to acknowledge Darlene Eastridge, Ph.D., my first social work professor, who helped me find my calling in this noble profession and bestowed upon me such a passion for teaching.

I want to acknowledge Annatjie Faul, Ph.D., my committee chair, who has been a phenomenal advisor, professor, colleague and friend throughout my graduate studies. Her devotion to students and the social work profession, as well as her willingness to join students in the learning process sets the standard for social work education. She has inspired me to set high standards for myself as I begin my own career as a social work educator and researcher. Ruth Huber, Ph.D., Director of the Doctoral program, and her commitment to students and the doctoral program are remarkable. I would also like acknowledge all my other committee members Karen Badger, Ph.D., Seana Golder, Ph.D., and Pam Yankeelov, Ph.D. for their time and effort in reading, editing and providing crucial feedback throughout this process. 


\title{
ABSTRACT \\ PREDICTORS OF CRITICAL THINKING AS A COMPONENT OF AN OUTCOMES ASSESSMENT IN A GRADUATE LELVE SCHOOL OF SOCIAL WORK
}

\author{
Tonya Michelle Tucker
}

July 2, 2008

This study utilized the standardized California Critical Thinking Skills Test (CCTST) Form 2000 to measure students' pretest and post test critical thinking abilities prior to and upon completion of a critical thinking infused curriculum. In addition, the researcher also tested a predictor model for students' entry level critical thinking skills, as well as two separate predictor models for students' acquired critical thinking skills. The researcher not only tested each of the models using the total scores, but also for the subscales of analytic, inference, evaluation, deductive and inductive. A paired samples $t$ test indicated there were no significant differences between pretest and posttest scores except for the inference subscale in which an increase was noted. Additional analysis indicated students with low pretest scores significantly improved on posttest; whereas students with high pretest scores produced significantly lower posttests scores. Separate hierarchical multiple regression analyses were used to test the predictor models, which allowed the researcher to enter variables into the analysis according to the guiding conceptual models. Specifically, for the pretest and one posttest model, the variables were entered based on the generic variables of undergraduate GPA, months between 
undergraduate and graduate degree and type of undergraduate school; and the and the discipline specific variables of pretest self-efficacy score, years of social work experience and undergraduate degree. The other posttest model was based on the student characteristics prior to entering the program of undergraduate GPA, months between undergraduate and entry into graduate school, years of social work experience, undergraduate major, type of undergraduate school and the student characteristics while in the program of type of program graduate GPA, mean hours worked per week, critical thinking subscale score. The demographic variables were consistently significant predictors across the pretest and posttest models, specifically White ethnicity. For the pretest models, undergraduate GPA was the strongest predictor across all models, except for inductive where it was still a significant predictor. The demographic variables of younger age and White ethnicity were the only significant predictors for the generic versus discipline specific models. The prior to and while in the program posttest model demonstrated similar findings; however, evaluation did include some additional variables as did inductive. These findings highlight the need for explicit critical thinking learning strategies targeted at not only improving social work students' ability to demonstrate higher order levels of thinking, but also to be culturally sensitive thus minimizing the influence of ethnicity on the development of critical thinking skills. 


\section{TABLE OF CONTENTS}

CHAPTER ONE: PROBLEM STATEMENT ................................................. 1

Social and Political Influences ...................................................................

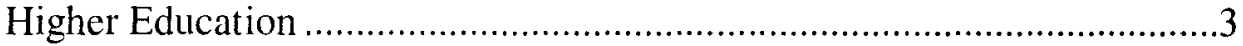

Legislation.....................................................................4

Servicemen's Readjustment Act .....................................4

The National Defense Education Act ..............................4

Educational Reports ...........................................................5

A Nation at Risk.......................................................6

Involvement in Learning ............................................

To Reclaim a Legacy .............................................

Integrity in the College Curriculum ...............................8

Time for Results....................................................... 10

Measuring Up .................................................10

A Test of Leadership......................................................11

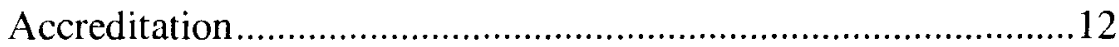

Performance Funding .................................................. 14

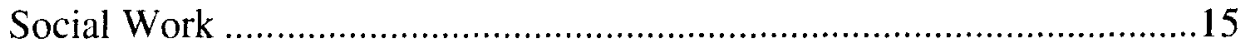

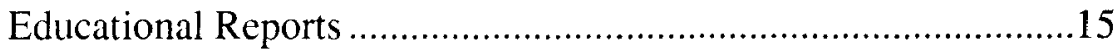

Flexner's Report....................................................15

Hollis Taylor Report .................................................16 


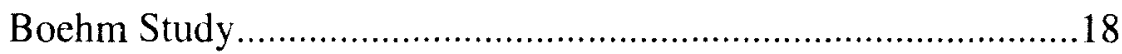



Curriculum Policy Statements ....................................................20

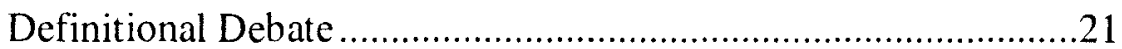

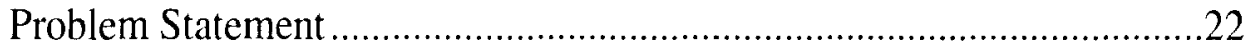

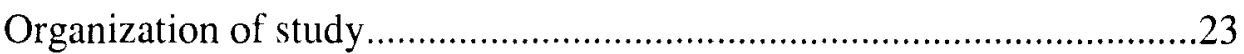

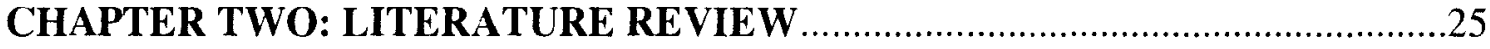

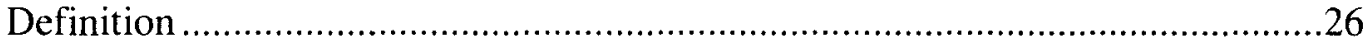

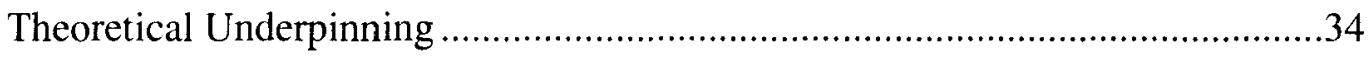

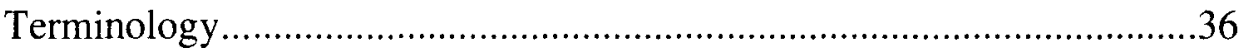

Advanced Knowledge Acquisition .................................................36

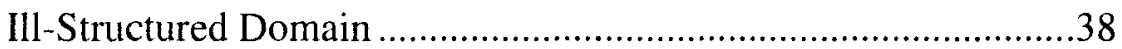

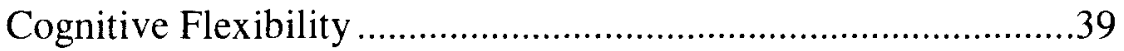

Crisscrossing Landscapes ...........................................................

Theoretical and Research Support ...........................................................41

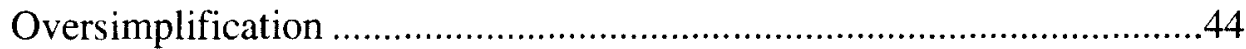

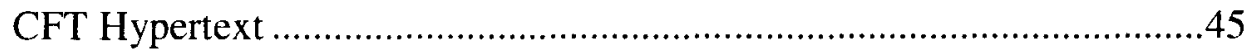

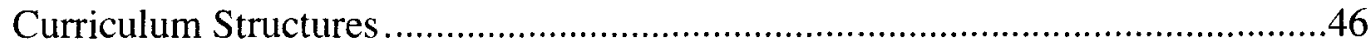



Watson Glaser Critical Thinking Appraisal..............................................50

Cornell Critical Thinking Test ..............................................................52

Collegiate Assessment of Academic Proficiency .....................................52

California Critical Thinking Skills Test.................................................53

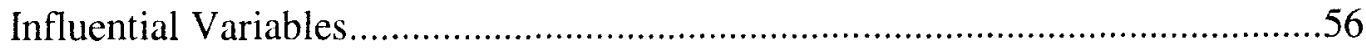

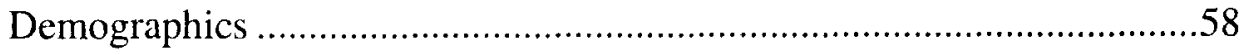




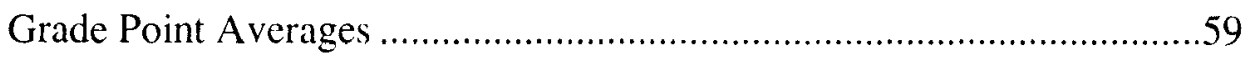

Time

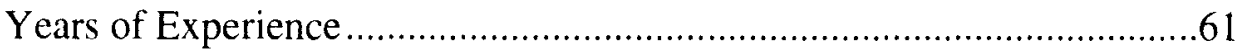

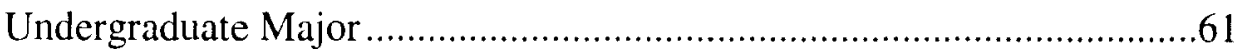

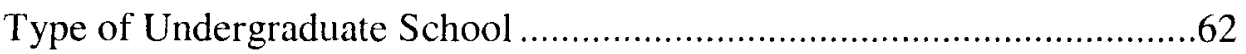

Mean Hours Worked Per Week ..............................................................62

Critical Thinking Self-Confidence....................................................63



Generic versus Discipline Specific .........................................................64

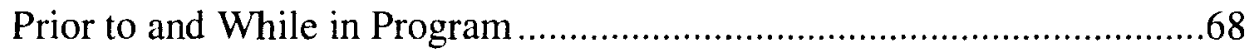



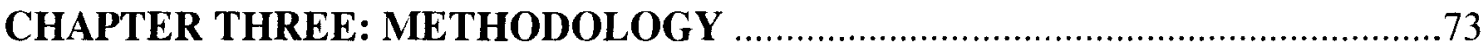

Purpose of Research and Hypotheses ...............................................................73

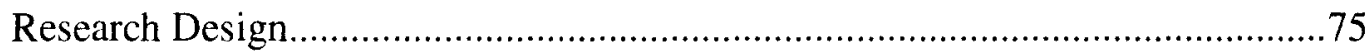

Sample

Data Sources

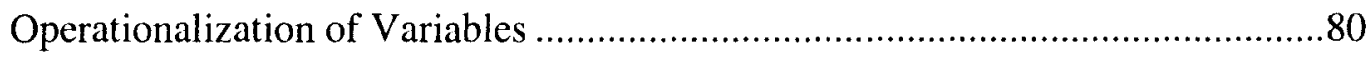

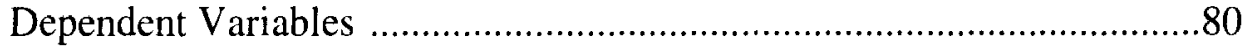

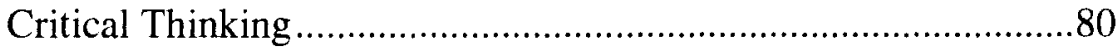

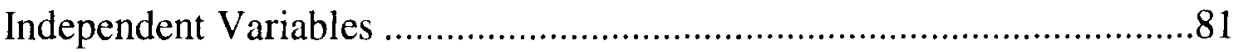



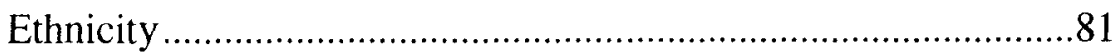

Age

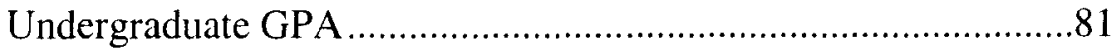

Time Between Undergraduate School and Entry............................81 
Social Work Experience

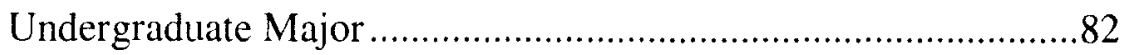

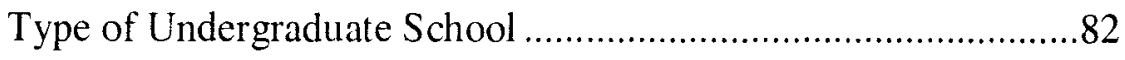

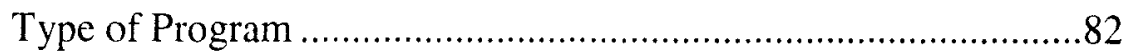

Mean Hours Worked Per Week ....................................................83



Critical Thinking Subscale of Self-Efficacy ...................................83

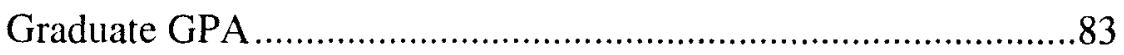

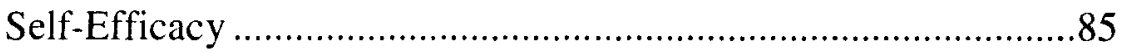

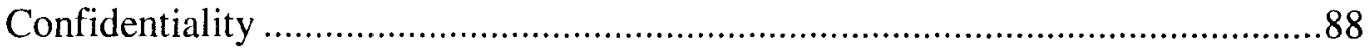

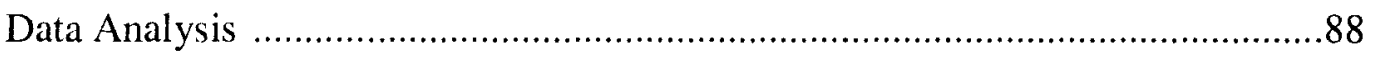

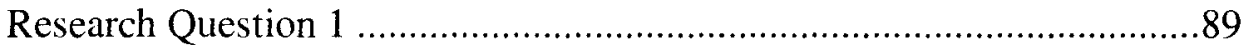

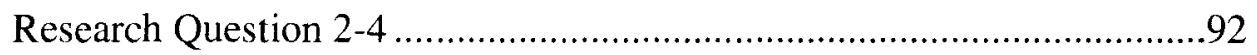

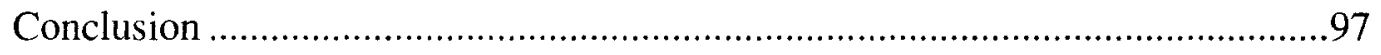

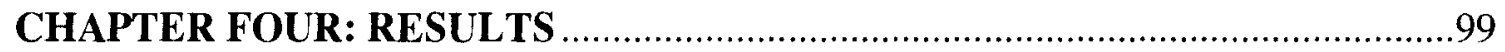





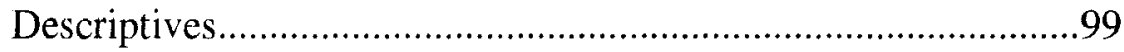

CCTST Pre and Posttest Scores................................................102

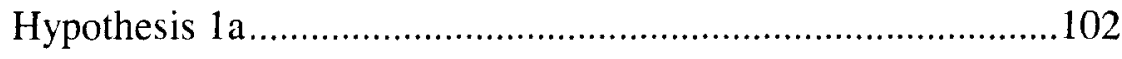

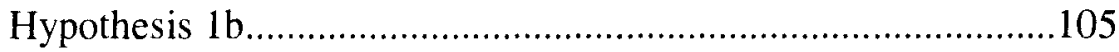

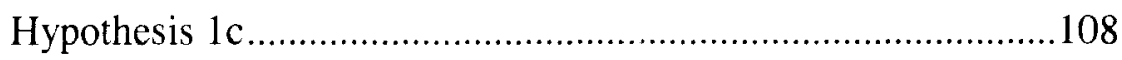

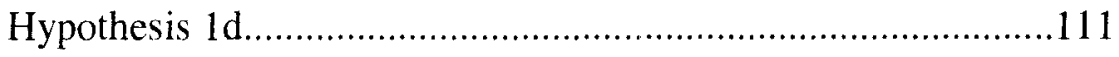

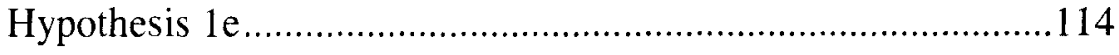

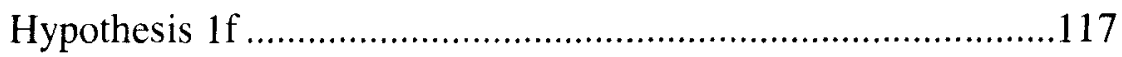


Research Question 2

Descriptives

Dependent Variable

Pretest CCTST Total Score Analysis

Pretest CCTST Inference Score Analysis

Pretest CCTST Analytic Score Analysis

Pretest CCTST Evaluation Score Analysis..................................140

Pretest CCTST Deductive Score Analysis.....................................144

Pretest CCTST Inductive Score Analysis .....................................149

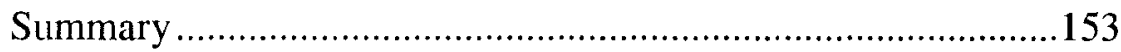

Research Question Three ....................................................................154

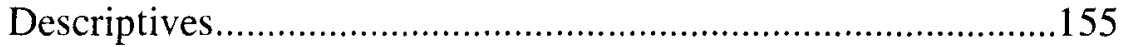

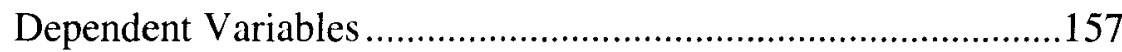

Posttest CCTST Total Score Analysis ........................................158

Posttest CCTST Inference Score Analysis ...................................163

Posttest CCTST Analytic Score Analysis .....................................168

Posttest CCTST Evaluation Score Analysis ................................172

Posttest CCTST Deductive Score Analysis .................................177

Posttest CCTST Inductive Score Analysis ....................................183

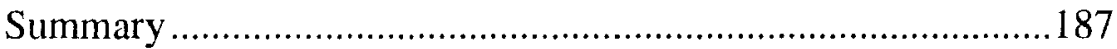

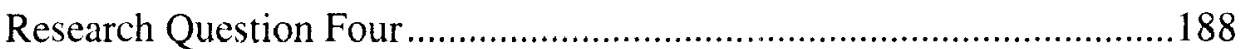

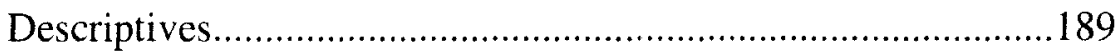

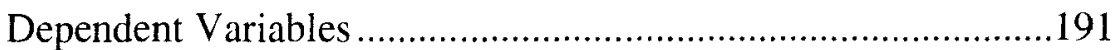

Posttest CCTST Total Score Analysis .........................................191 
Posttest CCTST Inference Score Analysis ..................................196

Posttest CCTST Analytic Score Analysis....................................201

Posttest CCTST Evaluation Score Analysis ...............................206

Posttest CCTST Deductive Score Analysis ................................212

Posttest CCTST Inductive Score Analysis .................................218

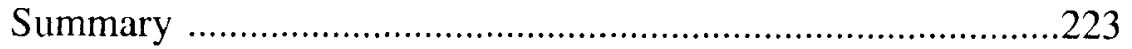



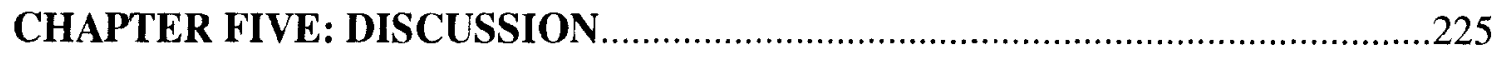

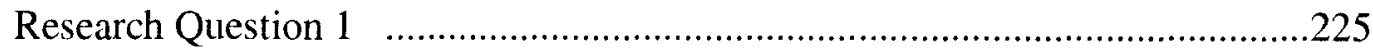



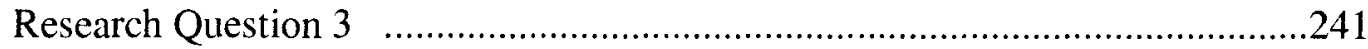

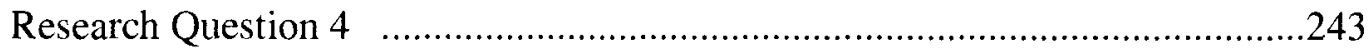

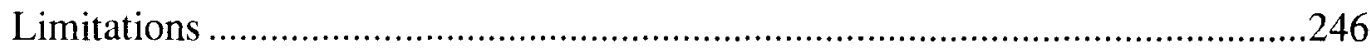

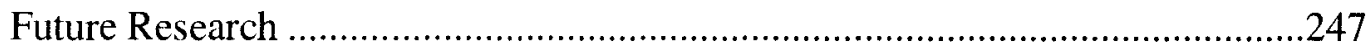

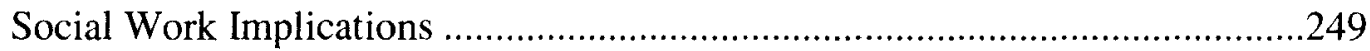

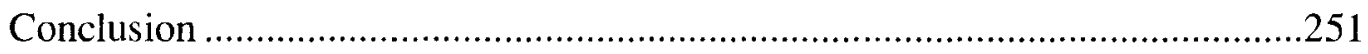

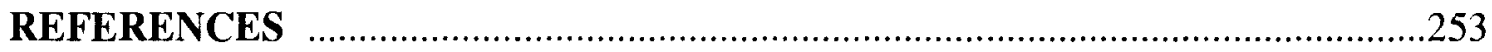

APPENDIX A: KENT SCHOOL CURRICULUM DESCRIPTION ..........................272

APPENDIX B: FOUNDATION PRACTICE SELF-EFFICACY SCALE .....................277

APPENDIX C: POSTTEST ASSESSMENT CRITICAL THINKING SKILLS AND



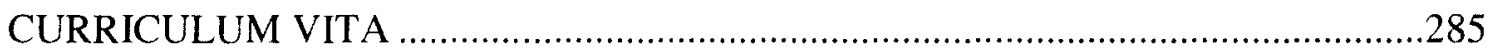




\section{LIST OF TABLES}

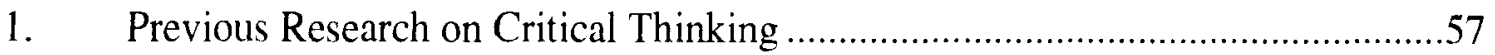

2. Pre and Post Test Administration Time Table .....................................................

3. Pure Posttest Sampling Strategy for Research Question 1 ...................................78

4. Pretest Sampling Strategy for research Question 2 2.........................................78

5. Not So Pure Posttest Sampling Strategy for Research Questions 3 and 4 _............79

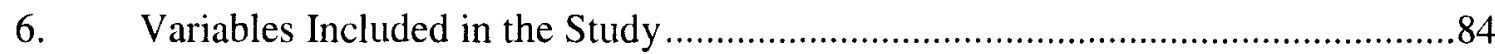

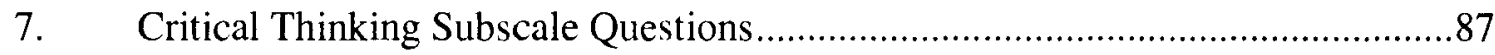

8. The Reliability, Content Validity, and Factor Loadings of the Critical Thinking

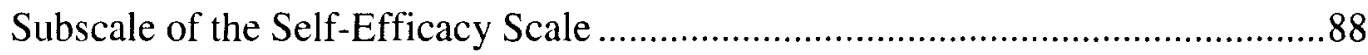

9. Descriptive Characteristics of the Pure Posttest Sample ....................................100

10. Descriptive Characteristics of the Three Group Variable......................................101

11. Descriptive Characteristics of CCTST Pre and Posttest Scores ..........................102

12. Hypothesis 1a Total Analysis Results Summary …............................................104

13. Hypothesis 1b Analytic Analysis Results Summary …....................................107

14. Hypothesis 1c Evaluation Analysis Results Summary .....................................110

15. Hypothesis 1d Inference Analysis Results Summary .....................................113

16. Hypothesis 1e Inductive Analysis Results Summary …...................................116

17. Hypothesis 1f Deductive Analysis Results Summary ......................................119

18. Summary of Pretest Predictor Blocks ……...................................................122

19. Descriptive Characteristics of the CCTST Pretest Sample ..................................124 
20. Descriptive Characteristics of CCTST Pretest Scores

21. Correlations Between CCTST Pretest Total Score and Predictor Variables

22. Partial Correlations Between CCTST Pretest Total Scores and Predictor Variables Controlling for Undergraduate GPA and Ethnicity 129

23. Hierarchical Regression Analysis of CCTST Pretest Total Scores 130

24. Correlations Between CCTST Pretest Inference Score and Predictor Variables 132

25. Partial Correlations Between CCTST Pretest Inference Scores and Predictor Variables Controlling for Undergraduate GPA and Ethnicity 134

26. Hierarchical Regression Analysis of CCTST Pretest Inference Scores. 135

27. Correlations Between CCTST Pretest Analytic Scores and Predictor Variables 137

28. Partial Correlations Between CCTST Pretest Analytic Scores and Predictor Variables Controlling for Ethnicity and Undergraduate GPA 138

29. Hierarchical Regression Analysis of CCTST Pretest Analytic Scores 140

30. Correlations Between CCTST Pretest Evaluation Scores and Predictor Variables 142

31. Partial Correlations Between CCTST Pretest Evaluation Scores and Predictor Variables Controlling for Ethnicity and Undergraduate GPA 143

32. Hierarchical Regression Analysis of CCTST Pretest Evaluation Scores 144

33. Correlations Between CCTST Pretest Deductive Scores and Predictor Variables 146

34. Partial Correlations Between CCTST Pretest Deductive Scores and Predictor Variables Controlling for Undergraduate GPA and Ethnicity. 148

35. Hierarchical Regression Analysis of CCTST Pretest Deductive Scores 149

36. Correlations Between CCTST Pretest Inductive Scores and Predictor Variables151 
37. Partial Correlations Between CCTST Pretest Inductive Scores and Predictor

Variables Controlling for Ethnicity and Undergraduate GPA

38. Hierarchical Regression Analysis of CCTST Pretest Inductive Scores

39. Pretest Model Summary of Total R Square and Significant Predictors for Each

Model

40. Summary of Posttest Predictor Blocks 155

41. Descriptive Characteristics of the Not So Pure Posttest Sample

42. Descriptive Characteristics of CCTST Posttest Scores 158

43. Correlations Between CCTST Posttest Total Score and Predictor Variables......160

44. Partial Correlations Between CCTST Posttest Total Scores and Predictor

Variables Controlling for CCTST Total Pretest and Ethnicity

45. Hierarchical Regression Analysis of CCTST Posttest Total Scores 163

46. Correlations Between CCTST Posttest Inference Score and Predictor Variables 165

47. Partial Correlations Between CCTST Posttest Inference Scores and Predictor Variables Controlling for CCTST Inference Pretest and Ethnicity 166

48. Hierarchical Regression Analysis of CCTST Posttest Inference Scores..... 167

49. Correlations Between CCTST Posttest Analytic Score and Predictor Variables 168

50. Partial Correlations Between CCTST Posttest Analytic Scores and Predictor Variables Controlling .170

51. Hierarchical Regression Analysis of CCTST Posttest Analytic Scores 171

52. Correlations Between CCTST Posttest Evaluation Score and Predictor Variables 174

53. Partial Correlations Between CCTST Posttest Evaluation Scores and Predictor Variables Controlling for CCTST Evaluation Pretest Ethnicity..... 
54. Hierarchical Regression Analysis of CCTST Posttest Evaluation Scores 176

55. Correlations Between CCTST Posttest Deductive Score and Predictor Variables 177

56. Partial Correlations Between CCTST Posttest Deductive Scores and Predictor Variables Controlling for CCTST Deductive Pretest and Ethnicity

57. Hierarchical Regression Analysis of CCTST Posttest Deduction Scores

58. Correlations Between CCTST Posttest Inductive Score and Predictor Variables 184

59. Partial Correlations Between CCTST Posttest Inductive Scores and Predictor

Variables Controlling for CCTST Inductive Pretest Ethnicity

60. Hierarchical Regression Analysis of CCTST Posttest Inductive Scores

61. Posttest Model Summary of R Square Change and Significant Predictors for

Generic versus Discipline Specific Model

62. Summary of Posttest Predictor Prior to Entry and While in Program Blocks .....189

63. Descriptive Characteristics of the Not So Pure Posttest Sample

64. Correlations Between CCTST Posttest Total Score and Predictor Variables

65. Partial Correlations Between CCTST Posttest Total Scores and Predictor

Variables Controlling for CCTST Total Pretest and Cumulative GPA

66. Hierarchical Regression Analysis of CCTST Posttest Total Scores 196

67. Correlations Between CCTST Posttest Inference Score and Predictor Variables 198

68. Partial Correlations Between CCTST Posttest Inference Scores and Predictor Variables Controlling for CCTST Inference Pretest and Ethnicity .200

69. Hierarchical Regression Analysis of CCTST Posttest Inference Scores. .201

70. Correlations Between CCTST Posttest Analytic Score and Predictor Variables 203 
71. Partial Correlations Between CCTST Posttest Analytic Scores and Predictor Variables Controlling for CCTST Analytic Pretest and Age at Pretest. 205

72. Hierarchical Regression Analysis of CCTST Posttest Analytic Scores .206

73. Correlations Between CCTST Posttest Evaluation Score and Predictor Variables208

74. Partial Correlations Between CCTST Posttest Evaluation Scores and Predictor Variables Controlling for CCTST Evaluation Pretest and Cumulative GPA......210

75. Hierarchical Regression Analysis of CCTST Posttest Evaluation Scores ...........212

76. Correlations Between CCTST Posttest Deductive Score and Predictor Variables214

77. Partial Correlations Between CCTST Posttest Deductive Scores and Predictor Variables Controlling for CCTST Deductive Pretest and Age at Pretest ............216

78. Hierarchical Regression Analysis of CCTST Posttest Deduction Scores ...........217

79. Correlations Between CCTST Posttest Inductive Score and Predictor Variables219

80. Partial Correlations Between CCTST Posttest Inductive Scores and Predictor Variables Controlling for CCTST Inductive Pretest and Cumulative GPA ........221

81. Hierarchical Regression Analysis of CCTST Posttest Inductive Scores .............223

82. Posttest Model Summary of R Square Change and Significant Predictors for Prior to While in Model .224 


\section{LIST OF FIGURES}

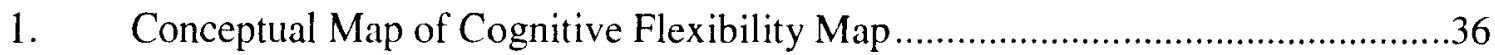

2. Five Stages of the Conceptual Model Development.............................................43

3. Conceptual Model to Explain Potential Predictors of Students' Entry Level

Critical Thinking Skills Using Generic and Discipline Specific Blocks .66

4. Conceptual Model to Explain Potential Predictors of Students' Acquired Level Critical Thinking Skills Using Generic and Discipline Specific Blocks .67

5. Conceptual Model to Explain Potential Predictors of Students' Acquired Critical Thinking Skills Using Prior to Entry and While in Program Blocks .69

6. Analysis Plan for Research Question One …....................................................92

7. Final Conceptual Model to Explain Predictors of Students' Entry Level Critical Thinking Skills Using Generic and Discipline Specific Blocks .241

8. Final Conceptual Model to Explain Predictors' of Students Entry Level Critical Thinking Skills Using Generic and Discipline Specific Blocks .243

9. Final Conceptual Model to Explain Predictors' of Students Acquired Level Critical Thinking Skills Using Prior to and While in Program Specific Blocks 246 


\section{CHAPTER ONE}

\section{Introduction}

Assessment of educational outcomes is gaining increasing attention in higher education through legislative requirements to obtain funding, policy requirements for accountability, mandates from accrediting bodies, and faculty/administrators' desire to ensure quality student learning (Palomba \& Banta, 2001; Palomba, \& Banta, 1999; Huba \& Freed, 2000; Breschiani, 2006; Banta, 2001; Allen, 2004; Mizikaci, 2006; Wolanin, 2003; A Test of Leadership, 2006). Colleges and universities have historically looked at enrollment and graduation rates as a measure of success; however, the assessment movement has inspired a closer examination of higher education and how well these institutions fulfill their mission and purpose resulting in a more focused approach to assessing educational outcomes (Banta, 2001). As a result, institutions are under significant pressures to produce reliable and valid assessments of student learning and provide evidence for how the results inform the decision making process (Allen, 2004).

This informed decision making process is a key component to assessing educational outcomes, whereas the data gathered is fed back into the program/institution. Thus, the process not only meets established government and accreditation guidelines, but also provides faculty with a valuable tool to improve their program/institution. As a result, not only do the assessment results provide valuable information on how well the program/institution is meeting its goals and objectives, but may also provide insight into how certain areas of the curriculum could be reformed to improve student learning. 
Curriculum reform involves various types of changes to how a school intends to carry out its mission, goals, and objectives. It may include an array of actions as minor as revising the wording of objectives or clarifying the mission statement or as complex as selecting a new theoretical foundation for the entire curriculum or altering the alignment of courses and assessment measures. A school's curriculum is the how, what, when, where, why, and to whom plan customized for individual schools. It includes the specific courses and their content, the underlying philosophy or purpose of the classes taken as a whole, pedagogical guidelines, assessment techniques, as well as specific components as required by the university and accreditation agencies (within higher education) (Handbook of Accreditation Standards and Procedures, 2003; Principals of Accreditation: Foundations for Quality Enhancement, 2001). The impetus for curriculum reform may be the faculty/administration of the individual program itself; however, it generally stems from directives of the university, accreditation agencies (both university and program specific), and/or politicians and other funding sources in attempts to promote continued quality improvement, optimize student learning, reflect the technological advancing environment and needs of society, provide consistency among schools/programs, and ensure accountability (Burke \& Minassians, 2002; Handbook of Accreditation Standards and Procedures, 2003; Hoyt, 1999; Principals of Accreditation: Foundations for Quality Enhancement, 2001).

How did the movement of assessing educational outcomes gain momentum? Why are legislators and accrediting bodies requiring more specific evidence of an institution's success? What factors contributed to the development of this movement? A historical analysis of assessment in higher education as well as its linkages with 
curriculum reform will be explored to provide an in depth understanding of these questions. The social and political influences will be discussed to include specific legislation, educational reports, accreditation and performance funding components and how they influenced assessment and curriculum reform in higher education. In addition to these factors, CSWE's Curriculum Policy Statement and social work definitional debates will also be discussed in regards to their influence on the assessment and curriculum reform process.

\section{Social and Political Influences}

\section{Higher Education}

Most assessment scholars recognize the 1980s as the beginning of the "assessment movement" or "scholarship of assessment" (Banta, 2001, 2002). Ewell (2002) pointed out the assessment movement has served two perspectives: assessment as a tool for institutions to improve curriculum and assessment as an accountability tool. These two socially constructed realities do not necessarily contradict each other; however, they do have a significant impact on how politicians, funding sources, parents, students and faculty define and implement assessment.

As mentioned previously, there are a variety of reasons for assessment and curriculum reform. Historically, numerous events and policies which have influenced the assessment of educational outcomes in higher education in general and social work specifically. In this examination of the historical context, the increased focus on assessment will be explored in regards to the relation of its impact on curriculum reform. The increased focus on assessment has sparked a renewed interest in curriculum reform and is seen as an instrument to inform curriculum decisions and enhance student learning 
(Allen, 2004; Angelo, 1999; Banta, 2001, 2002). Those factors which contributed most significantly to this process will be explored.

\section{Legislation}

Servicemen's Readjustment Act. With the passage of the Servicemen's Readjustment Act of 1944, otherwise known as the GI bill, veterans were provided with federal financial assistance to pursue a college education (History and Archival, n.d.) Henry (1975) and Forest \& Kinser (2002) reported that college enrollment tripled from 1955-1970, with over 2 million enrolled in 1946, over half of whom were veterans. With the enormous increase in enrollment after World War II and abundant governmental financial support, all was well in higher education with minimal focus on assessment, accountability, or significant curriculum reforms (Banta, 2001; Forest \& Kinser, 2002; Huba \& Freed, 2000). These trends in enrollment continued to progress to over four million in 1961 and to more than eight million in 1969 (Forest \& Kinser, 2002).

The National Defense Education Act. During the significant growth in enrollment, federal assistance also grew in addition to the GI bill. The National Defense Education Act was passed in 1958 which provided funding in the areas of science, mathematics, foreign languages and engineering (Forest \& Kinser, 2002). Although the act is mostly recognized for augmenting funding for education, it also increased attention on curriculum reform in science and math in particular as a response to the Soviet Union's launch of Sputnik and the perceived security threat to the United States (Flynn, 1995). This was the first curriculum reform generated specifically to serve the national, social and economic good of the country (Pinar, 2007). At that time, attention focused on utilizing assessment to improve American college graduates skills for the explicit purpose 
of competing with Russia's success at aerospace engineering. Since that time, this quality assurance movement and international competition has continued to gain momentum, further fueled by the assessment movement which came to play in the 1980s. With abundant enrollment and financial resources to support growth, higher education was at an all time high, but with peaks come valleys.

\section{Educational Reports}

The shift occurred in the 1970s when a substantial decrease in available financial resources spawned a closer examination of higher education and how well equipped students were to meet workforce challenges (Banta, 2001; Huba \& Freed, 2000). The U.S. looked for solutions to a major energy crisis with gas shortages in 1973 and 1977 , annual inflation rates increased to $10-15 \%$, the political disillusionment due to the Vietnam War and Watergate, and the Cold War plagued the U.S. (Lewis, 2004). The federal government struggled to fund the needs of a growing welfare population, criminal justice system, and energy crisis while also maintaining existing funding obligations (Burke \& Minassians, 2002; Huba \& Freed, 2000). These struggles would continue on into the 1990s as higher education continued to lose against welfare, criminal justice, and health care (Burke \& Minassians, 2002; Huba \& Freed, 2000). Universities and colleges also felt the struggle to maintain as they were unable to raise tuition at a rate to keep up with inflation rates and still maximizing accessibility for the majority of individuals seeking a college degree (Huba \& Freed, 2000). This shortage of resources sparked the critical examination of the effectiveness of higher education in preparing students for a diverse and ever changing workforce, thus renewing the attention to assessing educational outcomes (Huba \& Freed, 2000). 
A Nation at Risk. During the mid eighties, numerous special interest groups examined the status of higher education, generating reports and rankings which served as an impetus for conversation on changes in higher education, particularly in utilizing the assessment of educational outcomes to inform curriculum decisions and reform. For example, the U.S. News \& World Report published its first rankings of college and universities in 1983 (Forest \& Kinser, 2002). Other reports provided more detailed information and critiques of the strengths and weaknesses of higher education. These reports emphasized quality and evaluated the standing of institutions both nationally and internationally. Particularly, A Nation at Risk (1983), published by the National Commission on Excellence in Education under the direction of then Secretary of Education T. H. Bell, was the first of a series of reports to draw attention and reflection upon the current status of education in the United States. The study recognized that although the United States had long held the lead in such areas as "commerce, industry, science and technology innovation", its status was being seriously challenged, and a failing education system was seen as one of the primary causes (A Nation At Risk, 1983). Specifically, the report states that other countries are matching if not exceeding the United States due to the "rising tide of mediocrity that threatens our very future as a Nation and a people" (A Nation At Risk, 1983). High rates of functional illiteracy were noted in high school students as well as in adults, and SAT scores which had remained steady for over seventeen years were sharply declining (A Nation At Risk, 1983). These and other shocking statistics were provided to inform the reader of the seriousness of the risk to the United States if corrective action was not taken. The report focused primarily on teenage youth but had clear implications for higher education in that movement and 
trends beginning in the K-12 grades generally filters down to higher education in some form (Burke \& Minassians, 2002; A Nation At Risk, 1983; Wolanin, 2003). A Nation At Risk (1983) recommended the following changes:

- Strengthening curriculum requirements

- Utilizing precise and measurable standards

- Raising admission requirements

- Lengthening the school day and/or year

- Increasing accountability of educators and politicians responsible for providing financial support for recommendations

Involvement in Learning. Involvement in Learning (1984) written by scholars from the National Institute of Education, recommended high standards for student learning, engagement of active student learning, and frequent assessment linked with timely feedback and drew assessment attention more specifically to institutions of higher education (Banta, 2002; Ewell, 2004; Huba \& Freed, 2000; Palomba \& Banta, 1999, 2001). This report urged college and universities to become learning organizations and that student assessment information be utilized to inform improvement. This report was the first to focus more specifically on students and their learning instead of previous reports which primarily addressed teaching and programs of study (Answers.com, 2007; Guthrie, 2002). This study is noted to have prompted the first conference specifically focused on assessment in 1985 as an instrument to inform curriculum decisions (Banta, 2002; Palomba \& Banta, 2001).

To Reclaim a Legacy. To Reclaim a Legacy (1984) authored by William Bennett, focused specifically on the liberal arts education. Bennett argued higher education, and 
more particularly faculty, had been unfaithful to the liberal arts foundation and graduates were thus “culturally illiterate" (Mulcahy, 1986; Trimbur, 1986). Bennett's report continued to focus politicians, faculty, administrators, and the public on the ultimate goal of reform in higher education, yet provided a more narrow lens arguing for specific focus on Western civilization's rich historical culture (Mulcahy, 1986; Trimbur, 1986).

Integrity in the College Curriculum. Integrity in the College Curriculum (1985), written by the Association of American Colleges and Universities, focused on assessment in undergraduate education as well (Banta, 2002; Ewell, 2004). This report, however, was more critical of faculty than previous reports claiming faculty abdicated "their corporate responsibility for the undergraduate curriculum" (Adelman, 1987; Guthrie, 2002). The group recommended all undergraduate curriculum address the following "nine content-related experiences: inquiry; literacy; understanding numerical data; historical consciousness; the sciences; values; art; international and multicultural experiences; and study major specialization in depth" (Guthrie, 2002, p. 3). The group also wanted faculty to help students make the connection between what they learned in their courses with their everyday lives and work place (Guthrie, 2002).

Adelman (1987) conducted a content analysis on the written discussions surrounding Involvement in Learning (1984), To Reclaim a Legacy (1984), and Integrity in the College Curriculum (1985) which highlighted common attributions, designations and assertions between the reports. More specifically, attributions referred to certain characterizations such as timely, current, etc.; designations referred to certain people, groups, events, etc.; and assertions refers the way in which objects were characterized (Adelman, 1987). The analysis indicated that Integrity in the College Curriculum (1985) 
placed a greater emphasis on faculty responsibility; whereas, To Reclaim a Legacy (1984) gave more attention to administrators than the other reports (Adelman, 1987). Documents were more negative towards faculty and curriculum during the time period identified with Integrity in the College Curriculum (1985) than other time periods (Adelman, 1987). The curriculum of higher education was referred to using such terms as soupy, Swiss Cheese, junk food, and bubble gum (Adelman, 1987). Adelman (1987) continued his analysis explaining these metaphorical statements about curriculum were illustrative of the "passive, acted upon, served" nature of curriculum suggesting it may be more easily altered than faculty (p. 386).

Adelman (1987) utilized Harold Laswell's (1968) ideas on propaganda stating: "sociological propaganda, conveying a profound dissatisfaction with American education, had been building for five or six years before $A$ Nation at Risk was issued, and that, after that pivotal event, the national stage was open for statements which reinforced the rising myths and symbols of a new belief system in American education" (p. 374).

This perspective supports the idea of assessment being socially constructed in that propaganda was utilized to motivate and create discussions and opinions on the status of higher education and means to improve upon its current condition (Adelman, 1987). The written word is particularly powerful in discussions of higher education in that the "academic culture is a culture of print, and takes its validity from the written word. The written word allows explanation and reflection -key academic values- and not merely fact or doctrine" (Adelman, 1987, p. 375). 
Time for Results. Developed by the National Governors' Association, Time for Results (1987) made several recommendations which were expected to have a significant impact on education within the next five years (Rhodes, 1987). The report established seven questions that needed to be answered to improve schools and addressed such issues as teacher pay, more parental choices, leadership rewards, assistance to poor and illprepared children, maximum use of school buildings, and determining student learning (Alexander, 1987). The governors, with K-12 reform as their basis, put forth that colleges and universities should be held accountable for standards and the results of the assessment of student learning with specific consequences for the results (Ewell, 2004). The key component was to make assessment results public to better inform decision making and to help guide curriculum reform as well (Ewell, 2004). Time for Results (1987) argued strongly for performance-based education, as governors recognized the implications of education in the financial success and progress of their states saying, "We'll regulate less if schools produce better results" (Alexander, 1986, 1987; Ficklen, 1986). State governors recognized the impetus to economic success in their individual states was the employability and production of an educated and prepared workforce. Curriculum reform informed by assessment of educational outcomes was identified as the key to such a workforce. Yorke \& Knight (2006) argued "concern about the economic benefits of education has increased in the recent half-century" (p. 565) with specific emphasis that higher education should also "serve the national and social good".

Measuring Up. The National Center for Public Policy and Higher Education developed Measuring Up 2000 to provide a state by state comparison in preparation, participation, affordability, completion, benefits, and learning. This provided one of the 
first comparison tools and continued to provide data on individual states every two years through the current year 2006. The most remarkable finding in 2000 was the lack of data to support the degree or quality of student learning in individual states. According to Measuring Up 2000 and Measuring Up 2002, "all states lack information on the educational performance of college students that would permit systematic state or national comparisons". This trend changed in Measuring Up 2004 when five states provided enough data to be evaluated on student learning and Measuring Up 2006 when the number grew to nine. Measuring Up 2006 also included international comparisons for the first time, which continued to highlight that U.S. institutions of higher education were continuing to decline (Hebel, 2006). This is a discerning trend in light of previous warnings dating back to the early 1980 s which predicted the impending decline in the United States' higher education to compete internationally. This lack of attention to measuring student learning is reflective of the lack of attention in critically evaluating the effectiveness of curriculum. Gathering data on student learning outcomes could assist schools in making informed decisions regarding their curriculum as well as providing insight into areas of strength as well as those in need of reform.

A Test of Leadership. Continuing this trend, A Test of Leadership (2006), commissioned by Secretary of Education Margaret Spellings focused on affordability, quality, access and accountability. This report continues to sounded the same warnings as previous reports, i.e. international higher education exceeding graduation rates and level of education in the United States, ill-prepared high school and college graduates, and racial and ethnic disparities (A Test of Leadership: Charting the Future of U.S. Higher Education, 2006). The final recommendations were also familiar, i.e. improved 
K-12 preparation for higher education through clear standards, improved teacher education, address financial barriers, performance benchmarks in higher education, culture of accountability, etc. (A Test of Leadership: Charting the Future of U.S. Higher Education, 2006). Although there have been a variety of reports published since the 1980s, "according to Ewell, their messages were clear and strong: instruction in higher education must become learner-centered, and learners, faculty, and institutions all need feedback in order to improve" (Huba and Freed, 2000, p.17). This call clearly highlighted the need for the thorough assessment of educational outcomes in institutions of higher education as we continue to lose ground both internationally and within our own nation as graduates lack the appropriate skills/knowledge level to perform competently in the workforce (A Test of Leadership: Charting the Future of U.S. Higher Education, 2006).

\section{Accreditation}

The increased attention to assessment through the various reports and policy statements resulted in the development of accreditation bodies and standards, and in some cases, performance funding requirements which serve to "provide a new tool to restructure the way we do things" (Berger Schema, n.d.). The objectivation of assessment resulted in rules, regulations, guidelines, and tools institutions of higher education had to use as a result of the mandates of individual institutions, accrediting organizations, and state and federal government (Berger Schema, n.d.).

Huba and Freed (2000) argued to minimize governmental control of higher education, accreditation bodies became involved with the reform process and required institutions to "conduct outcomes assessment in order to maintain their status as accredited institutions" (p.17). In other words, to justify the effectiveness of the 
curriculum, schools had to "prove" the effectiveness of their curriculum through assessment and then utilize the results to inform curriculum decisions. As Ewell (2006) explained, accreditation bodies took the states' place as the impetus to produce student learning outcomes. Accreditation agencies evaluate and assess how well an organization meets specific criteria/guidelines and generally emphasize capacity and effectiveness (Allen, 2006). Not only do these agencies determine how well institutions are meeting their goals and objectives, they must also ascertain the availability of resources at these institutions necessary to meet their goals and objectives.

In 1997 Council for Higher Education Accreditation was created to not only grant accreditation for institutions of higher education but also to oversee the eligibility for grants and assistance to the current (Forest \& Kinser, 2002). CHEA is a non governmental higher education organization which oversees accreditation agencies and organizations as the organizing umbrella for accreditation in the United States (Allen, 2006; CHEA, n.d.). Accreditation is broken down into 6 regional Association of Colleges and Schools, i.e. Middle States, New England, North Central, Northwest, Southern and Western (Allen, 2006). Each of these bodies is responsible for accrediting colleges and universities in their perspective regions. Although accreditation is voluntary for the institutions, most generally funding is contingent upon successfully meeting accreditation standards. Specifically, if schools are not accredited by their respective accreditation organization, the students are not eligible for federal funding, i.e. grants, students loans, etc.

Accreditation organizations have also been responsive to the assessment movement in higher education. Specifically, the Department of Education mandated in 
1988 that all federally approved accreditation organizations include in their criteria for accreditation evidence of institutional outcomes" (Palomba \& Banta 1999, p. 2; Palomba \& Banta, 2001). These requirements have continued to become more specific, and accreditation bodies are requiring valid and reliable evidence of the institutions' ability not only to assess educational outcomes, but also to utilize data from the assessment to improve and inform curriculum reform decision making (Maki, P., 2004; Banta, 2002;

Hernon, et al, 2006; Palomba \& Banta, 2001; Allen, 2004; Palomba \& Banta, 1999; Huba \& Freed, 2000; Bresciani, 2006).

\section{Performance Funding}

Another consequence of the focus on assessment has been state level performance funding requirements, states began to base the amount of financial assistance provided annually to institutions of higher education upon measurements of student success through, for example, standardized pre and post test scores (Huba and Freed 2000). Tennessee became the first state to implement performance funding in higher education in 1979 and has been widely successful to date (Banta, et al, 1996; Palomba \& Banta, 2001; Banta, 2001; Burke \& Modarresi, 2001). Although the Tennessee criteria has evolved over the last several years, such factors as accreditation of university and programs/disciplines, graduation rates for minority and all students, improvement actions, enrollment goals for specific groups, i.e. African American, Hispanic, measurement of general education and major field, continue as consistent foci (Banta, et al, 1996). With Tennessee leading the way, 17 states had implemented performance funding by 2005 , with seven more likely forthcoming and four withdrawing (Burke \& Modarresi, 2001; Hoyt, 1999). Although not wide spread at this point, performance funding has brought 
assessment to the forefront for many colleges who depend on state funding to survive and has addressed not only limited financial resources, but also accountability. Banta, et al (1996) reports, in regards to Tennessee, there have been such benefits as engaging institutions that otherwise would not have been engaged in the assessment process, increasing faculty attention on assessment, and yielding valuable data in curriculum reform.

\section{Social Work}

\section{Educational Reports}

Although the reports and policies referred to above have had and continue to have an impact on social work education as a discipline within higher education, there were specific issues/events which impacted assessment in social work education. As higher education worked to prove its worth and standing in society, social work education was on a similar mission.

Flexner's Report. One of the most noted influences on social work education was the speech made by Abraham Flexner in 1915 in which he declared social work was not a profession (Flexner, 2001). Although this discussion will generally be confined from the 1940s to current, this noted speech continues to evoked heated discussions among social work educators and influenced curriculum, thus providing insight into the socially constructed aspect of social work education and how assessment gained focus and attention within the profession (Austin, 1983; Flexner, 2001; Greene, 2005). Flexner (2001) noted "the occupations of social workers are so numerous and diverse that no compact, purposefully organized educational discipline is feasible" (p. 162) and added that social work instructors had claimed "We don't know what to teach them" (p. 162). 
He argued that since the numerous roles, practice settings and frameworks of social work were so diverse and multiplistic, it was impossible to develop a comprehensive and coherent curriculum for the profession. Flexner (2001) further claimed social work did not have a unique body of knowledge to claim as its own as does medicine and law and lacks specific and teachable techniques, again highlighting the barriers or challenges in developing a comprehensive social work curriculum.

At this point, professional organizations were formed to address Flexner's charge and advance social work's standing as a profession. American Association of Schools of Social Work (AASSW) was developed in 1919 to establish educational standards for social work education (Calgary, 2007). From then until 1940's a buzz of activity in social work and its curricular requirements occurred, including the mandate for social work programs to have university affiliation as well as mandating two year graduate programs (Frumkin \& Lloyd, 1995). Disagreements among the profession led to the creation of additional organizations, i.e. the National Association of Schools of Social Administration and the National Council on Social Work Education, each attempting to regulate social work curriculum (Frumkin \& Lloyd, 1995). The AASSW developed the basic eight components of social work curriculum: public welfare, social casework, social group work, community organization, medical information, social research, psychiatry and social welfare administration; however, this did little to unite the profession nor social work education (Hollis \& Taylor, 1951).

Hollis-Taylor Report. The National Council on Social Work Education initiated a study to examine the problems of accreditation as well as the issue of more clearly defining the objectives of social work education. The group formed a committee; 
however, it was decided that an educational expert outside of social work may better serve the purpose and provide a more objective assessment of the issues challenging social work education (Hollis \& Taylor, 1951). Thus, Dr. Ernest V. Hollis, Chief of College Administration, Office of Education, Federal Security Agency was asked to take the lead position in the study. Hollis then selected Alice Taylor, Training Consultant, Bureau of Public Assistance, Federal Security Agency as Assistant Director (Hollis \& Taylor, 1951). In 1951, what became known as the Hollis-Taylor Report (Hollis \& Taylor, 1951) attempted to examine social work education and "build a framework of principals within which existing programs of social work education might be examined... and to develop a comprehensive structure within which what constitutes acceptable programs of social work education" and to do so in such a way as to unite the divisions growing within the profession (p. viii). The report reviewed the history of social work education and examined the progress social work had made in meeting Flexner's criteria for a profession. In 1952, AASSW and NASSA merged to form the current Council of Social Work Education (CSWE) which required that schools to address social services, human behavior, and social welfare policy and services within their curriculum (Calgary, 2007; Frumkin \& Lloyd, 1995; Greene, 2005). National Association of Social Work (NASW) was formed in 1955 through the merger of seven social work organizations which focused on the practice aspects of social work in an attempt to unify the social work profession and improve consistency in practice (Calgary, 2007; Holosko, 2003). Continued disagreement regarding curriculum, consistency among schools, the lack of guiding principles and continued tension among the two remaining professional 
organizations (NASW and CSWE) led way to another curriculum study in 1959 by CSWE: the Boehm Study (Boehm, 1959; Frumkin \& Lloyd, 1995; Greene, 2005).

Boehm Study. Around 1955 the Council on Social Work Education began a national social work curriculum study led by Dr. Werner W. Boehm of Rutgers University (Boehm, 1959). The study was completed in 1959 and yielded a 13 volume report consisting of 12 separate projects. According to Greene (2005), the Boehm Study generated a social work definition which refocused attention on enhancing social functioning of the individual and keeping the curriculum "broad enough to encompass work in all settings, practice methods, research, ethics, and values; and field education" (p. 44). Boehm (1959) discussed the difficulties of social work to agree upon and establish goals and purposes of the profession, making it nearly impossible to establish clear curriculum guidelines or evaluate how well individual schools of social work are meeting this goal. The study set out to ensure the formal purpose of social work would be written in such a way as to make the profession responsive to the "evolving character of the social work profession and the changing nature of its practice as it has responded to changing needs in society"(Boehm, 1959, p. 10). The report concluded "the focus on social relationships, however, is suggested as the distinguishing characteristics of the social work profession"(Boehm, 1959, p. 18).

\section{Accreditation}

The accreditation trends of higher education are also evident in program and disciplinary level accreditation as well. An example is the Council on Social Work Education (CSWE) which accredits schools of social work at the bachelor and master levels utilizing Educational Policy and Accreditation Standards (EPAS) to guide the 
process (Palomba \& Banta, 2001; Allen, 2006; Hull, et al, 1994). EPAS serve as a guideline for schools of social work by specifying curriculum content and the educational context in preparing students for social work practice (Handbook of Accreditation Standards and Procedures, 2003). For example, schools are required to include content on values and ethics, social justice, human behavior and social environment, diversity, social welfare policy, social work practice, research, and field education at both the baccalaureate and master's level with increased depth and breadth (Handbook of Accreditation Standards and Procedures, 2003). In addition to the curriculum content, CSWE outlined specifically in the EPAS that accredited schools of social work are required to have a specific assessment plan to evaluate the outcomes for each program objective, to include specific instruments, methods and procedures and must also demonstrate how data is used to inform curriculum decisions (CSWE, 2003).

In 2006, CSWE began the regular review process to update EPAS in attempt to integrate current needs of the social work profession. During the 2006 Annual CSWE Conference, participants listened to members of the Commission on Accreditation and the Commission on Curriculum regarding their vision for the new EPAS (Holloway \& Detlaff, 2006). Holloway explained the intent was to streamline EPAS making them user friendly, but developing an overarching intellectual framework, including a list of competencies, to guide accreditors and schools alike in curriculum development (Holloway \& Detlaff, 2006). One of the key components of the discussion was the desire for EPAS to move from "person in environment to person in an ever changing environment" being more responsive to the changing client population, similar to the goals outlined by Boehm Study in 1959. Interestingly, social work has continued to 
socially construct itself as a profession which may tend to complicate the matter of assessing educational outcomes. However, the revisions were intended to "focus more on what students learn rather than what students are taught" (Holloway \& Detlaff, 2006). And in fact a new version of EPAS (2008) released in April 2008, included assessment as one of the four key features in an integrated curriculum design recognizing assessment as an "integral component of competency-based education" (p.1).

\section{Curriculum Policy Statements}

CSWE also contributed significantly to assessment within social work through the curriculum policy statements which were written to provide guidelines and criteria for schools of social work. A series of these statements issued in 1962, 1971, 1984, and 1994 addressed the specifics of social work curriculum and specified content areas to be addressed in the curriculum; however, the 1994 statement was the first to specify "a series of individualized student outcomes measures" at both undergraduate and graduate levels (Frumkin \& Lloyd, 1995, p. 2240). This requirement of student outcomes measures was further expanded upon by the current Accreditation Standard 8.0 and 8.1, which required schools to have "assessment plans and procedures for evaluating the outcome of each program objective", to include "specific measurement procedures and methods to evaluate the outcome of each program objective", and to utilize the information gained from the assessment to improve the program through curriculum reform (Handbook of Accreditation Standards and Procedures, 2003, p. 17). This component links assessment and curriculum reform, by requiring the feedback loop of utilizing the information to inform curriculum decisions. This standard has been a particularly challenging task for schools (Cournoyer, 2001; Fisher, 2005; Gambrill, 2001; 
Garcia \& Floyd, 2002) and has resulted in formal suggestions issued by the Chair of the Commission on Accreditation (COA) Stephen Holloway in 2005. This document represented the first elaboration provided by $\mathrm{COA}$ in an attempt to assist schools of social work in implementing a thorough and effective outcomes assessment of their curriculum, by elaborating on the current EPAS and providing specific examples of tools and instruments, i.e. curriculum matrix, qualities of good program objectives, and discussion of various measurement options (Holloway, 2005). This elaboration again emphasized the utilization of assessment data to inform curriculum decisions by providing specific feedback on the current curriculum and by tracking and evaluating curriculum reform.

\section{Definitional Debate}

In addition to the debate of what should be taught in schools of social work was the underlying issue and lack of agreement on what the practice of social work includes. This definitional debate of social work, what schools of social work should teach and how to assess educational outcomes continues to date (Austin, 1983; Greene, 2005; Holosko, 2003; Peebles-Wilkins \& Shank, 2003). Hoffman \& Godenzi (2007) argue for the unification of NASW and CSWE in an attempt to unite the profession and "cease the internal competition" in light of dwindling resources (p. 184). Hoffman, who served as CSWE president until July 2007 , announced a meeting of sister organizations to take place in June 2007 to further explore and plan the unification and mission for the project (Hoffman \& Godenzi, 2007). The discussion resulted in an agreement to unite the professional organization by the year 2012 . 


\section{Problem Statement}

Although there may be a variety of outcomes for institutions and programs to select in their assessments of learning, promotion and development of critical thinking skills has been consistently highlighted as the ideal outcome at both the institution and program levels. Higher order levels of thinking (often referred to as critical thinking, evaluation, and/or synthesis) are a major focus in higher education and social work education specifically. The policy reports previously mentioned such as Involvement in Student Learning (1984), Integrity in the College Curriculum (1985), as well as the recent Spelling's Report (2006) highlighted the importance not only of improving student learning, but also to enhance students' high order level cognitive operations and to optimize informed decision making processes and practice in the prospective fields (Puzon, 1994; A Test of Leadership: Charting the Future of U.S. Higher Education, 2006). Program specific accreditation organizations, as well as a university's accreditation agencies, have emphasized critical thinking skills explicitly in their mandates(Handbook of Accreditation Standards and Procedures, 2003; Principals of Accreditation: Foundations for Quality Enhancement, 2001). CSWE established a specific curriculum objective stating students should have the ability to "apply critical thinking skills within the context of professional social work practice" (Handbook of Accreditation Standards and Procedures, 2003, p. 7) and the Southern Association of Colleges and Schools (SACS) requires a similar focus in their standards (Principals of Accreditation: Foundations for Quality Enhancement, 2001).

As the University of Louisville's Kent School of Social Work approached reaccreditation, faculty and administrators decided to revise the curriculum with a critical 
thinking emphasis and infuse critical thinking throughout all courses. Based on the critical thinking emphasis, program objectives were crafted, selected, and then linked to courses in the curriculum. Kent School's curriculum description is in Appendix A. To assess the educational outcomes of the program, Kent School utilized the following instruments: California Critical Thinking Skills Test (CCTST), Foundation Practice SelfEfficacy (FPSE), Foundation and Advanced Practicum Evaluations, and routine course evaluations and assignment rubrics.

The purposes of this study are to utilize the data gathered in this outcomes assessment process to (a) test a predictive model of students' critical thinking skills upon entry into Kent School of Social Work, (b) examine changes in students' critical thinking skills after completing a critical thinking infused curriculum, and (c) test two predictive models of successful critical thinking skills development for graduating Kent School of Social Work students.

\section{Organization of Study}

This dissertation is divided into five chapters. The first chapter gives the historical background of how assessment in higher education gained momentum and introduced the emphasis on critical thinking as a specific educational outcome. Chapter two provides a literature review of critical thinking to include the definition of critical thinking, measurement strategies, influential variables, as well as the theoretical underpinning and conceptual framework for the research. Chapter three describes the methodological components of the study, i.e. questions and hypotheses, research design, samples, data sources, operationalization of variables, and data analysis techniques. Chapter four 
presents the results of the analysis, and chapter five provides a discussion of the results, limitations, suggestions for future research, and implications for educators. 


\section{CHAPTER TWO}

\section{Introduction}

The previous chapter provided a historical review of the evolution of assessment in higher education and the factors which contributed to the current status of assessment. This chapter will build on this historical foundation by focusing on a particular area emphasized in the assessment movement, namely the prominence of critical thinking as a specific outcome for college graduates. Critical thinking was briefly introduced in the problem statement, but this chapter will explore critical thinking in regards to its various definitions, theoretical underpinnings, curriculum structures, measurement strategies, and influential variables, and will conclude with a conceptual framework for the proposed research study.

Critical thinking has gained prominence in higher education as it is viewed a "cure all" by assuming if students have well-developed critical thinking skills, the rest will follow or at least come easier (Ingle, 2007; Kurfiss, 1988; Rane-Szostak \& Robertson, 1996; Seelig, 1991). Critical thinking has been a unifying concept in higher education and across disciplines as it is viewed as a valuable multidisciplinary skill in a variety of contexts (Ingle, 2007). As society continues to change and evolve at an exponentially faster rate due to technological advances and increasingly complex social problems, it becomes even more necessary for college graduates, specifically social work graduates, to have the skills necessary to maintain effectiveness, and critical thinking is 
believed to be that skill (Gibbons \& Gray, 2004; Greene, 2005; Ingle, 2007; Seelig, 1991). Chaffee (1994) argued that critical thinking skills allows a person to consider new perspectives, encourages self-confidence and independent thinking, and promotes lifelong learning. This renewed interest in critical thinking has been encouraged by accreditation bodies and policy reports which have emphasized and required its development. Critical thinking is viewed not only as an important strategy to improving student learning, but also an avenue for students to develop the ability to perform higher order level cognitive operations to optimize informed decision making processes and practice in their prospective fields.

\section{Definition}

There may be agreement that critical thinking is a desirable skill expected of college graduates and of significant value in the workplace; however, there is not agreement as to what skills or attitudes make up critical thinking (Ingle, 2007). Although critical thinking is recognized as one of the most essential outcomes of a college education, it is not a novel concept (Williams, Oliver, \& Stockdale, 2004). Critical thinking has been recognized as an important concept to learning as far back as the days of Socrates, Plato, and Aristotle; however, numerous attempts have been made at defining critical thinking and outlining the skills necessary to develop such critical thinking (Kurfiss, 1988; Seelig, 1991; Staib, 2003). However, a general consensus on the definition of critical thinking has yet to be determined. The complexities of the critical thinking construct and the variations of perspectives across disciplines have contributed to this lack of consensus (A. Jones, 2007; Rane-Szostak \& Robertson, 1996; Staib, 2003). 
Reflective and creative thinking, logical reasoning, and cognitive processes are terms whose meaning are often blurred and intermingled in the discussion of critical thinking (Seelig, 1991). Even though these terms separately are not adequate to explain or describe the complex construct of critical thinking, each contributes to its meaning in a unique manner. The reflective thinking component of critical thinking dates back to the iconic work of Dewey (1933) in How We Think (originally published in 1910) who described reflective thinking as "an act of searching, hunting, and inquiring to find materials that will resolve the doubt, settle and dispose of the perplexity"(p. 12). These components of reflective thinking are still used today to describe critical thinking. Richard Paul (1992), Director of Research and Professional Development at the Center for Critical Thinking and Chair of the National Council for Excellence in Critical Thinking, defined critical thinking as thinking about ones thinking while thinking in order to make ones thinking better, again highlighting the reflective component of critical thinking. The creative element of critical thinking urges the learner to move beyond the acceptable and known solutions. To not be limited by what is already known about an idea, concept or experience, but be willing to look beyond and experiment with possible alternatives or solutions.

Logical reasoning, often referred to as the art of argumentation, is key to critical thinking as well. This component, in particular, dates back to ancient Greek times where truth was sought out by arguing or debating a topic through criticism and critical discussion (Kurfiss, 1988; Norris \& Phillips, 1987). Logical reasoning entails analyzing arguments, and finding errors or fallacies in the argument or thought processes, and constructing convincing counterarguments (Kurfiss, 1988). Reasoning is also commonly 
described as both inductive and deductive. Inductive reasoning refers to generalizations that can never be proven as absolute and are more susceptible to fallacies, such as attacking a person's credibility, falsely limiting the available choices, or drawing conclusions from minimal evidence or unrepresentative samples (Kurfiss, 1988). In contrast, deductive reasoning begins with a hypothesis and observations followed by an evaluation of the hypothesis based on the evidence and requires strict adherence to rules or guidelines such as the scientific method. Critical thinking expert Robert Ennis also focused on the assessment of arguments in his initial explication of critical thinking and then according to Norris and Phillips (1987) "extended the meaning to include not only the appraisal of statements but the whole process of reasonably and reflectively going about deciding what to believe or do" (p. 294).

Lastly is the cognitive component, which arguably is the most significant component to critical thinking in that it utilizes both reflective and creative thinking, as well as logical reasoning. All of these are considered cognitive processes an individual uses when employing critical thinking skills (Norris \& Phillips, 1987). Bloom's Taxonomy (Bloom, 1956) was developed in 1956 as an instrument to provide common terminology and explanations of degrees of student learning to assist faculty in discussing and sharing information and ideas about education as well as a tool for curriculum reform. The taxonomy includes a hierarchy of six levels of cognitive functioning, i.e. knowledge, comprehension, application, analysis, synthesis, and evaluation, with analysis, synthesis and evaluation being classified as higher order levels of thinking associated with critical thinking (Bloom, 1956; Hanna, 2007; Lord \& Baviskar, 2007). The taxonomy is frequently used to identify specific domains of learning that are key to 
developing critical thinking skills, particular in the context of developing and assessing objectives at both the course and institution level (Bloom, 1956; Facione, 1990e; Scriven \& Paul, 1992). Norris and Phillips (1987) explored the cognitive process of critical thinking in their comparison of schema theory to critical thinking theory in the context of reading comprehension. The authors described critical thinking as being process-oriented incorporating hierarchal stages of interpretation, interaction between the data from the text, the reader's experiences, as well as the understanding created from the reading. A reader employing critical thinking skills would use this information in creative and imaginative ways, negotiate between these various types of knowledge, and then finally determining how the interpretations are to be evaluated based on the information available (Norris \& Phillips, 1987).

Although these components are being discussed separately, a meta-analysis conducted by Bangert-Downs and Bankert (1990) suggested schools who utilized both the logic and reasoning components (described by the authors as internal validity) as well as the cognitive component of examining the quality of evidence (external validity) in their critical thinking instruction produced larger effect sizes. These findings supported the complexity of the critical thinking definition and the need to form a thorough and comprehensive definition to guide the explicit learning of critical thinking skills.

In addition to these various components of critical thinking, the influence of the various discipline specific orientations of the faculty has a significant impact on how critical thinking is defined within a department as well as institution wide. Jones (2007) provided an insightful analysis into the differences between faculty from the history and 
economics departments of two large research universities. A total of fourteen faculty members were asked about their conceptualization of critical thinking during in-depth semi-structured interviews, and distinct disciplinary differences were noted (A. Jones, 2007). The authors explained that historians embraced the multiple perspectives of history, exploring the motivations of events and actions, with an existential influence on ideas of humans' origin and purpose (A. Jones, 2007). Economics, however, was viewed as a more logical and rigid discipline that approached issues in a scientific, quantifiable, and mathematical manner with an emphasis on structured and formal processes (A. Jones, 2007). These discipline perspectives had a distinct impact on the way in which the faculty explained their conceptualizations of critical thinking. Economics viewed critical thinking as a specific problem solving method that required knowledge of the tools and application; whereas, history used critical thinking to examine the power relationships in the multiple perspectives of historical events (A. Jones, 2007). Although there were similarities noted in the interviews, the influences of the epistemological understandings of knowledge through their discipline specific lenses did, in fact, influence their conceptualization of critical thinking.

The notion of discipline specific differences in critical thinking conceptualizations is supported by the previously discussed requirements of accreditation agencies, in that not only are institutional level accreditation agencies requiring the obtainment of critical thinking objectives, but discipline specific accreditation bodies are also mandating this focus(Handbook of Accreditation Standards and Procedures, 2003; Holstein, Zangrilli, \& Taboas, 2006; Matthiesen \& Wilhelm, 2006; Principals of Accreditation: Foundations for Quality Enhancement, 2001). This emphasis is also evident in the rapidly increasing 
number of research studies on defining, teaching, and measuring critical thinking skills within a specific discipline. In particular, nursing programs have led the way in critical thinking research, examining predictors, effective pedagogical strategies, and the development of instruments to specifically measure critical thinking skills for nurses (Chaffee, 1994; Holstein et al., 2006; Matthiesen \& Wilhelm, 2006; Rane-Szostak \& Robertson, 1996; Rodriguez, 2000; Staib, 2003; Zygmont \& Schaefer, 2006).

The social work profession has also followed this trend to define critical thinking, accreditation requirements and research to improve students' critical thinking skills (Gibbons \& Gray, 2004; Greene, 2005; Plath, English, Connors, \& Beveridge, 1999; Seelig, 1991). According to Greene (2005), as the social work profession strived to redefine itself in the new millennium, the emphasis will be on developing reflective, critical practitioners who are committed to life long learning. Social work mirrors some of the same perspectives on critical thinking as both the history and economics department discussed in Jones' (2007) research in that multiple perspectives are valued in an increasingly complex and fluid society and the increased emphasis on evidence-based practice (Greene, 2005; Seelig, 1991). Gibbons and Gray (2004) describe critical thinking from a social work perspective as more than a rigid scientific process, but an application of discipline specific critical thinking skills in real life practice. Plath, English, Connors, and Beveridge (1999) described social work critical thinking skills as "the ability to tease out the factors impacting upon a situation, define a range of concepts and to integrate knowledge from a range of sources in making decisions about appropriate social work interventions in different contexts" (pp. 208-209). The new Educational Policy and Accreditation Standards (2008) prepared by CSWE, emphasize the development of such 
critical thinking skill sets as "principals of logic, scientific inquiry, and reasoned discernment" ability to "appraise and integrate multiple sources of knowledge, including research-based knowledge and practice wisdom, analyzing models." (p. 4). Each of these portrays the conceptualization of critical thinking within the social work perspective and the influence of discipline specific orientations on defining critical thinking.

In response to this definitional confusion, the American Philosophical Association asked Peter Facione to explore critical thinking and the necessary skills. Utilizing the qualitative Delphi Method, a group of forty-six experts were gathered in 1988 to explore the concept of critical thinking (Facione, 1990e). There were six rounds of questions in which responses were submitted to the coordinator who then shared the responses with each panel member while omitting their names. First, the group explored core elements of critical thinking to be expected at the undergraduate freshman and sophomore level, then the specific skills which make up critical thinking, the dispositional dimension of critical thinking, and specific recommendations for teaching and assessing critical thinking (Facione, 1990e).

The group conceptualized critical thinking as having two dimensions, cognitive skills and affective disposition arguing. Not only were there specific skill sets which were necessary to think critically, but there were also particular characteristics or affective dispositions of a critical thinker (Facione, 1990e).. The groups' consensus statement reads:

We understand critical thinking to be purposeful, self-regulatory judgment which results in interpretation, analysis, evaluation, and inference, as well as explanation of the evidential, conceptual, methodological, criteriological, or contextual 
considerations upon which that judgment is based. The ideal critical thinker is a habitually inquisitive, well-informed, trustful of reason, open-minded, flexible, fair minded in evaluation, honest in facing personal biases, prudent in making judgments, willing to reconsider, clear about issues, orderly in complex matters, diligent in seeking relevant information, reasonable in the selection of criteria, focused in inquiry and persistent in seeking results which are as precise as the subject and the circumstances on inquiry permit. (Facione, 1990a).

Ennis also discussed this concept of critical thinking being not only an ability, but also a disposition. For example, an individual may have critical thinking skills, but not the disposition to use them. Conversely, an individual may have the disposition to remain open-minded, look at the whole situation, be open to change but not possess the skills necessary to think critically (Facione, Facione, \& Giancarlo, 2000; Norris \& Phillips, 1987). The idea of individuals having a disposition to thinking again echoes some of Dewey's (1933) original ideas in that he described the "dispositional aspects of thinking as personal attributes" (Facione et al., 2000, p. 6). Facione, Facione, and Giancarlo (2000) expanded on this concept of disposition to critical thinking specifically in their research by exploring the relationship between critical thinking skills and disposition towards critical thinking by analyzing students scores on the California Critical Thinking Skills Test and the California Critical Thinking Dispositional Inventory. The group analyzed four separate sets of data: one group involved $19310^{\text {th }}$ grade students and found a statistically significant correlation of $r=.41$ between their scores; 133 accounting professionals' scores resulted in a correlation of only $\mathrm{r}=.091 ; 328$ nursing undergraduates yielded a statistically significant correlation of .318; 1557 undergraduate 
nursing students yielded a statistically significant correlation of $r=.201$ (Facione et al., 2000). Although statistically significant, these correlations are surprisingly weak; however, Facione, et al. (2000) found a stronger relationship between the CCTDI given at program entry with the CCTST given at the exit of the program $(\mathrm{r}=.233, \mathrm{p}<.001)$, indicating students with a stronger disposition at the beginning of the program showed greater skill development than those who had weaker dispositions. Researchers indicate this may discredit any theory of a one to one relationship between critical thinking and the disposition; however, argue "educational and professional success require developing one's thinking skills and nurturing one's consistent internal motivation to use those skills" (Facione et al., 2000, p. 35)

Thus, due to the multiple definitions offered for critical thinking it is vital that the school or program select the definition that is most consistent with the programs' goals and objectives (Rane-Szostak \& Robertson, 1996). The University of Louisville's Kent School of Social Work selected Paul and Scriven's (1992) definition as the guide for their critical thinking focused curriculum. Note that their definition utilizes some of the same concepts identified by the Delphi Report.

Critical thinking is the intellectually disciplined process of actively and skillfully conceptualizing, applying, analyzing, synthesizing, and/or evaluating information gathered from, or generated by, observation, experience, reflection, reasoning, or communication, as a guide to belief and action. (Scriven \& Paul, 1992).

\section{Theoretical Underpinning}

Cognitive Flexibility Theory (CFT) offers a unique and useful theoretical foundation for understanding critical thinking as it focuses on advanced knowledge 
acquisition and application and provides specific examples of instructional application. The CFT was developed by Dr. Rand L. Spiro, a professor of Learning, Technology and Culture at Michigan State University in the College of Education, and collaborators Paul Feltovich and Richard Coulson. Cognitive Flexibility Theory is classified as a constructivist theory with linkages to Bruner, Ausubel, Piaget and Salamon's media and learning interaction (Fitzgerald, Wilson, \& Semrau, 1997; Kearsley, 2006a; G. A. A. Lee, 2004; Spiro, Feltovich, Jacobson, \& Coulson, 1991a, 1991b). CFT is classified as a constructivist theory in that knowledge is constructed from current or previously learned knowledge and allows the learner to utilize more information than that which may be provided initially. However, CFT goes beyond the constructivist idea of "retrieving organized packets of knowledge of schemas" and suggests that individualized or compartmentalized pieces of knowledge are insufficient for the complexity of illstructured domains (Harden \& Stamper, 1999; Kearsley, 2006a, p. 1, 2006b, p. 1; Spiro, Feltovich et al., 1991b). CFT was developed to address the gap in advanced knowledge acquisition and students' ability to effectively utilize knowledge in a variety of settings by providing strategies for students to learn challenging material, encouraging flexibility in using knowledge in the work setting, "changing underlying ways of thinking" (Spiro, Collins, Thota, \& Feltovich, 2003, p. 5), and utilizing technology to promote these goals. Much of Spiro's research centers on minimizing linear instruction and oversimplification in instruction and learning that can interfere with acquiring advanced knowledge (BogerMehall, 1997; Spiro, Feltovich et al., 1991a). See Figure 1 for a concept map of CFT as developed by Spiro, which illustrates key concepts of the theory which will be explained in detail in the following section. 


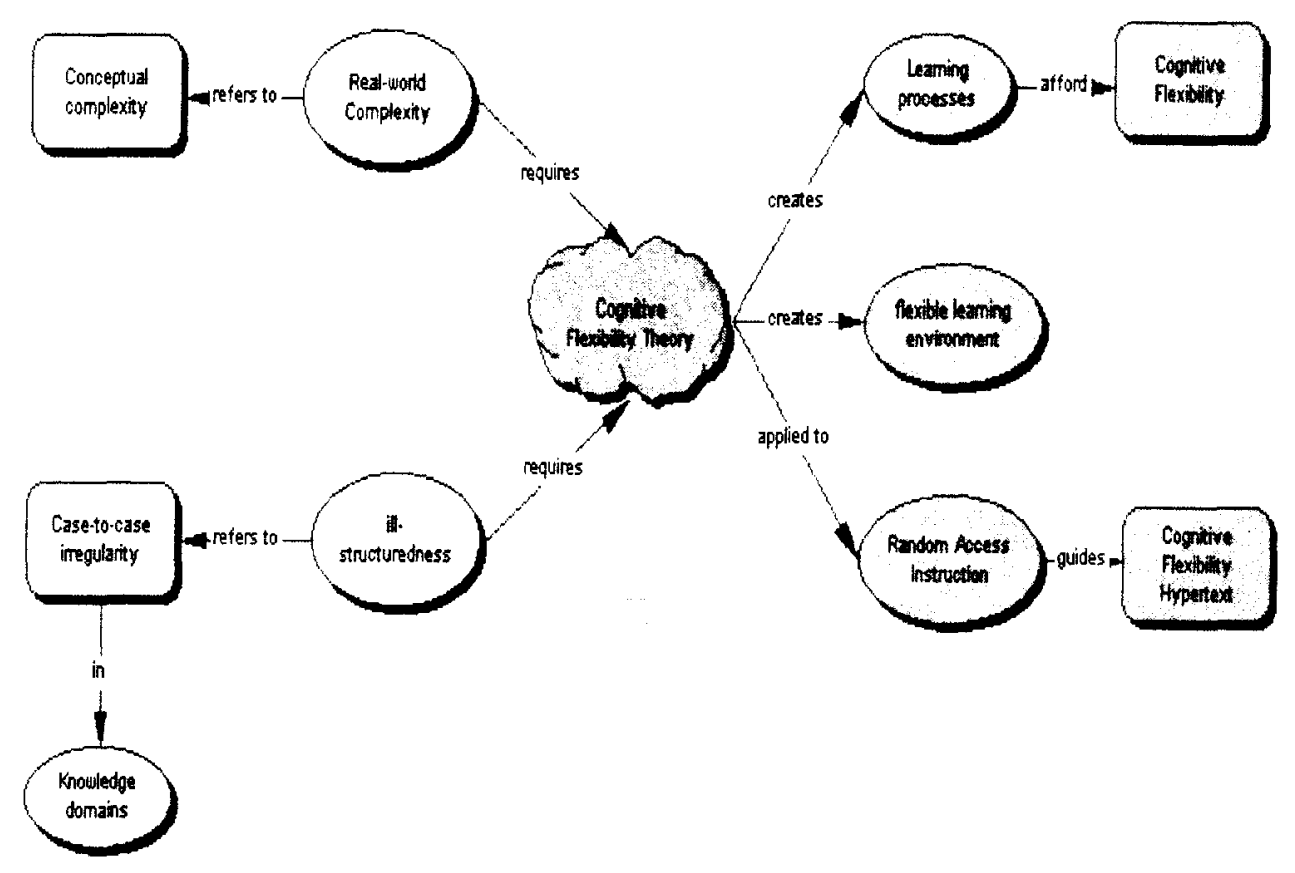

Figure 1: Conceptual map of Cognitive Flexibility Theory

To provide a more in depth understanding of CFT, key concepts such as advanced knowledge acquisition, ill-structured domains, cognitive flexibility, and crisscrossing landscapes are defined and explained regarding their relationship to the theory. The implications for social work education are explored throughout with specific attention to how CFT supports the critical thinking perspective emphasized by CSWE's accreditation and educational policies. A review of the oversimplification strategies which CFT attempts to address will be discussed as well as how CFT based hypertexts are used to overcome these barriers to advanced knowledge acquisition.

\section{Terminology}

\section{Advanced Knowledge Acquisition}

Cognitive Flexibility Theory attempts to address the deficits of advanced knowledge acquisition that institutions of higher education commonly struggle to 
overcome. Advanced knowledge acquisition refers to learning after the obtainment of the introductory level knowledge of an area, but prior to the knowledge gained from extensive experience (Spiro, Coulson, Feltovich, \& Anderson, 1988). Whereas, introductory level learning may involve rote learning; this approach may in fact interfere with acquiring advanced knowledge acquisition of the same subject later on in the individual's education (Spiro, Feltovich et al., 1991a). Schoenfield (1987) discussed the differences in inexpert and expert learners explaining that "inexpert learners are likely to seize on the first strategy" presented and without considering outcomes or results. In contrast, expert learners examine and analyze situations prior to selecting strategies, then they evaluate results to determine whether alternative methods may have been more appropriate (Evans, Kirby, \& Fabriger, 2003).

In social work specifically, various treatment options and techniques are available in assisting clients in meeting their desired goals. It is imperative for social workers to be able to integrate and evaluate which techniques or strategies would be of maximum benefit to clients. In addition, social worker must evaluate success and make necessary changes in response to the desired outcomes (expert learner), instead of learning one treatment strategy and using it indiscriminately regardless of the presenting problem (inexpert learner). In advanced knowledge acquisition, students must achieve a deeper, more complex understanding of the subject matter and critically contemplate and evaluate the material while experimenting with the flexible application of the knowledge in a variety of contexts. 


\section{Ill-structured Domain}

Ill-structured domain, a central concept in CFT, attempts to explain the case-tocase irregularity in advanced knowledge domains. Spiro, et al. (1991a) described illstructured domains as having two central characteristics: first, each situation or context within the domain involves multiple interactions within a variety of contexts, each of which is multifaceted in its own right; and second, due to the variability within the domains, there is not a minimal number of explanations or examples to explain each interaction. It is not that one explanation or perception is incorrect or false, but rather it is not thorough enough to accurately portray the concept (Spiro, Collins, \& Ramchandran, 2006; Spiro et al., 1988; Spiro, Feltovich et al., 1991b). To further explain the concept of ill-structured domains, social work practice provides such as example. Within social work practice multiple problems, populations, settings, and techniques can interact with each other at a variety of contexts. More specifically, social work encompasses such problems as child abuse, substance abuse, mental health, physical disability, poverty and discrimination with a variety of populations, i.e. male and/or females, adults, children or elderly, Hispanic, African American, students within a variety of settings such as a free clinic, for profit agencies, local, state, and federal government entities, and from a variety of treatment perspectives such as narrative, solution focused, behavioral and motivational interviewing. Each of these specific areas is evolving and expanding on a daily basis with new social problems, treatment options, and populations that present to social workers for help. In social work education, it is imperative that social work students be exposed to a variety of case examples in a variety of contexts within educational settings to develop a 
wide knowledge base from which to draw to competently and adequately serve future clients.

\section{Cognitive Flexibility}

Spiro and Jehng (1990) described cognitive flexibility as an individual's ability to transition from merely verbatim recall to spontaneously constructing knowledge in a variety of ways in response to ever-changing demands. These scholars held that

Cognitive flexibility includes the ability to represent knowledge from different conceptual and case perspectives and then, when the knowledge must later be used, the ability to construct from those different conceptual and case representations a knowledge ensemble tailored to the needs of the understanding or problem solving situation at hand (Spiro, Feltovich et al., 1991a, p. 24)

CFT seeks to develop and nurture expert learners by focusing on the ability to be flexible in their utilization of knowledge in real world situations. Social workers must be able to integrate and evaluate which techniques or strategies will be of maximum benefit to clients, evaluate their success, and make necessary changes to achieve the desired outcomes. Flexibility is thus, a vital tool of effective social work practice. In advanced knowledge acquisition, students must achieve a deeper, more complex understanding of the subject matter, critically contemplate and evaluate the material while experimenting with the flexible application of the knowledge in a variety of contexts (Spiro et al., 1988).

\section{Crisscrossing Landscapes}

Within the instructional context, CFT suggests that students comprehend the complexity of ill-structured domains through multiple case examples, perspectives, and representations of the same information in a variety of contexts (or crisscrossing) to 
nurture the cognitive flexibility necessary for acquiring advanced knowledge (Graddy, 2001). By examining multiple examples of the same ideas and concepts students "develop the mental scaffolding necessary for considering novel applications within the knowledge domain" (Graddy, 2001, p. 1). The ability to selectively utilize and construct knowledge to fit the needs of a particular situation at hand depends upon having as many examples from a variety of perspectives/contexts to refer to as possible (Spiro et al., 1988). Spiro, et. al (1991a) further explained that single explanations or examples do not provide a rich enough example of variability and complexity indicative of ill-structured domains.

Pichert and Anderson (1977) explored the influence of perspectives using schema theory in their research of student learning. Students were given a story to read from either a burglar or a home buyer's perspective and then were asked to identify important points in the story based on their assigned perspectives (Pichert \& Anderson, 1977). Findings indicated that "perspective can affect importance, which in turn affects learning" (Pichert \& Anderson, 1977, p. 312). This suggests that if learners rely on limited perspectives and cannot crisscross their cognitive skills, valuable information may be lost in the learning process. These findings are consistent with Spiro's argument of the importance of teaching from multiple perspectives to capture the complexity of illstructured domains. "Knowledge that will have to be used in many different ways, as will be the case in ill-structured domains, must be taught and mentally represented in many ways" (Spiro, Feltovich et al., 1991b, pp. 22-23). Spiro, Feltovich and Coulson (1991, p. 1). Beyond the multiple representations of content are the students' active involvement 
with comparing various perspectives and contexts through crisscrossing across landscapes of knowledge domains (Godshalk, Harvey, \& Moller, 2004).

\section{Theoretical and Research Support}

CFT was posed as a solution to reported barriers to advanced knowledge acquisition, particularly in ill-structured domains. Graddy (2001) argued that CFT "provides a framework for developing a case-based approach aimed at improving upper level cognitive skills (i.e. critical thinking), particularly the ability to transfer knowledge to novel situations" (p.1). The theoretical and research support for CFT corroborates its use in social work as well as higher education.

CFT's accommodation of multiple perspectives also builds upon another theorist in constructivist theorist, Jerome Bruner and his idea of a spiral curriculum. This idea advocates revisiting topics throughout the curriculum, while increasing the level of difficulty, complexity and depth of the area, and linking new knowledge or information to previous levels of learning on the same topic. Bruner argued that this approach increased the competency of learners (Harden \& Stamper, 1999). This idea of "mental scaffolding" is consistent with CFT (Graddy, 2001, p. 1). The layers of scaffolding in CFT, however, reflect the multiple representations of content from various perspectives/contexts as being more representative of the ill-structured domains highlighted in CFT. An example of the application of CFT based instruction involving multiple perspectives by Godshalk, Harvey and Moller (2004) was discussed previously. The authors utilized cognitive flexibility theory to teach learners about sexual harassment and then measured any change in attitudes. These authors argued that instruction based on CFT stressed the importance of weaving themes and perspectives into a whole to 
better understand the complexities of the topic at hand (Godshalk et al., 2004). A webbased instructional hypertext was used for learners to explore sexual harassment from the perspectives of the victim, harasser, administrator, and co worker, while serving as either a policy maker or juror (Godshalk et al., 2004). Additional resources, such as legal viewpoints and commentaries on such topics as power, societal views and individual responsibility, were included in the hypertext (Godshalk et al., 2004). Students then compared and contrasted the various perspectives, highlighting the crisscrossing component of CFT to enhance the learning process. Godshalk et al. (2004) reported that ...a task requiring learners to explore several opinions and options (through policy creation) was able to facilitate the goals of the instruction better than a task that forced learners to make a judgment (such as the task of the jury) possibly based on prior knowledge or stereotypes (Godshalk et al., 2004, p. 522) Salomon's (1977) theory of symbol systems highlighted this relationship between the tasks and their impact on learning in that the cognitive demands of a learning task and the learner's mastery of skills must be woven into a whole cloth for learning to occur (Kearsley, 2006e; Salomon, 1977).

Li and Johnson (2004) provided an example of how CFT can be used with groups of students from various backgrounds or interests, i.e., the micro/macro dichotomy within social work education. Figure 2 shows how a class was divided into two groups addressing separate content that were then shared with the other group. Each group gave feedback to the other, and the learning process was discussed. 


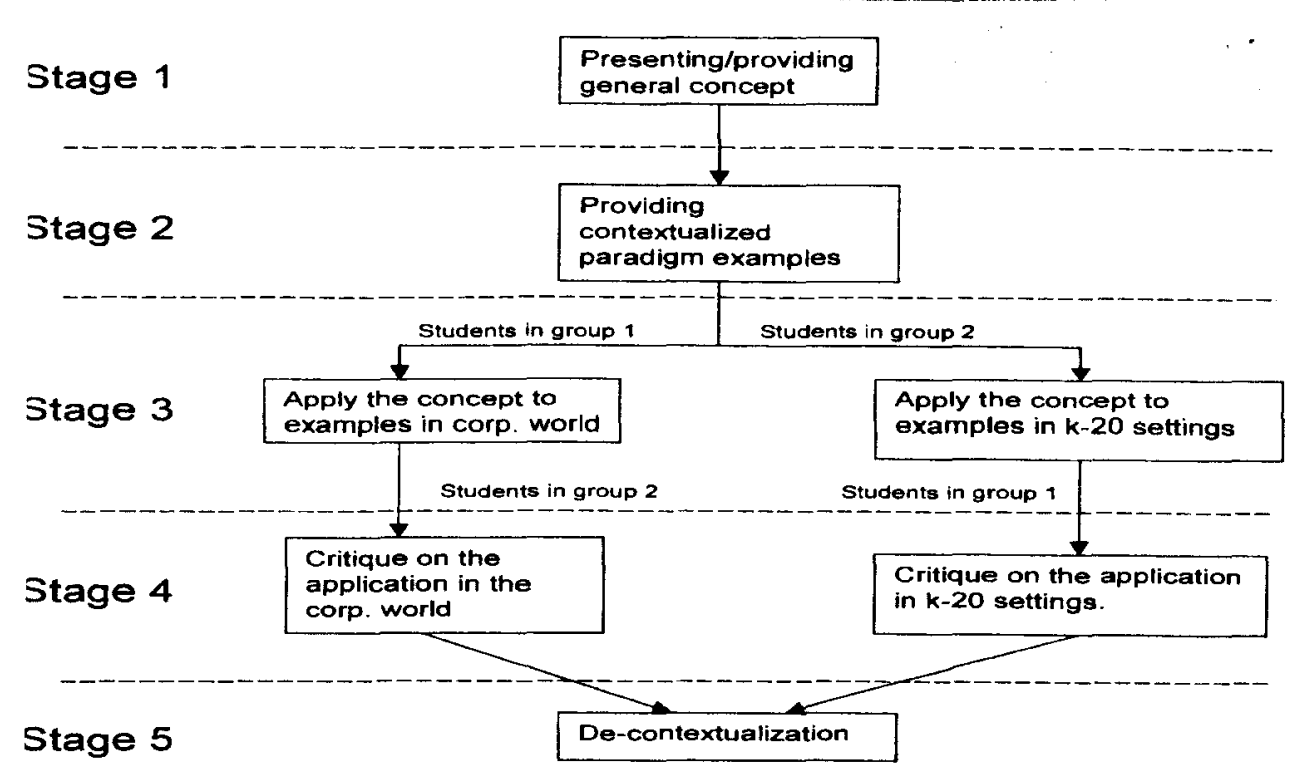

Flgure 1. The five stages of the model, from initial presentation to reflective decontextualization.

Figure 2: Five stages of the conceptual model developed (Li \& Johnson, 2004)

Utilizing the micro/macro example, students would receive instruction in various forms, i.e. lecture, readings, hypertext, field work, etc. (Stage 1-2) and would then be divided according to their interest; for example, group 1 would be micro and group 2 macro. Next, the students would complete an assignment on the new content but from the opposite perspective, i.e. the micro group would complete the assignment from the macro perspective and vise versa (Stage 3). The groups would present their results to each other, critique each other, and provide feedback based on their expertise (Step 4). Stage 5 requires students to internalize the information and its applications in real world settings highlighting the value of multiple perspectives (Li \& Johnson, 2004). This crisscrossing element of CFT is similar in principal to Ausubel's Subsumption Theory (Kearsley, 2006d) in that new knowledge can be integrated with previous learning in a crisscross fashion that results in new and existing knowledge and is consistent with Piaget's assimilation and accommodation processes of adaption (Kearsley, 2006c, 2006d). CFT 
integrates these key components of constructivist theory, i.e. Bruner, Piaget, Ausubel and Salomon in such a way as to maximize advanced knowledge acquisition, with particular emphasis on the utilization of theoretically based hypertext systems to foster this higher level of student learning.

\section{Oversimplification Strategies}

As previously stated, CFT was developed to address deficits in advanced knowledge acquisition. Spiro, Feltovich, Jacobson, Coulson (1991a) argued that failure to obtain the higher order levels of knowledge acquisition is common place and put forth several suggestions as to why institutions of higher education are struggling. Such oversimplification strategies as additivity, discreteness, and compartmentalization biases interfere with a learner's abilities to construct advanced knowledge, particularly within ill-structured domains (Spiro et al., 1988; Spiro, Feltovich et al., 1991a). Additivity bias occurs when parts of complex topics or concepts are examined and presented individually with the assumption once they are combined; they maintain their original characteristics (Spiro et al., 1988; Spiro, Feltovich et al., 1991a). For example, within the social work context, additivity would occur if the social worker did not recognize how the separate characteristics of child abuse and substance abuse could change if the issues occurred within the same client/family. Discreteness biases occurs when "continuously dimensioned attributes (like length) are bifurcated to their poles and continuous processes are instead segmented into discrete steps" (Spiro, Feltovich et al., 1991a, p. 26). Discreteness could occur in regarding to Kubler-Ross' stages of grief if the stages were viewed as individual and completely separate without overlap, or the erroneous perspective that once Stage 1 is completed the client moves forward, never back. 
Compartmentalization occurs when information/ideas, etc. are presented as separable and self-reliant as individual containers or compartments, when in fact they are highly interrelated on other ideas/concepts (Spiro et al., 1988; Spiro, Feltovich et al., 1991a). This compartmentalization of ideas/concepts restricts the development of advanced knowledge acquisition to ill-structured domains and may even prevent the useful comparisons of components that are, in fact, independent; however, examining relationships across conceptual structures aids understanding (Spiro et al., 1988). This means that there is an over reliance on a single explanation, rather than exploring the interconnectedness of a variety of linkages. For example, child abuse could be viewed in terms of its relationships with parental substance abuse; however, failure to explore other factors such as poverty and domestic violence narrows the view of child abuse.

\section{CFT Hypertext}

In attempt to overcome the oversimplification in instruction, Spiro, Coulson, Feltovich and Anderson (1988) argued the utilization of hypertext to facilitate the application of CFT as it provided an avenue for students to explore multiple perspectives/contexts that would be difficult in a regular lecture setting. Hypertext is a computer-generated technology that highlights words/titles to point readers to key web sites for supporting information (M. J. Lee \& Tedder, 2003). It facilitates a learner's exploration of ill-structured domains through a variety of pre-programmed linkages that are designed to optimize the promotion of complex and advanced learning acquisition. The program allows users to explore a domain from a variety of perspectives while also providing additional resources to support the learning process. CFT can utilize the technological advances to facilitate advanced knowledge acquisition. Utilizing web-based 
programs and technology to advance learning is not a new concept; however, Spiro, Feltovich, Jacobson and Coulson (1991a) argued that instructors needed the discipline to ground hypertext design in a suitable learning theory, i.e. CFT and not just develop a program with random multiple connections that could overwhelm students and inhibit advanced knowledge acquisition instead of fostering deeper and more complex understandings . The previously discussed hypertext program developed by Godshalk, Harvey, and Moller (2004) for sexual harassment training thus demonstrated the theoretical application of CFT to hypertext technology in learning (Godshalk et al., 2004).

\section{Curriculum Structures}

Once a definition and theoretical foundation is selected, it then becomes necessary to focus on the implementation strategies which most effectively facilitated and promoted the obtainment of critical thinking skills. There is a significant debate as to how critical thinking should be taught in the curriculum which then also includes the debate of whether critical thinking is a discipline specific or a generic skill (Ennis, 1989; Kurfiss, 1988; McPeck, 1990; Plath et al., 1999; Prawat, 1991). These issues applied at both the institutional level as well as the program level, particularly in light of accreditation agencies at both levels emphasizing critical thinking as a required outcome for students (Handbook of Accreditation Standards and Procedures, 2003; Principals of Accreditation: Foundations for Quality Enhancement, 2001). The following discussion will integrate these debates and explore the strengths and weaknesses.

Ennis (1989) suggested four models for critical thinking instruction, general, infusion, immersion, and a mixed method approach. According to Bangert-Drowns and 
Bankert (1990), the general model (also referred to as the stand-alone approach) refers to the explicit teaching of general critical thinking skills within a specific course, but not within a specific discipline; the infusion model (also referred to as the embedded approach) refers to explicitly teaching critical thinking skills within a specific discipline; and the immersion model suggests that critical thinking skills develop via a thorough indepth discipline specific knowledge, but without specific critical thinking instruction (Ennis, 1989; Prawat, 1991). The immersion model is consistent with the belief that critical thinking skills develop as a natural part of the educational process. On the surface it appears to be consistent with the belief that has largely been abandoned in recognition of the decline in American college graduates' ability to perform higher order levels of thinking; however, there is an assumption with the immersion model that teaching and learning goes far beyond basic memorization and seeks in-depth knowledge acquisition (Ennis, 1989; Facione, 1990b; Prawat, 1991; Puzon, 1994; A Test of Leadership:

Charting the Future of U.S. Higher Education, 2006; Williams et al., 2004). Ennis (1989) argued for utilizing the mixed methods approach to include a combination of the three to minimize the weaknesses of any single approach.

Bangert-Drowns and Bankert (1990) believes one of the most influential factors in students' gain of critical thinking skills is explicit instruction whether in a critical thinking course or across a curriculum. Rane-Szostak and Robertson (1996) state that a critical thinking course is necessary for significant improvement to occur in students' critical thinking skills. Facione's (1990b) research reported statistically significant results on pre and post test administrations of the California Critical Thinking Skills Test (CCTST) for students who took a course explicitly designed and taught to improve 
critical thinking skills of students $t(945)=2.44, \mathrm{p}<.0075$; however, there were no significant differences on pre and post test measures in the control group who took a philosophy course that was not an approved critical thinking course, $t(250)=.08, p=.938$. The experimental group consisted of students enrolled in psychology, philosophy, and reading courses; whereas, the control group consisted only of students in three sections of a philosophy course. All courses were considered introductory general education courses. Likewise, Williams, Oliver, Allin, Winn and Booher (2003) reported significant differences on a psychology specific critical thinking pre and post test instrument after a psychology human development course which included explicit critical thinking instruction and learning activities for students $t(109)=4.74, p<.001$. Plath, English, Connors and Beveridge (1999) reported significant differences in social workers' critical thinking skills on the Cornell Critical Thinking Test and Ennis-Weir Essay Test after a 32 hour/four week critical thinking unit $t(19)=3.19, p=.002$ for the Ennis-Weir Essay Test and $t(19)=1.58, p=.12$ (significant at the $93 \%$ level) for the Cornell Critical Thinking Test. Students had completed three years of the program, prior to the critical thinking unit. The researchers described the first three years of the program as relying on the immersion approach to critical thinking, whereas the 32 hour/4 week critical thinking unit within the social work program represented the infusion approach. Facione (1990b) study was based on the general approach and Williams, et. al (2003) relied on the discipline specific infusion approach; whereas Plath et. al (1999) utilized a discipline specific approach with both the immersion and infused models. Recognizing Plath's et al. (1999) research did not test the significance of the immersion portion of the curriculum, 
the similar thread between all three studies was the component of explicit instruction in critical thinking.

Although a critical thinking specific course or unit has demonstrated significant improvements of students' critical thinking skills, Terenzini, Springer, Pascarella and Nora (1993) explored the teaching of critical thinking skills from a curriculum perspective. They argued that the infusion of critical thinking in a curriculum to include the horizontal and vertical integration of critical thinking in multiple courses across the curriculum also promoted critical thinking skills (Terenzini et al., 1993). Although these ideas were applied in an undergraduate education context which crossed disciplinary boundaries, the vertical and horizontal integration of critical thinking could also be utilized within a specific discipline, as can the sequence and order of courses which also improved critical thinking (E. Jones, 1992; Terenzini et al., 1993). Kurfiss (1988) also supported this perspective stating "students' thinking abilities will remain limited unless faculty combine forces to cultivate thinking skills deliberately throughout the curriculum" (p. 91). Kurfiss argued that critical thinking could be taught in a single course or across the curriculum; however, it was essential that faculty work together to provide students opportunities to practice and use the critical thinking skills in multiple courses and contexts.

This perspective echoed some of the same issues Cognitive Flexibility Theory (CFT) addressed, i.e. the complexity of ill-structured knowledge domains, such as critical thinking, require that students be provided with opportunities to learn about, experience, and practice critical thinking skills from multiple perspectives by crisscrossing landscapes to fully achieve the advanced knowledge acquisition necessary for critical 
thinking and the cognitive flexibility to apply those skills as needed. Utilizing the principals of CFT within the context of critical thinking instruction provided faculty with tools to ensure multiple opportunities for students to learn and use critical thinking skills.

A similar approach was taken by faculty and administrators at the Kent School of Social Work as they worked to integrate critical thinking skills across the social work curriculum. See Appendix A for Kent School's curriculum description which outlines the theoretical principals guiding the curriculum.

\section{Measurement Strategies}

As critical thinking gained attention in the educational setting, scholars began developing means to measure critical thinking utilizing the definitions formed.

Standardized instruments in particular became a focus as their usage allowed comparison across various groups and settings. Rane-Szostak and Robertson (1996) suggested the following criteria should be examined when selecting an instrument: the particular definition of critical thinking that was used to guide the development of each instrument, whether the instrument is norm or criterion-referenced, sensitivity to growth, validity and reliability and the feasibility for the particular setting.

\section{Watson-Glaser Critical Thinking Appraisal}

The Watson-Glaser Critical Thinking Appraisal (WGCTA) was originally developed in 1964 by Goodwin Watson and Edward Maynard Glaser. Although the instrument had been used in educational settings, it was largely marketed to the business industry as a tool for hiring and promotion screening ("Watson-Glaser Critical Thinking Appraisal," 2007). The instrument has undergone numerous revisions through the years and is currently offered as Form A, B and S. The WGCTA Forms A and B each consist 
of 80 questions to be completed in 60 minutes. Gadzella, Baloglu and Stephens reported reliability and validity statistics conducted by Watson and Glaser (1980) stating "The split-half reliability correlated from 10 norm groups ranged from .69 to .85 , test-retest reliability for 96 students' responses was .73, and alternate-form reliability for 228 students' responses to Forms A and B was .75" (p. 620). Gadzella, Baloglu and Stephens (2001) reported an internal consistency of the WGCTA was .86 for 135 students, with a split-half reliability of .65 . The concurrent validity for the students' grades and the total WGCTA was $r=.42(p<.001)$. The short version on the instrument, Form $S$, was developed in 1994 and includes 40 questions to be completed within 45 minutes. Gadzella, Hogan, Masten, Stacks, Stephens, Zascavage (2006) tested Form S on 486 undergraduate students and reported a reliability coefficient of .92 .

Although the versions vary in length, all three forms assess students' total critical thinking ability using five subscales, i.e. inference, recognition of assumptions, deduction, interpretation, and evaluation of arguments (Gadzella et al., 2002; Loo \& Thorpe, 1999). The guiding definition used by Watson \& Glaser (1994) is as follows: (1) attitudes of inquiry that involve an ability to recognize the existence of problems and an acceptance of the general need for evidence in support of what is asserted to be true; (2) knowledge of the nature of valid inferences, abstractions, and generalizations in which the weight or accuracy of different kinds of evidence are logically determined; and (3) skills in employing and applying the above attitudes and knowledge (p. 9) 


\section{Cornell Critical Thinking Test}

The Cornell Critical Thinking Test (CCTT) was originally developed in 1971 and is available in two levels. Level $\mathrm{X}$ was developed for grades 4-14 and Level $\mathrm{Z}$ was developed for college level students and adults. For the purposes of this discussion, Level $\mathrm{Z}$ will be discussed further. "Correlations from split-half reliability testing for Level $\mathrm{Z}$ range from 0.55 to 0.76 " (Rane-Szostak \& Robertson, 1996, p. 4). The test was designed by Robert Ennis and Jason Millman and includes 50 multiple choice questions to be answered in 50 minutes (Erwin, 2000). The test assesses students' generic critical thinking skills of induction, deduction, value judgment, observation, credibility, assumptions, and meaning, providing both total and subscale measures (Adams, Whitlow, Stover, \& Johnson, 1996; Erwin, 2000). The CCTT was developed on Ennis, Millman and Tomko's (1985) definition of critical thinking as "the process of reasonably deciding what to believe and do" (p. 1).

\section{Collegiate Assessment of Academic Proficiency}

The previous instruments were designed specifically to measure only critical thinking; however, the Collegiate Assessment of Academic Proficiency in particular was designed to assess general educational outcomes at the end of the first two years or upon completion of general education requirements ("Collegiate Assessment of Academic Proficiency ", 2000). This instrument will be included in the discussion due to the growing movement to select a single measurement to be used in all college and universities as a universal ruler for accountability and the CAAP's growing popularity in higher education. The Collegiate Assessment of Academic Proficiency (CAAP) is a standardized instrument for the assessment of postsecondary education developed by 
$\mathrm{ACT}$ and offers six individual test modules, i.e. reading, writing skills, writing essay, mathematics, science and critical thinking ("CAAP Technical Handbook 2007-2008,"). The CAAP has been in use since 1990 and has gained standing in higher education as an outcome measure which allows comparison of colleges and universities and their ability to meet educational outcomes. The critical thinking component consists of four separate passages students read and answer a total of 32 multiple choice questions within 40 minutes. "Reliability of the CAAP has been established at .87 for test $88 \mathrm{~A}$ and .86 for test $88 \mathrm{~B}$ with raw score standard deviations of 6.65 and 5.70 respectively and standard error of measurements of 2.40 and 2.46 respectively, with a KR-20 reliability coefficient of .92" (Sisung, 2005, p. 86). Although the ACT organization does not provide a specific definition of critical thinking, the critical thinking test module measures students on clarifying, analyzing, evaluating, and extending arguments. The results do not provide subscale measurements only a total critical thinking score. Depending on the needs of the individual school, this instrument is useful in that it provides schools the options of customizing which modules students take and also allows the addition of up to nine questions specific to the particular school ("CAAP Technical Handbook 2007-2008,"). This allows the school to assess not only critical thinking skills, but also other areas of student learning.

\section{California Critical Thinking Skills Test}

The standardized California Critical Thinking Skills Test (CCTST) Form 2000 is the most preferred instrument for assessing critical thinking skills of college level students and relies upon the Delphi Report's definition of critical thinking discussed previously. The CCTST consists of 34 multiple choice questions and can be administered 
in 45 minutes in either an online or paper format. Cronbach's Alpha from the CCTST ranged from .78 to .84 for the total instrument (Facione et al., 2000).

The results of the CCTST provide six different scores. The CCTST total score targets the strength or weakness of one's skill in making reflective, reasoned judgments about what to believe or what to do and includes the sum of analysis, inference, and evaluation (Facione, 2007). Scores were then generated based on the categorization of inductive and deductive reasoning. Inductive reasoning refers to empirical generalizations about observations and then forming tentative conclusions (basing predictions on past experiences) (Facione, 2007). Deductive reasoning, in contrast, begins with a hypothesis and observations, and then an evaluation of the hypothesis based on the evidence. Deductive reasoning includes the strict application and adherence to set rules or guidelines (Facione, 2007). Scores based on the more contemporary notions of analysis, inference, and evaluation is also provided. Analysis refers to the student's ability to dissect arguments and identify the assumptions and premises regarding the conclusions of claims being made (Facione, 2007). Inference refers to the student's ability to draw accurate conclusions based on reasons and evidence (Facione, 2007). Evaluation refers to a student's ability to determine the strengths and weaknesses in an argument, or to determine the believability of a claim (Facione, 2007).

Utilizing the California Critical Thinking Skills Test (CCTST), Facione conducted four experiments to evaluate the reliability and validity of the CCTST and examined group differences and predictors. His findings were published in four separate Technical Reports \#1-4: the first reported on experimental validation and content validity of the CCTST (Facione, 1990b). The second experiment examined the predictive factors 
of critical thinking (Facione, 1990a), and then third specifically examined gender, race, major, CT Self-Esteem and the CCTST (Facione, 1990d). The fourth report focused on interpreting the CCTST, group norms and sub-scores (Facione, 1990c).

Facione $(1990 \mathrm{~b}, 1990 \mathrm{c})$ reported that group norms were based on totaling the four experiments to assess the validity and reliability of the CCTST. The mean pretest score was 15.890 and a $\mathrm{SD}=$ of 4.457 ; minimum of 2 and maximum of 29 and the mean posttest score was 17.272 with a $\mathrm{SD}=$ of 4.823 ; minimum of 3 and maximum 31 (Facione, 1990b, 1990c). Facione reported a reliability coefficient of .69 for the pretest and .68 for the posttest; however, note the increase to .78 to .84 for the total instrument for the current Form 2000 (Facione, 1990b).

Although each instrument measures the concept of critical thinking, the particular definitions and subscales vary, as do the populations the instrument was designed to assess. For example, the CAAP was designed to specifically assess undergraduate students during their first two years of college and may not be as appropriate for the graduate levels. The Watson-Glaser is utilized more in the business industry than in educational settings. The CAAP instrument also does not provide a specific definition of critical thinking to assess the compatibility with the school's definition of critical thinking as do CCTST or the Watson-Glaser. Even those instrument which do provide specific explanations of the critical thinking definition which guide the instrument development, it remains essential for the definition to be consistent with the program's definition to ensure an accurate assessment. 


\section{Influential Variables}

In reviewing the literature regarding critical thinking and its measurement, numerous influential variables were explored as potential predictors of the critical thinking skill development of graduate level social work students. See Table 1 for a summary of previous research cited in the discussion of influential variables. 
Table 1

Previous Research on Critical Thinking

\begin{tabular}{|c|c|c|c|c|}
\hline $\begin{array}{c}\text { Author \& } \\
\text { Year }\end{array}$ & Instrument & Measuring Points & Variables & Findings \\
\hline $\begin{array}{l}\text { Bohr, } \\
1992\end{array}$ & CAAP & $\begin{array}{l}\text { Pre and post to } \\
\text { education students }\end{array}$ & Type of school & $\begin{array}{l}\text { No significant differences between } \\
\text { research univ. and comm. college }\end{array}$ \\
\hline $\begin{array}{l}\text { Facione, } \\
1990\end{array}$ & CCTST & $\begin{array}{l}\text { Pre and Post Test } \\
\text { Critical thinking } \\
\text { specific course }\end{array}$ & $\begin{array}{l}\text { SAT verbal, SAT } \\
\text { Math, GPA and } \\
\text { pretest, age }\end{array}$ & $\begin{array}{l}\text { SAT verbal, SAT math, GPA and } \\
\text { pretest scores explained } 71 \% \text { of } \\
\text { posttest scores. Age and hours } \\
\text { completed were not significant }\end{array}$ \\
\hline $\begin{array}{l}\text { Facione, } \\
1990\end{array}$ & CCTST & $\begin{array}{l}\text { Pre and Post Test } \\
\text { Critical thinking } \\
\text { specific course }\end{array}$ & $\begin{array}{l}\text { Gender, ethnicity } \\
\text { and major (on } \\
\text { post test only) }\end{array}$ & $\begin{array}{l}\text { Significant differences on posttest } \\
\text { scores based on gender, ethnicity } \\
\text { and major }\end{array}$ \\
\hline $\begin{array}{l}\text { Gadzella } \\
\text { \& Masten, } \\
1998\end{array}$ & WGCTA & Once & Major & $\begin{array}{l}\text { Psychology/Special Ed. Majors } \\
\text { scored higher than Sociology/Social } \\
\text { Work/Criminal Justice on total and } \\
\text { interpretation and evaluation }\end{array}$ \\
\hline $\begin{array}{l}\text { Gadzella, } \\
\text { Baloglu \& } \\
\text { Stephens, } \\
2002 \\
\end{array}$ & WGCTA & $\begin{array}{l}\text { Once to ed. psy. } \\
\text { students }\end{array}$ & GPA & $\begin{array}{l}\text { Significant correlation between } \\
\text { scores and GPA }\end{array}$ \\
\hline $\begin{array}{l}\text { Gellin } \\
2003\end{array}$ & $\begin{array}{l}\text { WGCTA, } \\
\text { CCTT, } \\
\text { CCTST, } \\
\text { CAAP }\end{array}$ & $\begin{array}{l}\text { Meta-Analysis of } 8 \\
\text { studies from } 1991 \\
\text { to } 2000\end{array}$ & $\begin{array}{l}\text { Greek life, clubs } \\
\text { and org. faculty } \\
\text { interaction, peer } \\
\text { interaction, } \\
\text { living on campus } \\
\text { and employment }\end{array}$ & $\begin{array}{l}\text { Students involved in Greek life, } \\
\text { clubs, organizations, peer } \\
\text { interaction, living on campus and } \\
\text { employment experienced a .14 gain }\end{array}$ \\
\hline $\begin{array}{l}\text { Ingle, } \\
2007\end{array}$ & CCTST & $\begin{array}{l}\text { Once to } \\
\text { community college } \\
\text { and univ. students }\end{array}$ & Gender, age & Age and gender not significant \\
\hline Jones & & $\begin{array}{l}\text { Interviews with } \\
\text { faculty }\end{array}$ & Major & $\begin{array}{l}\text { Based on the interviews, researchers } \\
\text { found differences in how the } \\
\text { disciplines defined critical thinking }\end{array}$ \\
\hline $\begin{array}{l}\text { Loken, } \\
2005\end{array}$ & CCTST & Once to athletes & $\begin{array}{l}\text { Gender, type of } \\
\text { institution, length } \\
\text { of enrollment }\end{array}$ & $\begin{array}{l}\text { No significant difference on gender } \\
\text { or type of institution, but there was } \\
\text { for length of program, i.e. those in } 2 \\
\text { year program scored higher than } \\
\text { those in } 3 \text { year program. }\end{array}$ \\
\hline $\begin{array}{l}\text { Rodriguez, } \\
2000\end{array}$ & $\begin{array}{l}\text { California } \\
\text { Critical } \\
\text { Thinking } \\
\text { Disposition } \\
\text { Inventory } \\
\text { (CCTDI) } \\
\text { and CT } \\
\text { application } \\
\end{array}$ & Once & $\begin{array}{l}\text { Gender, age, year } \\
\text { of experience }\end{array}$ & $\begin{array}{l}\text { No significant differences on } \\
\text { Observation of Critical Thinking } \\
\text { Skills Application, but there were } \\
\text { significant differences on all three } \\
\text { variables on the CCTDI, i.e. older } \\
\text { males with more experience rated } \\
\text { themselves higher. }\end{array}$ \\
\hline $\begin{array}{l}\text { Wilson, } \\
2002\end{array}$ & CCTST & $\begin{array}{l}\text { Once to Southern } \\
\text { Baptist students }\end{array}$ & $\begin{array}{l}\text { Hours worked, } \\
\text { GPA }\end{array}$ & $\begin{array}{l}\text { GPA significant predictor of CT } \\
\text { total, analysis, evaluation, inference, } \\
\text { deductive and inductive. Hours } \\
\text { worked was a significant predictor } \\
\text { of inference }\end{array}$ \\
\hline
\end{tabular}




\section{Demographics}

The most dominant demographic variables discussed in the literature were age, gender, and race. Facione (1990d) measured the growth of critical thinking skills achieved by undergraduate students who completed a critical thinking course and concluded that White male students tend to acquire critical thinking skills better than female students and students from other ethnic groupings. What is interesting to note is that previous research found no significant gender differences in critical thinking scores on pretest or single administrations (Ingle, 2007; Loken, 2005; Rodriguez, 2000); however, Facione's (Facione, 1990d) study found males scored significantly higher than females on posttest scores $\mathrm{t}(683.94)=2.42, \mathrm{p}=.016(1990 \mathrm{~d})$. Facione hypothesized males and females may learn critical thinking skills differently and may respond differently to pedagogical methods or learning activities. Likewise, not all racial groups benefit equally from completing a critical thinking course, in that "blacks $(n=13)$ and foreign $(n=7)$ students register the largest gains, two points, from pretest to posttest. On average whites (n=395) gained 1.3" (Facione, 1990d, p. 6). The majority of research regarding age found it to be an insignificant predictor of critical thinking. Facione's (1990a) research indicated age was not a significant predictor of critical thinking skills with undergraduate students utilizing the CCTST, as did Ingle (2007) who also utilized the CCTST as well as the Ennis-Weir Critical Thinking Essay Test to measure critical thinking of undergraduate students from a public four year university as well as a community college. Pearson (1991) uniquely reported age as a significant predictor of critical thinking skills of community college students utilizing the Watson-Glaser Critical Thinking Appraisal. A noted limitation of these studies is their consistent focus on 
undergraduate students, which may contribute to a lack of variability in age groups. The majority of undergraduate students fall in the 18 to 25 range; whereas graduate student populations may have significantly more variability in age.

\section{Grade Point Average}

GPA is also a commonly explored variable although the context of its usage varies. The GPA may refer to either high school GPA, undergraduate GPA, or graduate GPA depending on the methodology of the particular study. For example, researchers may want to explore the GPA of students prior to their entry into a program or while they are in a program. Pascarella, Bohr, Nora, Zusman, Inman, Desler (1993) explored high school GPA as an influential variable in critical thinking skills of undergraduate college students and found the higher the high school grades, the higher the critical thinking scores. Wilson (2002) utilized the CCTST to obtain a one time measurement of undergraduates students' critical thinking skills and found that college GPA was a significant predictor of overall critical thinking $(\mathrm{t}=6.702, \mathrm{p}=.000)$, analysis $(\mathrm{t}=5.418$, $\mathrm{p}=.000)$, evaluation $(\mathrm{t}=3.995, \mathrm{p}=.000)$, and inference skills $(\mathrm{t}=5.926, \mathrm{p}=.000)$, as well as deductive $(\mathrm{t}=6.689, \mathrm{p}=.000)$ and inductive reasoning $(\mathrm{t}=3.647 . \mathrm{p}=.000)$ in that the higher the GPA the higher the scores the higher the appropriate CCTST score. However, high school GPA was not a significant predictor. Gadzella, Baloglu and Stephens (2002) utilized Watson-Glaser Critical Thinking Appraisal (WGCTA) to measure the critical thinking skills of both undergraduate and graduate level students. Their results indicated the total WGCTA and the subscales of inference, deduction, and interpretation correlated significantly with college level GPAs (Gadzella et al., 2002). In addition, Facione (1990a) tested a predictor model utilizing SAT verbal, SAT math, college GPA, and 
pretest scores of graduate level students which explained $71 \%$ of the variance in post test critical thinking scores.

\section{Time}

Some researchers have argued that critical thinking develops as the result of experience or as a natural result of a college education and/or experience (Facione, 1990a; Gellin, 2003a, 2003b). It was assumed in higher education that as students progressed through their studies their critical thinking skills naturally developed. Facione (1990a) explored this time or maturation philosophy by using the college units completed variable for students across multiple disciplines and found it not to be a significant predictor of student's post test scores. However, this research was based on pre and post test measurements after a single critical thinking course. Loken (2005) examined a variation of the time variable by exploring the critical thinking skills of undergraduate level students utilizing the CCTST. The research involved students from ten different undergraduate athletic trainer programs. The athletic trainer accreditation bodies require programs to be at least two years in length, but may be longer at the programs' discretion (Loken, 2005). An independent-samples $t$ test was conducted and found students who attended the two year program scored significantly higher than students who attended the three year program $\mathrm{t}(71)=3.365, \mathrm{p}=.001$ (Loken, 2005). Although this study compared the length of a program, it compared programs from different schools, thus different curriculums. There is no discussion of the guiding framework for the curriculums other than the professional accreditation guidelines and no noted emphasis on critical thinking. 


\section{Years of Experience}

Rodriguez (2000) measured the critical thinking skills of registered licensed nurses at a public hospital using the California Critical Thinking Disposition Inventory (CCTDI) and the Observation of Critical Thinking Skills Application Tool. There was no significant correlation between years of experience and critical thinking application; however, there were significant correlations between years of experience and the CCTDI subscales of open-mindedness, maturity and total (Rodriguez, 2000). Thus, the more experienced the nurses were the higher they rated themselves on open-mindedness, maturity, and critical thinking dispositions. Note, neither of these instruments are direct measures of critical thinking; rather one measures the use of critical thinking skills and the other the disposition to use critical thinking skills.

\section{Undergraduate Major}

To explore the potential influence of undergraduate major on critical thinking skills, Facione (1990d) explored the potential predictive strength of this variable after a critical thinking specific course. Majors were not listed individually, rather grouped together in six clusters of three to six majors decided on by the researcher. Undergraduate major was not a significant predictor of pretest scores $F(5,1995)=1.47, \mathrm{p}=.1995$; however, it was a significant predictor of post test scores, $\mathrm{F}(6,719)=5.23, p=.000$ ) (Facione, 1990d). The highest posttest scores were from the cluster including letters, languages, English, liberal studies, history, and humanities ( $M=18.50)$, followed by mathematics, engineering, statistics and computer science $(M=18.18)$ and then social sciences, psychology, human services, and teaching (M=16.93) (Facione, 1990d). Gadezella and Masten (1998) also specifically examined differences between two groups, 
i.e. psychology and special education versus sociology, social work, and criminal justice majors utilizing a single administration of the Watson-Glaser Critical Thinking Appraisal. Researchers reported psychology and special education majors scored significantly higher on the total score $F(1,38)=4.95, p<.03$, the subscales of interpretation $F(1,38)=5.07, p<.03$, and evaluation of arguments $F(1,38)=5.93, p<.03$. Facione (1990d) hypothesized the reason for the significance on the posttest may be due to the discipline specific differences in the critical thinking courses completed.

\section{Type of Undergraduate School}

Bohr, Pascarella, Nora, Zusman, and Jacobs (1992) examined differences in undergraduate level students from a public community college and from a research university utilizing the Collegiate Assessment of Academic Proficiency controlling for precollege cognitive skills, age, work, place of residence, and enrollment status. Bohr, Pascarella, Nora, Zusman, and Jacobs (1992) and Pascarella, Bohr, and Nora (1994) found no differences between students from a community college and those from a research intensive university on changes in reading comprehension, mathematics, and critical thinking. This particular study only included freshman students; therefore, different results may result with graduate level students.

\section{Mean Hours Worked Per Week}

Gellin (2003b) conducted a meta-analysis of eight studies and found "students who worked while attending school experienced a 0.13 effect gain in critical thinking when compared to students who did not work" (p. 752). Wilson (2002) utilized the CCTST and found hours worked per week to be a significant predictor of inference skills $t(379)=1.995, p=.047$, but not of the total critical thinking score or the other sub scales. 


\section{Critical Thinking Self-confidence}

Facione (1990d) explored students' critical thinking self-confidence as a potential predictor of critical thinking skills on the CCTST. The students' self-confidence was measured at both pre and post test administration with a single question "Critical thinking and being logical are quite easy for me" (Facione, 1990d, p. 9). Students were asked to respond (a) yes, to be honest it is, (b) well, I sort of agree, (c) no, not really, (d) are you kidding. Analysis revealed critical thinking self-confidence was not a significant predictor of scores. Of particular interest, Facione noted, was students' apparent overconfidence ( $80 \%$ at pretest and $84 \%$ at posttest were positive responses) based on posttest means of 16.83 with only $49.5 \%$ correct out of 34 items.

This discussion provided an insight into various influential variables in the critical thinking literature and laid the foundation for the current research. Previous researchers have examined these variables in various contexts: undergraduate and graduate, general and discipline specific; course and curriculum; and private and public universities. However, the current research will built a conceptual model to examine predictors of critical thinking in a graduate level school of social work in a public university both before and after a critical thinking infused curriculum.

\section{Conceptual Frameworks}

As this study was conducted primarily for exploratory purposes, it utilized prior research on assessing critical thinking to develop strategies to explore the critical thinking skills particularly of graduate level social work students. As a result of a comprehensive literature review, the researcher selected two conceptual perspectives to more fully explore the complexity of social work students' critical thinking skills. Specifically, 
researchers examined the predictive value of characteristics of students prior to and while in the graduate level social work program as well as generic versus discipline specific characteristics. Both of these perspectives offered a unique window into exploring influential predictors of students' critical thinking skills before and/or after the completion of a critical thinking infused curriculum based on specific groupings of the influential variables previously discussed. Each of the conceptual perspectives will be discussed in further detail; in addition, the potential knowledge gained and their usefulness in improving students' critical thinking skills will be explored.

The researcher utilized these conceptual perspectives to develop models which explored not only total critical thinking scores, but also each of the sub scores, i.e. inductive and deductive reasoning, analysis, evaluation, and inference within each of the perspectives. Exploring the subscales of critical thinking provided more detailed information regarding the strengths and weaknesses of students, which in turn could be used to inform faculties' pedagogical strategies in enhancing students' critical thinking skills, as well as to inform curriculum decisions. For example, if incoming students have stronger analysis skills than inference, specific learning activities could be utilized to build upon the students' strength in analysis to target improvement in inference skills, or if exiting students demonstrate stronger inductive reasoning skills than deductive, strategies could be developed to create more opportunities in the curriculum for students to gain deductive reasoning skills.

\section{Generic Versus Discipline Specific}

To explore the previously discussed debate about curriculum structures in regards to whether critical thinking is a generic or discipline specific skill, another conceptual 
perspective was selected to explore critical thinking of graduate level social work students, generic versus discipline specific blocks. The research in this area is rather limited, primarily comparing differences on a discipline specific measure of critical thinking to a generic critical thinking instrument after a single course (Williams et al., 2004) or simply measuring pre and post test critical thinking skills within a specific discipline such as nursing (Rane-Szostak \& Robertson, 1996; Staib, 2003), without considering groupings of predictor variables based on the generic and discipline specific dichotomy. This research will attempt to address this gap by exploring predictor models of critical thinking using the blocks of generic versus discipline specific variables. This will not only provide insight into predictors of students' entry level as well as acquired critical thinking skills, but will also provide additional insight into which variables the curriculum influences the most by determining if there are any differences in the entry level and acquired models.

The following categories and variables were selected: (a) student demographic characteristics: gender, race and age; (b) generic variables: undergraduate GPA, months since undergraduate degree, and type of undergraduate institution and (c) discipline specific variables: total scores on a self-efficacy scale, years of social work related experience prior to entering the program, and undergraduate major. As this conceptual perspective was utilized to examine both entry level as well as acquired critical thinking skills, it was important that both sets of models include the same variables; therefore, the following influential variables discussed in the prior to entry and while in program perspective will not be used: graduate GPA, mean hours worked per week, and type of program. See Figures 3 and 4 for the conceptual models guiding this perspective. 


\section{BLOCK 1}

DEMOGRAPHIC VARIABLES

*Gender

*Ethnicity

*Age

\section{BLOCK 2}

GENERIC VARIABLES

*Undergraduate GPA

*Months between undergraduate degree and entry into graduate program

*Type of Undergraduate school

\section{BLOCK 3}

DISCIPLINE SPECIFIC VARIABLES

*Pretest Foundation Practice Self-

Efficacy Total

*Years of social work experience

*Undergraduate degree

*Each of the independent variables in this box will be tested separately in a regression model

Figure 3: Conceptual model to explain potential predictors of students' entry level critical thinking skills using generic and discipline specific blocks 


\begin{tabular}{|l|}
\hline BLOCK 2 \\
DEMOGRAPHIC VARIABLES \\
*Gender \\
*Ethnicity \\
*Age \\
\end{tabular}

\section{BLOCK 1}

CONTROL VARIABLE

*Pretest scores on the appropriate dependent variable (total critical thinking, deductive reasoning, inductive reasoning, analysis, evaluation and inference)

*Length of time in the program when pretest was administered

\section{BLOCK 3}

GENERIC VARIABLES

*Undergraduate GPA

* Months between undergraduate degree and entry into graduate program

*Type of Undergraduate school

\section{BLOCK 4}

DISCIPLINE SPECIFIC VARIABLES

*Pretest Foundation Practice Self-

Efficacy Total

*Years of social work experience

*Undergraduate degree

\section{DEPENDENT VARIABLES*}

Acquired Total Critical Thinking

Acquired Deductive Reasoning

Acquired Inductive Reasoning

Acquired Analysis

Acquired Evaluation

Acquired Inference
*Each of the independent variables in this box will be tested separately in a regression model

Figure 4: Conceptual model to explain potential predictors of students' acquired level critical thinking skills using generic and discipline specific blocks 


\section{Prior to and While in Program}

In examining potential predictors of critical thinking scores, some researchers have categorized the variables as those students possess at entry into the program/class and those students have while in the program/class in an attempt to differentiate between what students entered the program with versus what they gained as a result of the class or program (Pascarella et al., 1993; Terenzini et al., 1993; Wilson, 2002). Specifically, Terenzini (1993) explored the variable groupings of precollege traits, out of class experiences, and class-related experiences. This type of grouping allowed the researcher to examine separately the variables which students come to the school with versus those variables in which the school may have some level of influence over in regards to the development of students' critical thinking skills. Therefore, the following categories and variables were selected: (a) student demographic characteristics: gender, race, and age; (b) student characteristics at entry into the Master of Science in Social Work (MSSW) program: undergraduate GPA, months since undergraduate degree, years of social work related experience prior to entering the program, undergraduate major, and type of undergraduate institution, and (c) student characteristics while in the program: whether students were in the 30 or 60 hour programs, their graduate GPAs, mean hours worked per week while in the program, and scores on a self-efficacy scale. See Figure 5 for the conceptual model utilizing prior to entry and while in program perspective. Note, based on the prior to entry and while in program grouping blocks, this model will be utilized only to explore the acquired critical thinking skills of students at graduation. 


\begin{tabular}{|c|c|}
\hline $\begin{array}{l}\text { BLOCK 2 } \\
\text { DEMOGRAPHICS } \\
\text { *Gender } \\
\text { *Ethnicity } \\
\text { *Age }\end{array}$ & $\begin{array}{l}\text { BLOCK } 1 \\
\text { CONTROL VARIABLES } \\
\text { *Pretest score on the appropriate } \\
\text { dependent variable (Total critical } \\
\text { thinking, inductive reasoning, } \\
\text { deductive reasoning, analysis, } \\
\text { evaluation, inference) } \\
\text { *Length of time in program when } \\
\text { pretest was administered }\end{array}$ \\
\hline $\begin{array}{l}\text { BLOCK } 3 \\
\text { STUDENT CHARACTERISTICS AT ENTRY } \\
\text { *Undergraduate GPA } \\
\text { *Months between undergraduate degree and } \\
\text { entry into graduate school } \\
\text { *Years of social work experience } \\
\text { *Undergraduate major } \\
\text { *Type of undergraduate school }\end{array}$ & $\begin{array}{l}\text { evaluation, inference) } \\
\text { *Length of time in program when } \\
\text { pretest was administered }\end{array}$ \\
\hline $\begin{array}{l}\text { BLOCK } 4 \\
\text { STUDENT CHARACTERISTICS WHILE IN }\end{array}$ & $\begin{array}{l}\text { Acquired Evaluation } \\
\text { Acquired Inference }\end{array}$ \\
\hline $\begin{array}{l}\text { *Type of program } \\
\text { *Graduate GPA } \\
\text { *Mean hours worked per week while in } \\
\text { program } \\
{ }^{*} \text { Critical thinking sub scale of a pretest }\end{array}$ & $\begin{array}{l}\text { *Each of the independent } \\
\text { variables in this box will be } \\
\text { tested separately in a } \\
\text { regression model }\end{array}$ \\
\hline
\end{tabular}

\section{Figure 5: Conceptual model to explain potential predictors of students' acquired critical thinking scores using prior to entry and while in program blocks}

Although most of the variables used in these models were operationalized similar to previous research, some were tailored to the specifics of this particular research study and the guiding conceptual perspectives. For example, the variable of GPA was utilized as both undergraduate GPA and graduate GPA for the prior to entry and while in program model to represent the GPAs of students prior to entry into the graduate social work program and at their completion of their social work program. Whereas, in the generic versus discipline specific models only the undergraduate GPA variable was used to ensure a mirror image of the blocks for both the entry and acquired critical thinking models. 
The time variable was customized to reflect two different variables in both the prior to and while in the program blocks. Although the literature used college units and comparison of a two and four year program to explore differences, this research will build upon this foundation and customize variables to fit the research at hand. To continue to explore the idea of critical thinking developed as the result of experience or a college education, researchers will examine the length of time between undergraduate degree and entry into graduate school as a potential predictor of critical thinking, assuming the longer the time between degrees the more experienced the individual. This variable will also be explored as a potential predictor in the generic block as well. In addition, the variable of type of program ( 30 hours versus 60 hours) was identified as a potential predictor for the prior to entry and while in program model based on the CSWE guidelines for accredited graduate schools. CSWE mandates a Master's of Social Work program shall consist of 60 hours based on specific curriculum guidelines; however, students may be admitted as advanced standing students if they have a Bachelor's of Social Work degree from an accredited school in which the student only had to take 30 hours (Handbook of Accreditation Standards and Procedures, 2003). As this particular study involved a specific critical thinking infused curriculum, students in the 60 hour program would have had twice as many courses with a critical thinking emphasis as the 30 hours students and thus may potentially score higher on a critical thinking instrument. Although Loken (2005) found students in the shorter program to have higher scores than those in the longer program, the current research focused not only on students in the same academic discipline, but within the same institution and one with a critical thinking infused curriculum. 
Previous research explored critical thinking self confidence as a potential predictor based on a single question; however, this study will utilize a social work specific self-efficacy measure, Foundation Practice Self-Efficacy (FPSE) instead. Although the FPSE is not a critical thinking specific instrument, it does ask social work students to rate their abilities on certain critical thinking skills within social work practice, i.e. "How confident are you that you can: apply critical thinking skills within the context of professional social work practice; analyze social policies, evaluate research studies, evaluate your own practice interventions, etc." Therefore, for the prior to entry and while in program model, a critical thinking subscale of the pretest FPSE will be utilized as a potential predictor in the while in the program block. However, for the generic versus discipline specific models, the total score will be utilized under the discipline specific block as the FPSE is a social work specific instrument. Additional details about the FPSE and the critical thinking sub scale will be provided in Chapter 3 under operationalization of variables (See Appendix B for a copy of the FPSE).

Researchers will also examine the undergraduate major as a potential predictor; however, students will be categorized into smaller groups. Typically, students enrolling in a graduate social work program come from either a social work, psychology or sociology background; therefore lacking the variability identified in Facione's (1990d) study.

The type of undergraduate institution variable was also be explored in the context of a teaching focused or research intensive institution. Faculty at research intensive schools have increasing responsibilities to bring in research dollars to the institution while also generating publications and balancing teaching loads (Grunwald \& Peterson, 
2003). Although all faculty members are evaluated on teaching, research and service, the rewards systems at research intensive universities generally place more emphasis on the research and publication component than on teaching and service (Banta, 2005;

Grunwald \& Peterson, 2003; Meier \& Thannert, 2006). Therefore, although faculty at both teaching and research universities as a whole value student learning, faculty at teaching universities may have more time to focus on pedagogical strategies to enhance student learning and critical thinking skills than faculty at research intensive universities (Grunwald \& Peterson, 2003; Hadden \& Davies, 2002).

\section{Conclusion}

This chapter provided a literature review of critical thinking in regards to its various definitions, theoretical underpinnings, curriculum structures, measurement strategies and influential variables, which led to the development of multiple conceptual models. The following chapter will build upon these conceptual models and provide a comprehensive explanation of the methodology to include hypothesis, design, sample, operationalization of variables, and data analysis. 


\section{CHAPTER THREE}

\section{Methodology}

\section{Purpose of Research and Hypotheses}

The major purpose of this study was to examine changes in student's critical thinking skill development after completing a critical thinking infused curriculum and to test predictor models regarding entry level as well as acquired critical thinking skills of students at graduation from the Kent School of Social Work MSSW program. Due to the exploratory nature of this study, the limited research regarding graduate level critical thinking skills, and the even more limited research regarding graduate level social work students' critical thinking skills, the specific degree to which each variable will contribute to the model is not known; it is merely hypothesized based on the literature that the variables will produce a statistically significant model to predict critical thinking skills. This research seeks to fill the gap in the literature which addressing social work specific critical thinking skills. Specifically, the following research questions were posed:

I. Did students show significant improvement between pre and posttest on their tested ability to think critically as measured by the California Critical Thinking Skills Test (CCTST)?

Hypothesis 1a: Students' tested ability to think critically (CCTST) will significantly improve between total scores on the pre and posttests. 
Hypothesis 1b: Students' analytic skills (CCTST) will significantly improve between pre and posttests.

Hypothesis 1c: Students' evaluation skills (CCTST) will significantly improve between pre and posttests.

Hypothesis 1d: Students' inference skills (CCTST) will significantly improve between pre and posttests.

Hypothesis 1e: Students' inductive reasoning skills (CCTST) will significantly improve between pre and posttests.

Hypothesis 1f: Students' deductive reasoning skills (CCTST) will significantly improve between pre and posttests.

II. To what extent can entry level critical thinking skills of graduating MSSW students at the Kent School of Social Work be explained by the demographic variables of gender, race, and age, the generic variables of undergraduate GPA, months since undergraduate degree, and type of undergraduate institution, and the discipline specific variables of self-efficacy at pretest, years of social work experience, and undergraduate degree?

Which of the predictor blocks included in the regression model has the strongest explanatory power for entry level critical thinking skills?

Due to the exploratory nature of this research, no specific hypotheses will be defined for this research question.

III. To what extent can acquired critical thinking skills of graduating MSSW students at the Kent School of Social Work be explained by the demographic variables of gender, race, and age, the generic variables of undergraduate GPA, 
months since undergraduate degree, and type of undergraduate institution and the discipline specific variables of self-efficacy at pretest, years of social work experience, and undergraduate degree?

Which of the predictor blocks included in the regression model has the strongest explanatory power for acquired critical thinking skills?

Due to the exploratory nature of this research, no specific hypotheses will be defined for this research question.

IV. To what extent can acquired critical thinking skills (defined as total CCTST score, as well as scores on the subscales of inductive reasoning, deductive reasoning, analysis, evaluation and inference) of graduating MSSW students at the Kent School of Social Work be explained by the demographics of gender, race and age, the student characteristics at entry into the program of undergraduate GPA, months since undergraduate degree, years of social work related experience prior to entering program, undergraduate major, and type of undergraduate institution, and the student characteristics while in school of 30 vs. $60 \mathrm{hr}$ student, graduate GPA, mean hours worked per week while in program, and critical thinking subscale of self-efficacy at posttest? Which of the mentioned predictor blocks best explain acquired critical thinking skills? Due to the exploratory nature of this research, no specific hypotheses will be defined for this research question.

\section{Research Design}

An exploratory pre-experimental one group pretest-posttest design was used in this study to measure the ability of students to acquire critical thinking skills after being 
exposed to a critical thinking curriculum. A predictive analysis was conducted to determine the best predictors that can explain acquired critical thinking skills at graduation.

Maturation and history were both threats to the internal validity of this research study due to the time lapse between the pre and posttests (Singleton \& Straits, 2005). Testing may also have been a threat to this research design, as students may become more comfortable the second time the instruments were given as they become more familiar with what to expect (Singleton \& Straits, 2005). This design controlled for instrumentation as the instruments were standardized and electronically scored. Statistical regression could have been a potential threat with this type of study if, for example, only students with extremely low pretest scores were included in the study. It would then be highly likely that the post test scores would show improvement (regression towards the group mean) because the extreme of the pretest scores, thus potentially leading to the incorrect assumption of improvement due to program, rather than the natural regression of scores to the mean (Rubin \& Babbie, 2008). By including all students in the current study, this threat was controlled.

\section{Sample}

When Kent School first initiated their assessment process in August of 2006, it was necessary to capture pretest scores on all students who were currently enrolled in the graduate program. Pretests were administered in the Advanced Research sequences as well as the Human Behavior Social Environment courses to capture all students. This included students newly admitted as well as students who had been enrolled for various time periods. Therefore, there was variation in the amount of time each student had been 
enrolled in the program, thus necessitating the control of this variable in posttest data analyses through the creation of a variable for the number of hours in the program when pretest was completed. The following year pretests were administered during orientation and the post test instruments were administered during the $4^{\text {th }}$ last week of the students' final semester of studies in the Advanced Research II courses. See Table 2 for Pre and Posttest Administration Time Table.

\section{Table 2}

\section{Pre and Posttest Administration Time Table}

\begin{tabular}{|l|l|l|l|l|}
\hline & Aug. 2006 pretest & April 2007 posttest & Aug. 2007 pretest & $\begin{array}{l}\text { April 2008 } \\
\text { posttest }\end{array}$ \\
\hline $\begin{array}{l}\text { All students enrolled } \\
\text { as of Aug. 06 }\end{array}$ & $\mathrm{X}$ & & & \\
\hline $\begin{array}{l}\text { Students graduating } \\
\text { May 07 }\end{array}$ & & $\mathrm{X}$ & & \\
\hline $\begin{array}{l}\text { Newly enrolled } \\
\text { students as of Aug. 07 }\end{array}$ & & & $\mathrm{X}$ & \\
\hline $\begin{array}{l}\text { Students graduating } \\
\text { May 08 }\end{array}$ & & & & $\mathrm{X}$ \\
\hline
\end{tabular}

All students who graduated from the Kent School of Social Work between May 2007 and May 2008 and participated in the assessment process were included in the original population of students $(\mathrm{N} \approx 556)$. Based on the specifics of each research question, a particular sample of students was selected from this population of students.

Specifically, for Research Question 1, students from the Pure Posttest sample were selected. This sample includes students admitted in Fall 2006 for the 60 hour program, students admitted in Fall 2006 for the 30 hour program, and students admitted in Fall 2007 in the 30 hour program who at a minimum graduated and had completed the pre and post test critical thinking (CT and PCT). The Pure Posttest Sample included N=104. See Table 3 for a summary of the sampling strategy. 


\section{Table 3}

Pure Posttest Sampling Strategy for Research Question 1

\begin{tabular}{|l|l|l|l|l|}
\hline Test Completed & $\begin{array}{l}1^{\text {st }} \text { year } 60 \text { hour } \\
\text { Fall } 06\end{array}$ & $\begin{array}{l}1^{\text {st }} \text { year 30 } \\
\text { hour Fall 06 }\end{array}$ & $\begin{array}{l}1^{\text {st }} \text { year 30 } \\
\text { hour Fall 07 }\end{array}$ & $\begin{array}{l}\text { Total number of } \\
\text { pretest scores }\end{array}$ \\
\hline CT PCT & 2 & 0 & 0 & 2 \\
\hline CT PCT SE & 8 & 1 & 6 & 15 \\
\hline CT PCT SE PSE & 30 & 26 & 29 & 85 \\
\hline PCT SE & 0 & 0 & 1 & 1 \\
\hline CT PCT PSE & 1 & 0 & 0 & 1 \\
\hline Total & 41 & 27 & 36 & 104 \\
\hline
\end{tabular}

NOTE: CT is pretest critical thinking, PCT is post test critical thinking, SE is pretest selfefficacy, PSE is post test self-efficacy.

Research Question 2 included students from the Pretest sample. This sample includes students admitted in Fall 2006 in the 60 hour and 30 hour programs and students admitted in Fall 2007 in the 60 hour and 30 hour programs who had completed the pretest on critical thinking. The Pretest sample included $N=304$. See Table 4 for a summary of the sampling strategy.

Table 4

Pretest Sampling Strategy for Research Question 2

\begin{tabular}{|c|c|c|c|c|c|}
\hline & $\begin{array}{l}1^{\text {st }} \text { year } 60 \\
\text { hour Fall } \\
06\end{array}$ & $\begin{array}{l}1^{\text {st }} \text { year } 30 \\
\text { hour Fall } \\
06\end{array}$ & $\begin{array}{l}1^{\text {st }} \text { year } \\
30 \text { hour } \\
\text { Fall } 07\end{array}$ & $\begin{array}{l}1^{\text {st }} \text { year } 60 \\
\text { hour Fall } 07\end{array}$ & $\begin{array}{l}\text { Total number of } \\
\text { pretest scores }\end{array}$ \\
\hline CT & 2 & 0 & 0 & 2 & 4 \\
\hline CT PCT & 2 & 0 & 0 & 0 & 2 \\
\hline CT PCT SE & 8 & 1 & 6 & 0 & 15 \\
\hline CT PCT SE PSE & 30 & 26 & 29 & 0 & 85 \\
\hline CT PCT PSE & 1 & 0 & 0 & 0 & 1 \\
\hline CT SE & 69 & 4 & 8 & 112 & 193 \\
\hline CT SE PSE & 1 & & 3 & 0 & 4 \\
\hline Total & 113 & 31 & 46 & 114 & 304 \\
\hline
\end{tabular}

NOTE: CT is pretest critical thinking, PCT is post test critical thinking, SE is pretest selfefficacy, PSE is post test self-efficacy. 
Research Question 3 and 4 included students from the Not So Pure Posttest

sample. This sample included students admitted in Fall 2006 for the 60 hour and 30 hour programs, students in their second year of the 60 hour program as of Fall 2006 and Fall 2007, students admitted in Fall 2007 in the 30 hour program who had completed at least the posttest test critical thinking (PCT). The Not So Pure Posttest Sample included N= 179. For this sample, the time in the program when pretest was completed, was controlled for in the analysis. See Table 5 for a summary of the sampling strategy.

\section{Table 5}

Not So Pure Posttest Sampling Strategy for Research Question 3 and 4

\begin{tabular}{|l|l|l|l|l|l|l|}
\hline & $\begin{array}{l}1^{\text {st }} \text { year } \\
60 \text { hour } \\
\text { Fall 06 }\end{array}$ & $\begin{array}{l}1^{\text {st }} \text { year } \\
30 \text { hour } \\
\text { Fall 06 }\end{array}$ & $\begin{array}{l}2^{\text {nd }} \text { year } \\
60 \text { hour } \\
\text { Fall 06 }\end{array}$ & $\begin{array}{l}1^{\text {st }} \text { year } \\
30 \text { hour } \\
\text { Fall 07 }\end{array}$ & $\begin{array}{l}2^{\text {nd }} \text { year } \\
60 \text { hour } \\
\text { Fall 07 }\end{array}$ & $\begin{array}{l}\text { Total number } \\
\text { of pretest } \\
\text { scores }\end{array}$ \\
\hline CT PCT & 2 & & 1 & & & 2 \\
\hline CT PCT SE & 8 & 1 & 3 & 6 & 3 & 21 \\
\hline CT PCT SE PSE & 30 & 26 & 52 & 29 & 15 & 152 \\
\hline PCT SE & 0 & 0 & 0 & 1 & 2 & 3 \\
\hline CT PCT PSE & 1 & 0 & 0 & 0 & 0 & 1 \\
\hline Total & 41 & 27 & 55 & 36 & 20 & 179 \\
\hline
\end{tabular}

NOTE: CT is pretest critical thinking, PCT is post test critical thinking, SE is pretest selfefficacy, PSE is post test self-efficacy.

\section{Data Sources}

Secondary data were analyzed. All of the variables in the hypotheses dwelled in existing data bases at the University of Louisville. This study is also part of Kent's plan to evaluate curriculum changes in preparation for the reaccreditation process.

Based on the curriculum description, the school administrators selected program objectives for both the foundation and advanced curriculum and linked each objective with multiple specific outcome measure. The overall program objectives were measured with the indirect measures of Foundation Practice Self-Efficacy (FPSE) and the direct 
measures of the California Critical Thinking Skills Test (CCTST). The FPSE and CCTST were administered in paper and pencil format in a pre and post test format.

Students' scores on the FPSE and CCTST at pretest were matched at posttest on the university assigned student identification numbers. A tracking method was established to ensure the administration of post test instruments at the appropriate times based on the progression of students through the curriculum.

All additional variables were obtained from the existing Kent School student database and merged with the different outcome measures. The final database is maintained by the Associate Dean for Academic Affairs.

\section{Operationalization of Variables}

\section{Dependent Variable}

Critical thinking. For all four research questions, tested ability of students to thinking critically was examined using the total critical thinking, deduction reasoning, inductive reasoning, analysis, evaluation, and inference scores as dependent variables. Critical thinking is defined as "the intellectual disciplined process of actively and skillfully conceptualizing, applying, analyzing, synthesizing and/or evaluating information gathered from or generated by observation, experience, reflection, reasoning, or communication, as a guide to belief or action" (Scriven \& Paul, 1992). The California Critical Thinking Skills Test (CCTST) was selected to measure students' critical thinking skills. See Chapter 2 for a complete description of this instrument. 


\section{Independent Variables}

Gender. Gender was operationalized as male or female. This information was originally obtained from the pretest and posttest administrations of both the critical thinking and self-efficacy instruments. If the information was missing from these records, the Kent School's student services data base was accessed in attempts to provide a more complete record.

Ethnicity. This information was also originally obtained from the pretest and posttest administrations of both the critical thinking and self-efficacy instruments with the following categories: Caucasian, African American, Hispanic, Asian, Native American and Other/Mixes. Due to the low number of respondents in some of the minority groupings, the ethnicity variable was dichotomized into White and Non-White. Kent School's student service database was accessed to complete missing data.

Age. Although the students' age was gathered on the pretest and posttest selfefficacy instruments, the researchers decided to calculate the students' age at pretest for this variable. The date students completed the pretest from the outcomes database and the date of birth from the student services database was utilized to calculate the age at pretest.

Undergraduate GPA. Undergraduate GPA was based on a 4.0 scale and was collected from the student services' database.

Time between undergraduate and entry into graduate school. The time between undergraduate and entry into graduate school was calculated by deducting the undergraduate graduation date from the date of entry into the graduate program. This information was obtained from the student services database. 
Social work experience. This variable was collected from the pretest self-efficacy instrument as the years of social work related full-time employment prior to entering the program.

Undergraduate major. Undergraduate major was collected from the self-efficacy pretest and posttest instruments and students were provided the options of: social work, psychology, sociology and other. To provide a complete dataset, the student services database was accessed to obtain missing data. Due to the large number of other majors (aside from social work, psychology and sociology), they were regrouped as other helping professions (mental health, counseling, child development) and other non helping professions (English, Political Science, Theater) and the previous groupings of social work, psychology and sociology were retained.

Type of undergraduate school. The Carnegie Foundation for the Advancement of Teaching developed a classification of colleges and universities to reflect those which are research intensive/extensive. This variable was operationalized as research vs. teaching. Those institutions identified as research intensive or extensive were categorized as research and the remaining institutions were classified as teaching. The data for this variable was obtained from the University of Washington's online listing of Carnegie Doctoral/Research Universities-Extensive (both public and private listings).

Type of program. This variable reflected the 30 hour and 60 hour classifications of the graduate social work program. This information was obtained from the pretest and posttest administrations of the self-efficacy instruments and missing data was obtained from the student services database. 
Mean hours worked per week. Mean hours worked per week was obtained from the posttest self-efficacy instruments to get the mean hours worked while in the program. The question was stated "If employed, hour many hours per week" and students then wrote in their responses, options were not provided.

Total self-efficacy. The total self-efficacy total was the mean score calculated from the pretest self-efficacy responses (see below for a full description of the instrument used).

Critical thinking subscale of self-efficacy. The critical thinking subscale total was the mean score calculated from the appropriate questions on the pretest self-efficacy responses (see below for a full description of the subscale used).

Graduate GPA. The graduate GPA was based on a 4.0 scale and was obtained from the student services database.

The predictor variables, operationalization, sources, as well as the specification of which models the variables were utilized are summarized in Table 6 . The self-efficacy instrument is provided in Appendix B and the critical thinking instrument is provided in Appendix C. 
Table 6

Variables Included in the Study

\begin{tabular}{|c|c|c|c|}
\hline VARIABLE & OPERATIONALIZATION & PRIMARY SOURCE & $\begin{array}{l}\text { CONCEPTUAL } \\
\text { PERSPECTIVE }\end{array}$ \\
\hline Gender & Male and Female & Pre and Post CT and SE & Both \\
\hline Ethnicity & White and Non White & Pre and Post CT and SE & Both \\
\hline Age & Years old at pretest & $\begin{array}{l}\text { Kent School student services } \\
\text { database }\end{array}$ & Both \\
\hline Undergrad GPA & $\begin{array}{l}\text { Undergraduate GPA on a } 4.0 \\
\text { scale }\end{array}$ & $\begin{array}{l}\text { Kent School student services } \\
\text { database }\end{array}$ & Both \\
\hline $\begin{array}{l}\text { Time between } \\
\text { undergrad and } \\
\text { entry into the } \\
\text { graduate school }\end{array}$ & Months & $\begin{array}{l}\text { Kent School student services } \\
\text { database }\end{array}$ & Both \\
\hline $\begin{array}{l}\text { Amount of } \\
\text { social work } \\
\text { experience }\end{array}$ & Years & Pre and Post SE & Both \\
\hline $\begin{array}{l}\text { Undergraduate } \\
\text { major }\end{array}$ & $\begin{array}{l}\text { Psychology, Sociology, Social } \\
\text { Work and Other }\end{array}$ & Pre and Post SE & Both \\
\hline $\begin{array}{l}\text { Type of } \\
\text { undergrad } \\
\text { college }\end{array}$ & $\begin{array}{l}\text { Research vs. Teaching, based } \\
\text { on Carnegie } \\
\text { Doctoral/Research } \\
\text { Universities Extensive } \\
\text { classification. }\end{array}$ & $\begin{array}{l}\text { Carnegie Classification } \\
\text { online listing provided by } \\
\text { University of Washington }\end{array}$ & Both \\
\hline $\begin{array}{l}\text { Type of } \\
\text { program }\end{array}$ & 30 vs. 60 hour & Pre and Post CT and SE & $\begin{array}{l}\text { Prior to and } \\
\text { While in } \\
\text { Program }\end{array}$ \\
\hline $\begin{array}{l}\text { Mean hours } \\
\text { worked per } \\
\text { week }\end{array}$ & Mean hours & Pre and Post SE & $\begin{array}{l}\text { Prior to and } \\
\text { While in } \\
\text { Program }\end{array}$ \\
\hline $\begin{array}{l}\text { Total Self- } \\
\text { efficacy }\end{array}$ & $\begin{array}{l}\text { Pretest total on the Foundation } \\
\text { Practice Self-Efficacy scale }\end{array}$ & Pre SE & $\begin{array}{l}\text { Generic versus } \\
\text { Discipline } \\
\text { Specific }\end{array}$ \\
\hline $\begin{array}{l}\text { Critical } \\
\text { Thinking } \\
\text { Subscale of } \\
\text { Self-Efficacy }\end{array}$ & $\begin{array}{l}\text { Pretest critical thinking sub } \\
\text { scale total on the Foundation } \\
\text { Practice Self-Efficacy scale }\end{array}$ & Pre SE & $\begin{array}{l}\text { Prior to and } \\
\text { While in } \\
\text { Program }\end{array}$ \\
\hline Graduate GPA & Graduate GPA on a 4.0 scale & $\begin{array}{l}\text { Kent School student services } \\
\text { database }\end{array}$ & $\begin{array}{l}\text { Prior to and } \\
\text { While in } \\
\text { Program }\end{array}$ \\
\hline
\end{tabular}


Self-efficacy. Self-efficacy is defined as "beliefs in one's capabilities to organize and execute the courses of action required to produce given attainments" (Bandura, 1997, pp.2-3). Self-efficacy was measured with the Foundation Practice Self-Efficacy (FPSE) tool developed by Holden, Anastas and Meenaghan (2003). FPSE is a 31 item scale based on Bandura's guidelines for self-efficacy scales and takes approximately 10-15 minutes to administer (Holden et al., 2003). The estimated readability according to FleschKincaid Grade Level was 9.5 (Holden et al., 2003; Holden, Anastas, Meenaghan, \& Metrey, 2002; Holden, Meenaghan, \& Anastas, 2005). Students were asked to rate their levels of confidence to perform specific tasks of social work practice on an 10 point scale $(0=$ cannot do it at all; $50=$ moderately certain can do $;$ and $100=$ certain can do $)$ (Holden et al., 2003; 2005).

To address content validity, researchers utilized CSWE's current EPAS to develop the items by using statements taken directly from the EPAS statements (Holden et al., 2003). To examine the construct validity of the FPSE, the Social Work Empowerment scale developed by Frans (1993) was utilized as a comparison measure; it was originally developed to "measure social workers' perceptions of personal and professional power" (p. 132). The SWE produced Cronbach's Alphas of .99 and .89 in the original studies and .88 in Holden, et al (2005), indicating the reliability of the instrument as a comparison measure for social work self-efficacy scales. The correlation between FPSE and SWE was $r=.57$ in the 2003 student and .58 in the 2005 study, contributing to the construct validity of the instrument (Holden et al., 2003; 2005). Both the 2003 and 2005 studies regarding the reliability of the FPSE produced Cronbach's 
Alpha levels between .96 and .97 , which exceeded the generally accepted value of .8 (Holden et al., 2003; Holden et al., 2005).

As stated previously, the generic versus discipline specific models utilized the total score on the FPSE; however, the prior to and while in program model utilized a critical thinking subscale within the FPSE. The questions making up the critical thinking subscale were selected based on a close examination of the questions included within the FPSE. See Appendix B for a copy of the FPSE survey as a guide for the discussion. Of the 31 questions included, the last fourteen asked about the student's confidence to work with specific populations and were thus eliminated from consideration on inclusion in the critical thinking subscale, leaving seventeen questions. Question 1 was included based on its specific reference to the application of critical thinking skills. Utilizing Bloom's Taxonomy (1956) to classify the questions, the researcher focused on the higher level thinking categories of application, analysis, synthesis, and evaluation and selected questions which conceptually fell in those categories, i.e. $3,5,7,8,9,10,11$, and 12 . Question 6 was also included as it addressed the utilization of theoretical frameworks and empirical evidence in social work practice. (See Table 7). These selected questions were subjected to factor analysis and reliability analysis to determine if they indeed could be used as a unidimensional indicator of confidence in using critical thinking skills. 


\section{Table 7}

\section{Critical Thinking Subscale Questions}

\begin{tabular}{|l|l|}
\hline Item \# & Question: How confident are you that you can... \\
\hline 1 & Apply critical thinking skills within the context of professional social work practice? \\
\hline 3 & $\begin{array}{l}\text { Understand the forms and mechanisms of oppression and discrimination and can } \\
\text { apply strategies of advocacy and social change that advance social and economic } \\
\text { justice? }\end{array}$ \\
\hline 5 & Apply the knowledge and skills of a generalist social work perspective? \\
\hline 6 & $\begin{array}{l}\text { Use theoretical frameworks supported by empirical evidence to understand } \\
\text { individual development and behavior across the life span and the interactions among } \\
\text { individuals and between individuals and families, groups, organizations, and } \\
\text { communities? }\end{array}$ \\
\hline 7 & Analyze social policies? \\
\hline 8 & Formulate social policies? \\
\hline 9 & Influence social policies? \\
\hline 10 & Evaluate research studies? \\
\hline 11 & Apply research findings to practice? \\
\hline 12 & Evaluate your own practice interventions? \\
\hline
\end{tabular}

A confirmatory factor analysis using a principal axis factoring extraction method was utilized to analyze the self-efficacy critical thinking subscale $(n=565)$. It is clear from the table that the items extracted from the self-efficacy scale could be seen as a reliable subscale of confidence in using critical thinking skills. The item-total correlations, $(\mathrm{M}=.79)$ and factor loadings $(\mathrm{M}=.81)$, both indicators of content validity, further demonstrated how well the scale items hung together as one construct. In addition, these items explained $65 \%$ of the variance in the total score. See Table 8 for a summary of the reliability, content validity and factor loadings of the critical thinking subscale of the self-efficacy pretest total. 


\section{Table 8}

The Reliability, Content Validity, and Factor Loadings of the Critical Thinking Subscale of the Self-Efficacy Scale

\begin{tabular}{|c|c|c|c|}
\hline Item \# & Critical Thinking Subscale & ITC & $\mathrm{FL}$ \\
\hline 1 & $\begin{array}{l}\text { Apply critical thinking skills within the context of professional } \\
\text { social work practice? }\end{array}$ & .73 & .75 \\
\hline 3 & $\begin{array}{l}\text { Understand the forms and mechanisms of oppression and } \\
\text { discrimination and can apply strategies of advocacy and social } \\
\text { change that advance social and economic justice? }\end{array}$ & .74 & .76 \\
\hline 5 & $\begin{array}{l}\text { Apply the knowledge and skills of a general ist social work } \\
\text { perspective? }\end{array}$ & .78 & .80 \\
\hline 6 & $\begin{array}{l}\text { Use theoretical frameworks supported by empirical evidence to } \\
\text { understand individual development and behavior across the life } \\
\text { span and the interactions among individuals and between } \\
\text { individuals and families, groups, organizations, and communities? }\end{array}$ & .79 & .81 \\
\hline 7 & Analyze social policies? & .84 & .86 \\
\hline 8 & Formulate social policies? & .82 & .84 \\
\hline 9 & Influence social policies? & .81 & .83 \\
\hline 10 & Evaluate research studies? & .76 & .79 \\
\hline 11 & Apply research findings to practice? & .79 & .82 \\
\hline \multirow[t]{2}{*}{12} & Evaluate your own practice interventions? & .80 & .82 \\
\hline & Mean & .79 & .81 \\
\hline
\end{tabular}

Note: ITC $=$ Item total correlation, FL = Factor Loadings

\section{Confidentiality}

The research team received IRB approval to gain access to the existing database created by Kent School of Social Work administrators for the purpose of assessing educational outcomes and informing curriculum decisions. Data was not gathered directly from students. Individual scores were kept in a secure database accessible only by the research team and results were reported only in aggregate.

\section{Data Analysis Plan}

During this section, each research question will be restated and then the appropriate data analysis plan for each question will be explained. The results of each analysis will then be discussed in the following chapter. 


\section{Research Question 1}

Did students show significant improvement between pre and posttest on their tested ability to think critically as measured by the California Critical Thinking Skills Test (CCTST) on the total and each of the five subscales of deductive reasoning, inductive reasoning, inference, evaluation and analysis?

This research question was analyzed utilizing four different analyses to get a richer understanding of students' progress or lack thereof between pretest and posttest administrations. First, the overall growth between pretest and posttest was examined utilizing paired samples $t$ test. The paired samples $t$ test requires the independent and dependent variables to be continuous, the measures should be a repeat measure of the same subjects (as in Question 1) or matched on the same variable, normal distribution of both measures, and at least thirty subjects (Abu-Bader, 2006). Normality distribution of the CCTST pre and post test measures at all levels of total, inference, analytic, evaluation, deductive and inductive was evaluated by examining the distribution plots with no violations noted. In examining the results of the analysis, it is important to ensure the number of cases at pretest and at post test is equal. The $t$ value and significance were the key statistics to review in this analysis. Significant $t$ values indicated significant differences between pre and post test scores. Once significance was determined, the mean score of both pre and post test measures was reviewed, the Pearson correlation coefficient indicated the positive or negative relationship between pre and post test scores, and mean differences between pre and post test scores.

Secondly, the researcher then split pretest and post test scores between certain student variables and reran the paired samples $t$ test. The researcher utilized the student 
grouping variables of gender, ethnicity, undergraduate major, type of program enrolled, months between undergraduate and entry into graduate school, type of undergraduate school, social work experience, as well as a new grouping variable based on where they scored on the CCTST on entry into the program. The researcher created this new variable for each of the pretest scales to reflect the grouping of scores into three equal groupings based on percentile cut offs for each appropriate pretest scale.

Third, based on prior work by Facione (1990d), the researcher examined how different students were upon entering the program (pretest) based on the groupings of gender, ethnicity, months between undergraduate and entry into graduate school, type of program enrolled, type of undergraduate institution, and years of social work experience by splitting the file based on the groupings and conducting independent $t$ tests. Lastly, the researcher examined how different students were upon completing critical thinking infused curriculum (post test) based on the same groupings and the same analysis techniques as previously stated for the pretest. The one-tailed level of significance was utilized when interpreting the $t$ tests for each hypothesis, as directionality was specified; however, when exploring differences based on the grouping variables (e.g., gender, ethnicity, etc.) the two-tailed level of significance was utilized as directionality was not hypothesized. This rationality was applied to the analyses of each hypothesis under Research Question 1.

To examine for group differences at pretest and posttest separately for the undergraduate major variable, a separate analysis was conducted. As the $t$ test is designed specifically to test for differences for only a two level independent variable, a ANOVA was used to test for group differences on undergraduate major, as the variable had five 
levels. Aside from the number of levels in the independent variable, the assumptions of the ANOVA are the same as the $t$ test, i.e. dependent variable must be continuous and at the interval level of measurement with a normal distribution, nominal level independent variable with homogeneity of variances (equal variance of all groups on the independent variable), and a sample size of at least 30 (Abu-Bader, 2006). The ANOVA produces an $F$ ratio, which measures the distance between the group means in standard error units. The greater the value of $F$ the more likely the differences are to be significant ( $p$ values). (Abu-Bader, 2006). Although the $F$ ratio and $p$ value indicate whether there are significant differences between groups, it does not indicate between which pair of groups the difference exists; therefore a post hoc is utilized. However, in this particular study post hoc analysis was not needed.

The See Figure 6 for a pictorial representation of this analysis and the specific analysis used at each step. 


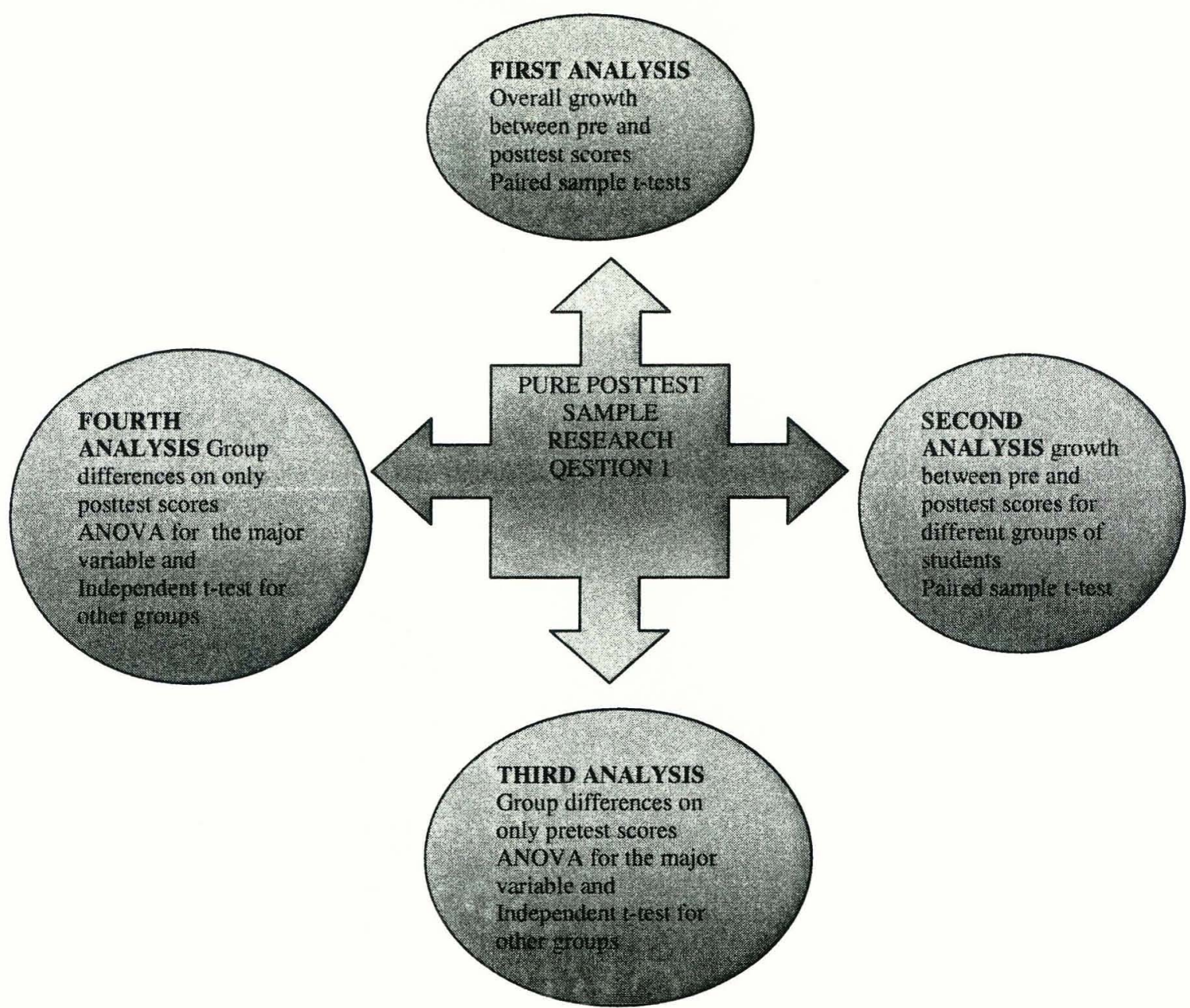

Figure 6 Analysis plan for research question 1

Research Questions 2-4

To what extent can entry level critical thinking skills of graduating MSSW students at the Kent School of Social Work be explained by the demographic variables of gender, race, and age, the generic variables of undergraduate GPA, months since undergraduate degree, and type of undergraduate institution, and the discipline specific variables of self-efficacy at pretest, years of social work experience, and undergraduate degree? 
To what extent can acquired critical thinking skills of graduating MSSW students at the Kent School of Social Work be explained by the demographic variables of gender, race, and age, the generic variables of undergraduate GPA, months since undergraduate degree, and type of undergraduate institution and the discipline specific variables of self-efficacy at pretest, years of social work experience, and undergraduate degree?

To what extent can acquired critical thinking skills (defined as total CCTST score, as well as scores on the subscales of inductive reasoning, deductive reasoning, analysis, evaluation and inference) of graduating MSSW students at the Kent School of Social Work be explained by the demographics of gender, race and age, the student characteristics at entry into the program of undergraduate GPA, months since undergraduate degree, years of social work related experience prior to entering program, undergraduate major, and type of undergraduate institution, and the student characteristics while in school of $30 \mathrm{vs.} 60 \mathrm{hr}$ student, graduate GPA, mean hours worked per week while in program, and critical thinking subscale of self-efficacy at posttest?

A hierarchical multiple regression analysis was conducted on the dependent variables (i.e. total, inductive, deductive, evaluation, analysis and inference) as stated in the different models to identify predictors of students' ability to think critically both at graduation and at entry into the program. A multiple regression is an extension of the Pearson correlation in that is tests for prediction and was used to "examine the effect of multiple independent variables (predictor variables) on one dependent variable (criterion variable) (Abu-Bader, 2006, p. 243). The multiple regression requires the dependent 
variable to be continuous data at interval or ratio level of measurement and should be normally distributed (Abu-Bader, 2006; Field, 2005; Meyers, Gamst, \& Guarina, 2006). The dependent variable should be normally distributed across each of the independent variables (Abu-Bader, 2006). A multiple regression analysis can accommodate independent variables at all four levels of measurement (ratio, interval, categorical and nominal); however, nominal and ordinal variables with more than two levels should be recoded into dichotomous dummy variables (Tabachnick \& Fidell, 2001). According to Cohen, Cohen, West and Aiken (2003) when recoding to a dummy variable, one group should serve as a reference group and is assigned a zero value. The selection of the reference group is based on the usefulness of the comparison, should not be a "waste basket category", and the sample size should not be small in comparison to the other groups (Cohen et al., 2003, pp. 303-304).

There are three methods of regression: standard, sequential (hierarchical), and stepwise. The hierarchical method was used in this study as it allowed the researcher to dictate the order in which the variables were entered into the equating theory. The two posttest prediction models each have specific control variables (See Figures 4-5) that were entered as the first block. The researcher treated the variables in the predictor model to be of greater importance than two nuisance or control variables, namely the pretest critical thinking scores and the length of time in the program when the pretest was completed. The control variables were therefore entered first as Block 1, after which the rest of the predictor variables were entered in three subsequent blocks. Each block was inspected for its predictor power, together with the individual variables in order to determine the strongest block as well as the strongest variables in each block for each of 
the models. Terenzini, Springer, Pascarella, and Nora (1993) supported controlling critical thinking pretest scores arguing the pretest scores may be the most significant predictor of posttest scores and "thus the probability was high that the influence of other predictor variables of theoretical and practical interest might be masked due to collinearity among the independent variables." (p. 6). Previous research has also indicated controlling for pretest scores alters the significance of correlations and predictors to posttest critical thinking scores (Facione, 1990a; Pascarella, 1989;

Pascarella \& Terenzini, 1991; Terenzini et al., 1993). Controlling for pretest and length of time in program when pretest completed allowed more specific focus on evaluating what the predictor variables added to the prediction over and above the lesser set of variables in Block 1 .

Major issues in conducting a multiple regression analysis included the following: sample size, multicollinearity, outliers, normality, linearity, and homoscedasticity of residuals. To ensure an appropriate sample size, Tabachnick and Fidell (2001) recommended the formula $N \geq 50+8 \mathrm{~m}$, in which $\mathrm{m}$ equals the number of predictor variables. For the current study, the maximum number of predictors used in any one model totaled 14, which yielded a required sample size of 162 students which was less than, the 304 students in the pretest sample and the 179 students in the posttest sample thus there was a sufficient sample size to examine all the hypothesized models. Multicollinearity occurs when the independent variables are correlated at .80 or higher with one another, resulting in two or more variables explaining the same area of variance in the dependent variable. Multicollinearity was evaluated through the SPSS output by examining the correlation matrixes, collinearity statistics, and diagnostics. A Variance 
Inflation Factor in excess of 10 indicates a problem, and eigenvalues close to 0 and condition indexes above 15 do as well (Meyers et al., 2006). Multicollinearity was noted in Research Question 4 between social work major and type of program. This issue is further discussed in Chapter 4 under Research Question 4 analysis results. No other violations of these guidelines occurred.

The data were also examined for outliers and their potential impact on the analysis and dealt with according to method by Osbourne and Oberby (2004). Meyers, Gamst and Guarina (2006) recommended that if the outliers are less than $10 \%$ of the sample and there is a difference in the analysis results with and without outliers, remove them from the analysis. Normality, linearity, and homoscedasticity were assessed through the output as well. According to Tabachnick and Fidell (2001)

the residuals (difference between the obtained and predicted DV scores) are normally distributed about the predicted DV scores, that residuals have a straightline relationship with predicted DV scores, and that the variance of the residuals about predicted DV scores is the same for all predicted scores (p. 119).

In examining the results, key statistics examined were the $\mathrm{R}^{2}$, the amount of variance explained; $\Delta R^{2} r$ (r square change), or the amount of change in $R^{2}$ resulting from the inclusion of a new predictor or block and $\beta$ (beta values), which indicated whether the relationship between the predictor and outcome was positive or negative and told whether it made a significant contribution to the model, as well as the relative importance to explained variance. The significance was determined through a t test, i.e. significant results indicated a significant contribution. The standardized betas were more directly comparable than the beta, as the standardized Beta was measured in standard deviations: 
When the predictor variable increased by one standard deviation, then the criterion variable increased by the amount of the standardized Beta.

\section{Conclusions}

This chapter provided the methodological foundation for the current study, by discussing in detail the proposed research questions, research design, sampling procedure, data sources, operationalization of variables as well as explaining in detail the data analyses plan. The following chapter will provide the detailed results of the statistical analyses of each research question and hypotheses. 


\section{CHAPTER FOUR}

\section{Results}

The purposes of this study were to utilize the data gathered in Kent School's outcomes assessment process to (a) examine changes in students' critical thinking skills after completing a critical thinking infused curriculum, (b) test a predictive model of students' critical thinking skills upon entry into the social work graduate program, and (c) test two predictive models of successful critical thinking skills development for graduating masters level social work students. This chapter discusses the results of the analyses for each individual research question derived from the overall purposes of the study.

\section{Research Question One}

The first analysis examines pretest and posttest differences on the CCTST as well as each of the subscales. Specifically, did students show significant improvement between pretest and posttest on their ability to think critically, as measured by the CCTST? The pure posttest sample as illustrated in Table 3 in Chapter 3 was utilized to answer this question.

\section{Descriptives}

Included in the pure posttest sample were 104 students. The multiple levels of ethnicity in the current study were recoded to $0=$ white and $1=$ nonwhite. There were $79.8 \%$ white students $(\mathrm{n}=83)$ and $20.2 \%(\mathrm{n}=21)$ non-white students. Most students were 
females $(83.7 \%, n=87)$, compared to $16.3 \%(n=17)$ men. The majority of students received their undergraduate degrees from teaching focused universities $(62.5 \%, \mathrm{n}=65)$ versus those students from research intensive undergraduate universities $(36.5 \%, \mathrm{n}=38)$.

Of the students where a major was reported, $59.6 \%(\mathrm{n}=62)$ majored in social work, $17.3 \%(n=18)$ majored in psychology, $6.7 \%(n=7)$ majored in sociology and $13.5 \%$ $(n=14)$ majored in non-helping other majors (e.g. Communications, Political Science, Theater) and $2.9 \%(\mathrm{n}=3)$ majored in other helping majors (e.g. Behavior Science, Child Development, Criminal Justice). Students enrolled in the 60 hour program constitute $39.4 \%(n=41)$ of the sample and those enrolled in the 30 hour program constitute $60.6 \%$ $(n=63)$.

From the initial data screening analysis, it was noted that two variables were severely positively skewed, i.e., months between undergraduate degree and entry into graduate school and years of social work experience. The average months between undergraduate degree and entry into graduate school was $37.37(\mathrm{SD}=58.13)$, with a range of 0 to 339.02 months and a skewness of 2.76 . The average years of social work experience was $2.36(\mathrm{SD}=3.75)$, with a range of 0 to 20 years and a skewness of 2.75 . The researcher utilized transformation processes as described by Tabachnick and Fidell (2001) in which a substantial positive skewness can be transformed with the inverse procedure $(\mathrm{NewX}=1 / \mathrm{x})$. The transformation process was used and did not improve the skewness; therefore both variables were dichotomized. Months between undergraduate degree and entry into graduate school was recoded into a year versus more than a year and years of social work experience was recoded into no experience versus experience. The majority of students entered graduate school in less than a year after their 
undergraduate degree $(62.5 \%, \mathrm{~N}=65)$; whereas, $37.5 \%(\mathrm{~N}=39)$ of students waited more than a year to enroll in graduate school. Those students with social work experience $(54.8 \%, \mathrm{~N}=57)$ made up the majority of the sample compared to those with no social work experience $(45.2 \%, \mathrm{~N}=47)$. These descriptive are summarized in Table 9.

\section{Table 9}

Descriptive Characteristics of the Pure Posttest Sample ${ }^{a}$

\begin{tabular}{lcc}
\hline Characteristic & N & $\%$ \\
\hline Social Work Experience & & \\
$\quad$ No experience & 47 & 45.2 \\
$\quad$ Experience & 57 & 54.8 \\
Time between undergrad. and graduate & & \\
school & 39 & 37.5 \\
$\quad$ More than a year & 65 & 62.5 \\
$\quad$ Less than a year & & \\
Type of Program & 41 & 39.4 \\
60 Hour Program & 63 & 60.6 \\
30 Hour Program & & \\
Ethnic Group & 21 & 20.2 \\
$\quad$ Non White & 83 & 79.8 \\
$\quad$ White & & \\
Gender & 87 & 83.7 \\
$\quad$ Female & 17 & 16.3 \\
$\quad$ Male & & \\
Undergraduate School & 38 & 36.5 \\
$\quad$ Research & 65 & 62.5 \\
Teaching & 1 & 1.0 \\
$\quad$ Missing & & \\
Undergraduate Degree & 62 & 59.6 \\
Social Work & 18 & 17.3 \\
Psychology & 7 & 6.7 \\
Sociology & 3 & 2.9 \\
Other Helping & 14 & 13.5 \\
Non Helping & & \\
\hline
\end{tabular}

${ }^{a}$ Due to rounding, not all categories equal $100 \%$. 
In addition to the previous descriptives, characteristics for the low, medium, and high performance groups of students at pretest were also calculated to provide a view of these different performance groups. These descriptive are summarized in Table 10.

Table 10

Descriptive Characteristics of the Three Groups ${ }^{a}$

\begin{tabular}{|c|c|c|c|c|c|c|}
\hline & Low & & Middle & & High & \\
\hline Characteristic & $\mathrm{n}$ & $\%$ & $\mathrm{n}$ & $\%$ & $\mathrm{n}$ & $\%$ \\
\hline \multicolumn{7}{|c|}{ Social Work Experience } \\
\hline No experience & 19 & 52.8 & 13 & 37.1 & 14 & 43.8 \\
\hline Experience & 17 & 47.2 & 22 & 62.9 & 18 & 56.2 \\
\hline \multicolumn{7}{|c|}{$\begin{array}{l}\text { Time between undergrad. } \\
\text { and graduate school }\end{array}$} \\
\hline More than a year & 11 & 30.6 & 13 & 37.1 & 15 & 46.9 \\
\hline Less than a year & 25 & 69.4 & 22 & 62.9 & 17 & 53.1 \\
\hline \multicolumn{7}{|l|}{ Type of Program } \\
\hline 60 Hour Program & 12 & 33.3 & 14 & 40.0 & 15 & 46.9 \\
\hline 30 Hour Program & 24 & 66.7 & 21 & 60.0 & 17 & 53.1 \\
\hline \multicolumn{7}{|l|}{ Ethnic Group } \\
\hline Non White & 7 & 19.4 & 10 & 28.6 & 4 & 12.5 \\
\hline White & 29 & 80.6 & 25 & 71.4 & 28 & 87.5 \\
\hline \multicolumn{7}{|l|}{ Gender } \\
\hline Female & 33 & 91.7 & 28 & 80.0 & 25 & 78.1 \\
\hline Male & 3 & 8.3 & 7 & 20.0 & 7 & 21.0 \\
\hline \multicolumn{7}{|c|}{ Undergraduate College } \\
\hline Research & 13 & 36.1 & 16 & 45.7 & 8 & 25.0 \\
\hline Teaching & 23 & 63.9 & 19 & 54.3 & 23 & 71.9 \\
\hline Missing & & & & & & \\
\hline \multicolumn{7}{|c|}{ Undergraduate Degree } \\
\hline Social Work & 24 & 66.7 & 20 & 57.1 & 17 & 53.1 \\
\hline Psychology & 6 & 16.7 & 5 & 14.3 & 7 & 21.9 \\
\hline Sociology & 2 & 5.6 & 4 & 11.4 & 1 & 3.1 \\
\hline Other Helping & 1 & 2.8 & 0 & 0.0 & 2 & 6.2 \\
\hline Non Helping & 3 & 8.3 & 6 & 17.1 & 5 & 15.6 \\
\hline
\end{tabular}

"Due to rounding, not all categories equal $100 \%$. 


\section{CCTST Pre and Posttest Scores}

The CCTST reported percentile scores to compare students' scores against a national sample of $4^{\text {th }}$ year college students utilizing an aggregated sample. The pretest total mean was at the $53^{\text {rd }}$ percentile. The posttest mean was at the $54^{\text {th }}$ percentile.

Students' average CCTST descriptives are summarized in Table 11.

\section{Table 11}

Descriptive Characteristics of CCTST Pre and Posttest Scores ${ }^{a}$

\begin{tabular}{lccccc}
\hline Scale & $\mathbf{N}$ & $\overline{\mathbf{X}}$ & SD & Range & $\begin{array}{c}\text { Maximum Points } \\
\text { Possible }\end{array}$ \\
\hline Pre Total & 103 & 17.20 & 4.40 & $6-28$ & 34 \\
Post Total & 103 & 17.49 & 4.32 & $9-28$ & 34 \\
Pre Analytic & 103 & 4.74 & 1.32 & $2-7$ & 7 \\
Post Analytic & 103 & 4.66 & 1.25 & $1-7$ & 7 \\
Pre Inference & 103 & 7.68 & 2.21 & $1-12$ & 16 \\
Post Inference & 103 & 8.10 & 2.46 & $3-13$ & 16 \\
Pre Evaluation & 103 & 4.79 & 2.06 & $0-10$ & 11 \\
Post Evaluation & 103 & 4.73 & 1.86 & $1-9$ & 11 \\
Pre Inductive & 103 & 10.01 & 2.71 & $3-16$ & 17 \\
Post Inductive & 103 & 10.02 & 2.24 & $5-15$ & 17 \\
Pre Deductive & 103 & 7.19 & 2.53 & $3-15$ & 17 \\
Post Deductive & 103 & 7.47 & 2.77 & $2-14$ & 17 \\
& & & & & \\
\hline
\end{tabular}

${ }^{a}$ Due to rounding, not all categories equal $100 \%$.

Hypothesis 1a: Students' tested ability to think critically (CCTST) will significantly improve between total scores on the pre and posttests

Hypothesis 1a predicted that students' ability to think critically (CCTST) would significantly improve between total scores on the pre and posttests. The CCTST total score reflects general critical thinking ability. Although the total mean scores did increase from 17.20 for the pretest to 17.49 at the posttest, the difference was not significant. The results of a one-tailed paired samples $t$ test refuted the hypothesis, $t(102)=-.94, p=.17$, indicating students' total scores did not significantly increase at posttest. 
There was no significant change between pretest and posttest total scores based on ethnicity, gender, undergraduate major, type of program enrolled, months between undergraduate and entry into graduate school, type of undergraduate school, and social work experience. However, significant differences were found between pretest and posttest scores when the sample was split based on the percentile groupings. The students who scored lower at pretest significantly improved their scores at posttest, $t(35)=-4.44$, $p=.00$; however, students who scored the highest at pretest significantly lowered their posttest total score $t(31)=2.01, p=.05$. There was no significant difference at posttest for those students in the middle group.

In regards to the group differences for pretest and posttest scores separately, there was no significant difference on the total pretest scores for ethnicity, but there were significant differences on the total posttest scores $t(102)=-2.30, p=.02$ in that Whites scored higher than Non white students. Students who entered graduate school less than a year after completing their undergraduate degrees showed trends toward higher pretest total scores on critical thinking $t(101)=-1.85, p=.07$. There were no other significant group differences on either the pretest or posttest scores. These results are summarized in Table 12. 
Table 12

Hypothesis 1a Total Analysis Results Summary

\begin{tabular}{|c|c|c|c|c|c|c|}
\hline Total CT & Mean 1 & Mean 2 & Diff & df & $\mathbf{t}$ & $\mathbf{p}$ \\
\hline \multicolumn{7}{|c|}{ Analysis 1: Overall growth between pre and post } \\
\hline Pre/post & Pre $=17.20$ & Post $=17.49$ & 102 & 102 & -.94 & .17 \\
\hline \multicolumn{7}{|c|}{ Analysis 2: Growth between pre and post for different groups of students } \\
\hline White & Pre $=17.44$ & Post $=17.96$ & -.52 & 81 & -1.55 & .29 \\
\hline Non-white & Pre $=16.29$ & Post $=15.62$ & .67 & 20 & 1.09 & .13 \\
\hline Males & Pre $=18.29$ & Post $=17.82$ & .47 & 16 & .63 & .54 \\
\hline Females & Pre $=16.99$ & Post $=17.42$ & -.43 & 85 & -1.32 & .19 \\
\hline No SW experience & Pre $=16.50$ & Post $=17.22$ &.-72 & 45 & -1.62 & .11 \\
\hline SW experience & Pre $=17.77$ & Post $=17.70$ & .07 & 56 & .17 & .86 \\
\hline More than a year & Pre $=18.23$ & Post $=18.18$ & .05 & 38 & .09 & .93 \\
\hline Less than a year & Pre $=16.56$ & Post $=17.06$ & -.48 & 63 & -1.43 & .16 \\
\hline 60 hour program & Pre $=17.54$ & Post $=18.07$ & -.54 & 40 & -1.02 & .31 \\
\hline 30 hour program & Pre $=16.98$ & Post $=17.10$ & -.11 & 61 & -.32 & .75 \\
\hline Teaching university & Pre $=17.60$ & Post $=17.75$ & -.15 & 64 & -.38 & .70 \\
\hline Research university & Pre $=16.43$ & Post $=16.97$ & -.54 & 36 & -1.20 & 24 \\
\hline Social Work & Pre $=17.00$ & Post $=17.10$ & -.10 & 60 & -.27 & 79 \\
\hline Psychology & Pre $=17.22$ & Post $=18.06$ & -.83 & 17 & -1.33 & .20 \\
\hline Sociology & Pre $=16.29$ & Post $=17.57$ & -1.29 & 6 & -.94 & .39 \\
\hline Helping Other & Pre $=17.33$ & Post $=16.67$ & .67 & 2 & .36 & .75 \\
\hline Non-helping other & Pre $=18.50$ & Post $=18$ & -.07 & 13 & -.07 & .95 \\
\hline Low critical thinkers & Pre $=12.61$ & Post $=14$ & -1.78 & 35 & -4.44 & .00 \\
\hline $\begin{array}{l}\text { Middle critical } \\
\text { thinkers }\end{array}$ & Pre $=17.14$ & Post $=17.20$ & -.06 & 34 & -.12 & .90 \\
\hline High critical thinkers & Pre $=22.44$ & Post $=21.28$ & 1.16 & 31 & 2.01 & .05 \\
\hline \multicolumn{7}{|c|}{ Analysis 3: Group differences on pretest only } \\
\hline Ethnicity & White $=17.44$ & $\begin{array}{l}\text { Non-White } \\
=16.29\end{array}$ & -1.15 & 101 & -1.06 & .29 \\
\hline Gender & Male $=18.29$ & Female $=16.99$ & -1.31 & 101 & -1.11 & .27 \\
\hline SW Experience & None $=16.50$ & Experience $=17.77$ & -1.27 & 101 & -1.45 & .15 \\
\hline Months between & $\geq$ a year $=18.23$ & $\leq$ a year $=16.58$ & -1.65 & 101 & -1.85 & .07 \\
\hline Type of program & $60=17.54$ & $30=16.98$ & .55 & 101 & 62 & .54 \\
\hline \multirow[t]{2}{*}{ Type of college } & Teaching $=17.60$ & Research $=16.43$ & 1.17 & 101 & 1.28 & .21 \\
\hline & & & & df & $F$ & $p$ \\
\hline Undergraduate major & & & & 4,102 & .40 & .81 \\
\hline
\end{tabular}




\begin{tabular}{|l|l|l|l|l|c|c|c|}
\hline \multicolumn{1}{|c|}{ Total CT } & \multicolumn{1}{c|}{ Mean 1 } & \multicolumn{1}{c|}{ Mean 2 } & Diff & df & t & p \\
\hline \multicolumn{2}{|c|}{ Analysis 4: Group differences on posttest only } \\
\hline Ethnicity & White $=17.99$ & $\begin{array}{l}\text { Non-White } \\
=15.62\end{array}$ & -2.37 & 102 & -2.30 & .02 \\
\hline Gender & Male $=17.82$ & Female $=17.45$ & -.38 & 102 & -.33 & .74 \\
\hline SW Experience & None $=17.28$ & Experience $=17.70$ & -.43 & 102 & -.50 & .62 \\
\hline Months between & $\geq$ a year $=18.18$ & $\leq$ a year=17.11 & -1.07 & 102 & -1.23 & .22 \\
\hline Type of program & $60=18.07$ & $30=17.14$ & .93 & 102 & 1.08 & .28 \\
\hline Type of college & Teaching=17.75 & Research=17.05 & .70 & 101 & .79 & .43 \\
\hline & & & & df & $\boldsymbol{F}$ & $\boldsymbol{p}$ \\
\hline Undergraduate major & & & & 4.103 & .42 & .80 \\
\hline
\end{tabular}

\section{Hypothesis 1b: Student's analytic skills (CCTST) will significantly improve between}

\section{pre and posttests}

Hypothesis $1 \mathrm{~b}$ predicted that students' analytic skills-the ability to think critically (CCTST) would significantly improve between pre and posttests. Analytic skill refers to the student's ability to dissect arguments and identify the assumptions and premises regarding the conclusions of claims being made (Facione, 2007). The results of a one-tailed paired samples $t$ test refuted this hypothesis, $t(102)=.57, p=.29$, indicating that students' analytic skills did not significantly increase at posttest. There was a trend in differences in pretest and posttest analytic skills based on the male grouping $t(16)=1.77$, $p=.10$ (two-tailed hypothesis). Men scored higher on their pretest $(\mathrm{M}=4.88)$ than on their posttest $(M=4.35)$. Significant differences were found between analytic pretest and posttest scores when the sample was split based on the percentile groupings. The students who scored the lowest at pretest significantly improved their scores at posttest, $t(43)=$ $-3.48, p=.00$; however, students who scored the highest at pretest significantly lowered their posttest total score $t(29)=6.02, p=.00$.

In regards to the group differences for pretest and posttest scores separately, significant difference were found on analytic pretest scores for social worker experience, 
in that those with no social work experience scored higher on pretest $t(101)=-2.06$, $p=.04$; however, there were no significant differences on the analytic posttests. Note Levene's was significant for the social work experience $(F=7.41, p=.01)$, therefore the $t$ value for unequal variances was reported. Students who entered graduate school less than a year after completing their undergraduate degrees showed trends in higher pretest scores for analytic reasoning $t(101)=-1.74, p=.08$. Regarding the type of undergraduate school students attended, those coming from research universities tended to have higher pretest scores for analytic $t(100)=1.76, p=.08$. These results are summarized in Table 13 . 
Table 13

Hypothesis $1 \mathrm{~b}$ Analytic Analysis Results Summary

\begin{tabular}{|c|c|c|c|c|c|c|}
\hline Total CT & Mean 1 & Mean 2 & Diff & df & $\mathbf{t}$ & $\mathbf{p}$ \\
\hline \multicolumn{7}{|c|}{ Analysis 1: Overall growth between pre and post } \\
\hline Pre/post & Pre $=4.74$ & Post $=4.66$ & .08 & 102 & .57 & 29 \\
\hline \multicolumn{7}{|c|}{ Analysis 2: Growth between pre and post for different groups of students } \\
\hline White & Pre $=4.80$ & Post $=4.76$ & .05 & 81 & .33 & .74 \\
\hline Non-white & Pre $=4.48$ & Post $=4.29$ & .19 & 20 & .55 & .59 \\
\hline Males & Pre $=4.88$ & Post $=4.35$ & .53 & 16 & 1.77 & .10 \\
\hline Females & Pre $=4.71$ & Post $=4.72$ & -.01 & 85 & -.08 & .94 \\
\hline No SW experience & Pre $=4.43$ & Post $=4.52$ & -.09 & 45 & -.41 & .68 \\
\hline SW experience & Pre $=4.98$ & Post $=4.77$ & .21 & 56 & 1.81 & .24 \\
\hline More than a year & Pre $=5.03$ & Post $=4.79$ & .23 & 38 & 1.14 & .26 \\
\hline Less than a year & Pre $=4.56$ & Post $=4.58$ & -.02 & 63 & -.09 & .93 \\
\hline 60 hour program & Pre $=4.83$ & Post $=4.78$ & .05 & 40 & .24 & .81 \\
\hline 30 hour program & Pre $=4.68$ & Post $=4.58$ & .10 & 61 & .53 & .60 \\
\hline Teaching university & Pre $=4.91$ & Post $=4.72$ & .19 & 64 & 1.10 & .28 \\
\hline Research university & Pre $=4.43$ & Post $=4.51$ & -.08 & 36 & -.34 & .73 \\
\hline Social Work & Pre $=4.66$ & Post $=4.54$ & .12 & 60 & .62 & .54 \\
\hline Psychology & Pre $=4.89$ & Post $=4.94$ & -.06 & 17 & -.24 & .82 \\
\hline Sociology & Pre $=4.71$ & Post $=5.14$ & -.43 & 6 & -.89 & .41 \\
\hline Helping Other & Pre $=5.00$ & Post $=5.00$ & .00 & 2 & .00 & 1.0 \\
\hline Non-helping other & Pre $=4.86$ & Post $=4.50$ & .36 & 13 & .84 & .42 \\
\hline Low critical thinkers & Pre $=3.48$ & Post $=4.14$ & -.66 & 43 & -3.48 & .00 \\
\hline $\begin{array}{l}\text { Middle critical } \\
\text { thinkers }\end{array}$ & Pre $=5.00$ & Post $=4.76$ & .24 & 28 & .94 & .35 \\
\hline High critical thinkers & Pre $=6.33$ & Post $=5.33$ & 1.0 & 29 & 6.0 & .00 \\
\hline \multicolumn{7}{|c|}{ Analysis 3: Group differences on pretest only } \\
\hline Ethnicity & White $=4.80$ & Non-White $=4.48$ & -.33 & 101 & -1.02 & .31 \\
\hline Gender & Male $=4.88$ & Female $=4.71$ & -.17 & 101 & -.49 & .62 \\
\hline SW Experience & None $=4.43$ & Experience $=4.98$ & -.55 & 101 & -2.06 & .04 \\
\hline Months between & $\geq$ a year $=5.03$ & $\geq$ a year $=4.56$ & -.46 & 101 & -1.74 & -.46 \\
\hline Type of program & $60=4.83$ & $30=4.68$ & .15 & 101 & .57 & .57 \\
\hline \multirow[t]{2}{*}{ Type of college } & Teaching $=4.91$ & Research $=4.43$ & .48 & 102 & 1.76 & .08 \\
\hline & & & & df & $F$ & $p$ \\
\hline Undergraduate major & & & & 4,102 & .17 & .95 \\
\hline
\end{tabular}




\begin{tabular}{|l|l|l|c|c|c|c|}
\hline \multicolumn{1}{|c|}{ Total CT } & \multicolumn{1}{c|}{ Mean 1 } & \multicolumn{1}{c|}{ Mean 2 } & Diff & df & t & p \\
\hline \multicolumn{2}{|c|}{ Analysis 4: Group differences on posttest only } \\
\hline Ethnicity & White $=4.75$ & Non-White $=4.29$ & -.46 & 102 & -1.53 & .13 \\
\hline Gender & Male $=4.35$ & Female $=4.71$ & .36 & 102 & 1.09 & .28 \\
\hline SW Experience & None $=4.51$ & Experience $=4.77$ & -.26 & 102 & -1.07 & .29 \\
\hline Months between & $\geq$ a year $=4.79$ & $\leq$ a year $=4.57$ & -.23 & 102 & -.89 & .37 \\
\hline Type of program & $60=4.78$ & $30=4.57$ & .21 & 102 & .84 & .41 \\
\hline Type of college & Teaching $=4.72$ & Research $=4.50$ & .22 & 101 & .88 & .38 \\
\hline & & & & df & $\boldsymbol{F}$ & $p$ \\
\hline Undergraduate major & & & & 4,103 & .77 & .55 \\
\hline
\end{tabular}

Hypothesis 1c: Students evaluation skills (CCTST) will significantly improve between pre and posttests

Hypothesis 1c predicted that students' evaluation skills (CCTST) would significantly improve between pre and posttests. Evaluation refers to a student's ability to determine the strengths and weaknesses in an argument, or to determine the believability of a claim (Facione, 2007). The results of a one-tailed paired samples $t$ test refuted this hypothesis, $t(102)=.32, p=.37$, indicating students' evaluation scores did not significantly improve at posttest. There were no significant differences in pre and post test evaluation scores based on the previously discussed student variables. Significant differences were found between evaluation pretest and posttest scores when the sample was split based on the percentile groupings. The students in the lowest percentile group (between 0 and $33^{\text {rd }}$ ) at pretest significantly improved their scores at posttest, $t(44)=$ $-3.25, p=.00$; however, the scores of students in the highest (above $66^{\text {th }}$ percentile) at pretest significantly diminished at posttest: total score $t(29)=3.30, p=.00$, and a trend toward improvement was indicated for students in the middle group (between the $33^{\text {rd }}$ and $66^{\text {th }}$ percentile) $t(35)=1.80, p=.08$. The group differences were examined separately 
for pretest and posttest on the evaluation scale. No significant differences or trends were found. These results are summarized in Table 14. 


\section{Table 14}

\section{Hypothesis 1c Evaluation Analysis Results Summary}

\begin{tabular}{|c|c|c|c|c|c|c|}
\hline Total CT & Mean 1 & Mean 2 & Diff & df & $t$ & $\mathbf{p}$ \\
\hline \multicolumn{7}{|c|}{ Analysis 1: Overall growth between pre and post } \\
\hline Pre/post & Pre $=4.79$ & Post $=4.73$ & .06 & 102 & .32 & 37 \\
\hline \multicolumn{7}{|c|}{ Analysis 2: Growth between pre and post for different groups of students } \\
\hline White & Pre $=4.93$ & Post $=4.84$ & .09 & 81 & .43 & 67 \\
\hline Non-white & Pre $=4.24$ & Post $=4.29$ & -.05 & 20 & -.11 & 91 \\
\hline Males & Pre $=5.29$ & Post $=4.59$ & .71 & 16 & 1.46 & .16 \\
\hline Females & Pre $=4.69$ & Post $=4.76$ & -.07 & 85 & -.36 & .72 \\
\hline No SW experience & Pre $=4.48$ & Post $=4$ & -.07 & 45 & -.28 & .78 \\
\hline SW experience & Pre $=5.04$ & Post $=4.88$ & .16 & 56 & .59 & .56 \\
\hline More than a year & Pre $=5.08$ & Post $=5.03$ & .05 & 38 & 14 & .89 \\
\hline Less than a year & Pre $=4.61$ & Post $=4$ & .06 & 63 & .34 & .73 \\
\hline 60 hour program & Pre $=4.88$ & Post $=5$ & -.17 & 40 & -.65 & .52 \\
\hline 30 hour program & Pre $=4.73$ & Post $=4.52$ & .21 & 61 & .86 & .39 \\
\hline Teaching university & Pre $=4.78$ & Post $=4.78$ & .00 & 64 & .00 & 1.00 \\
\hline Research university & Pre $=4.76$ & Post $=4.62$ & .14 & 36 & .47 & .08 \\
\hline Social Work & Pre $=4.74$ & Post $=4$ & .26 & 60 & 1.12 & .27 \\
\hline Psychology & Pre $=4.50$ & Post $=4.94$ & -.44 & 17 & -1.25 & .23 \\
\hline Sociology & Pre $=3.86$ & Post $=5$ & -1.14 & 6 & -1.26 & .26 \\
\hline Helping Other & Pre $=5.33$ & Post $=4.67$ & .67 & 2 & .38 & .74 \\
\hline Non-helping other & Pre $=5.71$ & Post $=5.43$ & .29 & 13 & .69 & .50 \\
\hline Low critical thinkers & Pre $=2.87$ & Post $=3.69$ & -.82 & 44 & -3.25 & .00 \\
\hline $\begin{array}{l}\text { Middle critical } \\
\text { thinkers }\end{array}$ & $\operatorname{Pre}=5.47$ & Post $=5.00$ & .47 & 35 & 1.80 & .08 \\
\hline High critical thinkers & Pre $=7.59$ & Post $=6.41$ & 1.18 & 21 & 3.30 & .00 \\
\hline \multicolumn{7}{|c|}{ Analysis 3: Group differences on pretest only } \\
\hline Ethnicity & White $=4.93$ & Non-White $=4.24$ & -.69 & 101 & -1.38 & .17 \\
\hline Gender & Male $=5.29$ & Female $=4.69$ & -.61 & 101 & -1.12 & .27 \\
\hline SW Exper & None $=4.48$ & Experience $=5.04$ & -.56 & 101 & -1.37 & .17 \\
\hline Months between & $\geq$ a year $=5.08$ & $\leq$ a year $=4.61$ & -.47 & 101 & -1.12 & .27 \\
\hline Type of program & $60=4.88$ & $30=4.73$ & .15 & 101 & .37 & .72 \\
\hline \multirow[t]{2}{*}{ Type of college } & Teaching $=4.78$ & Research $=4.76$ & .03 & 100 & .07 & .95 \\
\hline & & & & df & $F$ & $p$ \\
\hline iderg & & & & 4,102 & 1.23 & 30 \\
\hline
\end{tabular}




\begin{tabular}{|l|l|l|l|l|l|c|c|}
\hline \multicolumn{1}{|c|}{ Total CT } & \multicolumn{1}{c|}{ Mean 1 } & \multicolumn{2}{c|}{ Mean 2 } & Diff & df & t & $\mathbf{p}$ \\
\hline \multicolumn{2}{|c|}{ Analysis 4: Group differences on posttest only } \\
\hline Ethnicity & White $=4.84$ & Non-White $=4.29$ & -.56 & 102 & -1.23 & .22 \\
\hline Gender & Male $=4.59$ & Female $=4.76$ & .17 & 102 & .35 & .73 \\
\hline SW Experience & None $=4.55$ & Experience $=4.88$ & -.32 & 102 & -.89 & .38 \\
\hline Months between & $\geq$ a year=5.03 & $\begin{array}{l}\leq \text { than a } \\
\text { year=4.55 }\end{array}$ & -.47 & 102 & -1.26 & .21 \\
\hline Type of program & $60=5.05$ & $30=4.52$ & .53 & 102 & 1.42 & .16 \\
\hline Type of college & Teaching=4.78 & Research=4.63 & .15 & 101 & .40 & .69 \\
\hline & & & & df & $\boldsymbol{F}$ & $p$ \\
\hline Undergraduate major & & & & 4.103 & .86 & .49 \\
\hline
\end{tabular}

Hypothesis 1d: Students inference skills (CCTST) will significantly improve between pre and posttests

Hypothesis 1d predicted that students' inference skills (CCTST) would significantly improve between pre and posttests (high scores suggest improvement). Inference refers to the student's ability to draw accurate conclusions based on reasons and evidence (Facione, 2007). The results of a one-tailed paired samples $t$ test supported this hypothesis, $t(102)=-1.92, p=.03$. These findings indicate that students scored higher on their posttest inference scores $(M=8.10)$ than on their pretest inference scores $(M=$ 7.68).

There were significant differences in pre and post test inference skills based on White ethnicity $t(81)=-2.64, p=.01$ (two-tailed hypothesis), indicating that White students scored higher on posttest inference $(M=8.37)$ than on their pretest inferences score $(M=7.71)$. There was also a trend in the length of time between undergraduate school and entry into graduate school, $t(63)=-1.86, p=.07$ (two-tailed hypothesis). These findings suggest that students who entered graduate school less than a year after completing college scored higher on the posttest inference $(M=8.36)$ than on the pretest inference $(\mathrm{M}=8.13)$. There was also a trend in type of undergraduate school $t(64)=-1.79$, 
$p=.08$ (two-tailed hypothesis), indicating students from research intensive universities scored higher on inference posttest $(M=7.84)$ than on inference pretest $(M=7.24)$. In addition, there was a trend in social work major $t(60)=-1.93, p=.06$ (two-tailed hypothesis), in that students who did not have a social work major scored higher on inference posttest $(M=8.08)$ than on inference pretest $(M=7.61)$. Significant differences also were found between inference pretest and posttest scores when the sample was split based on the percentile groupings. The students who scored the lowest at pretest significantly improved their scores at posttest, $t(52)=-3.58, p=.00$. There were no significant differences for the middle or highest percentile groups.

When group differences between for pretest and posttest scores were examined separately, there was no significant differences on the inference pretest scores for ethnicity, but there were significant differences at posttest $t(102)=-2.29, p=.02$, in that Whites scored higher than Non white students. Students with less than a year between undergraduate and entry into graduate school demonstrated a trend toward higher scores at pretest $t(102)=-1.75, p=.08$. The Levene's test was significant; therefore the $t$ value for unequal variances was interpreted. No other significant difference or trends were noted for either pretest or posttest scores. These results are summarized in Table 15. 
Table 15

Hypothesis Id Inference Analysis Results Summary

\begin{tabular}{|c|c|c|c|c|c|c|}
\hline Total CT & Mean 1 & Mean 2 & Diff & df & $\mathbf{t}$ & $\mathbf{p}$ \\
\hline \multicolumn{7}{|c|}{ Analysis 1: Overall growth between pre and post } \\
\hline Pre/post & Pre $=7.68$ & Post $=8.10$ & -.42 & 102 & -1.92 & .03 \\
\hline \multicolumn{7}{|c|}{ Analysis 2: Growth between pre and post for different groups of students } \\
\hline White & Pre $=7.71$ & Post $=8.37$ & -.66 & 81 & -2.64 & .01 \\
\hline Non-white & Pre $=7.57$ & Post $=7.05$ & .52 & 20 & 1.37 & .19 \\
\hline Males & Pre $=8.12$ & Post $=8.88$ & -.77 & 16 & 1.77 & .10 \\
\hline Females & Pre $=7.59$ & Post $=7.94$ & -.35 & 85 & -1.60 & .11 \\
\hline No SW experience & Pre $=7.59$ & Post $=8.15$ & -.57 & 45 & -1.65 & .11 \\
\hline SW experience & Pre $=7.75$ & Post $=8.05$ & -.30 & 56 & -1.06 & .29 \\
\hline More than a year & Pre $=8.13$ & Post $=8.36$ & -.23 & 39 & -.69 & .49 \\
\hline Less than a year & Pre $=7.41$ & Post $=7.94$ & -.53 & 64 & -1.86 & .07 \\
\hline 60 hour program & Pre $=7.83$ & Post $=8.24$ & -.42 & 40 & -1.08 & .29 \\
\hline 30 hour program & Pre $=7.58$ & Post $=8.00$ & -.42 & 61 & -1.62 & .11 \\
\hline Teaching university & Pre $=7.91$ & Post $=8.25$ & -.34 & 64 & -1.17 & .25 \\
\hline Research university & Pre $=7.24$ & Post $=7.84$ & -.60 & 36 & -1.79 & .08 \\
\hline Social Work & Pre $=7.61$ & Post $=8.08$ & -.48 & 60 & -1.93 & .06 \\
\hline Psychology & Pre $=7.83$ & Post $=8.17$ & -.33 & 17 & -.50 & .62 \\
\hline Sociology & Pre $=7.71$ & Post $=7.43$ & .29 & 6 & .29 & .78 \\
\hline Helping Other & Pre $=7.00$ & Post $=7.00$ & .00 & 2 & .00 & 1.00 \\
\hline Non-helping other & Pre $=7.93$ & Post $=8.64$ & -.71 & 13 & -1.03 & .32 \\
\hline Low critical thinkers & Pre $=6.00$ & Post $=6.98$ & -.98 & 52 & -3.58 & .00 \\
\hline $\begin{array}{l}\text { Middle critical } \\
\text { thinkers }\end{array}$ & Pre $=8.52$ & Post $=8.55$ & -.03 & 30 & -.07 & .94 \\
\hline High critical thinkers & Pre $=11.00$ & Post $=10.47$ & .53 & 18 & 1.16 & .26 \\
\hline \multicolumn{7}{|c|}{ Analysis 3: Group differences on pretest only } \\
\hline Ethnicity & White $=7.71$ & Non-White $=7.57$ & -.14 & 101 & -.25 & .80 \\
\hline Gender & Male $=8.12$ & Female $=7.59$ & -.53 & 101 & -.89 & .37 \\
\hline SW Experience & None $=7.59$ & Experience $=7.75$ & -.17 & 101 & -.38 & .70 \\
\hline Months between & $\geq$ a year $=8.13$ & $\leq$ a year $=7.41$ & -.72 & 101 & -1.62 & .11 \\
\hline Type of program & $60=7.83$ & $30=7.58$ & .25 & 101 & .56 & .58 \\
\hline \multirow[t]{2}{*}{ Type of college } & Teaching $=7.91$ & Research $=7.24$ & .66 & 100 & 1.46 & .15 \\
\hline & & & & df & $F$ & $p$ \\
\hline Undergraduate major & & & & 4,102 & .15 & .96 \\
\hline
\end{tabular}




\begin{tabular}{|l|l|l|c|c|c|c|c|}
\hline \multicolumn{1}{|c|}{ Total CT } & \multicolumn{1}{c|}{ Mean 1 } & \multicolumn{1}{c|}{ Mean 2 } & Diff & df & t & p \\
\hline \multicolumn{2}{|c|}{ Analysis 4: Group differences on posttest only } \\
\hline Ethnicity & White $=8.40$ & Non-White $=7.05$ & -1.35 & 102 & -2.58 & .02 \\
\hline Gender & Male $=8.88$ & Female $=7.98$ & -.91 & 102 & -1.39 & .17 \\
\hline SW Experience & None $=8.21$ & Experience $=8.05$ & .16 & 102 & .33 & .74 \\
\hline Months between & $\geq$ a year=8.36 & $\begin{array}{l}\text { Sthan a } \\
\text { year=7.98 }\end{array}$ & -.37 & 102 & -.75 & .46 \\
\hline Type of program & $60=8.24$ & $30=8.05$ & .20 & 102 & .40 & .69 \\
\hline Type of college & Teaching=8.25 & Research=7.92 & .33 & 101 & .64 & .52 \\
\hline & & & & df & $\boldsymbol{F}$ & $p$ \\
\hline Undergraduate major & & & & 4,103 & .44 & .78 \\
\hline
\end{tabular}

Hypothesis 1e: Students' inductive reasoning skills (CCTST) will significantly improve between pre and posttests

Hypothesis 1e predicted that students' inductive reasoning (CCTST) would significantly improve between pre and posttests. Inductive reasoning refers to empirical generalizations about observations and then forming tentative conclusions (basing predictions on past experiences) (Facione, 2007). The results of a one-tailed paired samples $t$ test refuted this hypothesis, $t(102)=.05, p=.48$, indicating students' inductive reasoning skills did not significantly improve at posttest. Additionally, there were no significant differences in pre and posttest inductive scores based on the previously discussed student variables. Significant differences were found between inductive pretest and posttest scores when the sample was split based on the percentile groupings. The students who scored lower at pretest significantly improved their scores at posttest, $t(47)=-6.34, p=.00$; however, students who scored higher at pretest yielded significantly lower posttest total scores $t(30)=3.37, p=.00$, than did students in the middle percentile group $t(23)=3.91, p=.00$.

There were no statistically significant differences in the change between pre and posttest when group differences were scored separately by ethnicity, but there were 
significant differences on the posttest scores $t(102)=-2.07, p=.04$, in that White students scored higher than Non white students. Students who entered graduate school less than a year after completing their undergraduate degrees yielded statistically significantly higher scores at pretest on inductive $t(101)=-2.76, p=.01$; however, there was a trend toward posttest scores on inductive toward improvement $t(102)=-1.92, p=.06$. These results are summarized in Table 16. 
Table 16

Hypothesis 1e Inductive Analysis Results Summary

\begin{tabular}{|c|c|c|c|c|c|c|}
\hline Total CT & Mean 1 & Mean 2 & Diff & df & $\mathbf{t}$ & $\mathbf{p}$ \\
\hline \multicolumn{7}{|c|}{ Analysis 1: Overall growth between pre and post } \\
\hline Pre/post & Pre $=10.01$ & Post $=10.02$ & .39 & 102 & -.05 & .48 \\
\hline \multicolumn{7}{|c|}{ Analysis 2: Growth between pre and post for different groups of students } \\
\hline White & Pre $=10.20$ & Post $=10.24$ & -.05 & 81 & -.22 & .82 \\
\hline Non-white & Pre $=9.29$ & Post $=9.14$ & .14 & 20 & 29 & .78 \\
\hline Males & Pre $=10.18$ & Post $=9.76$ & .41 & 16 & .94 & .36 \\
\hline Females & Pre $=9.98$ & Post $=10.07$ & -.09 & 85 & -.42 & .68 \\
\hline No SW experience & Pre $=9.57$ & Post $=9.78$ & -.22 & 45 & -.71 & .48 \\
\hline SW experience & Pre $=10.37$ & Post $=10.21$ & .16 & 56 & .60 & .55 \\
\hline More than a year & Pre $=10.92$ & Post $=10.56$ & .36 & 38 & 1.07 & .29 \\
\hline Less than a year & Pre $=9.45$ & Post $=9.69$ & -.23 & 63 & -.95 & .07 \\
\hline 60 hour program & Pre $=10.29$ & Post $=10.41$ & -.12 & 40 & -.39 & .70 \\
\hline 30 hour program & Pre $=9.82$ & Post $=9.76$ & .07 & 61 & .25 & .81 \\
\hline Teaching university & Pre $=10.05$ & Post $=10.05$ & .00 & 64 & .00 & 1.00 \\
\hline Research university & Pre $=9.84$ & Post $=9.89$ & -.05 & 36 & -.16 & .88 \\
\hline Social Work & Pre $=9.84$ & Post $=9.79$ & .05 & 61 & .19 & .85 \\
\hline Psychology & Pre $=9.94$ & Post $=10.28$ & -.33 & 17 & -.79 & .44 \\
\hline Sociology & Pre $=9.43$ & Post $=10.00$ & -.57 & 6 & -.62 & .56 \\
\hline Helping Other & Pre $=10.67$ & Post $=10.67$ & .00 & 2 & .00 & 1.00 \\
\hline Non-helping other & Pre $=11.00$ & Post $=10.57$ & .43 & 13 & .75 & .47 \\
\hline Low critical thinkers & Pre $=7.73$ & Post $=9.08$ & -1.35 & 47 & -6.34 & .00 \\
\hline $\begin{array}{l}\text { Middle critical } \\
\text { thinkers }\end{array}$ & Pre $=10.76$ & Post $=9.21$ & 1.25 & 23 & 3.91 & .00 \\
\hline High critical thinkers & Pre $=13.19$ & Post $=12.10$ & 1.10 & 30 & 3.37 & .00 \\
\hline \multicolumn{7}{|c|}{ Analysis 3: Group differences on pretest only } \\
\hline Ethnicity & White $=10.20$ & Non-White $=9.29$ & -.91 & 101 & -1.38 & .17 \\
\hline Gender & Male $=10.18$ & Female $=9.98$ & -.20 & 101 & -.28 & .78 \\
\hline SW Experience & None $=9.57$ & Experience $=10.37$ & -.80 & 101 & -1.51 & .14 \\
\hline Months between & $\geq$ a year $=10.92$ & $\leq$ a year $=9.45$ & -1.47 & 101 & -2.76 & .01 \\
\hline Type of program & $60=10.29$ & $30=9.82$ & .47 & 101 & .86 & .39 \\
\hline \multirow[t]{2}{*}{ Type of college } & Teaching $=10.05$ & Research $=9.84$ & .21 & 100 & .37 & .71 \\
\hline & & & & df & $F$ & $p$ \\
\hline Undergrad major & & & & 4,102 & .65 & .63 \\
\hline
\end{tabular}




\begin{tabular}{|l|l|l|c|c|c|c|c|}
\hline \multicolumn{1}{|c|}{ Total CT } & \multicolumn{1}{c|}{ Mean 1 } & \multicolumn{1}{c|}{ Mean 2 } & Diff & df & t & p \\
\hline \multicolumn{2}{|c|}{ Analysis 4: Group differences on posttest only } \\
\hline Ethnicity & White $=10.25$ & Non-White $=9.14$ & -1.11 & 102 & -2.07 & .04 \\
\hline Gender & Male $=9.76$ & Female $=10.08$ & .32 & 102 & .53 & .60 \\
\hline SW Experience & None $=9.81$ & Experience $=10.21$ & -.40 & 102 & -.92 & .36 \\
\hline Months between & $\geq$ a year $=10.56$ & $\leq$ a year $=9.71$ & -.86 & 102 & -1.92 & .06 \\
\hline Type of program & $60=10.41$ & $30=9.78$ & .64 & 102 & 1.43 & .16 \\
\hline Type of college & Teaching=10.05 & Research=9.92 & .13 & 101 & .28 & .78 \\
\hline & & & & df & $\boldsymbol{F}$ & $p$ \\
\hline Undergraduate major & & & & 4,103 & .47 & .76 \\
\hline
\end{tabular}

\section{Hypothesis 1f: Students'deductive reasoning skills (CCTST) will significantly improve}

between pre and posttests

Hypothesis 1f predicted that students' deductive reasoning skills (CCTST) would significantly improve between pre and posttests. Deductive reasoning begins with a hypothesis and observations, then an evaluation of the hypothesis based on the evidence. Deductive reasoning includes the strict application and adherence to set rules or guidelines (Facione, 2007).The results of a one-tailed paired samples $t$ test refuted this hypothesis, $t(102)=-1.21, p=.11$, indicating students' deductive reasoning skills did not significantly improve at posttest. A trend was noted in the results on a two-tailed paired samples $t$ test for pre and post differences based on White ethnicity $t(81)=-1.80, p=.08$, in that, students of White ethnicity scored significantly higher on the posttest deductive as compared to the pretest. Neither were there significant differences in pre and posttest deductive scores based on the previously discussed student variables. Significant differences were found between deductive pretest and posttest scores when the sample was split based on the percentile groupings. The students who scored the lowest at pretest significantly improved their scores at posttest, $t(43)=-3.58, p=.00$. There were no significant differences in the middle or highest percentile groups. 
In regards to the group differences for pretest and posttest scores separately, there was no significant differences on the total pretest scores for ethnicity, but there was a trend for posttest deductive to improve $t(102)=-1.89, p=.06$, in that White students scored higher than Non white students. There was a trend noted in deductive pretest in that males scored higher than females $t(101)=-.28, p=.10$; however, there were no significant differences on the posttest scores based on gender. Regarding the type of college attended by graduate students, those coming from research universities showed a higher trend in the pretest scores for deductive $t(102)=1.98, p=.05$. Note for the results, Levene's was significant at $F=5.40, p=.02$, therefore the $t$ value for unequal variances was interpreted. This trend disappeared at posttest. These results are summarized in Table 17. 
Table 17

Hypothesis If Deductive Analysis Results Summary

\begin{tabular}{|c|c|c|c|c|c|c|}
\hline Total CT & Mean 1 & Mean 2 & Diff & df & $\mathbf{t}$ & p \\
\hline \multicolumn{7}{|c|}{ Analysis 1: Overall growth between pre and post } \\
\hline Pre/post & Pre $=7.19$ & Post $=7.47$ & -.27 & 102 & -1.21 & 11 \\
\hline \multicolumn{7}{|c|}{ Analysis 2: Growth between pre and post for different groups of students } \\
\hline White & Pre $=7.24$ & Post $=7.72$ & -.48 & 81 & -1.80 & .08 \\
\hline Non-white & Pre $=7.00$ & Post $=6.48$ & .52 & 20 & 1.50 & .15 \\
\hline Males & Pre $=8.12$ & Post $=8.6$ & .06 & 16 & .09 & .93 \\
\hline Females & Pre $=7.01$ & Post $=7.35$ & -.34 & 85 & -1.44 & .15 \\
\hline No SW experience & Pre $=6.93$ & Post $=7.43$ & -.50 & 45 & -1.45 & .15 \\
\hline SW experience & Pre $=7.40$ & Post $=7.49$ & -.09 & 56 & -.30 & .77 \\
\hline More than a year & Pre $=7.31$ & Post $=7.62$ & -.31 & 38 & -.78 & .44 \\
\hline Less than a year & Pre $=7.12$ & Post $=7.38$ & -.25 & 63 & -.92 & .36 \\
\hline 60 hour program & Pre $=7.24$ & Post $=7.66$ & -.42 & 40 & -1.01 & .32 \\
\hline 30 hour program & Pre $=7.16$ & Post $=7.34$ & -.18 & 61 & -.69 & .49 \\
\hline Teaching university & Pre $=7.55$ & Post $=7.71$ & -.15 & 64 & -.53 & .60 \\
\hline Research university & Pre $=6.59$ & Post $=7.08$ & -.49 & 36 & -1.33 & .19 \\
\hline Social Work & Pre $=7.16$ & Post $=7.31$ & -.15 & 60 & -.55 & .59 \\
\hline Psychology & Pre $=7.28$ & Post $=7.78$ & -.50 & 17 & -.75 & .46 \\
\hline Sociology & Pre $=6.86$ & Post $=7.57$ & -.71 & 6 & -.92 & .39 \\
\hline Helping Other & Pre $=6.67$ & Post $=6.00$ & .67 & 2 & .76 & .53 \\
\hline Non-helping other & Pre $=7.50$ & Post $=8.00$ & -.50 & 13 & -.71 & .49 \\
\hline Low critical thinkers & Pre $=4.80$ & Post $=5.89$ & -1.09 & 43 & -3.58 & .00 \\
\hline $\begin{array}{l}\text { Middle critical } \\
\text { thinkers }\end{array}$ & Pre $=7.48$ & Post $=7.52$ & -.04 & 26 & -.09 & .93 \\
\hline High critical thinkers & Pre $=10.25$ & Post $=9.59$ & .66 & 31 & 1.54 & .14 \\
\hline \multicolumn{7}{|c|}{ Analysis 3: Group differences on pretest only } \\
\hline Ethnicity & White $=7.24$ & Non-White $=7.00$ & -.24 & 101 & -.39 & .70 \\
\hline Gender & Male $=8.12$ & Female $=7.01$ & -1.11 & 101 & -1.66 & .10 \\
\hline SW Experience & None $=6.93$ & Experience $=7.40$ & -.47 & 101 & -.93 & .35 \\
\hline Months between & $\geq$ a year $=7.31$ & $\leq$ a year $=7.12$ & -.18 & 101 & -.35 & .72 \\
\hline Type of program & $60=7.24$ & $30=7.16$ & .08 & 101 & .16 & .87 \\
\hline \multirow[t]{2}{*}{ Type of college } & Teaching $=7.55$ & Research $=6.59$ & .96 & 101 & 1.85 & .07 \\
\hline & & & & df & $\boldsymbol{F}$ & $p$ \\
\hline Undergraduate major & & & & 4,102 & .12 & .98 \\
\hline
\end{tabular}




\begin{tabular}{|l|l|l|c|c|c|c|}
\hline \multicolumn{1}{|c|}{ Total CT } & \multicolumn{1}{c|}{ Mean 1 } & \multicolumn{1}{c|}{ Mean 2 } & Diff & df & \multicolumn{1}{c|}{ t } & p \\
\hline \multicolumn{2}{|c|}{ Analysis 4: Group differences on posttest only } & \multicolumn{3}{c|}{} \\
\hline Ethnicity & White $=7.73$ & $\begin{array}{l}\text { Non-White }= \\
6.48\end{array}$ & -1.26 & 102 & -1.89 & .06 \\
\hline Gender & Male $=8.06$ & Female $=7.37$ & -.69 & 102 & -.95 & .35 \\
\hline SW Experience & None $=7.47$ & Experience $=7.49$ & -.02 & 102 & -.04 & .97 \\
\hline Months between & $\geq$ a year $=7.62$ & $\leq$ a year $=7.40$ & -.22 & 102 & -.38 & .70 \\
\hline Type of program & $60=7.66$ & $30=7.37$ & .29 & 102 & .53 & .60 \\
\hline Type of college & $\begin{array}{l}\text { Teaching= } \\
\text { 7.71 }\end{array}$ & Research $=7.13$ & .57 & 101 & 1.02 & .31 \\
\hline & & & & df & $\boldsymbol{F}$ & $p$ \\
\hline Undergraduate major & & & & 4,103 & .43 & .79 \\
\hline
\end{tabular}

\section{Summary}

In summary, the single most significant finding with the pretest and posttest differences was with the inference subscale. This was the only scale ton which students demonstrated significant improvement between pretest and posttest administrations.

The most significant findings in the group differences between pretest and posttest were between the percentile ranking groupings. Those students who entered the program with low critical thinking skills significantly improved their posttest scores on each scale. Those students who entered with higher critical thinking skills scored significantly lower on the posttest analytic, although trends toward improvement were found in the evaluation and inductive scales. Students in the middle percentile group were less consistent with their scores: specifically there was only a single significant difference for inductive and a trend noted for evaluation in that the scores decreased at posttest. Although there were other significant difference and trends, they were inconsistent among the different scores. These findings are similar to those reported by Phillips, Chestnut and Rospond (2004) in their examination of CCTST pretest and posttest scores of pharmacy students. In this study students were divided into two groups (high and low). 
Although both groups significantly improved at posttest, students in the lower percentile group demonstrated a mean improvement of 3.3 points, while the students in the highest percentile group demonstrated a mean improvement of only .8 points.

Analyses that examined significant group differences on the pretest and posttest separately also yielded results that were somewhat divided as well. The most significant findings indicated there were no differences for ethnicity on any of the pretests; however, White students score higher at the posttest for totals, and the inference, inductive and deductive scales. Students with less than a year between undergraduate and graduate school scored higher on the pretest total, analytic, inference and inductive; however, these differences disappeared at posttest (aside from a significant finding that decreased to a trend for inductive). The remaining pretest differences: students with no experience scored higher on the analytic pretest, students from research universities scored higher on the analytic and deductive pretest and males scored higher deductive pretest, disappeared on the posttest scores. These results indicate that the group differences were not there after completion of the curriculum.

\section{Research Question Two}

The following analysis addressed the first of the three proposed predictive models, in which entry level critical thinking skills were explored utilizing the generic versus specific predictor blocks. In particular: Can entry level critical thinking skills of graduating MSSW students at the Kent School of Social Work be explained by the demographic variables of gender, race, and age, the generic variables of undergraduate GPA, months since undergraduate degree, and type of undergraduate institution, and the discipline specific variables of self-efficacy at pretest, years of social work experience, 
and undergraduate degree? The pretest model was illustrated in Figure 3; however, the different variables used in each block for these models are summarized again in Table 18 to guide the discussion of the prediction analysis. In addition, the pretest sample as illustrated in Table 4 was utilized to answer this research question.

\section{Table 18}

\section{Summary of Pretest Predictor Blocks}

\begin{tabular}{|l|l|}
\hline $\begin{array}{l}\text { Block 1 } \\
\text { Demographics }\end{array}$ & $\begin{array}{l}\text { Gender (dummy coded as Maleness) } \\
\text { Ethnicity (dummy coded as White Ethnicity) } \\
\text { Age }\end{array}$ \\
\hline $\begin{array}{l}\text { Block 2 } \\
\text { Generic }\end{array}$ & $\begin{array}{l}\text { Undergraduate GPA } \\
\text { Months between undergraduate degree and entry into graduate } \\
\text { program (dummy coded as More than a year between } \\
\text { undergrad and entry into graduate school) }\end{array}$ \\
\hline $\begin{array}{l}\text { Block 3 } \\
\text { Discipline Specific }\end{array}$ & $\begin{array}{l}\text { Self-Efficacy Pretest total } \\
\text { Years of Social Work experience (dummy coded as Social } \\
\text { work experience) } \\
\text { Undergraduate degree (dummy coded as Social Work major, } \\
\text { Psychology major, Sociology major and Other helping majors) }\end{array}$ \\
\hline
\end{tabular}

\section{Descriptives}

The descriptive information on 304 students is provided in Table 19. The average age was 30.06 years ( $\mathrm{SD}=8.34$ ) and the median was 26.7 . The youngest student was 21.4 and the oldest was 60 years old. There were $75 \%$ white students $(n=229)$ and $25 \%(n=75)$ non-white students. Most students were women $(83 \%, n=252)$, compared to $17 \%(n=51)$ men. The majority of students received their undergraduate degree from a teaching focused universities $(57 \%, \mathrm{n}=172)$ with an average undergraduate GPA of 3.27. There was minimal missing data in the database; however, the paper files were not accessible at the time of analysis. For $3 \%(n=7)$ of the students no major was reported. Of the students where a major was reported, $31 \%(n=94)$ majored in psychology, $27 \%(n=81)$ majored in 
social work, $11 \%(\mathrm{n}=33)$ majored in sociology and $21.7 \%(\mathrm{n}=66)$ majored in non-helping other majors (e.g. English, Political Science, Theater) and 7.2\% (n=22) majored in other helping majors (e.g. Mental Health Counseling, Child Development, and Criminal Justice). Students mean response on the Foundation Practice Self-Efficacy Scale was $74.28(\mathrm{SD}=15.53)$ out of a possible 100 points. As noted in the discussion of analyses results for Research Question 1, months between undergraduate and graduate school and social work experience was dichotomized. The majority of students entered graduate school in more than a year after their undergraduate degree $(51.6 \%, n=157)$; whereas, $48.4 \%(\mathrm{~N}=147)$ of students waited less than a year to enroll in graduate school. Those students with social work experience $(56.2 \%, \mathrm{n}=171)$ made up the majority of the sample compared to those with no social work experience $(43.8 \%, n=133)$. 
Table 19

Descriptive Characteristics of the Pretest Sample ${ }^{a}$

\begin{tabular}{|c|c|c|c|c|c|}
\hline Characteristic & $\mathbf{n}$ & $\%$ & $\overline{\mathbf{X}}$ & SD & Range \\
\hline Age at pretest (years) & 300 & & 30.06 & 8.34 & $21.4-60.0$ \\
\hline Undergraduate GPA & 287 & & 3.27 & .42 & $2.25-4.0$ \\
\hline Pretest Self-Efficacy & 296 & & 74.28 & 15.53 & $10-100$ \\
\hline \multicolumn{6}{|l|}{ Ethnic Group } \\
\hline Non White & 75 & 25 & & & \\
\hline White & 229 & 75 & & & \\
\hline \multicolumn{6}{|l|}{ Gender } \\
\hline Female & 252 & 83 & & & \\
\hline Male & 51 & 17 & & & \\
\hline Missing data & 1 & 1 & & & \\
\hline \multicolumn{6}{|l|}{ Undergraduate School } \\
\hline Research & 114 & 38 & & & \\
\hline Teaching & 172 & 57 & & & \\
\hline Missing & 18 & 6 & & & \\
\hline \multicolumn{6}{|c|}{$\begin{array}{l}\text { Time between undergrad. and } \\
\text { graduate school }\end{array}$} \\
\hline More than a year & 157 & $51.6 \%$ & & & \\
\hline Less than a year & 147 & $48.4 \%$ & & & \\
\hline \multicolumn{6}{|c|}{ Social Work Experience } \\
\hline No Experience & 133 & $43.8 \%$ & & & \\
\hline Experience & 171 & $56.2 \%$ & & & \\
\hline \multicolumn{6}{|l|}{ Undergraduate Degree } \\
\hline Social Work & 81 & 27 & & & \\
\hline Psychology & 94 & 31 & & & \\
\hline Sociology & 33 & 11 & & & \\
\hline Other Helping & 22 & 7.2 & & & \\
\hline Non Helping & 66 & 21.7 & & & \\
\hline Missing data & 7 & 3 & & & \\
\hline
\end{tabular}

${ }^{a}$ Due to rounding, not all categories equal $100 \%$.

\section{Dependent Variable}

The CCTST reported percentile scores to compare students' scores against a national sample of $4^{\text {th }}$ year college students utilizing an aggregated sample. The pretest total mean was at the $53^{\text {rd }}$ percentile. Students' average CCTST descriptives was summarized in Table 20. 
Table 20

Descriptive Characteristics of CCTST Pretest Scores ${ }^{a}$

\begin{tabular}{lccccc}
\hline Scale & $\mathbf{N}$ & $\overline{\mathbf{X}}$ & SD & Range & $\begin{array}{c}\text { Maximum } \\
\text { Score Possible }\end{array}$ \\
\hline Total & 304 & 17.30 & 4.36 & $5-29$ & 34 \\
Analytic & 304 & 4.70 & 1.34 & $1-7$ & 7 \\
Inference & 304 & 7.83 & 2.22 & $1-14$ & 16 \\
Evaluation & 304 & 4.77 & 1.95 & $0-10$ & 11 \\
Inductive & 304 & 10.12 & 2.51 & $3-16$ & 17 \\
Deductive & 304 & 7.18 & 2.60 & $1-15$ & 17 \\
& & & & \\
\hline
\end{tabular}

${ }^{\mathrm{a}}$ Due to rounding, not all categories equal $100 \%$.

Researchers did not replace missing values on any of the variables in the pretest variables as there was sufficient number of participants with complete data on all relevant variables.

\section{Pretest CCTST Total Score Analysis}

As part of the preliminary analysis to determine which independent variables to include in the final regression analysis, an analysis of variance (ANOVA) was conducted on undergraduate majors and pretest CCTST total scores with no significant differences between groups. An independent t-test was conducted on pretest CCTST total scores and students waiting more than a year between undergraduate and entry into graduate school and social work experience with no significant differences found. Additionally, independent $t$-tests were conducted on gender $t(301)=-2.14, p=.03$ and ethnicity $t(302)=-$ 4.63, $p=.00$ and significant differences were indicated. The initial analysis indicated the potential of eliminating the categorical variables where the different grouping did not show significant differences between the percentile groups on the CCTST pretest total scores; however, bivariate correlations on the dummy coded categorical variables as well 
as the other continuous variables were conducted to further investigate this decision making process.

Point biserial correlations were conducted on the binary dummy variables and Pearson product-moment correlations were conducted on all remaining variables in the pretest predictor model and are summarized in a correlation matrix in Table 21. There was a weak but significant positive correlation between CCTST pretest total scores and being male $r(303)=.12, p=.03$ and a significant but weak negative correlation between CCTST pretest total scores and pre self-efficacy scores $r(296)=-.12, p=.05$ and age $r(300)=-.13, p=.03$. There were also statistically significant positive moderate correlations between pretest scores and White ethnicity $r(304)=.26, p=.000$ and undergraduate GPA $r(287)=.26, p=.00$. Undergraduate degree was recoded into four separate variables of $1=$ social work, $0=$ non social work; $1=$ psychology, $0=$ non psychology; $1=$ sociology and $0=$ non sociology; $1=$ other helping majors, $0=$ other helping majors. In this case, other majors that were not classified as potential careers in helping, were used as the reference category. There was a positive trend noted with having psychology as an undergraduate major $r(304)=.09, p=.10$. The correlations did not indicate evidence of multicollinearity between the independent variables. 
Table 21

Correlations Between CCTST Pretest Total Score and Predictor Variables

\begin{tabular}{|c|c|c|c|c|c|c|c|c|c|c|c|c|c|}
\hline & 1 & 2 & 3 & $\overline{4}$ & 5 & 6 & 7 & $\overline{8}$ & $\overline{9}$ & 10 & 11 & 12 & 13 \\
\hline 1 & 1.00 & .05 & .11 & .01 & -.01 & -.07 & .03 & .04 & -.03 & .00 & -.01 & .04 & $.12 *$ \\
\hline 2 & & 1.00 & -.02 & $.23^{* *}$ & .09 & -.09 & -.01 & .09 & .09 & .07 & -.10 & -.11 & $26^{* * *}$ \\
\hline 3 & & & 1.00 & .02 & $.23^{* *}$ & -.02 & .03 & $.14^{*}$ & .03 & $-.13^{*}$ & .09 & -.04 & $-.13 *$ \\
\hline 4 & & & & 1.00 & $-.19 * *$ & $-.14^{*}$ & -.07 & -.05 & $21^{* *}$ & -.08 & -.08 & -.09 & $.26^{* *}$ \\
\hline 5 & & & & & 1.00 & -.06 & -.05 & $.3 * *$ & -.06 & .02 & -.02 & -.06 & .09 \\
\hline 6 & & & & & & 1.00 & .00 & .02 & $-.26^{* *}$ & $.16^{* *}$ & $18^{* *}$ & -.05 & -.04 \\
\hline 7 & & & & & & & 1.00 & $.12 *$ & $.12 *$ & -.09 & .08 & .03 & $-.12^{*}$ \\
\hline 8 & & & & & & & & 1.00 & $.17^{* *}$ & .05 & $-.12^{*}$ & .04 & .04 \\
\hline 9 & & & & & & & & & 1.00 & $-.4^{* *}$ & $-.21^{* *}$ & $-.17^{* *}$ & -.05 \\
\hline 10 & & & & & & & & & & 1.00 & $-.23^{* *}$ & $-.18^{* *}$ & $.09^{* * *}$ \\
\hline 11 & & & & & & & & & & & 1.00 & -.10 & -.06 \\
\hline 12 & & & & & & & & & & & & 1.00 & .08 \\
\hline 13 & & & & & & & & & & & & & 1.00 \\
\hline
\end{tabular}

\begin{tabular}{|c|c|c|c|}
\hline 1 & Being male (Female is reference category) & 8 & Social Work Experience ${ }^{I}$ \\
\hline 2 & White (Non-white is reference category) & 9 & Social Work Major \\
\hline 3 & Age at Pretest & 10 & Psychology Major \\
\hline 4 & Undergraduate GPA & 11 & Sociology Major \\
\hline 5 & $>$ a year between College \& Graduate School ${ }^{2}$ & 12 & Other helping major ${ }^{3}$ \\
\hline 6 & Undergraduate Research Institution $^{4}$ & 13 & CCTST Pretest Total \\
\hline 7 & Pre SE Total & & \\
\hline
\end{tabular}

The researcher then conducted partial correlations controlling for the strongest correlations as noted in the correlation matrix in Table 21 . The first partial correlation controlled for undergraduate GPA and the second controlled for both undergraduate GPA and ethnicity. See Table 22 for a summary of the results. The first partial correlation continued to show statistically significant weak positive correlations between CCTST pretest scores and being male $r(276)=.16, p=.01$, White ethnicity $r(276)=.20, p=.00$, and a year versus more than a year between undergraduate and entry into graduate school $r(276)=.13, p=.03$ and a weak statistically significant negative correlation with age at pretest $r(277)=-.14, p=.02$. The previous trend in having psychology as a major became

\footnotetext{
1 No experience is reference category

2 Less than a year between undergraduate and entry into graduate school is the reference category

${ }^{3}$ Non-helping other majors is reference category

${ }^{4}$ Undergraduate Teaching Institution is reference category
} 
a statistically significant weak positive correlation once undergraduate degree was controlled $r(276)=.14, p=.02$ and a trend developed in the self-efficacy pretest total $r(275)=-.11, p=.08$ and having social work as a major $r(275)=-.11, p=.07$. The second partial correlation indicated continued statistically significant correlations with being male $r(276)=.15, p=.01$, age $r(276)=-.13, \mathrm{p}=.03$, having psychology as a major $r(275)$ $=.13, p=.04$ and having social work as a major $r(275)=-.12, p=.05$. There was a continued trend with self-efficacy pretest total $r(275)=-.11, p=.08$. The variable more than a year between undergraduate and graduate school also transitioned from a statistically significant correlation to a trend $r(275)=.11, p=.06$. As a result of these preliminary analyses, the following variables were eliminated from the pretest total predictor model: (a) undergraduate research school, and (b) social work experience. 


\section{Table 22}

Partial Correlations Between CCTST Pretest Total Scores and Predictor Variables Controlling for Undergraduate GPA and Ethnicity

\begin{tabular}{|l|l|l|l|}
\hline Variable & $\begin{array}{l}\text { First Order } \\
\text { Correlation }\end{array}$ & $\begin{array}{l}\text { Partial Correlation } \\
\text { Controlling for } \\
\text { Undergraduate GPA }\end{array}$ & $\begin{array}{l}\text { Partial Correlation } \\
\text { Controlling for } \\
\text { Undergraduate GPA } \\
\text { and White Ethnicity }\end{array}$ \\
\hline Maleness & $.12^{*}$ & $.16^{*}$ & $.15^{*}$ \\
\hline White Ethnicity & $.26^{*}$ & $.20^{*}$ & $-.13^{*}$ \\
\hline Age at Pretest & $-.13^{*}$ & $-.14^{*}$ & $.11^{* *}$ \\
\hline Undergraduate GPA & $.26^{*}$ & $.13^{*}$ & \\
\hline $\begin{array}{l}\text { More than a year } \\
\text { between } \\
\text { undergraduate and } \\
\text { entry into graduate }\end{array}$ & .09 & .00 & .01 \\
\hline $\begin{array}{l}\text { Undergraduate } \\
\text { Research Institution }\end{array}$ & -.04 & $-.11^{* *}$ & $-.11^{* *}$ \\
\hline Pre SE Total & $-.12^{*}$ & .06 & .04 \\
\hline $\begin{array}{l}\text { Social work } \\
\text { experience }\end{array}$ & .04 & $-.11^{* *}$ & $-.12^{*}$ \\
\hline Social Work major & -.05 & $.14^{*}$ & $.13^{*}$ \\
\hline Psychology major & $.09^{* *}$ & -.03 & -.01 \\
\hline Sociology major & -.06 & -.06 & -.04 \\
\hline $\begin{array}{l}\text { Other Helping } \\
\text { major }\end{array}$ & -.08 & & \\
\hline
\end{tabular}

${ }^{*} \mathrm{p}<.05 ;{ }^{* *} \mathrm{p}<.1$

The initial hierarchical regression analysis was used to explore which of the remaining variables were the best predictors of CCTST pretest total scores and resulted in the elimination of all the dummy coded variables related to major, as well as the selfefficacy pretest total variable. The final hierarchical regression analysis revealed Block 1 with the following variables: age at pretest, White ethnicity and being male was a significant predictor of CCTST pretest totals, $\left(R^{2}=.10, F(3,286)=10.38, p=.00\right)$. Block 2 with the following variables: undergraduate GPA, more than a year between undergraduate and entry into graduate also significantly improved the model, $\left(\Delta R^{2}=.07\right.$, 
$p=.00$ ). The predictor model indicated younger white male students with higher GPAs and a longer time between undergraduate graduation and entry into graduate school have higher CCTST pretest scores. Younger age was the weakest predictor and undergraduate GPA the strongest predictor. This model accounted for $17 \%$ of the variability in CCTST pretest scores $\left(R^{2}=.17, F(5,286)=11.33, p=.00\right)$. Block 3 (discipline specific variables) did not contribute to the model. See Table 23 or a summary of the regression results.

Table 23

Hierarchical Regression Analysis of CCTST Pretest Total Scores (N=286)

\begin{tabular}{lccc}
\hline Variables & B & SE B & B \\
\hline Step 1 & & & \\
$\quad$ Demographic Variables: & & & \\
$\quad$ Age at Pretest & -0.07 & 0.03 & $-0.14^{*}$ \\
$\quad$ White Ethnicity & 2.47 & 0.57 & $0.24^{* *}$ \\
$\quad$ Maleness & 1.57 & 0.66 & $0.13^{*}$ \\
Step 2 & & & \\
$\quad$ Demographic Variables: & -0.09 & 0.03 & $-0.18^{* *}$ \\
$\quad$ Age at Pretest & 1.74 & 0.57 & $0.17^{* *}$ \\
$\quad$ White Ethnicity & 1.62 & 0.64 & $0.14^{*}$ \\
$\quad$ Maleness & & & \\
Generic Variables: & 2.69 & 0.61 & $0.25^{* *}$ \\
$\quad$ Undergraduate GPA & 1.45 & 0.51 & $0.17^{* *}$ \\
$\quad$ More than a year between & & & \\
$\quad$ undergraduate and entry into graduate & & & \\
&
\end{tabular}

Note: $R^{2}=0.10$ for Step $1 ; \Delta R^{2}=0.07$ for Step $2(p=0.00)$.

${ }^{*} p<0.05, * * p<.01$

\section{Pretest CCTST Inference Score Analysis}

Analysis of variance was conducted on undergraduate majors and pretest CCTST inference scores with no significant differences between groups. Individual independent $t$ tests were conducted on CCTST pretest inference scores and type of undergraduate, more than a year between undergraduate and entry into graduate school, social work experience indicated no significant difference. However, independent $t$ tests on CCTST 
pretest inference scores and gender $t(301)=-2.18, p=.03$ and ethnicity $t(302)=-4.28$, $p=.00$ indicated significant differences. Also note regarding the results for ethnicity, the Levene's test for equality of variance was significant at $F=6.39, p=.01$; therefore the equal variance not assumed portion of the independent $t$ test results was assumed. The initial analysis indicated the potentiality of eliminating the categorical variables where the different grouping did not have significant differences between the groups on CCTST pretest inference scores; however, additional evaluative analysis were conducted to further investigate this decision making process

Point biserial correlations were conducted on the binary dummy variables and Pearson product-moment correlations were conducted on all remaining variables in the pretest inference predictor model and are summarized in a correlation matrix in Table 24. There was a weak but significant positive correlation between CCTST pretest inference scores and being male $r(303)=.12, p=.03$ and a significant but weak negative correlation between CCTST pretest inference scores and age at pretest $r(300)=-.12, p=.05$. There were also statistically significant positive moderate correlations between pretest inference scores and white ethnicity $r(304)=.22, p=.000$ and undergraduate GPA $r(304)=.25$, $p=.000$. There was also a trend with having psychology as a major $r(304)=.10, p=.09$ and self efficacy pretest totals $r(296)=-.10, p=.11$. The correlations did not indicate evidence of multicollinearity between the independent variables. 
Table 24

Correlations Between CCTST Pretest Inference Score and Predictor Variables

\begin{tabular}{|c|c|c|c|c|c|c|c|c|c|c|c|c|c|}
\hline & 1 & 2 & 3 & 4 & 5 & 6 & 7 & $\overline{8}$ & $\overline{9}$ & 10 & 11 & 12 & 13 \\
\hline 1 & 1.00 & .05 & .11 & .01 & -.01 & -.07 & .03 & .04 & -.03 & .00 & -.01 & .04 & $.12^{*}$ \\
\hline 2 & & 1.00 & -.02 & $.23^{* *}$ & .09 & -.09 & -.01 & .08 & .09 & .07 & -.10 & -.11 & $.22 * *$ \\
\hline 3 & & & 1.00 & .02 & $23^{* *}$ & -.02 & .03 & $.14^{*}$ & .03 & $-.13^{*}$ & .09 & -.04 & $-.12 *$ \\
\hline 4 & & & & 1.00 & $-.19^{* *}$ & $-.14^{*}$ & .07 & -.05 & $.21 * *$ & -.08 & -.08 & -.09 & $.25^{* *}$ \\
\hline 5 & & & & & 1.00 & -.06 & -.05 & $.30^{* * *}$ & -.06 & .02 & -.02 & -.06 & .08 \\
\hline 6 & & & & & & 1.00 & .00 & .02 & $-.26^{* *}$ & $.16^{* *}$ & $.18 * *$ & -.05 & -.07 \\
\hline 7 & & & & & & & 1.00 & $.12 *$ & $.12 *$ & -.09 & .08 & .03 & $-.10^{* * *}$ \\
\hline 8 & & & & & & & & 1.00 & $.17^{* *}$ & .05 & $-.12 *$ & .04 & .00 \\
\hline 9 & & & & & & & & & 1.00 & $-.4^{* *}$ & $-.21^{* *}$ & $-.17 * *$ & -.07 \\
\hline 10 & & & & & & & & & & 1.00 & $-.23^{* *}$ & $.19 * *$ & $10^{* * *}$ \\
\hline 11 & & & & & & & & & & & 1.00 & -.10 & -.01 \\
\hline 12 & & & & & & & & & & & & 1.00 & -.00 \\
\hline 13 & & & & & & & & & & & & & 1.00 \\
\hline
\end{tabular}

\begin{tabular}{|l|l|r|l|}
\hline 1 & Being male (Female is reference category) & 8 & Social Work Experience $^{5}$ \\
\hline 2 & White (Non-white is reference category) & 9 & Social Work Major \\
\hline 3 & Age at Pretest & 10 & Psychology Major \\
\hline 4 & Undergraduate GPA & 11 & Sociology Major \\
\hline 5 & > a year between College \& Graduate School $^{7}$ & 12 & Other helping major $^{8}$ \\
\hline 6 & Undergraduate Research Institution $^{9}$ & 13 & CCTST Pretest Total \\
\hline 7 & Pre SE Total & & \\
\hline
\end{tabular}

${ }^{*} p \leq 0.05 ;{ }^{* *} p \leq 0.01$

The researcher then conducted partial correlations controlling for the strongest correlations as noted in the correlation matrix in Table 24 . The first partial correlation controlled for undergraduate GPA and the second controlled for both undergraduate GPA and ethnicity. See Table 25 for a summary of the results. The first partial correlation continued to show statistically significant weak positive correlations between CCTST pretest inference scores and being male $r(276)=.15, p=.02$, white ethnicity $r(276)=.16$, $p=.01$, and a statistically significant weak negative correlation with age at pretest $r(276)=$ $-.14, p=.02$ and having a social work $r(276)=-.12, p=.04$. The previous trend in having a

\footnotetext{
${ }^{5}$ No experience is reference category

${ }^{6}$ Non-helping other majors is reference category

Less than a year between undergraduate and entry into graduate school is the reference category

${ }^{8}$ Non-helping other majors is reference category

${ }^{9}$ Undergraduate Teaching Institution is reference category
} 
psychology major became a statistically significant weak positive correlation once undergraduate degree was controlled for $r(276)=.15, p=.01$ and a trend developed in more than a year between undergraduate and entry into graduate school $r(275)=.11$, $p=.06$. However, the previous trend with self efficacy pretest total became insignificant. The second partial correlation indicated a continued statistically significant correlations with being male $r(275)=.14, p=.02$, age $r(275)=-.13, \mathrm{p}=.03$, having psychology as a major $r(275)=.13$, and having social work as a major $r(275)=-.13, p=.03$. The previous trend in more than a year between undergraduate and entry into graduate school became insignificant. As a result of these preliminary analyses, the following variables were eliminated from the pretest inference predictor model: (a) undergraduate Research School, and (b) social work experience. 
Table 25

Partial Correlations Between CCTST Pretest Inference Scores and Predictor Variables Controlling for Undergraduate GPA and Ethnicity

\begin{tabular}{|l|l|l|l|}
\hline Variable & $\begin{array}{l}\text { First Order } \\
\text { Correlation }\end{array}$ & $\begin{array}{l}\text { Partial Correlation } \\
\text { Controlling for } \\
\text { Undergraduate GPA }\end{array}$ & $\begin{array}{l}\text { Partial Correlation } \\
\text { Controlling for } \\
\text { Undergraduate GPA } \\
\text { and Ethnicity }\end{array}$ \\
\hline Maleness & $.12^{*}$ & $.15^{*}$ & $.14^{*}$ \\
\hline White Ethnicity & $.22^{*}$ & $.16^{*}$ & $-.13^{*}$ \\
\hline Age at Pretest & $-.12^{*}$ & $-.14^{*}$ & \\
\hline Undergraduate GPA & $.25^{*}$ & $.11^{* *}$ & .10 \\
\hline $\begin{array}{l}\text { More than a year } \\
\text { between } \\
\text { undergraduate and } \\
\text { entry into graduate }\end{array}$ & .08 & -.04 & -.03 \\
\hline $\begin{array}{l}\text { Undergraduate } \\
\text { research institution }\end{array}$ & -.07 & .08 & -.08 \\
\hline Pre SE Total & $-.10^{* *}$ & .00 & -.01 \\
\hline $\begin{array}{l}\text { Social work } \\
\text { experience }\end{array}$ & .00 & $-.12^{*}$ & $-.13^{*}$ \\
\hline Social Work major & -.07 & $.15^{*}$ & $.14^{*}$ \\
\hline Psychology major & $.10^{* *}$ & .01 & .02 \\
\hline Sociology major & -.01 & .02 & .03 \\
\hline Other helping major & .00 & & \\
\hline
\end{tabular}

${ }^{*} \mathrm{p}<.05 ;{ }^{* *} \mathrm{p}<.1$

The initial hierarchical regression analysis was used to explore which of the remaining variables were the best predictors of CCTST pretest inference scores and resulted in the elimination of all the dummy coded variables related to major, as well as the self-efficacy pretest total variable. The final hierarchical regression analysis revealed Block 1 with the following variables: age at pretest, White ethnicity and being male was a significant predictor of CCTST pretest inference scores, $\left(R^{2}=.08, F(3,283)=8.08\right.$, $p=.00$ ). Block 2 with the following variables: undergraduate GPA, more than a year between undergraduate and entry into graduate also significantly improved the model, $\left(\Delta R^{2}=.06, p=.00\right)$. The predictor model indicated younger white male students with higher 
GPAs and a longer time between undergraduate graduation and entry into graduate school have higher CCTST pretest inference scores. Younger age was the weakest predictor and undergraduate GPA was the strongest predictor. This model accounted for $14.1 \%$ of the variability in CCTST pretest inference scores $\left(R^{2}=.14, F(5,286)=9.22\right.$, $p=.000$ ). Block 3 (discipline specific variables) did not contribute to the model. See Table 26 for a summary of the regression results.

Table 26

Hierarchical Regression Analysis of CCTST Pretest Inference Scores (N=287)

\begin{tabular}{lccc}
\hline Variables & B & SE B & B \\
\hline Step 1 & & & \\
$\quad$ Demographic Variables: & & & \\
$\quad$ Age at Pretest & -0.03 & 0.01 & $-0.13^{* *}$ \\
$\quad$ White Ethnicity & 1.05 & 0.29 & $0.21^{*}$ \\
$\quad$ Maleness & 0.78 & 0.34 & $0.13^{* *}$ \\
Step 2 & & & \\
$\quad$ Demographic Variables: & -0.04 & 0.01 & $-0.17^{*}$ \\
$\quad$ Age at Pretest & 0.70 & 0.29 & $0.14^{* *}$ \\
$\quad$ White Ethnicity & 0.80 & 0.33 & $0.14^{* *}$ \\
$\quad$ Maleness & & & \\
Generic Variables: & 1.30 & 0.31 & $0.25^{*}$ \\
$\quad$ Undergraduate GPA & 0.66 & 0.26 & $0.15^{*}$ \\
$\quad$ More than a year between undergraduate and entry & & & \\
$\quad$ into graduate school & & & \\
\hline
\end{tabular}

Note: $R^{2}=0.08$ for Step $1 ; \Delta R^{2}=0.06$ for Step $2(p<0.00)$.

${ }^{*} p \leq 0.01,{ }^{* *} p<.05$

\section{Pretest CCTST Analytic Score Analysis}

Analysis of variance was conducted on undergraduate majors and pretest CCTST analytic scores found a trend in the differences between groups $F(4,296)=2.36, p=.05$. The Tukey HSD post hoc test was ran to determine which groups were different. The results indicated a trend in that students with a psychology major score higher than 
students with an other helping major (mean difference $=.82$ ) and students with non helping majors scored significantly higher that students with other helping majors (mean difference=.92). Individual independent $t$ tests were conducted on CCTST pretest analytic scores and gender, type of undergraduate, and social work experience indicated no significant difference. However, independent $t$ tests on CCTST pretest analytic scores and ethnicity $t(302)=-2.97, p=.00$ and less than a year between undergraduate and entry into graduate school $t(302)=-2.59, p=.01$, indicated significant differences. The initial analysis indicated the potentiality of eliminating the categorical variables where the different groupings did not show significant differences between the groups on the CCTST pretest analytic scores; however, bivariate correlations on the dummy coded categorical variables as well as the other continuous variables were conducted to further investigate this decision making process

Point biserial correlations were conducted on the binary dummy variables and Pearson product-moment correlations were conducted on all remaining variables in the pretest analytic predictor model and are summarized in a correlation matrix in Table 27. There was a significant but weak positive correlation between CCTST pretest analytic scores and White ethnicity $r(304)=.17, p=.00$, undergraduate GPA $r(287)=.16, p=.00$ and more than a year between undergraduate and entry into graduate school $r(304)=, 15$, $p=.01$. A significant but weak negative correlation was found between CCTST pretest analytic scores and self efficacy pretest total $r(296)=-.15, p=.00$ and having other helping professions as a major $r(304)=-.15, p=.01$. The correlations did not indicate evidence of multicollinearity between the independent variables. 
Table 27

Correlations Between CCTST Pretest Analytic Scores and Predictor Variables

\begin{tabular}{|c|c|c|c|c|c|c|c|c|c|c|c|c|c|}
\hline & 1 & 2 & 3 & 4 & 5 & 6 & 7 & 8 & 9 & 10 & 11 & 12 & 13 \\
\hline 1 & 1.00 & .05 & .11 & .01 & -.01 & -.07 & .03 & .04 & -.03 & .00 & -.01 & .04 & .01 \\
\hline 2 & & 1.00 & -.02 & $.23^{* *}$ & . 09 & -.09 & -.01 & .08 & .09 & .07 & -.10 & -.11 & $17^{* *}$ \\
\hline 3 & & & 1.00 & .02 & $.23^{* *}$ & -.02 & .03 & $.14 *$ & .03 & $-.13^{*}$ & .09 & -.04 & -.04 \\
\hline 4 & & & & 1.00 & $-.19 * *$ & $-.14 *$ & -.07 & -.05 & $21^{* *}$ & -.08 & -.08 & -.09 & $.16^{* *}$ \\
\hline 5 & & & & & 1.00 & -.06 & -.05 & $.3^{* *}$ & -.06 & .02 & -.02 & -.06 & $.15^{*}$ \\
\hline 6 & & & & & & 1.00 & .00 & .02 & $-.26 * *$ & $.16^{* *}$ & $.18^{* *}$ & -.05 & -.06 \\
\hline 7 & & & & & & & 1.00 & $.12 *$ & $.12^{*}$ & -.09 & .08 & .03 & $-.15^{* *}$ \\
\hline 8 & & & & & & & & 1.00 & $.17^{* *}$ & .05 & $-.12^{*}$ & .04 & .06 \\
\hline 9 & & & & & & & & & 1.00 & $-.4^{* *}$ & $-.21^{* *}$ & $-.17^{* *}$ & -.01 \\
\hline 10 & & & & & & & & & & 1.00 & $-.23^{* *}$ & $-.19^{* * *}$ & .06 \\
\hline 11 & & & & & & & & & & & 1.00 & -.10 & -.06 \\
\hline 12 & & & & & & & & & & & & 1.00 & $-.15 *$ \\
\hline 13 & & & & & & & & & & & & & 1.00 \\
\hline
\end{tabular}

\begin{tabular}{|l|l|r|l|}
\hline 1 & Being male (Female is reference category) & 8 & Social Work Experience \\
\hline 2 & White (Non-white is reference category) & 9 & Social Work Major $^{11}$ \\
\hline 3 & Age at Pretest & 10 & Psychology Major $^{12}$ \\
\hline 4 & Undergraduate GPA $^{12}$ & 11 & Sociology Major \\
\hline 5 & > a year between College \& Graduate School $^{14}$ & 12 & Other helping major $^{15}$ \\
\hline 6 & Undergraduate Research Institution $^{16}$ & 13 & CCTST Pretest Total \\
\hline 7 & Pre SE Total & & \\
\hline
\end{tabular}

${ }^{*} p \leq 0.05 ;{ }^{* *} p \leq 0.01$

The researcher then conducted partial correlations controlling for the strongest correlations as noted in the correlation matrix in Table 27. The first partial correlation controlled for ethnic group and the second controlled for both undergraduate GPA and ethnicity. See Table 28 for a summary of the results. The first partial correlation continued to show statistically significant weak positive correlations between CCTST pretest analytic scores and undergraduate GPA $r(276)=.14, p=.02$ and more than a year between undergraduate and entry into graduate school $r(276)=.14, p=.02$ and a

\footnotetext{
${ }^{10}$ No experience is reference category

11 Non-helping other major is reference category

${ }^{12}$ Non-helping other major is reference category

13 Non-helping other major is reference category

${ }_{15}^{14}$ Less than a year between undergraduate and entry into graduate school is the reference category

${ }^{15}$ Non-helping other major is reference category

${ }^{16}$ Undergraduate Teaching Institution is reference category
} 
statistically significant weak negative correlation with self efficacy pretest total $r(276)=$ $.15, p=.01$ and those having other helping major $r(276)=-.13, p=.03$. The second partial correlation indicated a continued statistically significant correlations with more than a year between undergraduate and entry into graduate school $r(275)=.17, p=.00$, self efficacy pretest total $r(275)=-.14, \mathrm{p}=.02$, and those with other helping majors $r(275)=-$ $.13, p=.03$. As a result of these preliminary analyses, the following variables were eliminated from the pretest analytic predictor model: (a) gender, (b) age at pretest, (c) undergraduate research school, and (d) social work experience.

\section{Table 28}

Partial Correlations Between CCTST Pretest Analytic Scores and Predictor Variables Controlling for Ethnicity and Undergraduate GPA

\begin{tabular}{|l|l|l|l|}
\hline Variable & $\begin{array}{l}\text { First Order } \\
\text { Correlation }\end{array}$ & $\begin{array}{l}\text { Partial Correlation } \\
\text { Controlling for } \\
\text { Ethnic Group }\end{array}$ & $\begin{array}{l}\text { Partial Correlation } \\
\text { Controlling for } \\
\text { Undergrad GPA and } \\
\text { Ethnicity }\end{array}$ \\
\hline Maleness & .01 & .01 & .01 \\
\hline White Ethnicity & $.17^{*}$ & & -.03 \\
\hline Age at Pretest & -.04 & -.03 & $.17^{*}$ \\
\hline Undergraduate GPA & $.16^{*}$ & $.14^{*}$ & $.13^{*}$ \\
\hline $\begin{array}{l}\text { More than a year between } \\
\text { undergrad and entry into } \\
\text { graduate }\end{array}$ & $.15^{*}$ & & -.02 \\
\hline $\begin{array}{l}\text { Undergrad research } \\
\text { institution }\end{array}$ & -.06 & -.04 & $-.14^{*}$ \\
\hline Pre SE Total & $-.15^{*}$ & $-.15^{*}$ & .08 \\
\hline Social work experience & .06 & .07 & -.06 \\
\hline Social Work major & -.01 & -.03 & .07 \\
\hline Psychology major & .06 & -.06 & -.05 \\
\hline Sociology major & -.06 & -.06 & $-.13^{*}$ \\
\hline Other helping major & $-.15^{*}$ & $-.13^{*}$ & \\
\hline
\end{tabular}
$* \mathrm{p}<.05$

The hierarchical regression analysis revealed Block 1 (White ethnicity) was a significant predictor of CCTST pretest analytic scores, $\left(R^{2}=.03, F(1,279)=8.76, p=.00\right)$. 
Block 2 with the following variables: undergraduate GPA, more than a year between undergraduate and entry into graduate school was also significant, $\left(\Delta R^{2}=.05, p=.00\right)$, as was Block 3 with the following variables: self-efficacy pretest total, helping major, social work major, sociology major, and psychology major also significantly improved the model, $\left(\Delta R^{2}=.04, p=.04\right)$. The predictor model indicated white students with higher GPAs, a longer time between undergraduate graduation and entry into graduate school, and with a non helping major have higher CCTST pretest analytic scores. Psychology major was the weakest predictor and undergraduate GPA was the strongest predictor. This model accounted for $12 \%$ of the variability in CCTST pretest analytic scores $\left(R^{2}=\right.$ $.12, F(8,279)=4.23, p=.000)$. The See Table 29 for a summary of the regression results. 
Table 29

Hierarchical Regression Analysis of CCTST Pretest Analytic Scores (N=280)

\begin{tabular}{lccc}
\hline Variables & B & SE B & $B$ \\
\hline $\begin{array}{l}\text { Step 1 } \\
\quad \text { Demographic Variables: }\end{array}$ & & & \\
$\quad$ White Ethnicity & 0.55 & 0.19 & $0.18^{*}$ \\
$\quad$ Step 2 & & & \\
$\quad$ Demographic Variables: & 0.39 & 0.19 & $0.13^{* *}$ \\
$\quad$ White Ethnicity & & & \\
$\quad$ Generic Variables: & 0.59 & 0.20 & $0.18^{*}$ \\
$\quad$ Undergraduate GPA & 0.46 & 0.16 & $0.17^{*}$ \\
$\quad$ More than a year between undergrad and entry into & & & \\
$\quad$ graduate school & & & \\
Step 3 & & & \\
$\quad$ Demographic Variables: & 0.35 & 0.19 & $0.11^{\mathrm{a}}$ \\
$\quad$ White Ethnicity & & & \\
$\quad$ Generic Variables: & 0.56 & 0.20 & $0.17^{*}$ \\
$\quad$ Undergraduate GPA & 0.41 & 0.16 & $0.15^{*}$ \\
$\quad$ More than a year between undergrad and entry into & & & \\
$\quad$ graduate school & & & \\
$\quad$ Discipline Specific Variables: & -0.01 & 0.01 & $-0.11^{\mathrm{a}}$ \\
$\quad$ Self-Efficacy Pretest Total & -0.29 & 0.22 & -0.10 \\
$\quad$ Social Work major & -0.08 & 0.21 & -0.03 \\
$\quad$ Psychology major & -0.37 & 0.30 & -0.08 \\
$\quad$ Sociology major & -0.73 & 0.32 & $-.14^{* *}$ \\
$\quad$ Other helping major & & & \\
\hline
\end{tabular}

Note: $R^{2}=0.03$ for Step $1 ; \Delta R^{2}=0.05$ for Step $2(p<0.00) ; \Delta R^{2}=0.04$ for Step 3 $(p<0.04) .{ }^{*} p \leq 0.01, * * p<.05,{ }^{a} p \leq .10$

\section{Pretest CCTST Evaluation Score Analysis}

Analysis of variance was conducted on undergraduate majors and pretest CCTST evaluation scores with no significant differences between groups. Individual independent $\mathrm{t}$ tests were conducted on CCTST pretest evaluation scores and type of undergraduate, more than a year between undergraduate and entry into graduate school, and social work experience indicated no significant difference. However, independent $t$ tests on CCTST pretest evaluation scores and gender $t(301)=-2.20, p=.03$ and ethnicity $t(302)=-3.74$, 
$p=.00$ indicated significant differences. Also note, in regards to the results for ethnicity, the Levene's test for equality of variance was significant at $F=4.18, p=.04$; therefore the equal variance not assumed portion of the independent $t$ test results was interpreted. The initial analysis indicated the potentiality of eliminating the categorical variables where the different grouping did not show significant differences between the groups on the CCTST pretest evaluation scores; however, bivariate correlations on the dummy coded categorical variables as well as the other continuous variables were conducted to further investigate this decision making process

Point biserial correlations were conducted on the binary dummy variables and Pearson product-moment correlations were conducted on all remaining variables in the pretest analytic predictor model and are summarized in a correlation matrix in Table 30. There was a significant but weak positive correlation between CCTST pretest evaluation scores and being male $r(303)=.13, p=.03$, White ethnicity $r(304)=.21, p=.00$, undergraduate GPA $r(287)=.19, p=.00$. A significant but weak negative correlation was found between CCTST pretest evaluation scores and age at pretest $r(300)=-.13, p=.03$. The correlations did not indicate evidence of multicollinearity between the independent variables. 
Table 30

Correlations Between CCTST Pretest Analytic Scores and Predictor Variables

\begin{tabular}{|c|c|c|c|c|c|c|c|c|c|c|c|c|c|}
\hline & 1 & 2 & 3 & 4 & 5 & 6 & 7 & 8 & 9 & 10 & 11 & 12 & 13 \\
\hline 1 & 1.00 & .05 & 11 & 01 & -.01 & -.07 & .03 & .04 & -.03 & .00 & -.01 & .04 & $.13^{*}$ \\
\hline 2 & & 1.00 & -.02 & $.23^{* *}$ & .09 & -.09 & -.01 & .08 & .09 & .07 & -.10 & -.11 & $21^{* *}$ \\
\hline 3 & & & 1.00 & .02 & $23 * *$ & -.02 & .03 & $.14^{*}$ & .03 & $-.13^{*}$ & .09 & -.04 & $-.13^{*}$ \\
\hline 4 & & & & 1.00 & $-.19 * *$ & $-.14^{*}$ & -.07 & -.05 & $.21^{* *}$ & -.08 & -.08 & -.09 & $19 * *$ \\
\hline 5 & & & & & 1.00 & -.06 & -.05 & $3^{* *}$ & -.06 & .02 & -.02 & -.06 & .01 \\
\hline 6 & & & & & & 1.00 & .00 & .02 & $-.26^{* *}$ & $.16^{* *}$ & $.18 * *$ & -.05 & .03 \\
\hline 7 & & & & & & & 1.00 & $.12 *$ & $.12 *$ & -.09 & .08 & .03 & .05 \\
\hline 8 & & & & & & & & 1.00 & $.17^{* *}$ & .05 & $-.12 *$ & .04 & .05 \\
\hline 9 & & & & & & & & & 1.00 & $-.4 * *$ & $-.21^{* * *}$ & $-.17^{* *}$ & -.02 \\
\hline 10 & & & & & & & & & & 1.00 & $-.23^{* *}$ & $-.19^{* *}$ & .06 \\
\hline 11 & & & & & & & & & & & 1.00 & -.10 & -.08 \\
\hline 12 & & & & & & & & & & & & 1.00 & -.07 \\
\hline 13 & & & & & & & & & & & & & 1.00 \\
\hline
\end{tabular}

\begin{tabular}{|r|l|r|l|}
\hline 1 & Being male (Female is reference category) & 8 & Social Work Experience $^{17}$ \\
\hline 2 & White (Non-white is reference category) $^{17}$ & 9 & Social Work Major $^{18}$ \\
\hline 3 & Age at Pretest & 10 & Psychology Major $^{19}$ \\
\hline 4 & Undergraduate GPA $^{20}$ \\
\hline 5 & > a year between College \& Graduate School $^{21}$ & 11 & Sociology Major $^{20}$ \\
\hline 6 & Undergraduate Research Institution $^{23}$ & 13 & Cther helping major $^{22}$ \\
\hline 7 & Pre SE Total & & \\
\hline
\end{tabular}

${ }^{*} p \leq 0.05 ;{ }^{* *} p \leq 0.01$

The researcher then conducted partial correlations controlling for the strongest correlations as noted in the correlation matrix in Table 30 . The first partial correlation controlled for ethnic group and the second controlled for both undergraduate GPA and ethnicity. See Table 31 for a summary of the results. The first partial correlation continued to show statistically significant weak positive correlations between CCTST pretest evaluation scores and undergraduate $\operatorname{GPA} r(276)=.15, p=.01$ and being male $r(276)=.16, p=.01$ and a statistically significant weak negative correlation with age at

\footnotetext{
17 No experience is reference category

18 Non-helping other major is reference category

${ }_{19}$ Non-helping other major is reference category

20 Non-helping other major is reference category

21 Less than a year between undergraduate and entry into graduate school is the reference category

22 Non-helping other major is reference category

23 Undergraduate Teaching Institution is reference category
} 
pretest $r(276)=-.12, p=.05$. The second partial correlation indicated a continued statistically significant correlations with being male $r(275)=.16, p=.01$ and age at pretest $r(275)=-.12, p=.05$. As a result of these preliminary analyses, the following variables were eliminated: (a) more than a year between undergraduate and entry into graduate school, (b) undergraduate research school, (c) self-efficacy pretest total, (d) social work experience, (e) all undergraduate dummy variables.

\section{Table 31}

Partial Correlations Between CCTST Pretest Evaluation Scores and Predictor Variables Controlling for Ethnicity and Undergraduate GPA

\begin{tabular}{|c|c|c|c|}
\hline Variable & $\begin{array}{l}\text { First Order } \\
\text { Correlation }\end{array}$ & $\begin{array}{l}\text { Partial Controlling } \\
\text { for Ethnic Group }\end{array}$ & $\begin{array}{l}\text { Partial Controlling } \\
\text { for Undergraduate } \\
\text { GPA and Ethnicity }\end{array}$ \\
\hline Maleness & $.13^{*}$ & $.16^{*}$ & $.16^{*}$ \\
\hline White Ethnicity & $.21 *$ & & \\
\hline Age at Pretest & $-.13^{*}$ & $-.12 *$ & $-.12^{*}$ \\
\hline Undergraduate GPA & $.19^{*}$ & $.15^{*}$ & \\
\hline $\begin{array}{l}\text { More than a year } \\
\text { between } \\
\text { undergraduate and } \\
\text { entry into graduate }\end{array}$ & .01 & -.01 & .02 \\
\hline $\begin{array}{l}\text { Undergraduate } \\
\text { research institution }\end{array}$ & .03 & .05 & .07 \\
\hline Pre SE Total & -.05 & -.05 & -.04 \\
\hline $\begin{array}{l}\text { Social work } \\
\text { experience }\end{array}$ & .05 & .04 & .05 \\
\hline Social Work major & -.02 & -.04 & -.07 \\
\hline Psychology major & .06 & .06 & .07 \\
\hline Sociology major & -.08 & -.03 & -.02 \\
\hline Other helping major & -.07 & -.05 & -.05 \\
\hline
\end{tabular}

$* \mathrm{p}<.05$

The hierarchical regression analysis revealed Block 1with the following variables: age at pretest, White ethnicity and being male was a significant predictor of CCTST pretest evaluation scores, $\left(R^{2}=.08, F(3,286)=7.99, p=.000\right)$. Block 2 which included undergraduate GPA was also significant, $\left(\Delta R^{2}=.02, p=.01\right)$. The predictor model 
indicated younger white male students with higher GPAs have higher CCTST pretest evaluation scores. Age at pretest was the weakest predictor and undergraduate GPA and white ethnicity were the strongest predictors. This model accounted for $10.1 \%$ of the variability in CCTST pretest evaluation scores $\left(R^{2}=.10, F(4,286)=7.93, p=.000\right)$. Block 3 (discipline specific variables) did not contribute to the model. The See Table 32 for a summary of the regression results.

\section{Table 32}

Hierarchical Regression Analysis of CCTST Pretest Evaluation Scores ( $N=287)$

\begin{tabular}{lccc}
\hline Variables & B & SE B & $\boldsymbol{\beta}$ \\
\hline Step 1 & & & \\
Demographic Variables: & & & \\
$\quad$ Age at Pretest & -0.03 & 0.01 & $-0.13^{* *}$ \\
White Ethnicity & 0.91 & 0.26 & $0.20^{*}$ \\
$\quad$ Gender & 0.75 & 0.30 & $0.14^{* *}$
\end{tabular}

\section{Step 2}

Demographic Variables:

$\begin{array}{lrrl}\text { Age at Pretest } & -0.03 & 0.01 & -0.13^{* *} \\ \text { White Ethnicity } & 0.74 & 0.27 & 0.16^{*} \\ \text { Maleness } & 0.75 & 0.30 & 0.14^{* *}\end{array}$

\section{Generic Variables:}
Undergraduate GPA
0.75
0.27
$0.16^{* *}$

Note: $R^{2}=0.08$ for Step $1 ; \Delta R^{2}=0.02$ for Step $2(p<0.01)$. ${ }^{*} p \leq 0.01, * * p<.05$

\section{Pretest CCTST Deductive Score Analysis}

Analysis of variance was conducted on undergraduate majors and pretest CCTST deductive scores with no significant differences between groups. Individual independent $\mathrm{t}$ tests were conducted on CCTST pretest deductive scores and type of undergraduate, more than a year between undergraduate and entry into graduate school, social work experience indicated no significant difference. However, independent $t$ tests on CCTST 
pretest deductive scores and gender $t(301)=-2.48, p=.01$ and ethnicity $t(302)=-4.05$, $p=.00$ indicated significant differences. Also note, in regards to the results for ethnicity, the Levene's test for equality of variance was significant at $F=8.12, p=.01$; therefore the equal variance not assumed portion of the independent $t$ test results was interpreted. The initial analysis indicated the potentiality of the categorical variables where the different groupings did not show significant differences between the groups on the CCTST pretest deductive; however, bivariate correlations on the dummy coded categorical variables as well as the other continuous variables were conducted to further investigate this decision making process.

Point biserial correlations were conducted on the binary dummy variables and Pearson product-moment correlations were conducted on all remaining variables in the pretest deductive predictor model and are summarized in a correlation matrix in Table 33. There was a significant but weak positive correlation between CCTST pretest deductive scores and being male $r(303)=.14, p=.01$, White ethnicity $r(304)=.20, p=.00$, and undergraduate GPA $r(287)=.28, p=.00$. A significant but weak negative correlation was found between CCTST pretest deductive scores and age at pretest $r(300)=-.18, p=.00$. There was also a trend for self-efficacy pretest total $r(296)=-.10, p=.08$, having a psychology major $r(304)=.11, p=.06$, and having an other helping major $r(304)=-.10$, $p=.09$. The correlations did not indicate evidence of multicollinearity between the independent variables. 
Table 33

Correlations Between CCTST Pretest Deductive Scores and Predictor Variables

\begin{tabular}{|c|c|c|c|c|c|c|c|c|c|c|c|c|c|}
\hline & 1 & 2 & 3 & 4 & 5 & 6 & 7 & 8 & 9 & 10 & $\pi$ & $\sqrt{12}$ & 13 \\
\hline 1 & 1.00 & .05 & .11 & .01 & -.01 & -.07 & .03 & .04 & -.03 & .00 & -.01 & .04 & $.14^{*}$ \\
\hline 2 & & 1.00 & -.02 & $.23^{* *}$ & .09 & -.09 & -.01 & .08 & .09 & .07 & -.10 & -.11 & $.20^{* *}$ \\
\hline 3 & & & 1.00 & .02 & $23 * *$ & -.02 & .03 & $.14^{*}$ & .03 & $-.13^{*}$ & .09 & -.04 & $-18 * *$ \\
\hline 4 & & & & 1.00 & $-.19 * *$ & $-.14 *$ & -.07 & -.05 & $.21^{* * *}$ & -.08 & -.08 & -.09 & $29 * *$ \\
\hline 5 & & & & & 1.00 & -.06 & -.05 & $.3^{* *}$ & -.06 & .02 & -.02 & -.06 & .03 \\
\hline 6 & & & & & & 1.00 & .00 & .02 & $-.26^{* *}$ & $.16^{* *}$ & $.18^{* *}$ & -.05 & -.06 \\
\hline 7 & & & & & & & 1.00 & $.12^{*}$ & $.12 *$ & -.09 & .08 & .03 & $-.10 * * *$ \\
\hline 8 & & & & & & & & 1.00 & $.17^{* *}$ & .05 & $-.12 *$ & .04 & .01 \\
\hline 9 & & & & & & & & & 1.00 & $-.4^{* *}$ & $-.2 l^{* *}$ & $-.17^{* *}$ & -.05 \\
\hline 10 & & & & & & & & & & 1.00 & $-.23 * *$ & $-.19 * * *$ & .11 \\
\hline 11 & & & & & & & & & & & 1.00 & -.10 & -.03 \\
\hline 12 & & & & & & & & & & & & 1.00 & $-.10^{* * * *}$ \\
\hline 13 & & & & & & & & & & & & & 1.00 \\
\hline
\end{tabular}

\begin{tabular}{|l|l|r|l|}
\hline 1 & Being male (Female is reference category) & 8 & Social Work Experience \\
\hline 2 & White (Non-white is reference category) & 9 & Social Work Major ${ }^{25}$ \\
\hline 3 & Age at Pretest & 10 & Psychology Major ${ }^{26}$ \\
\hline 4 & Undergraduate GPA & 11 & Sociology Major \\
\hline 5 & $>$ a year between College \& Graduate School \\
\hline 6 & 12 & Other helping major ${ }^{29}$ \\
\hline 6 & Undergraduate Research Institution ${ }^{30}$ & 13 & CCTST Pretest Total \\
\hline 7 & Pre SE Total & & \\
\hline
\end{tabular}

${ }^{*} p \leq 0.05 ;{ }^{* *} p \leq 0.01$

The researcher then conducted partial correlations controlling for the strongest correlations as noted in the correlation matrix in Table 33. The first partial correlation controlled for undergraduate GPA and the second controlled for both undergraduate GPA and ethnic group. See Table 34 for a summary of the results. The first partial correlation continued to show statistically significant weak positive correlations between CCTST pretest deductive scores and being male $r(276)=.17, p=.01$ and white ethnicity $r(276)=$ $.14, p=.02$, and a statistically significant weak negative correlation with age at pretest $r(276)=-.20, p=.00$. The previous trends noted in the point biserial and Pearson

\footnotetext{
${ }^{24}$ No social work experience is reference point

${ }_{25}$ Non-helping other major is reference category

26 Non-helping other major is reference category

${ }^{27}$ Non-helping other major is reference category

${ }^{28}$ Less than a year between undergraduate and entry into graduate school is the reference category

${ }^{29}$ Non-helping other major is reference category

${ }^{30}$ Undergraduate Teaching Institution is reference category
} 
correlations with self-efficacy pretest total and having an other helping as a major became insignificant after controlling for undergraduate GPA; however, the trend in having psychology as a major became significant $r(276)=.15, p=.01$. In addition, a trend formed in not having social work as a major $r(276)=-.11, p=.06$. The second partial correlation indicated a continued statistically significant correlations with being male $r(275)=.16, p=.01$, age at pretest $r(275)=-.19, \mathrm{p}=.00$, and having psychology as a major $r(275)=.14, p=.02$. The trend with not having social work as a major also continued $r(275)=-.12, p=.05$. As a result of these preliminary analyses, the following variables were eliminated from the pretest deductive predictor model: (a) more than a year between undergraduate and entry into graduate school, (b) undergraduate Research school, (c) self-efficacy pretest totals, and (d) social work experience. 


\section{Table 34}

Partial Correlations Between CCTST Pretest Deductive Scores and Predictor Variables Controlling for Undergraduate GPA and Ethnicity

\begin{tabular}{|l|l|l|l|}
\hline Variable & $\begin{array}{l}\text { First Order } \\
\text { Correlation }\end{array}$ & $\begin{array}{l}\text { Partial Correlation } \\
\text { Controlling for } \\
\text { Undergraduate GPA }\end{array}$ & $\begin{array}{l}\text { Partial Correlation } \\
\text { Controlling for } \\
\text { Undergraduate GPA } \\
\text { and Ethnicity }\end{array}$ \\
\hline Maleness & $.14^{*}$ & $.17^{*}$ & $.16^{*}$ \\
\hline White Ethnicity & $.20^{*}$ & $-14^{*}$ & $-.19^{*}$ \\
\hline Age at Pretest & $-.18^{*}$ & $-.20^{*}$ & \\
\hline Undergraduate GPA & $.28^{*}$ & & .07 \\
\hline $\begin{array}{l}\text { More than a year } \\
\text { between undergraduate } \\
\text { and entry into graduate } \\
\text { school }\end{array}$ & .03 & .08 & -.01 \\
\hline $\begin{array}{l}\text { Undergrad Research } \\
\text { Inst. }\end{array}$ & -.06 & -.02 & -.09 \\
\hline Pre SE Total & $-.10^{* *}$ & -.09 & .02 \\
\hline Social work experience & .01 & .03 & $-.12^{* *}$ \\
\hline Social Work major & -.05 & $-.11^{* *}$ & $.14^{* *}$ \\
\hline Psychology major & $.11^{* *}$ & $.15^{*}$ & .00 \\
\hline Sociology major & -.03 & -.01 & -.07 \\
\hline Other Helping major & $-.10^{* *}$ & -.08 & \\
\hline
\end{tabular}

${ }^{*} \mathrm{p}<.05,{ }^{* *} \mathrm{p}<.10$

The initial hierarchical regression analysis was used to explore which of the remaining variables were the best predictors of CCTST pretest inference scores and resulted in the elimination of all the dummy coded variables related to major. The final hierarchical regression analysis revealed Block 1 with the following variables: age at pretest, White ethnicity, being male, was a significant predictor of CCTST pretest deductive scores, $\left(R^{2}=.10, F(3,286)=10.04, p=.00\right)$. Block 2 , which included undergraduate GPA, also significantly improved the model, $\left(\Delta R^{2}=.06, p=.00\right)$. The predictor model indicated younger white male students with higher GPAs tend to have higher CCTST pretest deductive scores. Undergraduate GPA is the strongest predictors and White ethnicity was the weakest predictor. This model accounted for $16 \%$ of the 
variability in CCTST pretest deductive scores $\left(R^{2}=.16, F(4,286)=13.17, p=.000\right)$. Block 3 (discipline specific variables) did not contribute to the model. The See Table 35 for a summary of the regression results.

\section{Table 35}

Hierarchical Regression Analysis of CCTST Pretest Deductive Scores $(N=287)$

\begin{tabular}{lccc}
\hline Variables & B & SE B & $\boldsymbol{\beta}$ \\
\hline Step 1 & & & \\
$\quad$ Demographic Variables: & & & \\
$\quad$ Maleness & 1.09 & 0.39 & $0.16^{*}$ \\
White Ethnicity & 1.09 & 0.34 & $0.18^{*}$ \\
$\quad$ Age at Pretest & -0.06 & 0.02 & $-0.20^{*}$
\end{tabular}

Step 2

Demographic Variables:

Age at Pretest

White Ethnicity

Maleness

Generic Variables:

Undergraduate GPA

$\begin{array}{rrr}-0.06 & 0.02 & -0.20^{*} \\ 0.74 & 0.34 & 0.12^{* *} \\ 1.09 & 0.38 & 0.16^{*}\end{array}$

$1.59 \quad 0.35 \quad 0.25^{*}$

Note: $R^{2}=0.10$ for Step $1 ; \Delta R^{2}=0.06$ for Step $2(p<0.00)$.

${ }^{*} p \leq 0.01,{ }^{* *} p<.05$

\section{Pretest CCTST Inductive Score Analysis}

Analysis of variance was conducted on undergraduate majors and pretest CCTST inductive scores with no significant differences between groups. Individual independent t tests were conducted on CCTST pretest inductive scores and gender, type of undergraduate and social work experience indicated no significant difference. However, independent $t$ tests on CCTST pretest inductive scores and ethnicity $t(302)=-4.21, p=.00$, and less than a year between undergraduate and entry into graduate education $t(302)=$ $-2.27, p=.02$ indicated significant differences. The initial analysis indicated the potentiality of eliminating the categorical variables where the different groupings did not 
show significant differences between the groups on the CCTST pretest deductive scores; however, bivariate correlations on the dummy coded categorical variables as well as the other continuous variables was conducted to further investigate this decision making process

Point biserial correlations were conducted on the binary dummy variables and Pearson product-moment correlations were conducted on all remaining variables in the pretest inductive predictor model and are summarized in a correlation matrix in Table 36. There was a significant but weak positive correlation between CCTST pretest inductive scores and White ethnicity $r(304)=.24, p=.00$, undergraduate GPA $r(287)=.16, p=.01$, and more than a year between undergraduate and entry into graduate school $r(304)=.13$, $p=.02$. There was also a trend for self-efficacy pretest total $r(296)=-.10, p=.10$. The correlations did not indicate evidence of multicollinearity between the independent variables. 
Table 36

Correlations Between CCTST Pretest Inductive Scores and Predictor Variables

\begin{tabular}{|c|c|c|c|c|c|c|c|c|c|c|c|c|c|}
\hline & 1 & 2 & 3 & 4 & 5 & 6 & 7 & 8 & 9 & 10 & 11 & 12 & 13 \\
\hline 1 & 1.00 & .05 & 11 & .01 & -.01 & -.07 & .03 & .04 & .03 & .00 & -.01 & .04 & .07 \\
\hline 2 & & 1.00 & -.02 & $.23^{* *}$ & .09 & -.09 & -.01 & .08 & .09 & .07 & -.10 & -.11 & $24 * *$ \\
\hline 3 & & & 1.00 & .02 & $.23^{* *}$ & -.02 & .03 & $.14^{*}$ & .03 & $-.13 *$ & .09 & -.04 & -.04 \\
\hline 4 & & & & 1.00 & $-.19 * *$ & $-.14^{*}$ & -.07 & -.05 & $.21^{* *}$ & -.08 & -.08 & -.09 & $16^{* *}$ \\
\hline 5 & & & & & 1.00 & -.06 & -.05 & $.3^{* *}$ & -.06 & .02 & -.02 & -.06 & $.13 *$ \\
\hline 6 & & & & & & 1.00 & .00 & .02 & $-.26^{* * *}$ & $.16^{* *}$ & $.18^{* *}$ & -.05 & -.00 \\
\hline 7 & & & & & & & 1.00 & $.12 *$ & $.12 *$ & -.09 & .08 & .03 & $.10^{\text {**** }}$ \\
\hline 8 & & & & & & & & 1.00 & $17 * *$ & .05 & $-.12 *$ & .04 & .06 \\
\hline 9 & & & & & & & & & 1.00 & $-.4 * *$ & $-.21^{* *}$ & $-.17^{* *}$ & -.03 \\
\hline 10 & & & & & & & & & & 1.00 & $-.23^{* * *}$ & $-.19 * *$ & .05 \\
\hline 11 & & & & & & & & & & & 1.00 & -.10 & -.07 \\
\hline 12 & & & & & & & & & & & & 1.00 & -.03 \\
\hline 13 & & & & & & & & & & & & & 1.00 \\
\hline
\end{tabular}

\begin{tabular}{|l|l|r|l|}
\hline 1 & Being male (Female is reference category) & 8 & Social Work Experience \\
\hline 2 & White (Non-white is reference category) & 9 & Social Work Major ${ }^{32}$ \\
\hline 3 & Age at Pretest & 10 & Psychology Major \\
\hline 4 & Undergraduate GPA & 11 & Sociology Major \\
\hline 5 & $>$ a year between College \& Graduate School \\
\hline 6 & 12 & Other helping major ${ }^{36}$ \\
\hline 7 & Undergraduate Research Institution ${ }^{37}$ & 13 & CCTST Pretest Total \\
\hline
\end{tabular}

${ }^{*} p \leq 0.05 ;{ }^{* *} p \leq 0.01$

The researcher then conducted partial correlations controlling for the strongest correlations as noted in the correlation matrix in Table 36. The first partial correlation controlled for ethnic group and the second controlled for both undergraduate GPA and ethnic group. See Table 37 for a summary of the results. The first partial correlation indicated only one remaining statistically significant weak positive correlation between CCTST pretest inductive scores and undergraduate GPA $r(276)=.12, p=.05$. The previous trend noted in the point biserial and Pearson correlations with self-efficacy

\footnotetext{
${ }^{31}$ No social work experience is reference point

${ }^{32}$ Non-helping other major is reference category

${ }^{33}$ Non-helping other major is reference category

${ }_{34}^{34}$ Non-helping other major is reference category

${ }^{35}$ Less than a year between undergraduate and entry into graduate school is the reference category

${ }_{37}^{36}$ Non-helping other major is reference category

37 Undergraduate Teaching Institution is reference category
} 
pretest total became insignificant after controlling for undergraduate GPA. The second partial correlation indicated only one statistically significant weak positive correlation with more than a year between undergraduate and entry into graduate school $r(275)=.13$, $p=.04$. As a result of these preliminary analyses, only the following variables were eliminated from the pretest inductive model: (a) maleness, (b) age at pretest, (c) undergraduate Research school, (d) self-efficacy pretest total, (e) social work experience, (f) all binary dummy major variables.

\section{Table 37}

Partial Correlations Between CCTST Pretest Inductive Scores and Predictor Variables Controlling for Ethnicity and Undergraduate GPA

\begin{tabular}{|c|c|c|c|}
\hline Variable & $\begin{array}{l}\text { First Order } \\
\text { Correlation }\end{array}$ & $\begin{array}{l}\text { Partial Correlation } \\
\text { Controlling for } \\
\text { Ethnic Group }\end{array}$ & $\begin{array}{l}\text { Partial Correlation } \\
\text { Controlling for } \\
\text { Undergraduate GPA } \\
\text { and Ethnicity }\end{array}$ \\
\hline Maleness & .07 & .09 & .09 \\
\hline White Ethnicity & $.24 *$ & & \\
\hline Age at Pretest & -.04 & -.03 & -.03 \\
\hline Undergraduate GPA & $.16^{*}$ & $.12^{*}$ & \\
\hline $\begin{array}{l}\text { More than a year } \\
\text { between } \\
\text { undergraduate and } \\
\text { entry into graduate }\end{array}$ & $.13^{*}$ & .10 & $.13^{*}$ \\
\hline $\begin{array}{l}\text { Undergraduate } \\
\text { research institution }\end{array}$ & .00 & .02 & .03 \\
\hline Pre SE Total & $-.10^{* *}$ & -.10 & -.09 \\
\hline $\begin{array}{l}\text { Social work } \\
\text { experience }\end{array}$ & .06 & .05 & .05 \\
\hline Social Work major & -.03 & -.05 & -.08 \\
\hline Psychology major & .05 & .06 & .07 \\
\hline Sociology major & -.07 & -.03 & -.03 \\
\hline Other helping major & -.03 & -.01 & .00 \\
\hline
\end{tabular}

${ }^{*} \mathrm{p}<.05,{ }^{* *} \mathrm{p}<.10$

The hierarchical regression analysis revealed Block 1, which included white ethnicity, was a significant predictor of CCTST pretest inductive scores, $\left(R^{2}=.06, F(1\right.$, 
$286)=17.58, p=.00$ ). Block 2 with the following variables: more than a year between undergraduate and entry into graduate education, undergraduate GPA, also significantly improved the model, $\left(\Delta R^{2}=.31, p=.01\right)$. The predictor model indicated white students with higher GPAs and more than a year between undergraduate school and entry into graduate school tend to have higher CCTST pretest inductive scores. White ethnicity was the strongest predictor and more than a year between undergraduate and entry into graduate school and undergraduate GPA were the weakest. This model accounted for $9 \%$ of the variability in CCTST pretest inductive scores $\left(R^{2}=.09, F(3,286)=9.19, p=.000\right)$. Block 3 (discipline specific variables) did not contribute to the model. The See Table 38 for a summary of the regression results.

\section{Table 38}

Hierarchical Regression Analysis of CCTST Pretest Inductive Scores (N=287)

\begin{tabular}{lccc}
\hline Variables & B & SE B & $\beta$ \\
\hline $\begin{array}{l}\text { Step 1 } \\
\text { Demographic Variables: }\end{array}$ & & & \\
$\quad$ White Ethnicity & 1.41 & 0.34 & $0.24^{*}$ \\
$\begin{array}{l}\text { Step 2 } \\
\quad \text { Demographic Variables: }\end{array}$ & & & \\
$\quad \begin{array}{llll}\text { White Ethnicity } \\
\text { Generic Variables: }\end{array}$ & 1.15 & 0.34 & $0.20^{*}$ \\
$\quad$ Undergraduate GPA & 0.88 & 0.37 & $0.14^{* *}$ \\
$\quad$ More than a year between undergrad and entry into grad & 0.71 & 0.30 & $0.14^{* *}$ \\
& & & \\
\hline
\end{tabular}

Note: $R^{2}=0.06$ for Step $1 ; \Delta R^{2}=0.03$ for Step $2(p<0.01)$.

${ }^{*} p \leq 0.01, * * p<.05$

\section{Summary}

To provide a summary of the hierarchical regression analyses for the pretest generic versus discipline specific models, the results were summarized in Table 39. The 
table provides the total variance explained by each final model, all variables in the final model, the strongest predictor, as well as those predictors at trend level.

\section{Table 39}

\section{Pretest Model Summary of Total $R$ Square and Significant Predictors for the Generic versus Discipline Specific Models}

\begin{tabular}{|l|l|l|l|l|l|l|}
\hline CCTST Pretest & Total & Inference & Analytic & Evaluation & Deductive & Inductive \\
\hline Total $R^{2}$ & .17 & .14 & .12 & .10 & .16 & .09 \\
\hline Age & -.18 & -.17 & & -.13 & -.20 & \\
\hline White Ethnicity & .17 & .14 & $.11^{* *}$ & $.16^{*}$ & .12 & $.20^{*}$ \\
\hline Maleness & .14 & .14 & & .14 & .16 & \\
\hline $\begin{array}{l}\text { Undergraduate } \\
\text { GPA }\end{array}$ & $.25^{*}$ & $.25^{*}$ & $.17^{*}$ & $.16^{*}$ & $.25^{*}$ & .14 \\
\hline $\begin{array}{l}\text { More than a } \\
\text { year between }\end{array}$ & .17 & .15 & .15 & & & .14 \\
\hline $\begin{array}{l}\text { Self-Efficacy } \\
\text { Pretest }\end{array}$ & & & $-.11^{* *}$ & & & \\
\hline Other Helping & & & $-.14^{* *}$ & & & \\
\hline Social Work & & & -.10 & & & \\
\hline Psychology & & & -.03 & & & \\
\hline Sociology & & & -.08 & & & \\
\hline
\end{tabular}

Note: * Indicates strongest predictor, $* *$ indicates a trend.

\section{Research Question Three}

The following analysis addressed the second of the three proposed predictive models, in which acquired level critical thinking skills were explored utilizing the generic versus specific predictor blocks. In particular: Can acquired critical thinking skills of graduating MSSW students at the Kent School of Social Work be explained by the demographic variables of gender, race, and age, the generic variables of undergraduate GPA, months since undergraduate degree, and type of undergraduate institution, and the discipline specific variables of self-efficacy at pretest, years of social work experience, and undergraduate degree? This posttest model was illustrated in Figure 4; however, the different variables used in each block for these models are summarized again in Table 40 
to guide the discussion of the prediction analysis. In addition, the Not So Pure Posttest sample as illustrated in Table 5 was utilized to answer this question.

\section{Table 40}

\section{Summary of Posttest Predictor Blocks}

\begin{tabular}{|l|l|}
\hline $\begin{array}{l}\text { Block 1 } \\
\text { Control }\end{array}$ & $\begin{array}{l}\text { CCTST Pretest (appropriate to specific model) } \\
\text { Length of time in program when pretest was administered }\end{array}$ \\
\hline $\begin{array}{l}\text { Block 2 } \\
\text { Demographic }\end{array}$ & $\begin{array}{l}\text { Gender (dummy coded as maleness) } \\
\text { Ethnicity (dummy coded as White Ethnicity) } \\
\text { Age }\end{array}$ \\
\hline $\begin{array}{l}\text { Block 3 } \\
\text { Generic }\end{array}$ & $\begin{array}{l}\text { Undergraduate GPA } \\
\text { Months between undergraduate degree and entry into } \\
\text { graduate program (dummy coded as More than a year } \\
\text { between undergrad and entry into graduate school) }\end{array}$ \\
\hline $\begin{array}{l}\text { Block 4 } \\
\text { Discipline Specific }\end{array}$ & $\begin{array}{l}\text { Self-Efficacy Pretest total } \\
\text { Years of Social Work experience (dummy coded as Social } \\
\text { work experience } \\
\text { Undergraduate degree (dummy coded in Social Work major, } \\
\text { Psychology major, Sociology major and Other helping } \\
\text { majors) }\end{array}$ \\
\hline
\end{tabular}

\section{Descriptives}

A total of 179 students were included in the posttest sample. The average age was 29.8 years $(S D=7.83)$ and median age of 26.8 . The youngest student was 21.9 and the oldest was 56.7 years old. There were $79.9 \%$ white students $(\mathrm{N}=143)$ and $20.1 \%(\mathrm{~N}=36)$ non-white students. Most students were females $(83.8 \%, \mathrm{~N}=150)$, compared to $16.2 \%$ $(\mathrm{N}=29)$ men. The majority of students received their undergraduate degree from a teaching focused university $(58.7 \%, \mathrm{~N}=105)$ with an average undergraduate GPA of 3.26. Of the students where a major was reported, $35.8 \%(\mathrm{~N}=64)$ majored in social work, $29.6 \%(\mathrm{~N}=53)$ majored in psychology, $11.7 \%(\mathrm{~N}=21)$ majored in sociology and $17.9 \%$ $(\mathrm{N}=32)$ majored in non-helping other majors (e.g. English, Political Science, Theater) and 
$3.9 \%(\mathrm{~N}=7)$ majored in other helping majors (eg. Mental Health Counseling, Child Development, Criminal Justice). Students mean response on the Foundation Practice Self-Efficacy Scale was $76.89(\mathrm{SD}=14.29)$ out of a possible 100 points. As noted in the discussion of analyses results for Research Question 1, months between undergraduate and graduate school and social work experience was dichotomized. The majority of students entered graduate school less than a year after their undergraduate degree (52.5\%, $\mathrm{N}=94)$; whereas, $47.5 \%(\mathrm{~N}=85)$ of students waited more than a year to enroll in graduate school. Those students with social work experience $(58.1 \%, \mathrm{~N}=104)$ made up the majority of the sample compared to those with no social work experience $(41.9 \%, \mathrm{~N}=75)$. Students' average CCTST pretest score descriptives are as follows: total average of 17.32 $(\mathrm{SD}=4.41)$ with a range of 6 to 28 ; analytic average $4.70(\mathrm{SD}=1.37)$ with a range of 1 to 7; inference average $7.76(\mathrm{SD}=2.22)$ with a range of 1 to 12 ; evaluation average 4.87 $(\mathrm{SD}=1.95)$ with a range of 0 to 10 ; induction average $10.09(\mathrm{SD}=2.58)$ with a range of 3 to 16 ; deduction average $7.23(\mathrm{SD}=2.62)$ with a range of 1 to 14 . The length of time in program when pretest was administered averaged $9.94(\mathrm{SD}=13.39)$ with a range of 0 to 59.99 months. This information is summarized in Table 41 . 
Descriptive Characteristics of the Not So Pure Posttest Sample ${ }^{a}$

\begin{tabular}{|c|c|c|c|c|c|}
\hline Characteristic & $\mathbf{N}$ & $\%$ & $\overline{\mathbf{X}}$ & SD & Range \\
\hline Age at pretest (years) & 179 & & 29.85 & 7.83 & $21.94-56.71$ \\
\hline Undergraduate GPA & 175 & & 3.26 & 0.41 & $2.05-4.0$ \\
\hline CCTST Pretest Total & 176 & & 17.32 & 4.41 & 6 to 28 \\
\hline CCTST Pretest Analytic & 176 & & 4.70 & 1.37 & 1 to 7 \\
\hline CCTST Pretest Inference & 176 & & 7.76 & 2.22 & 1 to 12 \\
\hline CCTST Pretest Evaluation & 176 & & 4.87 & 1.95 & 0 to 10 \\
\hline CCTST Pretest Inductive & 176 & & 10.09 & 2.58 & 3 to 16 \\
\hline CCTST Pretest Deductive & 176 & & 7.23 & 2.61 & 1 to 14 \\
\hline Length of Time in Program & 175 & & 9.94 & 13.39 & .00 to 59.99 \\
\hline Pretest Self-Efficacy & 175 & & 76.89 & 14.29 & $10-100$ \\
\hline \multicolumn{6}{|l|}{ Ethnic Group } \\
\hline Non White & 36 & 20.1 & & & \\
\hline White & 143 & 79.9 & & & \\
\hline \multicolumn{6}{|l|}{ Gender } \\
\hline Female & 150 & 83.8 & & & \\
\hline Male & 29 & 16.2 & & & \\
\hline \multicolumn{6}{|l|}{ Undergraduate School } \\
\hline Research & 72 & 40.2 & & & \\
\hline Teaching & 105 & 58.7 & & & \\
\hline Missing & 2 & 1.1 & & & \\
\hline \multicolumn{6}{|l|}{$\begin{array}{l}\text { Time between undergrad. and } \\
\text { graduate school }\end{array}$} \\
\hline More than a year & 85 & 47.5 & & & \\
\hline Less than a year & 94 & 52.5 & & & \\
\hline \multicolumn{6}{|l|}{ Social Work Experience } \\
\hline No Experience & 75 & 41.9 & & & \\
\hline Experience & 104 & 58.1 & & & \\
\hline \multicolumn{6}{|l|}{ Undergraduate Degree } \\
\hline Social Work & 64 & 35.8 & & & \\
\hline Psychology & 53 & 29.6 & & & \\
\hline Sociology & 21 & 11.7 & & & \\
\hline Other Helping & 7 & 3.9 & & & \\
\hline Non Helping & 32 & 17.9 & & & \\
\hline
\end{tabular}

${ }^{a}$ Due to rounding, not all categories equal $100 \%$.

\section{Dependent Variable}

The CCTST reported percentile scores to compare students' scores against a national sample of $4^{\text {th }}$ year college students utilizing an aggregated sample. The pretest 
total mean was at the $54^{\text {th }}$ percentile. The posttest mean was at $58^{\text {th }}$ percentile. A summary of the descriptive information is provided in Table 42 .

Table 42

Descriptive Characteristics of CCTST Posttest Scores ${ }^{a}$

\begin{tabular}{lcrccc}
\hline Scale & $\mathbf{N}$ & $\overline{\mathbf{X}}$ & SD & Range & $\begin{array}{c}\text { Maximum } \\
\text { Points Possible }\end{array}$ \\
\hline Total & 178 & 18.12 & 4.47 & $9-30$ & 34 \\
Analytic & 178 & 4.75 & 1.32 & $1-7$ & 7 \\
Inference & 178 & 8.35 & 2.49 & $3-14$ & 16 \\
Evaluation & 178 & 5.02 & 1.98 & $1-10$ & 11 \\
Inductive & 178 & 10.42 & 2.47 & $5-16$ & 17 \\
Deductive & 178 & 7.70 & 2.77 & $2-15$ & 17 \\
\hline
\end{tabular}

${ }^{\mathrm{a}}$ Due to rounding, not all categories equal $100 \%$.

\section{Posttest CCTST Total Score Analysis}

Analysis of variance was conducted on undergraduate majors and posttest CCTST total posttest scores with no significant differences between groups. An independent $t$ test was conducted on posttest CCTST total scores and gender, type of undergraduate school, more than a year between undergraduate and entry into graduate school and social work experience with no significant differences found. Additionally, an independent $t$ test was conducted on ethnicity $t(178)=-4.17, p=.00$ indicating significant differences. Also note, in regards to the results for ethnicity, the Levene's test for equality of variance was significant at $F=5.40, p=.02$; therefore the equal variance not assumed portion of the independent $t$ test results was interpreted. The initial analysis indicated the potentiality of eliminating the categorical variables where the different groupings did not show significant differences between the groups the on CCTST posttest total scores; however, bivariate correlations on the dummy coded categorical variables as well as the other continuous variables were conducted to further investigate this decision making process. 
Point biserial correlations were conducted on the binary dummy variables and Pearson product-moment correlations were conducted on all remaining variables in the posttest predictor model and are summarized in a correlation matrix in Table 43. There was a strong and significant positive correlation between CCTST posttest total and CCTST pretest total scores $r(175)=.76, p=.00$ and a moderate and positive correlation between CCTST posttest total scores and White ethnicity $r(178)=.26, p=.00$. In addition, a weak but significant positive correlation was noted with having a psychology major $r(178)=.17, p=.03$ and a weak but significant negative correlation with students having a social work major $r(178)=-.17, p=.03$. There was also a weak but significant negative correlation with age at pretest $r(178)=-.19, p=.01$. The correlations did not indicate evidence of multicollinearity between the independent variables. 
Table 43

Correlations Between CCTST Posttest Total Scores and Predictor Variables

\begin{tabular}{|c|c|c|c|c|c|c|c|c|c|c|c|c|c|c|c|}
\hline & 1 & 2 & 3 & 4 & 5 & 6 & 7 & 8 & 9 & 10 & 11 & 12 & 13 & 14 & 15 \\
\hline 1 & 1.00 & -.01 & .08 & .15 & $-.16^{*}$ & .07 & .09 & -.07 & .09 & -.05 & .07 & -.02 & -.11 & .07 & $.76 * *$ \\
\hline 2 & & 1.00 & .01 & .06 & $.37 * *$ & $-.26^{* *}$ & $32^{* *}$ & .03 & .08 & $-.51^{* *}$ & $.19^{*}$ & .15 & $.16^{*}$ & $.16^{*}$ & .08 \\
\hline 3 & & & 1.00 & .07 & $.19^{*}$ & -.03 & .07 & $-.18^{*}$ & .04 & .01 & .01 & .03 & .01 & $.09^{\circ}$ & .04 \\
\hline 4 & & & & 1.00 & -.08 & .07 & .03 & .12 & .14 & .05 & .02 & .10 & .03 & .07 & $.26 * *$ \\
\hline 5 & & & & & 1.00 & -.06 & $30^{* *}$ & -11 & .16 & -12 & -.14 & .16 & .04 & .09 & $-19^{* *}$ \\
\hline 6 & & & & & & 1.00 & $-.24^{* * *}$ & -.18 & .90 & $.33 * *$ & -14 & -.10 & -.07 & -.03 & .09 \\
\hline 7 & & & & & & & 1.00 & $-.27^{* *}$ & $.29^{* *}$ & -.08 & -.03 & -.07 & .04 & .10 & .03 \\
\hline 8 & & & & & & & & 1.00 & -.09 & $-.33^{* *}$ & .17 & .09 & .13 & .02 & .03 \\
\hline 9 & & & & & & & & & 1.00 & .11 & .03 & -.07 & .11 & $.21^{* *}$ & -.00 \\
\hline 10 & & & & & & & & & & 1.00 & $-.48 * *$ & $-27 * *$ & $-15^{*}$ & .10 & $-.17^{*}$ \\
\hline 11 & & & & & & & & & & & 1.00 & $-.24^{* *}$ & -.13 & .06 & $.17^{*}$ \\
\hline 12 & & & & & & & & & & & & 1.00 & -.07 & -.05 & .03 \\
\hline 13 & & & & & & & & & & & & & 1.00 & .07 & -.06 \\
\hline 14 & & & & & & & & & & & & & & 1.00 & .05 \\
\hline 15 & & & & & & & & & & & & & & & 1.00 \\
\hline
\end{tabular}

\begin{tabular}{|c|c|c|c|}
\hline 1 & CCTST Pretest Total & & Social Work Experience ${ }^{38}$ \\
\hline 2 & Length of time in program & 10 & Social Work Major? ${ }^{39}$ \\
\hline 3 & Being male (female is reference category) & 11 & Psychology Major? $^{40}$ \\
\hline 4 & White ethnicity (Non-white is reference category) & 12 & Sociology Major? $^{41}$ \\
\hline 5 & Age at Pretest & 13 & Other helping major? ${ }^{42}$ \\
\hline 6 & Undergrad GPA & 14 & Pre SE Total \\
\hline 1 & $>$ a year between College \& Graduate School $^{43}$ & 15 & CCST Posttest Total \\
\hline 8 & Undergrad Research Institution & & \\
\hline
\end{tabular}

${ }^{*} p \leq 0.05 ;{ }^{* *} p \leq 0.01$

The researcher then conducted partial correlations controlling for the strongest correlations as noted in the correlation matrix in Table 43. The first partial correlation controlled for CCTST pretest total and the second controlled for both CCTST pretest total and ethnicity. See Table 44 for a summary of the results. In the first partial correlation the significant moderate positive correlation of White ethnicity transitioned to a weak positive correlation $r(162)=.23, p=.00$. The significant weak negative correlation of having a social work major $r(162)=-.20, p=.01$ and weak positive

\footnotetext{
${ }^{38}$ No social work experience is reference category

Non-helping other major is reference category

Non-helping other major is reference category

${ }^{41}$ Non-helping other major is reference category

${ }^{42}$ Non-helping other major is reference category

${ }^{43}$ Less than a year between undergraduate and entry into graduate school is the reference category

${ }^{44}$ Undergraduate Teaching Institution is reference category
} 
correlation of having a psychology major $r(162)=.20, p=.01$ continued. The significant weak negative correlations between CCTST posttest scores and age at pretest transitioned to a trend $r(162)=-.14, p=.09$. A trend developed in the correlation between CCTST posttest total scores and length of time in program when pretest was completed developed $r(162)=.14, p=.08$. The second partial correlation indicated a continued statistically significant weak correlations with having a social work major $r(161)=-.21, p=.01$ and having a psychology major $r(161)=.19, \mathrm{p}=.02$. The trend in length of time in program when pretest was administered continued $r(161)=.14, \mathrm{p}=.07$ and no social work experience $r(161)=-.14, p=.07$. As a result of these preliminary analyses, the following variables were eliminated from the posttest total predictor model: (a) maleness, (b) undergraduate GPA, (c) more than a year between undergraduate school and entry into graduate school, (d) undergraduate research school, (e) social work experience, (f) selfefficacy pretest total 


\section{Table 44}

Partial Correlations Between CCTST Posttest Total Scores and Predictor Variables Controlling for CCTST Total Pretest and Ethnicity

\begin{tabular}{|l|l|l|l|}
\hline Variable & $\begin{array}{l}\text { First Order } \\
\text { Correlation }\end{array}$ & $\begin{array}{l}\text { Partial Correlation } \\
\text { Controlling for } \\
\text { CCTST Total } \\
\text { Pretest }\end{array}$ & $\begin{array}{l}\text { Partial Correlation } \\
\text { Controlling for } \\
\text { CCTST Total } \\
\text { Pretest and White } \\
\text { Ethnicity }\end{array}$ \\
\hline CCTST Total Pretest & $.76^{*}$ & & \\
\hline $\begin{array}{l}\text { Length of time in } \\
\text { program at pretest }\end{array}$ & .08 & $.14^{* *}$ & $.14^{* *}$ \\
\hline Maleness & .04 & -.00 & -.02 \\
\hline White Ethnicity & $.26^{*}$ & $.23^{*}$ & \\
\hline Age at Pretest & $-.19^{*}$ & $-.14^{* *}$ & -.12 \\
\hline Undergraduate GPA & .09 & .06 & .05 \\
\hline $\begin{array}{l}\text { More than a year } \\
\text { between undergraduate } \\
\text { and entry into graduate }\end{array}$ & .03 & -.08 & -.09 \\
\hline $\begin{array}{l}\text { Undergraduate Research } \\
\text { Institution }\end{array}$ & -.03 & .01 & -.02 \\
\hline Pre SE Total & -.05 & .00 & -.02 \\
\hline Social work experience & -.00 & -.10 & $-.14^{* *}$ \\
\hline Social Work major & $-.17^{*}$ & $-.20^{*}$ & $-.21^{*}$ \\
\hline Psychology major & $.17^{*}$ & $.20^{*}$ & $.19^{*}$ \\
\hline Sociology major & .03 & .08 & .09 \\
\hline Other helping major & -.06 & .03 & .03 \\
\hline$*$ p $<05 * *$ p $<1$ & & & \\
\hline
\end{tabular}

The initial hierarchical regression analysis was used to explore which of the remaining variables were the best predictors of CCTST posttest total scores and resulted in the elimination of all the dummy coded variables related to major. The final hierarchical regression analysis revealed the control variables entered in Block 1 with the following variables, CCTST pretest total and length of time in program when pretest was administered, was a significant predictor of CCTST posttest totals, $\left(R^{2}=.57, F(2,178)=\right.$ $116.92, p=.00$ ). Block 2 with the following variables, White ethnicity and age at pretest also significantly improved the model, $\left(\Delta R^{2}=.04, p=.00\right)$. The predictor model indicated 
younger white have higher CCTST posttest scores. White ethnicity was the strongest predictor and age at pretest was the weakest predictor. Note the control variables were not included in the reporting of the strongest and weakest predictors. This model accounted for $61 \%$ of the variability in CCTST posttest scores $\left(R^{2}=.61, F(4,178)=\right.$ 66.93, $p=.00$ ). Block 3 (generic variables) and Block 4 (discipline specific variables) did not contribute to the model. See Table 45 for a summary of the regression results.

\section{Table 45}

Hierarchical Regression Analysis of CCTST Posttest Total Scores (N=179)

\begin{tabular}{lccc}
\hline Variables & B & SE B & $\beta$ \\
\hline Step 1 & & & \\
$\quad$ Control Variables: & & & \\
$\quad$ CCTST Pretest Total & 0.76 & 0.50 & $0.75^{*}$ \\
$\quad$ Length of Time in Program & 0.03 & 0.02 & $0.08^{\mathrm{a}}$ \\
Step 2 & & & \\
$\quad$ Control Variables: & & & \\
$\quad$ CCTST Pretest Total & 0.72 & 0.50 & $0.71^{*}$ \\
$\quad$ Length of Time in Program & 0.05 & 0.02 & $0.13^{*}$ \\
$\quad \begin{array}{l}\text { Demographic Variables: } \\
\quad \text { White Ethnicity }\end{array}$ & 1.71 & 0.53 & $0.16^{*}$ \\
$\quad$ Age at pretest & -0.06 & 0.03 & $-0.11^{* *}$ \\
& & & \\
\hline
\end{tabular}

Note: $R^{2}=0.57$ for Step $1 ; \Delta R^{2}=0.04$ for Step $2(p=0.00)$. ${ }^{*} p<0.05,{ }^{*} p<.01,{ }^{\mathrm{a}} p \leq .10$

\section{Posttest CCTST Inference Score Analysis}

Analysis of variance was conducted on undergraduate majors and posttest CCTST inference scores with no significant differences between groups. Individual independent $t$ tests were conducted on CCTST posttest inference scores and gender, type of undergraduate school, more than a year between undergraduate and entry into graduate school, social work experience indicated no significant difference. However, independent $\mathrm{t}$ test on CCTST posttest inference scores and ethnicity $t(178)=-3.92, p=.00$ indicated 
significant differences. Note Levene's Test for Equality of Variance was significant ( $\mathrm{F}=9.03, p=.00)$; therefore the equal variances not assumed portion of the analysis was reported. The initial analysis indicated the potentiality of eliminating the categorical variables where the different grouping did not have significant differences between the groups on CCTST posttest inference scores; however, additional evaluative analysis was conducted to further investigate this decision making process

Point biserial correlations were conducted on the binary dummy variables and Pearson product-moment correlations were conducted on all remaining variables in the posttest predictor model and are summarized in a correlation matrix in Table 46. There was a strong and significant positive correlation between CCTST posttest inference and CCTST pretest inference scores $r(175)=.56, p=.00$ and a moderate and positive correlation between CCTST posttest inference scores and White ethnicity $r(178)=.25$, $p=.00$. In addition, a weak but significant negative correlation was noted with age at pretest $r(178)=-.18, p=.02$. A trend was noted with students with a psychology major $r(178)=.13, p=.09$. The correlations did not indicate evidence of multicollinearity between the independent variables. 


\section{Correlations Between CCTST Posttest Inference Scores and Predictor Variables}

\begin{tabular}{|c|c|c|c|c|c|c|c|c|c|c|c|c|c|c|c|}
\hline & 1 & 2 & 3 & 4 & 5 & 6 & 7 & 8 & 9 & 10 & 11 & 12 & 13 & 14 & 15 \\
\hline 1 & 1.00 & $-(t) 1$ & .08 & 15 & $-16^{*}$ & .07 & .09 & -.07 & 09 & -.05 & .07 & .02 & -.11 & -.07 & $.76^{* *}$ \\
\hline 2 & & 1.00 & .01 & .06 & $.37 * *$ & $-.26 * *$ & $.32 * *$ & .03 & .08 & $-.51^{* *}$ & $19 *$ & .15 & $.16^{*}$ & $.16^{*}$ & .08 \\
\hline 3 & & & 1.00 & .07 & $.19^{*}$ & .03 & .07 & $-.18^{*}$ & .04 & .01 & .01 & .03 & -.01 & .09 & .04 \\
\hline 4 & & & & 1.00 & -.198 & .07 & .03 & 12 & 14 & .05 & .02 & 10 & .03 & .07 & $26^{* *}$ \\
\hline 5 & & & & & 1.00 & -.06 & $.30^{* *}$ & -.11 & 16 & -12 & -.14 & .16 & .04 & .09 & $-19 * *$ \\
\hline 6 & & & & & & 1.00 & $-.24 * *$ & -18 & .90 & $.33^{* *}$ & -.14 & .10 & -.07 & -.03 & .09 \\
\hline 7 & & & & & & & 1.00 & $-.27 * *$ & $.29 * *$ & .08 & -.03 & -.107 & .04 & .10 & 03 \\
\hline 8 & & & & & & & & 1.00 & -.09 & $-.33^{* *}$ & .17 & .09 & .13 & .02 & .03 \\
\hline 9 & & & & & & & & & 1.00 & .11 & .03 & -.07 & .11 & $.21^{* * *}$ & -.00 \\
\hline 10 & & & & & & & & & & 1.00 & $-.48 * *$ & $-.27 * *$ & $-.15^{*}$ & .10 & $-17^{*}$ \\
\hline 11 & & & & & & & & & & & 1.00 & $-24^{* *}$ & -.13 & .06 & $.17 *$ \\
\hline 12 & & & & & & & & & & & & 1.00 & .07 & -.05 & .03 \\
\hline 13 & & & & & & & & & & & & & 1.00 & .07 & -.06 \\
\hline 14 & & & & & & & & & & & & & & 1.00 & -.05 \\
\hline 15 & & & & & & & & & & & & & & & 1.00 \\
\hline
\end{tabular}

\begin{tabular}{|l|l|r|l|}
\hline 1 & CCTST Pretest Total & 9 & Social Work Experience $^{45}$ \\
\hline 2 & Length of time in program & 10 & Social Work Major? \\
\hline 3 & Being male (female in reference category) $^{46}$ & 11 & Psychology Major? $^{47}$ \\
\hline 4 & White ethnicity (Non-white is reference category) $^{47}$ & 12 & Sociology Major? $^{48}$ \\
\hline 5 & Age at Pretest $^{43}$ & Other helping major? $^{49}$ \\
\hline 6 & Undergrad GPA $^{4}$ & 14 & Pre SE Total \\
\hline 7 & a year between College \& Graduate School $^{50}$ & 15 & CCST Posttest Total \\
\hline 8 & Undergrad Research Institution $^{51}$ & \\
\hline
\end{tabular}
${ }^{*} p \leq 0.05 ;{ }^{* *} p \leq 0.01$

The researcher then conducted partial correlations controlling for the strongest correlations as noted in the correlation matrix in Table 46 . The first partial correlation controlled for CCTST pretest inference and the second controlled for both CCTST pretest inference and ethnicity. See Table 47 for a summary of the results. In the first partial correlation, White ethnicity transitioned to a weak positive correlation $r(162)=.22$, $p=.01$. The trend with those students with a psychology major $r(162)=.16, p=.04$ transitioned to a significant weak positive correlation. A trend developed in the correlation between CCTST posttest inference scores and male gender $r(162)=.13$,

\footnotetext{
45 No social work experience is reference category

46 Non-helping other major is reference category

47 Non-helping other major is reference category

48 Non-helping other major is reference category

49 Non-helping other major is reference category

${ }^{50}$ Less than a year between undergraduate and entry into graduate school is the reference category

51 Undergraduate Teaching Institution is reference category
} 
$p=.09$. In the second partial correlation only a single trend in students with a psychology major $r(161)=.15, p=.06$ was indicated. As a result of these preliminary analyses, the following variables were eliminated from the posttest inference predictor model: (a) undergraduate GPA, (b) more than a year between undergraduate school and entry into graduate school, (c) undergraduate research school, (d) social work experience, (e) selfefficacy pretest total.

\section{Table 47}

Partial Correlations Between CCTST Posttest Inference Scores and Predictor Variables Controlling for CCTST Inference Pretest and Ethnicity

\begin{tabular}{|l|l|l|l|}
\hline Variable & $\begin{array}{l}\text { First Order } \\
\text { Correlation }\end{array}$ & $\begin{array}{l}\text { Partial Correlation } \\
\text { Controlling for } \\
\text { CCTST Inference } \\
\text { Pretest }\end{array}$ & $\begin{array}{l}\text { Partial Correlation } \\
\text { Controlling for } \\
\text { CCTST Inference } \\
\text { Pretest and White } \\
\text { Ethnicity }\end{array}$ \\
\hline $\begin{array}{l}\text { CCTST Inference } \\
\text { Pretest }\end{array}$ & $.56^{*}$ & & \\
\hline $\begin{array}{l}\text { Length of time in } \\
\text { program at pretest }\end{array}$ & .02 & .04 & .04 \\
\hline Maleness & .10 & $.13^{* *}$ & .12 \\
\hline White Ethnicity & $.25^{*}$ & $.22^{*}$ & \\
\hline Age at Pretest & $-.18^{*}$ & -.10 & -.09 \\
\hline Undergraduate GPA & .11 & .06 & .04 \\
\hline $\begin{array}{l}\text { More than a year } \\
\text { between undergraduate } \\
\text { and entry into graduate }\end{array}$ & -.02 & -.07 & -.09 \\
\hline $\begin{array}{l}\text { Undergraduate Research } \\
\text { Institution }\end{array}$ & .01 & & .07 \\
\hline Pre SE Total & .02 & .06 & .03 \\
\hline Social work experience & -.04 & .07 & .06 \\
\hline Social Work major & -.06 & -.08 & -.11 \\
\hline Psychology major & $.13^{* *}$ & $.16^{*}$ & -.08 \\
\hline Sociology major & -.02 & -.04 & $.15^{* *}$ \\
\hline Other helping major & -.06 & -.02 & -.04 \\
\hline *p<.05; **p<.1 & & & -.02 \\
\hline
\end{tabular}


The initial hierarchical regression analysis was used to explore which of the remaining variables were the best predictors of CCTST posttest inference scores and resulted in the elimination of all the dummy coded variables related to major, as well as gender and age at pretest. The final hierarchical regression analysis revealed the control variables entered in Block 1with the variables of CCTST pretest inference and length of time in program when pretest was administered, was a significant predictor of CCTST posttest inference, $\left(R^{2}=.30, F(2,177)=38.17, p=.00\right)$. Block 2 , which included White ethnicity, also significantly improved the model, $\left(\Delta R^{2}=.04, p=.00\right)$. The predictor model indicated students with White ethnicity have higher CCTST posttest inference scores. White ethnicity was the single predictor aside from the control variables. This model accounted for $34.3 \%$ of the variability in CCTST posttest inference scores $\left(R^{2}=.34, F(3\right.$, 177 ) $=30.26, p=.00$ ). Block 3 (generic variables) and Block 4 (discipline specific variables) did not contribute to the model. See Table 48 for a summary of the regression results.

Table 48

Hierarchical Regression Analysis of CCTST Posttest Inference Scores $(N=179)$

\begin{tabular}{lccc}
\hline Variables & B & SE B & B \\
\hline Step 1 & & & \\
$\quad$ Control Variables: & & & \\
$\quad$ CCTST Pretest Inference & 0.62 & 0.07 & $0.55^{*}$ \\
$\quad$ Length of Time in Program & 0.01 & 0.01 & 0.03 \\
Step 2 & & & \\
$\quad$ Control Variables: & & & \\
$\quad$ CCTST Pretest Inference & 0.60 & 0.07 & $0.53^{*}$ \\
$\quad$ Length of Time in Program & 0.01 & 0.01 & 0.04 \\
$\quad \begin{array}{l}\text { Demographic Variables: } \\
\quad \text { White Ethnicity }\end{array}$ & 1.23 & 0.38 & $0.20^{*}$ \\
& & & \\
\hline
\end{tabular}

Note: $R^{2}=0.30$ for Step 1; $\Delta R^{2}=0.04$ for Step $2(p=0.00)$.

${ }^{*} p<0.05,{ }^{* *} p<.01$ 


\section{CCTST Posttest Analytic Analysis Results}

Analysis of variance was conducted on undergraduate majors and posttest CCTST analytic scores with no significant differences between groups. Individual independent $\mathrm{t}$ tests conducted on CCTST posttest analytic scores and gender, ethnicity, type of undergraduate, more than a year between undergraduate and entry into graduate school, and social work experience indicated no significant difference. Bivariate correlations on the dummy coded categorical variables as well as the other continuous variables were conducted to further investigate this decision making process.

Point biserial correlations were conducted on the binary dummy variables and Pearson product-moment correlations were conducted on all remaining variables in the posttest predictor model and are summarized in a correlation matrix in Table 49. There was a strong and significant positive correlation between CCTST posttest analytic and CCTST pretest analytic scores $r(175)=.38, p=.00$ and a weak and negative correlation between CCTST posttest analytic scores and age at pretest $r(178)=-.20, p=.01$. A trend was noted in students with a social work major $r(178)=-.13, p=.09$. The correlations did not indicate evidence of multicollinearity between the independent variables. 
Table 49

Correlations Between CCTST Posttest Analytic Score and Predictor Variables

\begin{tabular}{|c|c|c|c|c|c|c|c|c|c|c|c|c|c|c|c|}
\hline & 1 & 2 & 3 & 4 & 5 & 6 & 7 & 8 & 9 & 10 & 11 & 12 & 13 & 14 & 15 \\
\hline 1 & 1.00 & -.02 & .05 & .06 & -.03 & -02 & 11 & -.08 & 10 & -.04 & .10 & 00 & -.08 & -.14 & $38^{* *}$ \\
\hline 2 & & 1.00 & -.01 & -.06 & $.37^{* * *}$ & $-.26^{* *}$ & $.32 * *$ & .03 & .08 & $-.51^{* *}$ & $.19 *$ & 15 & $16^{*}$ & $.16^{*}$ & .03 \\
\hline 3 & & & 1.00 & .07 & $.19 *$ & -.03 & .07 & $-.18^{*}$ & .04 & .01 & .01 & .03 & -.01 & .09 & -.10 \\
\hline 4 & & & & 1.00 & -.08 & .07 & .03 & .12 & .14 & .05 & .02 & .01 & .03 & .07 & .11 \\
\hline 5 & & & & & 1.00 &. .06 & $30^{* * *}$ & -.11 & $.16^{*}$ & -.12 & -.14 & .16 & .04 & .09 & $-.20^{* *}$ \\
\hline 6 & & & & & & 1.00 & $-.24 * *$ & -.12 & 90 & $33 * *$ & -.14 & -.10 & -.07 & -.03 & .05 \\
\hline 7 & & & & & & & 1.00 & $-.27 * *$ & $.29 * *$ & -.08 & -.03 & -.07 & .04 & 10 & -.01 \\
\hline 8 & & & & & & & & 1.00 & -.09 & $-.33 * *$ & $17^{*}$ & .09 & 13 & .02 & -.08 \\
\hline 9 & & & & & & & & & 1.00 & .11 & .03 & .08 & 11 & $.21^{* * * *}$ & -.02 \\
\hline 10 & & & & & & & & & & 1.00 & $-.48 * *$ & $-.27 * *$ & $-.15 *$ & .10 & $-.13 * * *$ \\
\hline 11 & & & & & & & & & & & 1.00 & $-.24 * *$ & -.13 & .06 & .07 \\
\hline 12 & & & & & & & & & & & & 1.00 & -.07 & .05 & .06 \\
\hline 13 & & & & & & & & & & & & & 1.00 & .07 & -.01 \\
\hline 14 & & & & & & & & & & & & & & 1.00 & -.11 \\
\hline 15 & & & & & & & & & & & & & & & 1.00 \\
\hline
\end{tabular}

\begin{tabular}{|c|c|c|c|}
\hline 1 & CCTST Pretest Total & & Social Work Experience ${ }^{52}$ \\
\hline 2 & Length of time in program & & Social Work Major? $^{53}$ \\
\hline 3 & Being male (female is reference category) & 11 & Psychology Major? $^{54}$ \\
\hline 4 & White ethnicity (Non-white is reference category) & 12 & Sociology Major? ${ }^{55}$ \\
\hline 5 & Age at Pretest & 13 & Other helping major? $^{56}$ \\
\hline 6 & Undergrad GPA & 14 & Pre SE Total \\
\hline 7 & $>$ a year between College \& Graduate School ${ }^{57}$ & 15 & CCST Posttest Total \\
\hline 8 & Undergrad Research Institution $^{5}$ & & \\
\hline
\end{tabular}

${ }^{*} p \leq 0.05 ;{ }^{* *} p \leq 0.01$

The researcher then conducted partial correlations controlling for the strongest correlations as noted in the correlation matrix in Table 49. The first partial correlation controlled for CCTST pretest analytic and the second controlled for both CCTST pretest analytic and age at pretest. See Table 50 for a summary of the results. In the first partial correlation, age at pretest $r(162)=-.20, p=.01$ continued as a weak significant negative correlation. In the second partial correlation only a single trend in students with a social work major $r(161)=-14, p=.08$ was indicated. As a result of these preliminary analyses,

\footnotetext{
52 No social work experience is reference category

53 Non-helping other major is reference category

54 Non-helping other major is reference category

55 Non-helping other major is reference category

56 Non-helping other major is reference category

57 Less than a year between undergraduate and entry into graduate school is the reference category

58 Undergraduate Teaching Institution is reference category
} 
the following variables were eliminated from the posttest analytic predictor model: (a)

maleness, (b) White Ethnicity, (c) undergraduate GPA, (d) more than a year between

undergraduate school and entry into graduate school, (e) undergraduate research school,

(f) social work experience, (g) self-efficacy pretest total .

Table 50

Partial Correlations Between CCTST Posttest Analytic Scores and Predictor Variables Controlling for CCTST Analytic Pretest and Ethnicity

\begin{tabular}{|c|c|c|c|}
\hline Variable & $\begin{array}{l}\text { First Order } \\
\text { Correlation }\end{array}$ & $\begin{array}{l}\text { Partial Correlation } \\
\text { Controlling for } \\
\text { CCTST Analytic } \\
\text { Pretest }\end{array}$ & $\begin{array}{l}\text { Partial Correlation } \\
\text { Controlling for } \\
\text { CCTST Analytic } \\
\text { Pretest and White } \\
\text { Ethnicity }\end{array}$ \\
\hline $\begin{array}{l}\text { CCTST Analytic } \\
\text { Pretest }\end{array}$ & $.38^{*}$ & & \\
\hline $\begin{array}{l}\text { Length of time in } \\
\text { program at pretest }\end{array}$ & .03 & .04 & .12 \\
\hline Maleness & -.10 & -.12 & -.08 \\
\hline White Ethnicity & .11 & .06 & .05 \\
\hline Age at Pretest & $-.20^{*}$ & $-.20^{*}$ & \\
\hline Undergraduate GPA & .05 & .09 & .07 \\
\hline $\begin{array}{l}\text { More than a year } \\
\text { between } \\
\text { undergraduate and } \\
\text { entry into graduate }\end{array}$ & .01 & -.06 & .01 \\
\hline $\begin{array}{l}\text { Undergraduate } \\
\text { Research Institution }\end{array}$ & -.08 & -.08 & -.11 \\
\hline Pre SE Total & -11 & -.07 & -.04 \\
\hline $\begin{array}{l}\text { Social work } \\
\text { experience }\end{array}$ & .02 & -.01 & .02 \\
\hline Social Work major & -.13 & -.11 & -.14 \\
\hline Psychology major & .07 & .04 & .02 \\
\hline Sociology major & .06 & .06 & .08 \\
\hline Other helping major & -.01 & .03 & .04 \\
\hline
\end{tabular}

${ }^{*} \mathrm{p}<.05 ;{ }^{* *} \mathrm{p}<.1$

The initial hierarchical regression analysis was used to explore which of the remaining variables were the best predictors of CCTST posttest analytic scores and 
resulted in the elimination of all the dummy coded variables related to major. The final hierarchical regression analysis revealed the control variables entered in Block 1with the following variables: CCTST pretest analytic and length of time in program when pretest was administered, was a significant predictor of CCTST posttest analytic, $\left(R^{2}=.14, F(2\right.$, $177)=14.42, p=.000$ ). Block 2 , which included age at pretest, also significantly improved the model, $\left(\Delta R^{2}=.05, p=.000\right)$. The predictor model indicated younger students have higher CCTST posttest analytic scores. Age at pretest was the only variable in the model aside from the control variables. This model accounted for $19 \%$ of the variability in CCTST posttest analytic scores $\left(R^{2}=.19, F(3,177)=13.274, p=.000\right)$. Block 3 (generic variables) and Block 4 (discipline specific variables) did not contribute to the model. See Table 51 for a summary of the regression results.

\section{Table 51}

Hierarchical Regression Analysis of CCTST Posttest Analytic Scores (N=179)

\begin{tabular}{lccc}
\hline Variables & B & SE B & B \\
\hline Step 1 & & & \\
$\quad$ Control Variables: & & & \\
$\quad$ CCTST Pretest Analytic & 0.36 & 0.07 & $0.38^{*}$ \\
$\quad$ Length of Time in Program & 0.00 & 0.01 & 0.03 \\
Step 2 & & & \\
$\quad$ Control Variables: & & & \\
$\quad$ CCTST Pretest Analytic & 0.36 & 0.07 & $0.37^{*}$ \\
$\quad$ Length of Time in Program & 0.01 & 0.01 & 0.11 \\
$\quad \begin{array}{l}\text { Demographic Variables: } \\
\quad \text { Age at Pretest }\end{array}$ & -0.04 & 0.01 & $-0.23^{*}$ \\
& & & \\
\hline
\end{tabular}

Note: $R^{2}=0.14$ for Step $1 ; \Delta R^{2}=0.05$ for Step $2(p=0.00)$.

${ }^{*} p<0.05,{ }^{* *} p<.01$ 


\section{CCTST Posttest Evaluation Score Analysis}

Analysis of variance conducted on undergraduate majors and CCTST posttest evaluation scores found significant differences between groups $F(4,171)=2.58, p=.04$, $\mathrm{y}^{2}=.057$. The Tukey HSD post hoc test was ran to determine which major groups were different. The results indicated students with social work majors scored significantly lower on the CCTST evaluation posttest than students with a psychology major (mean difference $=-1.08$ ). Individual independent $t$ tests were conducted on CCTST posttest evaluation scores and gender, type of undergraduate, more than a year between undergraduate and entry into graduate school, and social work experience indicated no significant difference. However, independent $t$ tests on CCTST posttest evaluation scores and ethnicity $t(178)=-2.76, p=.01$ indicated significant differences. The initial analysis indicated the potentiality of eliminating the categorical variables where the different grouping did not show significant differences between the groups on the CCTST posttest evaluation scores; however, bivariate correlations on the dummy coded categorical variables as well as the other continuous variables were conducted to further investigate this decision making process.

Point biserial correlations were conducted on the binary dummy variables and Pearson product-moment correlations were conducted on all remaining variables in the posttest predictor model and are summarized in a correlation matrix in Table 52. There was a strong and significant positive correlation between CCTST posttest evaluation and CCTST pretest evaluation scores $r(175)=.60, p=.00$ and a weak and positive correlation between CCTST posttest evaluation scores and white ethnicity $r(178)=.20, p=.01$ and students having a psychology major $r(178)=.17, p=.02$. There was also a weak but 
significant negative correlation with students who had a social work major $r(178)=-.21$, $p=.01$. A trend was noted with length of time in program when pretest was administered $r(174)=.14, p=.07$. The correlations did not indicate evidence of multicollinearity between the independent variables. 
Table 52

Correlations Between CCTST Posttest Evaluation Score and Predictor Variables

\begin{tabular}{|c|c|c|c|c|c|c|c|c|c|c|c|c|c|c|c|}
\hline & 1 & 2 & 3 & 4 & 5 & 6 & 7 & 8 & 9 & 10 & 11 & 12 & 13 & 14 & 15 \\
\hline 1 & 1.00 & .02 & .07 & $.19^{*}$ & -.10 & .03 & .07 & .00 & .12 & -.05 & .04 & -.07 & -.08 & -.03 & $.60^{* *}$ \\
\hline 2 & & 1.00 & .01 & -.06 & $.37^{* *}$ & $-.26 * *$ & $.32^{* *}$ & .03 & .08 & $-.51^{* *}$ & $.19^{*}$ & .15 & $.16^{*}$ & $16^{*}$ & $.14^{* * *}$ \\
\hline 3 & & & 1.00 & .07 & $.19 *$ & -.03 & .07 & $-18^{*}$ & .04 & .01 & .01 & .03 & -.01 & .09 & .03 \\
\hline 4 & & & & 1.00 & -.08 & .07 & .03 & .12 & .14 & .05 & .02 & .01 & .0 .3 & .07 & $.20^{* * *}$ \\
\hline 5 & & & & & 1.00 & -.06 & $.30^{* *}$ & -.11 & $.16^{*}$ & -.12 & -.14 & .16 & .04 & .09 & -.08 \\
\hline 6 & & & & & & 1.00 & $-.24 * *$ & -.12 & .90 & $33 * *$ & -.14 & -.10 & -.07 & -.03 & .04 \\
\hline 7 & & & & & & & 1.00 & $-.27 * *$ & $.29 * *$ & -.08 & -.03 & -.07 & .04 & .10 & .09 \\
\hline 8 & & & & & & & & 1,00 & -.09 & $-.33^{* * *}$ & $.17^{*}$ & .09 & .13 & .02 & -.02 \\
\hline 9 & & & & & & & & & 1.00 & .11 & .03 & -.08 & 11 & $.21^{* * *}$ & .03 \\
\hline 10 & & & & & & & & & & 1.00 & $-48 * *$ & $-.27 * *$ & $-.15^{*}$ & .10 & $-.21 * *$ \\
\hline 11 & & & & & & & & & & & 1.00 & $-.24 * *$ & -.13 & .06 & $.17^{*}$ \\
\hline 12 & & & & & & & & & & & & 1.00 & -.07 & -.05 & .06 \\
\hline 13 & & & & & & & & & & & & & 1.00 & .07 & -.05 \\
\hline 14 & & & & & & & & & & & & & & 1.00 & -.05 \\
\hline 15 & & & & & & & & & & & & & & & 1.00 \\
\hline
\end{tabular}

\begin{tabular}{|r|l|r|l|}
\hline 1 & CCTST Pretest Total & 9 & Social Work Experience $^{59}$ \\
\hline 2 & Length of time in program & 10 & Social Work Major? \\
\hline 3 & Being male (female is reference category) & 11 & Psychology Major? $^{61}$ \\
\hline 4 & White ethnicity (Non-white is reference category) & 12 & Sociology Major? \\
\hline 5 & Age at Pretest & 13 & Other helping major? $^{63}$ \\
\hline 6 & Undergrad GPA & 14 & Pre SE Total \\
\hline 7 & $>$ a year between College \& Graduate School & \\
\hline 8 & Undergrad Research Institution & 15 & CCST Posttest Total \\
\hline
\end{tabular}

${ }^{*} p \leq 0.05 ;{ }^{* *} p \leq 0.01$

The researcher then conducted partial correlations controlling for the strongest correlations as noted in the correlation matrix in Table 52. The first partial correlation controlled for CCTST posttest evaluation and the second controlled for both CCTST posttest evaluation and social work major. See Table 53 for a summary of the results. In the first partial correlation, having a social work major $r(162)=-.22, p=.00$ continued as a weak significant negative correlation and having a psychology major $r(162)=.19$, $p=.02$ continued as a weak positive correlation. Length of time in the program when pretest was administered became a weak significant positive correlation $r(162)=.17$,

\footnotetext{
${ }^{59}$ No experience is reference category

${ }^{60}$ Non-helping other major is reference category

${ }^{61}$ Non-helping other major is reference category

62 Non-helping other major is reference category

${ }^{63}$ Non-helping other major is reference category

${ }^{64}$ Less than a year between undergraduate and entry into graduate school is the reference category

${ }^{65}$ Undergraduate Teaching Institution is reference category
} 
$p=.03$. Two variables demonstrated trends, White ethnicity $r(162)=.16, p=.05$ and having a sociology major $r(162)=.15, p=.05$. The second partial correlation resulted in only two trends, white ethnicity $r(161)=.17, p=.04$ and undergraduate research school $r(161)=-.14, p=.08$. As a result of these preliminary analyses, the following variables were eliminated from the posttest evaluation predictor model: (a) maleness, (b) age at pretest, (c) undergraduate GPA, (d) more than a year between undergraduate school and entry into graduate school, (e) undergraduate research school, (f) social work experience,

(g) self-efficacy pretest total.

\section{Table 53}

\section{Partial Correlations Between CCTST Posttest Evaluation Scores and Predictor Variables Controlling for CCTST Evaluation Pretest and Ethnicity}

\begin{tabular}{|l|l|l|l|}
\hline Variable & $\begin{array}{l}\text { First Order } \\
\text { Correlation }\end{array}$ & $\begin{array}{l}\text { Partial Correlation } \\
\text { Controlling for } \\
\text { CCTST Evaluation } \\
\text { Pretest }\end{array}$ & $\begin{array}{l}\text { Partial Correlation } \\
\text { Controlling for } \\
\text { CCTST Evaluation } \\
\text { Pretest and White } \\
\text { Ethnicity }\end{array}$ \\
\hline $\begin{array}{l}\text { CCTST Evaluation } \\
\text { Pretest }\end{array}$ & $.60^{*}$ & $.17^{*}$ & .07 \\
\hline $\begin{array}{l}\text { Length of time in } \\
\text { program at pretest }\end{array}$ & $.14^{* *}$ & -.03 & -.02 \\
\hline Maleness & .03 & $.16^{* *}$ & $.17^{* *}$ \\
\hline White Ethnicity & $.20^{* *}$ & -.04 & -.07 \\
\hline Age at Pretest & -.08 & .01 & .09 \\
\hline Undergraduate GPA & .03 & .06 & .05 \\
\hline $\begin{array}{l}\text { More than a year between } \\
\text { undergraduate and entry } \\
\text { into graduate }\end{array}$ & .09 & & $-.14^{* *}$ \\
\hline $\begin{array}{l}\text { Undergraduate Research } \\
\text { Institution }\end{array}$ & -.02 & -.05 & -.09 \\
\hline Pre SE Total & -.05 & -.11 & -.01 \\
\hline Social work experience & .03 & -.04 & .04 \\
\hline Social Work major & $-.21^{*}$ & $-.22^{*}$ & .09 \\
\hline Psychology major & $.17^{*}$ & $.19^{*}$ & -.04 \\
\hline Sociology major & .06 & $.15^{* *}$ & \\
\hline Other helping major & -.05 & -.11 & \\
\hline
\end{tabular}

${ }^{*} \mathrm{p}<.05 ; * * \mathrm{p}<.1$ 
The initial hierarchical regression analysis was used to explore which of the remaining variables were the best predictors of CCTST posttest evaluation scores and resulted in the elimination of all the dummy coded variables related to major. The final hierarchical regression analysis revealed the control variables entered in Block 1 with the following variables of CCTST pretest analytic and length of time in program when pretest was administered, was significant predictor of CCTST posttest analytic, $\left(R^{2}=.37\right.$, $F(2,177)=50.86, p=.00)$. Block 2 , which included White ethnicity, indicated a trend $\left(\Delta R^{2}=.01, p=.08\right)$. The predictor model indicated students of White ethnicity have higher CCTST posttest analytic scores. White ethnicity was the only predictor aside from the control variables. This model accounted for $38 \%$ of the variability in CCTST posttest evaluation scores $\left(R^{2}=.38, F(3,177)=35.33, p=.00\right)$. Block 3 (generic variables) and Block 4 (discipline specific variables) did not contribute to the model. See Table 54 for a summary of the regression results.

\section{Table 54}

Hierarchical Regression Analysis of CCTST Posttest Evaluation Scores (N=177)

\begin{tabular}{lccc}
\hline Variables & B & SE B & B \\
\hline Step 1 & & & \\
$\quad$ Control Variables: & & & \\
$\quad$ CCTST Pretest Analytic & 0.61 & 0.06 & $0.59^{*}$ \\
$\quad$ Length of Time in Program & 0.02 & 0.01 & $0.13^{* *}$ \\
Step 2 & & & \\
$\quad$ Control Variables: & & & \\
$\quad$ CCTST Pretest Analytic & 0.58 & 0.06 & $0.57^{*}$ \\
$\quad$ Length of Time in Program & 0.02 & 0.01 & $0.13^{* *}$ \\
$\quad \begin{array}{l}\text { Demographic Variables: } \\
\quad \text { White Ethnicity }\end{array}$ & 0.53 & 0.30 & $0.11^{\mathrm{a}}$ \\
& & & \\
\hline
\end{tabular}

Note: $R^{2}=0.37$ for Step $1 . R^{2}=0.01, p=.08$

${ }^{*} p<0.05,{ }^{* *} p<.01,{ }^{\mathrm{a}} p \leq .10$ 


\section{CCTST Posttest Deductive Score Analysis}

Analysis of variance was conducted on undergraduate majors and posttest CCTST deductive posttest scores with no significant differences between groups. Individual independent $t$ tests were conducted on CCTST posttest deductive scores and gender, type of undergraduate, more than a year between undergraduate and entry into graduate school, social work experience indicated no significant difference. However, independent $t$ tests on CCTST posttest deductive scores and ethnicity $t(178)=-3.38, p=.00$ indicated significant differences. Also note, in regards to the results for ethnicity, the Levene's test for equality of variance was significant at $F=7.1, p=.01$; therefore the equal variance not assumed portion of the independent $t$ test results was interpreted. The initial analysis indicated the potentiality of the categorical variables where the different groupings did not show significant differences between the groups on the CCTST posttest deductive; however, bivariate correlations on the dummy coded categorical variables as well as the other continuous variables were conducted to further investigate this decision making process.

Point biserial correlations were conducted on the binary dummy variables and Pearson product-moment correlations were conducted on all remaining variables in the posttest predictor model and are summarized in a correlation matrix in Table 55. There was a strong and significant positive correlation between CCTST posttest deductive and CCTST pretest deductive scores $r(175)=.63, p=.00$ and a weak and positive correlation between CCTST posttest deductive scores and White ethnicity $r(178)=.20, p=.01$ and having a psychology major $r(178)=.16, p=.04$. A weak negative correlation was noted with age at pretest $r(178)=-.18, p=.02$. A trend was noted in students in undergraduate 
GPA $r(174)=.13, p=.09$. The correlations did not indicate evidence of multicollinearity between the independent variables. 
Table 55

Correlations Between CCTST Posttest Deductive Score and Predictor Variables

\begin{tabular}{|c|c|c|c|c|c|c|c|c|c|c|c|c|c|c|c|}
\hline & 1 & 2 & 3 & 4 & 5 & 6 & 7 & 8 & 9 & 10 & 11 & 12 & 13 & 14 & 15 \\
\hline I & 1.00 & .00 & .10 & .07 & -.12 & .07 & .01 & -.11 & .03 & -.01 & .04 & -.05 & -.10 & -.06 & $63^{* *}$ \\
\hline 2 & & 1.00 & -.01 & -.06 & $.37 * *$ & $-.26^{* * *}$ & $.32 * *$ & .03 & .08 & $-.51 * *$ & $.19 *$ & $.15^{*}$ & $.16^{*}$ & $.16^{*}$ & -.00 \\
\hline 3 & & & 1.00 & .07 & $.19^{*}$ & -.03 & .07 & $-.18^{*}$ & .04 & .01 & .01 & .03 & -.01 & .09 & .08 \\
\hline 4 & & & & 1.00 & .08 & .07 & 03 & .12 & .14 & .05 & .02 & .01 & .03 & .07 & $.20^{* *}$ \\
\hline 5 & & & & & 1.00 & -.06 & $.30^{* *}$ & -.11 & $16^{*}$ & -.12 & -.14 & $.16^{*}$ & .04 & .09 & $-.18^{*}$ \\
\hline 6 & & & & & & 1.00 & $-.24 * *$ & -.12 & .90 & $33 * *$ & -.14 & -10 & -.07 & -.03 & $.13^{* * *}$ \\
\hline 7 & & & & & & & 1.00 & $-.27^{* *}$ & $.29^{* *}$ & -.08 & -.03 & -.07 & .04 & .10 & -.04 \\
\hline 8 & & & & & & & & 1.00 & .09 &.$- .33 * *$ & $.17^{*}$ & .09 & .13 & .02 & -.03 \\
\hline 9 & & & & & & & & & 1.00 & .11 & .03 & -.08 & .11 & $.21^{* *}$ & -.02 \\
\hline 10 & & & & & & & & & & 1.00 & $-.48 * *$ & $-.27^{* *}$ & $-.15^{*}$ & .10 & -.11 \\
\hline 11 & & & & & & & & & & & 1.00 & $-24^{* *}$ & -.13 & .06 & .16 \\
\hline 12 & & & & & & & & & & & & 1.00 & -.07 & -.05 & .01 \\
\hline 13 & & & & & & & & & & & & & 1.00 & .07 & -.07 \\
\hline 14 & & & & & & & & & & & & & & 1.00 & .00 \\
\hline 15 & & & & & & & & & & & & & & & 1.00 \\
\hline
\end{tabular}

\begin{tabular}{|c|c|c|c|}
\hline 1 & CCTST Pretest Total & & Social Work Experience ${ }^{66}$ \\
\hline 2 & Length of time in program & 10 & Social Work Major? ${ }^{67}$ \\
\hline 3 & Being male (female is reference category) & 11 & Psychology Major? $^{68}$ \\
\hline 4 & White ethnicity (Non-white is reference category) & 12 & Sociology Major? ${ }^{69}$ \\
\hline 5 & Age at Pretest & 13 & Other helping major? $^{70}$ \\
\hline 6 & Undergrad GPA & 14 & Pre SE Total \\
\hline 7 & $>$ a year between College \& Graduate School ${ }^{71}$ & 15 & CCST Posttest Deductive \\
\hline 8 & Undergrad Research Institution $^{7}$ & & \\
\hline
\end{tabular}

${ }^{*} p \leq 0.05 ;{ }^{* *} p \leq 0.01$

The researcher then conducted partial correlations controlling for the strongest correlations as noted in the correlation matrix in Table 55. The first partial correlation controlled for CCTST pretest deductive and the second controlled for both CCTST pretest deductive and ethnicity. See Table 56 for a summary of the results. In the first partial correlation, White ethnicity $r(162)=.19, p=.02$ continued as a weak positive correlation as did having a psychology major $r(162)=.20, p=.01$. Age at pretest $r(162)=$ $-.16, p=.04$ also continued as a weak significant negative correlation. A negative trend developed with having social work as a major $r(162)=-.14, p=.08$. In the second partial

\footnotetext{
${ }^{66}$ No experience is reference category

${ }^{67}$ Non-helping other major is reference category

68 Non-helping other major is reference category

${ }^{69}$ Non-helping other major is reference category

${ }^{70}$ Non-helping other major is reference category

${ }^{71}$ Less than a year between undergraduate and entry into graduate school is the reference category

${ }^{72}$ Undergraduate Teaching Institution is reference category
} 
correlation two trends continued, having a social work major $r(161)=-15, p=.06$ and age at pretest $r(161)=-15, p=.06$. Having a psychology major $r(161)=.19, p=.02$ also continued as a weak significant positive correlation. As a result of these preliminary analyses, the following variables were eliminated from the posttest deductive predictor model: (a) maleness, (b) undergraduate GPA, (c) more than a year between undergraduate school and entry into graduate school, (d) undergraduate research school, (e) social work experience, (f) self-efficacy pretest total .

\section{Table 56}

\section{Partial Correlations Between CCTST Posttest Deductive Scores and Predictor Variables Controlling for CCTST Deductive Pretest and Ethnicity}

\begin{tabular}{|l|l|l|l|}
\hline Variable & $\begin{array}{l}\text { First Order } \\
\text { Correlation }\end{array}$ & $\begin{array}{l}\text { Partial Correlation } \\
\text { Controlling for } \\
\text { CCTST Deductive } \\
\text { Pretest }\end{array}$ & $\begin{array}{l}\text { Partial Correlation } \\
\text { Controlling for } \\
\text { CCTST Deductive } \\
\text { Pretest and White } \\
\text { Ethnicity }\end{array}$ \\
\hline $\begin{array}{l}\text { CCTST Deductive } \\
\text { Pretest }\end{array}$ & $.63^{*}$ & & \\
\hline $\begin{array}{l}\text { Length of time in } \\
\text { program at pretest }\end{array}$ & -.00 & .00 & .01 \\
\hline Maleness & .08 & .04 & .02 \\
\hline White Ethnicity & $.20^{*}$ & $.19^{*}$ & $-.15^{* *}$ \\
\hline Age at Pretest & $-.18^{*}$ & $-.16^{*}$ & .11 \\
\hline Undergraduate GPA & $.13^{* *}$ & .12 & -.08 \\
\hline $\begin{array}{l}\text { More than a year } \\
\text { between } \\
\text { undergraduate and } \\
\text { entry into graduate }\end{array}$ & -.04 & -.06 & \\
\hline $\begin{array}{l}\text { Undergraduate } \\
\text { Research Institution }\end{array}$ & -.03 & & .00 \\
\hline Pre SE Total & .00 & .03 & .04 \\
\hline $\begin{array}{l}\text { Social work } \\
\text { experience }\end{array}$ & -.02 & .04 & -.09 \\
\hline Social Work major & -.11 & -.06 & $-.15^{* *}$ \\
\hline Psychology major & $.16^{*}$ & $-.14^{* *}$ & $.19^{*}$ \\
\hline Sociology major & .01 & $.20^{*}$ & .05 \\
\hline Other helping major & -.07 & .05 & -.03 \\
\hline
\end{tabular}

${ }^{*} \mathrm{p}<.05 ;{ }^{* *} \mathrm{p}<.1$ 
The initial hierarchical regression analysis was used to explore which of the remaining variables were the best predictors of CCTST posttest deductive scores and resulted in the elimination of all the dummy coded variables related to. The final hierarchical regression analysis revealed the control variables entered in Block 1with the variables CCTST pretest deductive and length of time in program when pretest was administered, was a significant predictor of CCTST posttest deductive, $\left(R^{2}=.39, F(2\right.$, $178)=55.84, p=.00$ ). Block 2 with the variables of White Ethnicity and Age at Pretest also significantly improved the model, $\left(\Delta R^{2}=.04, p=.00\right)$. The predictor model indicated younger students of White ethnicity have higher CCTST posttest deductive scores. White ethnicity was the strongest predictor and age at pretest was administered was the weakest predictor. Note the control variables were not included in the reporting of the strongest and weakest predictors. This model accounted for $43 \%$ of the variability in CCTST posttest deductive scores $\left(R^{2}=.43, F(4,178)=32.20, p=.00\right)$. Block 3 (generic variables) and Block 4 (discipline specific variables) did not contribute to the model. See Table 57 for a summary of the regression results. 
Hierarchical Regression Analysis of CCTST Posttest Deduction Scores (N=178)

\begin{tabular}{lccc}
\hline Variables & B & SE B & B \\
\hline Step 1 & & & \\
$\quad$ Control Variables: & & & \\
$\quad$ CCTST Pretest Deduction & 0.66 & 0.06 & $0.62^{*}$ \\
$\quad$ Length of Time in Program & 0.00 & 0.01 & 0.00 \\
Step 2 & & & \\
$\quad$ Control Variables: & & & \\
$\quad$ CCTST Pretest Deduction & 0.64 & 0.06 & $0.60^{*}$ \\
$\quad$ Length of Time in Program & 0.01 & 0.01 & 0.05 \\
Demographic Variables & & & \\
$\quad$ White Ethnicity & 1.10 & 0.40 & $0.16^{*}$ \\
$\quad$ Age at Pretest & -0.04 & 0.02 & $-0.11^{\mathrm{a}}$ \\
& & & \\
\hline
\end{tabular}

Note: $R^{2}=0.39$ for Step $1 ; \Delta R^{2}=0.04$ for Step $2(p=0.00)$.

${ }^{*} p<0.05,{ }^{* *} p<.01,{ }^{\mathrm{a}} p \leq .10$

\section{CCTST Posttest Inductive Score Analysis}

Analysis of variance was conducted on undergraduate majors and CCTST posttest inductive scores with no significant differences between groups. Individual independent $t$ tests were conducted on CCTST posttest inductive scores and gender, type of undergraduate and social work experience indicated no significant difference. However, an independent $t$ test on CCTST posttest inductive scores ethnicity $t(178)=-3.28, p=.00$ indicated significant differences. The initial analysis indicated the potentiality of eliminating the categorical variables where the different groupings did not show significant differences between the groups on the CCTST posttest inductive scores; however, bivariate correlations on the dummy coded categorical variables as well as the other continuous variables was conducted to further investigate this decision making process. 
Point biserial correlations were conducted on the binary dummy variables and Pearson product-moment correlations were conducted on all remaining variables in the posttest predictor model and are summarized in a correlation matrix in Table 58. There was a strong and significant positive correlation between CCTST posttest inductive and CCTST pretest inductive scores $r(175)=.65, p=.00$ and a weak and positive correlation between CCTST posttest inductive scores and White ethnicity $r(178)=.24, p=.00$. A weak negative correlation was noted with age at pretest $r(178)=-.15, p=.04$ and having a social work major $r(178)=-.18, p=.02$. A trend was noted with having a psychology major $r(174)=.13, p=.09$ and length of time in the program when pretest was administered $r(174)=.15, p=.05$. The correlations did not indicate evidence of multicollinearity between the independent variables. 
Table 58

Correlations Between CCTST Posttest Inductive Score and Predictor Variables

\begin{tabular}{|c|c|c|c|c|c|c|c|c|c|c|c|c|c|c|c|}
\hline & 1 & 2 & 3 & 4 & 5 & 6 & 7 & 8 & 9 & 10 & 11 & 12 & 13 & 14 & 1.5 \\
\hline 1 & 1.00 & -.01 & .03 & $.18^{*}$ & $-.15^{*}$ & .05 & 15 & -04 & 12 & -.08 & .08 & 02 & -.09 & -.05 & $65 * *$ \\
\hline 2 & & 1.00 & -.01 & -.06 & $.37 * *$ & $-.26^{* *}$ & $32^{* *}$ & .03 & .08 & $-.51 * *$ & $.19 *$ & $.15^{*}$ & $16^{*}$ & $16^{*}$ & .15 \\
\hline 3 & & & 1.00 & .07 & $19 *$ & -.03 & .07 & $-.18^{*}$ & .04 & .01 & .01 & .03 & -.01 & .09 & -.01 \\
\hline 4 & & & & 1.00 & .08 & .07 & .03 & .12 & 14 & .05 & .02 & .01 & .03 & .07 & $.24 * *$ \\
\hline 5 & & & & & 1.00 & -.06 & $.30^{* *}$ & -.11 & $.16^{*}$ & -.12 & -.14 & $.16^{*}$ & .04 & .09 & $-.15^{*}$ \\
\hline 6 & & & & & & 1,00 & $-.24^{* *}$ & -.12 & 90 & $.33^{* *}$ & -.14 & -.10 & -.07 & -.03 & .02 \\
\hline 7 & & & & & & & 1.00 & $-.27 * *$ & $.29 * *$ & -.08 & -.03 & -.07 & .04 & .10 & .10 \\
\hline 8 & & & & & & & & 1.00 & -.09 & $-.33 * *$ & $.17 *$ & .09 & 13 & .02 & -.01 \\
\hline 9 & & & & & & & & & 1.00 & .11 & .03 & .08 & .11 & $.21 * *$ & .02 \\
\hline 10 & & & & & & & & & & 1.00 & $-.48^{* *}$ & $-.27 * *$ & $-.15^{*}$ & .10 & -.18 \\
\hline 11 & & & & & & & & & & & 1.00 & $-.24^{* *}$ & -.13 & .06 & .13 \\
\hline 12 & & & & & & & & & & & & 1.00 & -.07 & -.05 & .04 \\
\hline 13 & & & & & & & & & & & & & 1.00 & .07 & -.02 \\
\hline 14 & & & & & & & & & & & & & & 1.00 &., 08 \\
\hline 15 & & & & & & & & & & & & & & & 1.00 \\
\hline
\end{tabular}

\begin{tabular}{|c|c|c|c|}
\hline 1 & CCTST Pretest Total & 9 & Social Work Experience $^{73}$ \\
\hline 2 & Length of time in program & 10 & Social Work Major? $^{74}$ \\
\hline 3 & Being male (female is reference category) & 11 & Psychology Major? $^{75}$ \\
\hline 4 & White ethnicity (Non-white is reference category) & 12 & Sociology Major? ${ }^{76}$ \\
\hline 5 & Age at Pretest & 13 & Other helping major? $^{77}$ \\
\hline 6 & Undergrad GPA & 14 & Pre SE Total \\
\hline 7 & $>$ a year between College \& Graduate School $^{78}$ & 15 & CCST Posttest Deductive \\
\hline 8 & Undergrad Research Institution ${ }^{79}$ & & \\
\hline
\end{tabular}

The researcher then conducted partial correlations controlling for the strongest correlations as noted in the correlation matrix in Table 58. The first partial correlation controlled for CCTST pretest deductive and the second controlled for both CCTST pretest deductive and ethnicity. See Table 59 for a summary of the results. In the first partial correlation, White ethnicity $r(162)=.17, p=.03$ continued as a weak positive correlation. Having a social work major continued as a weak negative correlation $r(162)$ $=-.17, p=.03$. Length of time in program when pretest was administered $r(162)=.21$, $p=.01$ transitioned into a weak significant positive correlation. In the second partial

\footnotetext{
73 No experience is reference category

74 Non-helping other major is reference category

75 Non-helping other major is reference category

76 Non-helping other major is reference category

77 Non-helping other major is reference category

78 Less than a year between undergraduate and entry into graduate school is the reference category

79 Undergraduate Teaching Institution is reference category
} 
correlation, having a social work major $r(161)=-18, p=.02$ continued as a weak negative correlation and length of time in the program when pretest was administered $r(161)=$ $.21, p=.01$ continued as a weak positive correlation. As a result of these preliminary analyses, the following variables were eliminated from the posttest inductive predictor model: (a) maleness, (b) undergraduate GPA, (c) more than a year between undergraduate school and entry into graduate school, (d) undergraduate research school, (e) social work experience, (f) self-efficacy pretest total.

\section{Table 59}

Partial Correlations Between CCTST Posttest Inductive Scores and Predictor Variables Controlling for CCTST Inductive Pretest and Ethnicity

\begin{tabular}{|l|l|l|l|}
\hline Variable & $\begin{array}{l}\text { First Order } \\
\text { Correlation }\end{array}$ & $\begin{array}{l}\text { Partial Correlation } \\
\text { Controlling for } \\
\text { CCTST Inductive } \\
\text { Pretest }\end{array}$ & $\begin{array}{l}\text { Partial Correlation } \\
\text { Controlling for } \\
\text { CCTST Inductive } \\
\text { Pretest and White } \\
\text { Ethnicity }\end{array}$ \\
\hline $\begin{array}{l}\text { CCTST Inductive } \\
\text { Pretest }\end{array}$ & $.65^{*}$ & $.21^{*}$ & $.21^{*}$ \\
\hline $\begin{array}{l}\text { Length of time in } \\
\text { program at pretest }\end{array}$ & $.15^{* *}$ & -.02 & -.03 \\
\hline Maleness & -.01 & $.17^{*}$ & $-.08^{*}$ \\
\hline White Ethnicity & $.24^{*}$ & $-.05^{*}$ & -.03 \\
\hline Age at Pretest & $-.15^{*}$ & -.02 & -.02 \\
\hline Undergraduate GPA & .02 & -.01 & \\
\hline $\begin{array}{l}\text { More than a year } \\
\text { between } \\
\text { undergraduate and } \\
\text { entry into graduate }\end{array}$ & .10 & & -.06 \\
\hline $\begin{array}{l}\text { Undergraduate } \\
\text { Research Institution }\end{array}$ & -.01 & -.04 & -.09 \\
\hline Pre SE Total & -.08 & -.08 & -.10 \\
\hline $\begin{array}{l}\text { Social work } \\
\text { experience }\end{array}$ & .02 & -.07 & $-.18^{*}$ \\
\hline Social Work major & $-.18^{*}$ & $-.17^{*}$ & .10 \\
\hline Psychology major & $.13^{* *}$ & .11 & .07 \\
\hline Sociology major & .04 & .06 & .04 \\
\hline Other helping major & -.02 & .04 & \\
\hline
\end{tabular}

${ }^{*} \mathrm{p}<.05 ;{ }^{* *} \mathrm{p}<.1$ 
The initial hierarchical regression analysis was used to explore which of the remaining variables were the best predictors of CCTST posttest inductive scores and resulted in the elimination of all the dummy coded variables related to major. The final hierarchical regression analysis revealed the control variables entered in Block 1with the following variables: CCTST pretest inductive and length of time in program when pretest was administered was a significant predictor of CCTST posttest inductive, $\left(R^{2}=.43, F(2\right.$, $178)=67.39, p=.000$ ). Block 2 , which included White Ethnicity and age at pretest, also significantly improved the model, $\left(\Delta R^{2}=.03, p=.01\right)$. The predictor model indicated younger White students have higher CCTST posttest inductive scores. White ethnicity was the strongest predictor and age at pretest was administered was the weakest predictor. Note the control variables were not included in the reporting of the strongest and weakest predictors. This model accounted for $46.4 \%$ of the variability in CCTST posttest inductive scores $\left(R^{2}=.46, F(4,178)=37.62, p=.00\right)$. Block 3 (generic variables) and Block 4 (discipline specific variables) did not contribute to the model. See Table 60 for a summary of the regression results. 
Table 60

Hierarchical Regression Analysis of CCTST Posttest Inductive Scores (N=179)

\begin{tabular}{lccc}
\hline Variables & B & SE B & B \\
\hline $\begin{array}{l}\text { Step 1 } \\
\quad \text { Control Variables: }\end{array}$ & & & \\
$\quad$ CCTST Pretest Inductive & 0.62 & 0.06 & $0.64^{*}$ \\
$\quad$ Length of Time in Program & 0.03 & 0.01 & $0.15^{*}$ \\
$\begin{array}{l}\text { Step 2 } \\
\quad \text { Control Variables: }\end{array}$ & & & \\
$\quad$ CCTST Pretest Inductive & 0.58 & 0.06 & $0.60^{*}$ \\
$\quad$ Length of Time in Program & 0.04 & 0.01 & $0.20^{*}$ \\
Demographic Variables: & & & \\
$\quad$ White Ethnicity & 0.82 & 0.35 & $0.13^{*}$ \\
$\quad$ Age at Pretest & -0.04 & 0.02 & $-0.12^{\mathrm{a}}$ \\
& & & \\
\hline
\end{tabular}

Note: $R^{2}=0.43$ for Step $1 ; \Delta R^{2}=0.03$ for Step $2(p=0.01)$.

${ }^{*} p<0.05,{ }^{* *} p<.01,{ }^{\mathrm{a}} p<.10$

\section{Summary}

To provide a summary of the hierarchical regression analyses for the posttest generic versus discipline specific models, the results were summarized in Table 61 . The table provides the total variance explained by each final model, all variables in the final model, the strongest predictor, as well as those predictors at trend level. Note the control variables were not identified by strength or weakness, but only as variables included in the final model.

\section{Table 61}

Posttest Model Summary of R Square Change and Significant Predictors for Generic versus Discipline Specific Model

\begin{tabular}{|l|l|l|l|l|l|l|}
\hline CCTST Posttest & Total & Analytic & Inference & Evaluation & Inductive & Deductive \\
\hline$\Delta R^{2}$ & 4 & 4.5 & 4 & 1.1 & 3.7 & 3 \\
\hline Pretest & .71 & .37 & .53 & .57 & .60 & .60 \\
\hline $\begin{array}{l}\text { Length of time in } \\
\text { program }\end{array}$ & .13 & .11 & .04 & .13 & .20 & .05 \\
\hline Age & -.11 & $-.23^{*}$ & & & $-.12^{* *}$ & $-.11^{* *}$ \\
\hline White Ethnicity & $.16^{*}$ & & $.20^{*}$ & $.11^{* *}$ & $.13^{*}$ & $.16^{*}$ \\
\hline
\end{tabular}

Note: ${ }^{*}$ Strongest predictor, ${ }^{* *}$ Trend 


\section{Research Question Four}

The following analysis addressed the last of the three proposed predictive models, in which acquired critical thinking skills were explored utilizing the prior to entry and while in program predictor blocks. In particular: Can acquired critical thinking skills (defined as total CCTST score, as well as scores on the subscales of inductive reasoning, deductive reasoning, analysis, evaluation and inference) of graduating MSSW students at the Kent School of Social Work be explained by the demographic variables of gender, race and age, the student characteristics at entry into the program of undergraduate GPA, months since undergraduate degree, years of social work related experience prior to entering program, undergraduate major, and type of undergraduate institution, and the student characteristics while in school of $30 \mathrm{vs.} 60 \mathrm{hr}$ student, graduate GPA, mean hours worked per week while in program, and critical thinking subscale of self-efficacy at posttest? Which of the mentioned predictor blocks explain acquired critical thinking skills the best? This posttest model was illustrated in Figure 6; however, the different variables used in each block for these models are summarized again in Table 62 to guide the discussion of the prediction analysis. In addition, the Not So Pure Posttest sample as illustrated in Table 5 was utilized to answer this question. 


\section{Table 62}

Summary of Posttest Predictor Prior to Entry and While in Program Blocks

\begin{tabular}{|c|c|}
\hline $\begin{array}{l}\text { Block } 1 \\
\text { Control }\end{array}$ & $\begin{array}{l}\text { CCTST Pretest (appropriate to specific model) } \\
\text { Length of time in program when pretest was administered }\end{array}$ \\
\hline $\begin{array}{l}\text { Block } 2 \\
\text { Demographic }\end{array}$ & $\begin{array}{l}\text { Gender (dummy coded as maleness) } \\
\text { Ethnicity (dummy coded as White Ethnicity) } \\
\text { Age }\end{array}$ \\
\hline $\begin{array}{l}\text { Block } 3 \\
\text { Prior to Entry }\end{array}$ & $\begin{array}{l}\text { Undergraduate GPA } \\
\text { Months between undergraduate degree and entry into } \\
\text { graduate program (dummy coded as More than a year } \\
\text { between undergrad and entry into graduate school) } \\
\text { Years of Social Work experience (dummy coded as Social } \\
\text { work experience } \\
\text { Undergraduate degree (dummy coded in Social Work major, } \\
\text { Psychology major, Sociology major and Other helping } \\
\text { majors) } \\
\text { Type of Undergraduate School }\end{array}$ \\
\hline $\begin{array}{l}\text { Block } 4 \\
\text { While in program }\end{array}$ & $\begin{array}{l}\text { Type of Program } \\
\text { Cumulative GPA } \\
\text { Mean hours worked per week while in program } \\
\text { Critical thinking subscale of a pretest self-efficacy scale }\end{array}$ \\
\hline
\end{tabular}

\section{Descriptives}

A total of 179 students were included in the posttest sample. This question utilized the same sample population as Question 3 and thus includes the same descriptive information. The only exception includes the exclusion of self-efficacy pretest total and the inclusion of additional model specific variables. See Table 63 for a summary. In regards to the type of program, $64.8 \%(\mathrm{~N}=116)$ are enrolled in the 60 hours program and $35.2 \%(\mathrm{~N}=63)$ were enrolled in the 30 hour program. The average cumulative graduate GPA was $3.70(\mathrm{SD}=.23)$ with a range of 3.03 to 4.0 . The mean hours worked per week while in the program was $30.59(\mathrm{SD}=11.90)$ with a range on 0 to 60 . Students mean response on the critical thinking subscale of Foundation Practice Self-Efficacy Scale was $67.15(\mathrm{SD}=16.76)$ out of a possible 100 points. 


\section{Table 63}

Descriptive Characteristics of the Not So Pure Posttest Sample

\begin{tabular}{|c|c|c|c|c|c|}
\hline Characteristic & $\mathbf{N}$ & $\%$ & $\bar{X}$ & SD & Range \\
\hline Age at pretest (years) & 179 & & 29.85 & 7.83 & $21.94-56.71$ \\
\hline Undergraduate GPA & 175 & & 3.26 & 0.41 & $2.05-4.0$ \\
\hline CCTST Pretest Total & 176 & & 17.32 & 4.41 & 6 to 28 \\
\hline CCTST Pretest Analytic & 176 & & 4.70 & 1.37 & 1 to 7 \\
\hline CCTST Pretest Inference & 176 & & 7.76 & 2.22 & 1 to 12 \\
\hline CCTST Pretest Evaluation & 176 & & 4.87 & 1.95 & 0 to 10 \\
\hline CCTST Pretest Inductive & 176 & & 10.09 & 2.58 & 3 to 16 \\
\hline CCTST Pretest Deductive & 176 & & 7.23 & 2.17 & 1 to 14 \\
\hline Length of Time in Program & 175 & & 9.94 & 13.39 & .00 to 59.99 \\
\hline Cumulative GPA & 177 & & 3.70 & .23 & 3.03 to 4.0 \\
\hline Mean Hours Worked & 119 & & 30.59 & 11.90 & 0 to 60 \\
\hline $\begin{array}{l}\text { Critical Thinking Subscale of } \\
\text { Self-Efficacy }\end{array}$ & 175 & & 67.15 & 16.76 & $10-100$ \\
\hline \multicolumn{6}{|l|}{ Ethnic Group } \\
\hline Non White & 36 & 20.1 & & & \\
\hline White & 143 & 79.9 & & & \\
\hline \multicolumn{6}{|l|}{ Type of Program } \\
\hline 60 Hour & 116 & 64.8 & & & \\
\hline 30 Hour & 63 & 35.2 & & & \\
\hline \multicolumn{6}{|l|}{ Gender } \\
\hline Female & 150 & 83.8 & & & \\
\hline Male & 29 & 16.2 & & & \\
\hline \multicolumn{6}{|l|}{ Undergraduate College } \\
\hline Research & 72 & 40.2 & & & \\
\hline Teaching & 105 & 58.7 & & & \\
\hline Missing & 2 & 1.1 & & & \\
\hline \multicolumn{6}{|l|}{$\begin{array}{l}\text { Time between undergrad. } \\
\text { and graduate school }\end{array}$} \\
\hline More than a year & 85 & 47.5 & & & \\
\hline Less than a year & 94 & 52.5 & & & \\
\hline \multicolumn{6}{|l|}{ Social Work Experience } \\
\hline No Experience & 75 & 41.9 & & & \\
\hline Experience & 104 & 58.1 & & & \\
\hline \multicolumn{6}{|l|}{ Undergraduate Degree } \\
\hline Social Work & 64 & 35.8 & & & \\
\hline Psychology & 53 & 29.6 & & & \\
\hline Sociology & 21 & 11.7 & & & \\
\hline Other Helping & 7 & 3.9 & & & \\
\hline Non Helping & 32 & 17.9 & & & \\
\hline
\end{tabular}

${ }^{\mathrm{a}}$ Due to rounding, not all categories equal $100 \%$. 


\section{Dependent Variable}

Students' CCTST posttest scores as described in Question 3 continue as the dependent variables in Question 4. This information is summarized in Table 42.

\section{Posttest CCTST Total Score Analysis}

Analysis of variance was conducted on undergraduate majors and posttest CCTST total posttest scores with no significant differences between groups. An independent $t$ test was conducted on posttest CCTST total scores and gender, type of undergraduate school, more than a year between undergraduate and entry into graduate school and social work experience with no significant differences found. Additionally, an independent t tests were conducted on ethnicity $t(178)=-4.17, p=.00$ and type of program $t(178)=2.19$, $p=.03$ indicating significant differences. Also note, in regards to the results for ethnicity, the Levene's test for equality of variance was significant at $F=5.40, p=.02$; therefore the equal variance not assumed portion of the independent $t$ test results was interpreted. The initial analysis indicated the potentiality of eliminating the categorical variables where the different groupings did not show significant differences between the groups the on CCTST posttest total scores; however, bivariate correlations on the dummy coded categorical variables as well as the other continuous variables were conducted to further investigate this decision making process.

Point biserial correlations were conducted on the binary dummy variables and Pearson product-moment correlations were conducted on all remaining variables in the posttest predictor model and are summarized in a correlation matrix in Table 64. There was a strong and significant positive correlation between CCTST posttest total and CCTST pretest total scores $r(175)=.76, p=.00$ and a moderate and positive correlation 
between CCTST posttest total scores and cumulative GPA $r(176)=.28, p=.00$ and White ethnicity $r(178)=.26, p=.00$. In addition, a weak but significant positive correlation was noted those students having a psychology major $r(178)=.17, p=.03$ and a weak but significant negative correlation with those students having a social work major $r(178)=$ $.17, p=.03,60$ hour program $r(178)=-.16, p=.03$ and age at pretest $r(178)=-.17, p=.03$. There was a strong significant positive correlation between social work major and type of program $r(179)=.94, p=.00$, indicating evidence of multicollinearity between the two independent variables. As a result of this finding, the binary major variables and type of program will not be used simultaneously in any of the final regressions for the prior to entry and while in program models. 


\section{Table 64}

\section{Correlations Between CCTST Posttest Total Score and Predictor Variables}

\begin{tabular}{|c|c|c|c|c|c|c|c|c|c|c|c|c|c|c|c|c|c|c|}
\hline & 1 & 2 & 3 & 4 & 5 & 6 & 7 & 8 & 9 & 10 & 11 & 12 & 13 & 14 & 15 & 16 & 17 & 18 \\
\hline 1 & 1.00 & -.01 & .03 & $.18^{*}$ & $.15^{*}$ & .05 & 15 & .04 & 12 & -.08 & .08 & .02 & .09 & -.05 & $65^{* *}$ & -11 & .02 & $.76^{* *}$ \\
\hline 2 & & 1.00 & .01 & -.06 & $.37 * *$ & $-.26^{* *}$ & $.32^{* *}$ & .03 & .08 & $-.51^{* *}$ & $19 *$ & $.15^{*}$ & $.16^{*}$ & $.16^{*}$ & 15 & $.20^{*}$ & $.29 * *$ & .08 \\
\hline 3 & & & 1.00 & .07 & $.19 *$ & -.03 & .07 & $-.18^{*}$ & .04 & -.01 & .01 & .03 & -.01 & .09 & -.01 & -.04 & .88 & .04 \\
\hline 4 & & & & 1.00 & -.08 & .07 & 0.3 & .12 & .14 & .05 & .02 & .01 & .0 .3 & .07 & $.24^{* *}$ & -.12 & 08 & $.26^{* * *}$ \\
\hline 5 & & & & & 1.00 & -.06 & $.30^{* *}$ & -.11 & $.16^{*}$ & -.12 & -14 & $.16^{*}$ & .04 & .09 & $-.15^{*}$ & .02 & $16^{*}$ & $-19 * *$ \\
\hline 6 & & & & & & 1.00 & $-.24^{* *}$ & -.12 & 90 & $33^{* *}$ & .14 & -.10 & -.07 & -.03 & .02 & -.07 & -.02 & 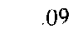 \\
\hline 7 & & & & & & & 1.00 & $-.27^{* *}$ & $29 * *$ & .08 & .03 & -.07 & .04 & .10 & .10 & .17 & .10 & .03 \\
\hline 8 & & & & & & & & 1.00 & -.09 & $-33^{* *}$ & $.17^{*}$ & .09 & .13 & .02 & -.01 & -.15 & -.01 & -.03 \\
\hline 9 & & & & & & & & & 1.00 & .11 & .03 & -.08 & .11 & $21 * *$ & .02 & $.28 * *$ & $16^{*}$ & .00 \\
\hline 10 & & & & & & & & & & 1.00 & $-48 * *$ & $-.27^{* *}$ & $15 *$ & .10 & -.18 & .09 & -.03 & $.17^{*}$ \\
\hline 11 & & & & & & & & & & & 1.00 & $-24^{* *}$ & -.13 & .06 & 13 & .00 & .12 & $.17 *$ \\
\hline 12 & & & & & & & & & & & & 1.00 & -.07 & -.05 & .04 & -.19 & -.05 & .03 \\
\hline 13 & & & & & & & & & & & & & 1.00 & .07 & -.02 & .07 & .07 & .06 \\
\hline 14 & & & & & & & & & & & & & & 1.00 & -.08 & .08 & .04 & -.16 \\
\hline 15 & & & & & & & & & & & & & & & 1.00 & -.11 & .00 & $28 * *$ \\
\hline 16 & & & & & & & & & & & & & & & & 1.00 & $.21^{*}$ & -.07 \\
\hline 17 & & & & & & & & & & & & & & & & & 1.00 & -.02 \\
\hline 18 & & & & & & & & & & & & & & & & & & 1.00 \\
\hline
\end{tabular}

\begin{tabular}{|c|c|c|}
\hline 1 & CCTST Pretest Total & 10 Social Work Major? $^{80}$ \\
\hline 2 & Length of time in program & 11 Psychology Major? ${ }^{81}$ \\
\hline 3 & Being male (female is reference category) & 12 Sociology Major? $^{82}$ \\
\hline 4 & White ethnicity (Non-white is reference category) & 13 Other helping major? ${ }^{83}$ \\
\hline 5 & Age at Pretest & 14 Type of program ${ }^{84}$ \\
\hline 6 & Undergrad GPA & 15 Cumulative GPA \\
\hline 7 & $>$ a year between College \& Graduate School ${ }^{85}$ & 16 Employment Hours \\
\hline 8 & Undergrad Research Institution ${ }^{86}$ & 17 CT Subscale \\
\hline 9 & Social Work Experience ${ }^{87}$ & \begin{tabular}{l|l}
18 & CCST Posttest Total \\
\end{tabular} \\
\hline
\end{tabular}

${ }^{*} p \leq 0.05 ;{ }^{* *} p \leq 0.01$

The researcher then conducted partial correlations controlling for the strongest correlations as noted in the correlation matrix in Table 64 . The first partial correlation controlled for CCTST pretest total and the second controlled for both CCTST pretest total and cumulative GPA. See Table 65 for a summary of the results. In the first partial correlation the significant moderate positive correlations of cumulative GPA became insignificant and of White ethnicity continued $r(111)=.28, p=.00$. The significant weak

\footnotetext{
${ }^{80}$ Non-helping other major is reference category

${ }^{81}$ Non-helping other major is reference category

${ }^{82}$ Non-helping other major is reference category

${ }^{8.3}$ Non-helping other major is reference category

${ }^{84} 60$-hour program is reference group

${ }^{85}$ Less than a year between undergraduate and entry into graduate school is the reference category

${ }^{86}$ Undergraduate Teaching Institution is reference category

${ }^{87}$ No experience is reference category
} 
negative correlations of having a social work major $r(111)=-.22, p=.02$ and 60 hour program type of program continued $r(111)=-.23, p=.01$ continued as did the weak positive correlation of having a psychology major $r(111)=.19, p=.04$ continued. A trend developed in the correlation between CCTST posttest total scores and social work experience $r(111)=-.16, p=.10$. The second partial correlation indicated a continued statistically significant moderate correlation with White ethnicity $r(110)=.28, p=.01$. The weak negative correlations of having a social work major $r(110)=-.21, p=.03$ and 60 hour program $r(110)=-.22, p=.02$ and the weak positive correlation of having a psychology major $r(110)=.18, \mathrm{p}=.06$ transitioned to a trend. The trend in no social work experience $r(110)=-.16, \mathrm{p}=.09$ continued and a new trend developed in less than a year between undergraduate and entry into graduate school $r(110)=-.18, \mathrm{p}=.07$. As a result of these preliminary analyses, the following variables were eliminated from the posttest total predictor model: (a) maleness, (b) undergraduate GPA, (c) undergraduate research school, (d) mean hours worked at posttest, and (e)critical thinking subscale of selfefficacy pretest total. 


\section{Table 65}

Partial Correlations Between CCTST Posttest Total Scores and Predictor Variables Controlling for CCTST Total Pretest and Cumulative GPA

\begin{tabular}{|c|c|c|c|}
\hline Variable & $\begin{array}{l}\text { First Order } \\
\text { Correlation }\end{array}$ & $\begin{array}{l}\text { Partial Correlation } \\
\text { Controlling for } \\
\text { CCTST Total } \\
\text { Pretest }\end{array}$ & $\begin{array}{l}\text { Partial Correlation } \\
\text { Controlling for } \\
\text { CCTST Total } \\
\text { Pretest and } \\
\text { Cumulative }\end{array}$ \\
\hline $\begin{array}{l}\text { CCTST Total } \\
\text { Pretest }\end{array}$ & $.76^{*}$ & & \\
\hline $\begin{array}{l}\text { Length of time in } \\
\text { program at pretest }\end{array}$ & .08 & .11 & .10 \\
\hline Maleness & .04 & .04 & .05 \\
\hline White Ethnicity & $.26^{*}$ & $.28^{*}$ & $.28^{*}$ \\
\hline Age at Pretest & $-.20^{*}$ & -.11 & -.12 \\
\hline Undergraduate GPA & .09 & .06 & .04 \\
\hline $\begin{array}{l}\text { More than a year } \\
\text { between } \\
\text { undergraduate and } \\
\text { entry into graduate }\end{array}$ & .03 & -.15 & $-.18 * *$ \\
\hline $\begin{array}{l}\text { Undergraduate } \\
\text { Research Insti. }\end{array}$ & -.03 & .04 & .04 \\
\hline $\begin{array}{l}\text { Social Work } \\
\text { Experience }\end{array}$ & -.00 & -.16 & $-.16 * *$ \\
\hline Social Work major & $-.17 *$ & $-.22 *$ & $-.21 *$ \\
\hline Psychology major & $.17^{*}$ & $.19^{* *}$ & $.18^{* *}$ \\
\hline Sociology major & .03 & .06 & .06 \\
\hline Other helping major & -.06 & -.02 & -.01 \\
\hline $\begin{array}{l}\text { Type of program } \\
\text { enrolled }\end{array}$ & $-.16^{*}$ & $-.23^{*}$ & $-.23^{*}$ \\
\hline Cumulative GPA & $.28^{*}$ & .06 & \\
\hline $\begin{array}{l}\text { Mean hours worked } \\
\text { at posttest }\end{array}$ & -.07 & .02 & .02 \\
\hline $\begin{array}{l}\text { Critical thinking of } \\
\text { subscale of self- } \\
\text { efficacy pretest }\end{array}$ & -.02 & .04 & .04 \\
\hline
\end{tabular}

${ }^{*} \mathrm{p}<.05 ;{ }^{* *} \mathrm{p}<.1$

The initial hierarchical regression analysis was used to explore which of the remaining variables were the best predictors of CCTST posttest total scores and resulted in retaining four variables from the original model. The final hierarchical regression 
analysis revealed the control variables entered in Block 1with the following variables:

CCTST pretest total and length of time in program when pretest was administered, was a significant predictor of CCTST posttest totals, $\left(R^{2}=.57, F(2,178)=116.92, p=.00\right)$.

Block 2, which included White ethnicity and age at pretest, also significantly improved the model, $\left(\Delta R^{2}=.04, p=.00\right)$. The predictor model indicated younger Whites have higher CCTST posttest scores. White ethnicity was the strongest predictor and age at pretest was the weakest predictor. Note the control variables were not included in the reporting of the strongest and weakest predictors. This model accounted for $61 \%$ of the variability in CCTST posttest scores $\left(R^{2}=.61, F(4,178)=67.04, p=.00\right)$. Block 3 (prior to entry) and Block 4 (while in program) did not contribute to the model. See Table 66 for a summary of the regression results.

Table 66

Hierarchical Regression Analysis of CCTST Posttest Total Scores ( $N=179)$

\begin{tabular}{lccc}
\hline Variables & B & SE B & $\boldsymbol{\beta}$ \\
\hline Step 1 & & & \\
$\quad$ Control Variables: & & & \\
$\quad$ CCTST Pretest Total & 0.76 & 0.50 & $0.75^{* *}$ \\
$\quad$ Length of Time in Program & 0.03 & 0.02 & 0.08 \\
Step 2 & & & \\
$\quad$ Control Variables: & & & \\
$\quad$ CCTST Pretest Total & 0.72 & 0.50 & $0.71^{* *}$ \\
$\quad$ Length of Time in Program & 0.05 & 0.02 & $0.13^{* *}$ \\
$\quad$ Demographic Variables: & & & \\
$\quad$ White Ethnicity & 1.71 & 0.53 & $0.15^{* *}$ \\
$\quad$ Age at pretest & -0.06 & 0.03 & $-0.11^{*}$ \\
& & & \\
\hline
\end{tabular}

Note: $R^{2}=0.57$ for Step $1 ; \Delta R^{2}=0.04$ for Step $2(p=0.00) .{ }^{*} p<0.05,{ }^{*} p<.01$ 


\section{Posttest CCTST Inference Score Analysis}

Analysis of variance was conducted on undergraduate majors and pretest CCTST inference scores with no significant differences between groups. Individual independent $t$ tests were conducted on CCTST pretest inference scores and gender, type of undergraduate school, more than a year between undergraduate and entry into graduate school, social work experience indicated no significant difference. However, independent $t$ test on CCTST pretest inference scores and ethnicity $t(178)=-3.92, p=.00$ indicated significant differences. Note Levene's Test for Equality of Variance was significant $(\mathrm{F}=9.03, p=.00)$; therefore the equal variances not assumed portion of the analysis was reported. The initial analysis indicated the potentiality of eliminating the categorical variables where the different grouping did not have significant differences between the groups on CCTST pretest inference scores; however, additional evaluative analysis was conducted to further investigate this decision making process

Point biserial correlations were conducted on the binary dummy variables and Pearson product-moment correlations were conducted on all remaining variables in the posttest predictor model and are summarized in a correlation matrix in Table 67. There was a strong and significant positive correlation between CCTST posttest inference and CCTST pretest inference scores $r(175)=.56, p=.00$. A weak and positive correlation was noted as well between CCTST posttest inference scores and White ethnicity $r(178)=$ $.25, p=.00$, as well as cumulative GPA $r(176)=.23, p=.00$. In addition, a weak but significant negative correlation was noted with age at pretest $r(178)=-.18, p=.02$. A trend was noted with students with a psychology major $r(178)=.13, p=.10$. The correlations did not indicate any further evidence of multicollinearity between the 
independent variables, aside from the previous correlation noted between social work

major and type of program.

Table 67

Partial Correlations Between CCTST Posttest Total Score and Predictor Variables

Controlling for CCST Total Pretest and Cumulative GPA

\begin{tabular}{|c|c|c|c|c|c|c|c|c|c|c|c|c|c|c|c|c|c|c|}
\hline & 1 & 2 & 3 & 4 & 5 & 6 & 7 & 8 & 9 & 10 & 11 & 12 & 13 & 14 & 15 & 16 & 17 & 18 \\
\hline 1 & 1.00 & -.02 & .06 & .20 & $-20^{*}$ & 13 & .06 & -.08 & .00 & -.03 & .05 & .02 & -.10 & -.06 & $.36^{* *}$ & -.12 & -.04 & $56^{* * *}$ \\
\hline 2 & & 1.00 & -.01 & -.06 & $.37^{* *}$ & $-26 * *$ & $.32^{* * *}$ & .03 & .08 & $-.51^{* *}$ & $.19^{*}$ & .15 & $.16^{*}$ & $.52 * *$ & .12 & $.20 *$ & $.29 * *$ & .02 \\
\hline 3 & & & 1.00 & .07 & $.19 *$ & -.03 & .07 & $18^{*}$ & .04 & -.01 & .01 & .03 & -.01 & -.01 & .08 & -.04 & .08 & 10 \\
\hline 4 & & & & 1.00 & -.08 & .07 & .03 & .12 & .14 & .05 & .02 & .10 & .03 & .02 & .14 & -.12 & .08 & $.25 * *$ \\
\hline 5 & & & & & 1.00 & -.06 & $.30^{* *}$ & -.09 & .14 & -.14 & -.12 & $.16^{*}$ & .04 & -.08 & .01 & .02 & $.16^{*}$ & $-.18 *$ \\
\hline 6 & & & & & & 1.00 & $-.24^{* *}$ & -.12 & .09 & $.33^{* *}$ & -.14 & -10 & -.07 & $32^{* *}$ & $27^{* *}$ & -.07 & -.02 & .11 \\
\hline 7 & & & & & & & 1.00 & $-27^{* *}$ & $29 * *$ & -.08 & -.03 & -.07 & .04 & -.07 & $20^{* *}$ & .17 & 10 & .03 \\
\hline 8 & & & & & & & & 1.00 & .09 & $-.33^{* *}$ & .18 & .09 & .13 & -.32 & .10 & -.15 & .01 & .01 \\
\hline 9 & & & & & & & & & 1.00 & .11 & .03 & -.07 & .11 & $.15^{*}$ & .03 & $.28 * *$ & $.16^{*}$ & -.04 \\
\hline 10 & & & & & & & & & & 1.00 & $-48^{* *}$ & $-.27^{* *}$ & $-.15^{*}$ & .94 & $-25^{* *}$ & .09 & -.03 & -.06 \\
\hline 11 & & & & & & & & & & & 1.00 & $-.24^{* *}$ & -.13 & -.48 & .03 & .00 & .12 & $.13^{* * *}$ \\
\hline 12 & & & & & & & & & & & & 1.00 & -.07 & -.23 & .08 & -.19 & -.05 & -.02 \\
\hline 13 & & & & & & & & & & & & & 1.00 & -09 & -.01 & .07 & .07 & .06 \\
\hline 14 & & & & & & & & & & & & & & 1.00 & $-.26^{* *}$ & .08 & .04 & -.10 \\
\hline 15 & & & & & & & & & & & & & & & 1.00 & -.11 & .00 & $.23^{* *}$ \\
\hline 16 & & & & & & & & & & & & & & & & 1.00 & $.21^{*}$ & -.05 \\
\hline 17 & & & & & & & & & & & & & & & & & 1.00 & .01 \\
\hline 18 & & & & & & & & & & & & & & & & & & 1.00 \\
\hline
\end{tabular}

\begin{tabular}{|c|c|c|c|}
\hline 1 & CCTST Pre Inference & 10 & Social Work major ${ }^{88}$ \\
\hline 2 & Length of time & 11 & Psychology major ${ }^{89}$ \\
\hline 3 & Maleness (Female is reference category) & 12 & Sociology major ${ }^{20}$ \\
\hline 4 & White Ethnicity (Non-white is reference category) & 13 & Other helping major $^{91}$ \\
\hline 5 & Age at Pretest & 14 & Type of Program ${ }^{92}$ \\
\hline 6 & Undergrad GPA & 15 & Cumulative GPA \\
\hline 7 & $>$ A Year Between Undergrad and Grad School ${ }^{93}$ & 16 & Employment Hours \\
\hline 8 & Undergrad Research Institution. ${ }^{94}$ & 17 & CT Subscale \\
\hline 9 & SW Experience ${ }^{95}$ & 18 & CCTST Post Inference \\
\hline
\end{tabular}

${ }^{*} p \leq 0.05 ;{ }^{*} p \leq 0.01$

The researcher then conducted partial correlations controlling for the strongest

correlations as noted in the correlation matrix in Table 67. The first partial correlation controlled for CCTST pretest inference and the second controlled for both CCTST pretest

\footnotetext{
88 Non-helping other majors is reference category

89 Non-helping other majors is reference category

90 Non-helping other majors is reference category

91 Non-helping other majors is reference category

9260 hour program is reference category

93 Less than a year between undergraduate and entry into graduate school is the reference category

94 Undergraduate Teaching Institution is reference category

95 No experience is reference category
} 
inference and ethnicity. See Table 68 for a summary of the results. In the first partial correlation there was only one statistically significant correlation, as White ethnicity continued as a weak positive correlation $r(162)=.22, p=.02$. In the second partial correlation there were no statistically significant or trend correlations. As a result of these preliminary analyses, the following variables were eliminated from the posttest inference predictor model: (a) maleness, (b) undergraduate GPA, (c) more than a year between undergraduate school and entry into graduate school, (d) undergraduate research school, (e) social work experience, (f) 60 hour program, (g) mean hours worked at posttest, (h) critical thinking subscale of self-efficacy pretest total 


\section{Table 68}

Partial Correlations Between CCTST Posttest Inference Scores and Predictor Variables Controlling for CCTST Inference Pretest and Ethnicity

\begin{tabular}{|c|c|c|c|}
\hline Variable & $\begin{array}{l}\text { First Order } \\
\text { Correlation }\end{array}$ & $\begin{array}{l}\text { Partial Correlation } \\
\text { Controlling for } \\
\text { CCTST Inference } \\
\text { Pretest }\end{array}$ & $\begin{array}{l}\text { Partial Correlation } \\
\text { Controlling for } \\
\text { CCTST Inference } \\
\text { Pretest and White } \\
\text { Ethnicity }\end{array}$ \\
\hline $\begin{array}{l}\text { CCTST Inference } \\
\text { Pretest }\end{array}$ & $.56^{*}$ & & \\
\hline $\begin{array}{l}\text { Length of time in } \\
\text { program at pretest }\end{array}$ & .02 & .03 & .03 \\
\hline Maleness & .10 & .10 & .09 \\
\hline White Ethnicity & $.25 *$ & $.22 *$ & \\
\hline Age at Pretest & $-.18^{*}$ & -.08 & -.07 \\
\hline Undergraduate GPA & .11 & -.01 & -.02 \\
\hline $\begin{array}{l}\text { More than a year } \\
\text { between } \\
\text { undergraduate and } \\
\text { entry into graduate }\end{array}$ & -.02 & -.13 & -.15 \\
\hline $\begin{array}{l}\text { Undergraduate } \\
\text { Research Institution }\end{array}$ & .01 & .08 & .06 \\
\hline $\begin{array}{l}\text { Social work } \\
\text { experience }\end{array}$ & -.04 & -.09 & -.09 \\
\hline Social Work major & -.06 & -.10 & -.12 \\
\hline Psychology major & $.13^{*}$ & .11 & .10 \\
\hline Sociology major & -.02 & .03 & .02 \\
\hline Other helping major & -.06 & .07 & .08 \\
\hline 60 Hour Program & -.09 & -.09 & -.10 \\
\hline Cumulative GPA & $.23 * *$ & .06 & .05 \\
\hline $\begin{array}{l}\text { Mean hours worked } \\
\text { at pretest }\end{array}$ & -.05 & .01 & .03 \\
\hline $\begin{array}{l}\text { Critical Thinking } \\
\text { subscale of self- } \\
\text { efficacy scale }\end{array}$ & .01 & .14 & .14 \\
\hline
\end{tabular}

${ }^{*} \mathrm{p}<.05 ; * * \mathrm{p}<.10$

The initial hierarchical regression analysis was used to explore which of the remaining variables were the best predictors of CCTST posttest inference scores and resulted in retaining three variables from the original model. The final hierarchical 
regression analysis revealed the control variables entered in Block 1with the following variables: CCTST pretest inference and length of time in program when pretest was administered was a significant predictor of CCTST posttest inference, $\left(R^{2}=.30, F(2\right.$, $177)=38.17, p=.00)$. Block 2 , which included White ethnicity, also significantly improved the model, $\left(\Delta R^{2}=.04, p=.00\right)$. The predictor model indicated students with White ethnicity have higher CCTST posttest inference scores. White ethnicity was the only variable remaining in the final model, aside from the control variables. This model accounted for $34.3 \%$ of the variability in CCTST posttest inference scores $\left(R^{2}=.34, F(3\right.$, $177)=30.26, p=.00$ ). Block 3 (prior to entry) and Block 4 (while in program) did not contribute to the model. See Table 69 for a summary of the regression results.

\section{Table 69}

Hierarchical Regression Analysis of CCTST Posttest Inference Scores (N=179)

\begin{tabular}{lccc}
\hline Variables & B & SE B & B \\
\hline Step 1 & & & \\
$\quad$ Control Variables: & & & \\
$\quad$ CCTST Pretest Inference & 0.62 & 0.07 & $0.55^{*}$ \\
$\quad$ Length of Time in Program & 0.01 & 0.01 & 0.03 \\
Step 2 & & & \\
$\quad$ Control Variables: & & & \\
$\quad$ CCTST Pretest Inference & 0.60 & 0.07 & $0.53^{*}$ \\
$\quad$ Length of Time in Program & 0.01 & 0.01 & 0.04 \\
$\quad \begin{array}{l}\text { Demographic Variables: } \\
\quad \text { White Ethnicity }\end{array}$ & 1.23 & 0.38 & $0.20^{*}$ \\
& & & \\
\hline
\end{tabular}

Note: $R^{2}=0.30$ for Step $1 ; \Delta R^{2}=0.04$ for Step $2(p=0.00)$. ${ }^{*} p<0.05,{ }^{* *} p<.01$

\section{Posttest CCTST Analytic Analysis Results}

Analysis of variance was conducted on undergraduate majors and posttest CCTST analytic scores with no significant differences between groups. Individual independent $t$ 
tests conducted on CCTST posttest analytic scores and gender, ethnicity, type of undergraduate, more than a year between undergraduate and entry into graduate school, social work experience and type of program and no indicated no significant difference. Bivariate correlations on the dummy coded categorical variables as well as the other continuous variables were conducted to further investigate this decision making process.

Point biserial correlations were conducted on the binary dummy variables and Pearson product-moment correlations were conducted on all remaining variables in the posttest predictor model and are summarized in a correlation matrix in Table 70. There was a strong and significant positive correlation between CCTST posttest analytic and CCTST pretest analytic scores $r(175)=.38, p=.00$ and a weak and negative correlation between CCTST posttest analytic scores and age at pretest $r(178)=-.20, p=.01$. A weak positive correlation was noted with cumulative GPA $r(176)=.15, p=.04$. A trend was noted in students with a social work major $r(178)=-.13, p=.09$. The correlations did not indicate any further evidence of multicollinearity between the independent variables, aside from the previous correlation noted between social work major and type of program. 
Table 70

\section{Correlations between CCTST Posttest Analytic Score and Predictor Variables}

\begin{tabular}{|c|c|c|c|c|c|c|c|c|c|c|c|c|c|c|c|c|c|c|}
\hline & 1 & 2 & 3 & 4 & 5 & 6 & 7 & 8 & 9 & 10 & $\pi$ & 12 & 13 & 14 & 15 & 16 & 17 & 18 \\
\hline 1 & 1.00 & .02 & .05 & .06 & -.05 & -.02 & .11 & -.08 & .10 & -.04 & .10 & .00 & .08 & -.01 & .11 & -11 &. .10 & $.38 * *$ \\
\hline 2 & & 1.00 & -.01 & -.06 & $.37^{* *}$ & $-.26 * *$ & $32 * *$ & .03 & .08 & $-.51^{* *}$ & $.19 *$ & .15 & $.16^{*}$ & $-.52 * *$ & .12 & $.20^{*}$ & $29^{* *}$ & .03 \\
\hline 3 & & & 1.00 & .07 & $.19 *$ & -.03 & .07 & $-18^{*}$ & .04 & -01 & .01 & .03 & .01 & -.01 & -.08 & -.04 & .08 & -.10 \\
\hline 4 & & & & 1.00 & -.08 & .07 & .03 & .12 & .14 & .05 & .02 & .10 & .03 & .02 & .14 & -.12 & .08 & .11 \\
\hline 5 & & & & & 1.00 & -.06 & $.30^{* *}$ & .09 & .14 & -.14 & -.12 & $.16 *$ & (1) 4 & -.08 & .01 & .02 & $.16^{*}$ & $-20 * *$ \\
\hline 6 & & & & & & 1.00 & $-.24^{* *}$ & -12 & .09 & $.33 * *$ & .14 & -10 & -.07 & $.32 * * *$ & $.27 * *$ & -.07 & -.02 & .05 \\
\hline 7 & & & & & & & 1.00 & $27^{* *}$ & $29 * *$ & -.08 & -.03 & .07 & .04 & -.07 & $.20 * *$ & 17 & .10 & .01 \\
\hline 8 & & & & & & & & 1.00 & -.09 & $-33 * *$ & .17 & .09 & .13 & -.32 & .10 & .15 & -.01 & -.08 \\
\hline 9 & & & & & & & & & 1.00 & .11 & .03 & .07 & .11 & $.15^{*}$ & .03 & $.28 * *$ & $16 *$ & .02 \\
\hline 10 & & & & & & & & & & 1.00 & $-.48^{* *}$ & $-.27^{* *}$ & $-.15 *$ & .94 & $-25^{* *}$ & .09 & -.03 & $-.13^{* * *}$ \\
\hline 11 & & & & & & & & & & & 1.00 & $-.24^{* *}$ & -.13 & -.48 & .03 & .00 & .12 & .07 \\
\hline 12 & & & & & & & & & & & & 100 & .07 & -.23 & .08 & -.19 & .05 & .06 \\
\hline 13 & & & & & & & & & & & & & 1.00 & .09 & -.01 & .07 & .07 & -.01 \\
\hline 14 & & & & & & & & & & & & & & 1.00 & $-26^{* *}$ & .08 & .04 & -.10 \\
\hline 15 & & & & & & & & & & & & & & & 1.00 & -.11 & .00 & .15 \\
\hline 16 & & & & & & & & & & & & & & & & 1.00 & $21 *$ & .00 \\
\hline 17 & & & & & & & & & & & & & & & & & 1.00 & .09 \\
\hline 18 & & & & & & & & & & & & & & & & & & 1.00 \\
\hline
\end{tabular}

\begin{tabular}{|c|c|c|c|}
\hline 1 & CCTST Pre Analytic & 10 & Social Work major ${ }^{96}$ \\
\hline 2 & Length of time & 11 & Psychology major $^{\text {ग }}$ \\
\hline 3 & Maleness (Female is reference category) & 12 & Sociology major $^{98}$ \\
\hline 4 & White Ethnicity (Non-white is reference category) & 13 & Other helping major ${ }^{\text {ग9 }}$ \\
\hline 5 & Age at Pretest & 14 & Type of Program ${ }^{100}$ \\
\hline 6 & Undergrad GPA & 15 & Cumulative GPA \\
\hline 7 & > A Year Between Undergrad and Grad School ${ }^{101}$ & 16 & Employment Hours \\
\hline 8 & Undergrad Research Institution. $^{102}$ & 17 & CT Subscale \\
\hline 9 & SW Experience ${ }^{103}$ & 18 & CCTST Post Analytic \\
\hline
\end{tabular}

${ }^{*} p \leq 0.05 ;{ }^{* *} p \leq 0.01$

The researcher then conducted partial correlations controlling for the strongest correlations as noted in the correlation matrix in Table 70. The first partial correlation controlled for CCTST pretest analytic and the second controlled for both CCTST pretest analytic and age at pretest. See Table 71 for a summary of the results. In the first partial correlation, the only significant correlation indicated was a weak negative correlation

\footnotetext{
96 Non-helping other majors is reference category

97 Non-helping other majors is reference category

98 Non-helping other majors is reference category

99 Non-helping other majors is reference category

10060 hour program is reference category

101 Less than a year between undergraduate and entry into graduate school is the reference category

102 Undergraduate Teaching Institution is reference category

103 No experience is reference category
} 
with age at pretest $r(110)=-.23, p=.02$. In the second partial correlation only a single trend in students with a type of program $r(109)=-16, p=.10$ was indicated. As a result of these preliminary analyses, the following variables were eliminated from the posttest analytic predictor model: (a) maleness, (b) White Ethnicity, (c) undergraduate GPA, (d) more than a year between undergraduate school and entry into graduate school, (e) undergraduate research school, (f) social work experience, (g) mean hours employed at posttest, (h) critical thinking subscale of self efficacy pretest scale. 
Table 71

Partial Correlations Between CCTST Posttest Analytic Scores and Predictor Variables Controlling for CCTST Analytic Pretest and Age at Pretest

\begin{tabular}{|c|c|c|c|}
\hline Variable & $\begin{array}{l}\text { First Order } \\
\text { Correlation }\end{array}$ & $\begin{array}{l}\text { Partial Correlation } \\
\text { Controlling for } \\
\text { CCTST Inference } \\
\text { Pretest }\end{array}$ & $\begin{array}{l}\text { Partial Correlation } \\
\text { Controlling for } \\
\text { CCTST Inference } \\
\text { Pretest and Age at } \\
\text { Pretest }\end{array}$ \\
\hline $\begin{array}{l}\text { CCTST Inference } \\
\text { Pretest }\end{array}$ & $.38^{*}$ & & \\
\hline $\begin{array}{l}\text { Length of time in } \\
\text { program at pretest }\end{array}$ & .03 & -.04 & .06 \\
\hline Maleness & -.10 & -.10 & -.06 \\
\hline White Ethnicity & .11 & .08 & .07 \\
\hline Age at Pretest & $-.20^{*}$ & -.23 & \\
\hline Undergraduate GPA & .05 & .12 & .08 \\
\hline $\begin{array}{l}\text { More than a year } \\
\text { between } \\
\text { undergraduate and } \\
\text { entry into graduate }\end{array}$ & .01 & -.11 & -.02 \\
\hline $\begin{array}{l}\text { Undergraduate } \\
\text { Research Institution }\end{array}$ & -.09 & -.08 & -.09 \\
\hline $\begin{array}{l}\text { Social work } \\
\text { experience }\end{array}$ & .02 & -.06 & -.02 \\
\hline Social Work major & $-.13 * *$ & -.10 & -.15 \\
\hline Psychology major & .07 & .03 & .01 \\
\hline Sociology major & .06 & -.04 & -.02 \\
\hline Other helping major & -.01 & -.09 & -.05 \\
\hline 60 Hour Program & -.10 & -.12 & $-.16 * *$ \\
\hline Cumulative GPA & .15 & .06 & .08 \\
\hline $\begin{array}{l}\text { Mean hours worked } \\
\text { at pretest }\end{array}$ & .00 & .05 & .07 \\
\hline $\begin{array}{l}\text { Critical Thinking } \\
\text { subscale of self- } \\
\text { efficacy scale }\end{array}$ & -.09 & -.02 & .04 \\
\hline
\end{tabular}

The initial hierarchical regression analysis was used to explore which of the remaining variables were the best predictors of CCTST posttest analytic scores and resulted in retaining three variables from the original model. The final hierarchical 
regression analysis revealed the control variables entered in Block 1with the following variables: CCTST pretest analytic and length of time in program when pretest was administered, was a significant predictor of CCTST posttest analytic, $\left(R^{2}=.14, F(2\right.$, $177)=14.42, p=.00$ ). Block 2 , which included age at pretest, also significantly improved the model, $\left(\Delta R^{2}=.05, p=.00\right)$. The predictor model indicated younger students have higher CCTST posttest analytic scores. Age at pretest was the only remaining predictor in the final model, aside from the control variables. This model accounted for $19 \%$ of the variability in CCTST posttest analytic scores $\left(R^{2}=.19, F(3,177)=13.27, p=.00\right)$. Block 3 (prior to entry) and Block 4 (while in program) did not contribute to the model. See Table 72 for a summary of the regression results.

Table 72

Hierarchical Regression Analysis of CCTST Posttest Analytic Scores (N=179)

\begin{tabular}{lccc}
\hline Variables & B & SE B & B \\
\hline Step 1 & & & \\
$\quad$ Control Variables: & & & \\
$\quad$ CCTST Pretest Analytic & 0.36 & 0.07 & $0.38^{*}$ \\
$\quad$ Length of Time in Program & 0.00 & 0.01 & 0.03 \\
Step 2 & & & \\
$\quad$ Control Variables: & & & \\
$\quad$ CCTST Pretest Analytic & 0.36 & 0.07 & $0.37^{*}$ \\
$\quad$ Length of Time in Program & 0.01 & 0.01 & 0.11 \\
$\quad \begin{array}{l}\text { Demographic Variables: } \\
\quad \text { Age at Pretest }\end{array}$ & -0.04 & 0.01 & $-0.23^{*}$ \\
& & & \\
\hline
\end{tabular}

Note: $R^{2}=0.14$ for Step $1 ; \Delta R^{2}=0.05$ for Step $2(p=0.00)$. ${ }^{*} p<0.05,{ }^{* *} p<.01$

\section{Posttest CCTST Evaluation Score Analysis}

Analysis of variance conducted on undergraduate majors and CCTST posttest evaluation scores found significant differences between groups $F(4,171)=2.58, p=.04$, 
$\mathrm{\eta}^{2}=.057$. The Tukey HSD post hoc test was ran to determine which major groups were different. The results indicated students with social work majors scored significantly lower on the CCTST evaluation posttest than students with a psychology major (mean difference $=-1.08)$. Individual independent $t$ tests were conducted on CCTST posttest evaluation scores and gender, type of undergraduate, more than a year between undergraduate and entry into graduate school, and social work experience indicated no significant difference. However, independent t tests on CCTST posttest evaluation scores and ethnicity $t(178)=-2.76, p=.01$ and type of program $t(178)=2.52, p=.01$ indicated significant differences. The initial analysis indicated the potentiality of eliminating the categorical variables where the different grouping did not show significant differences between the groups on the CCTST posttest evaluation scores; however, bivariate correlations on the dummy coded categorical variables as well as the other continuous variables were conducted to further investigate this decision making process.

Point biserial correlations were conducted on the binary dummy variables and Pearson product-moment correlations were conducted on all remaining variables in the posttest predictor model and are summarized in a correlation matrix in Table 73 . There was a strong and significant positive correlation between CCTST posttest evaluation and CCTST pretest evaluation scores $r(175)=.60, p=.00$ and a weak and positive correlation between CCTST posttest evaluation scores and white ethnicity $r(178)=.20, p=.01$, students having a psychology major $r(178)=.17, p=.02$, and cumulative GPA $r(176)=$ $.22, p=.00$. There were also weak but significant negative correlations with students who had a social work major $r(178)=-.21, p=.01$ and 60 hour program $r(178)=-.19, p=.01$. The correlations did not indicate any further evidence of multicollinearity between the 
independent variables, aside from the previous correlation noted between social work

major and type of program.

\section{Table 73}

\section{Correlations between CCTST Posttest Evaluation Score and Predictor Variables}

\begin{tabular}{|c|c|c|c|c|c|c|c|c|c|c|c|c|c|c|c|c|c|c|}
\hline & 1 & 2 & 3 & 4 & 5 & 6 & 7 & 8 & 9 & 10 & 11 & 12 & 13 & 14 & 15 & 16 & 17 & 18 \\
\hline 1 & 1.00 & .02 & .08 & $.19^{*}$ & -.10 & .03 & .07 & .00 & .12 & -.05 & .04 & -.07 & -.08 & -.06 & .11 & -.03 & -.06 & $.60^{* *}$ \\
\hline 2 & & 1.00 & -.01 & -.06 & $.37 * *$ & $-.26 * *$ & $.32 * *$ & .03 & .08 & $-.51 * *$ & $.19 *$ & .15 & $16^{*}$ & $-.52^{* *}$ & .12 & $20^{*}$ & $.29 * *$ & $.14^{* * *}$ \\
\hline 3 & & & 1.00 & .07 & $.19^{*}$ & -.03 & .07 & $-.18^{*}$ & .04 & -.01 & .01 & .03 & -.01 & -.01 & -.08 & -.04 & .08 & .03 \\
\hline 4 & & & & 1.00 & -.08 & .07 & .03 & .12 & .14 & .05 & .02 & .10 & .03 & .02 & .14 & -.12 & .08 & $20 * *$ \\
\hline 5 & & & & & 1.00 & -.06 & $.30 * *$ & -.09 & .14 & -14 & -.12 & $.16^{*}$ & .04 & -.08 & .01 & .02 & $.16^{*}$ & -.09 \\
\hline 6 & & & & & & 1.00 & $-.24 * *$ & -.12 & .09 & $.33^{* *}$ & -.14 & -.10 & -.07 & $32 * *$ & $27^{* *}$ & -.07 & -.02 & $.03^{* * *}$ \\
\hline 7 & & & & & & & 1.00 & $-.27 * *$ & $.29 * *$ & -.08 & -.03 & .07 & .04 & -.07 & $20^{* *}$ & .17 & .10 & .09 \\
\hline 8 & & & & & & & & 1.00 & -.09 & $-.33 * *$ & 17 & .09 & .13 & -.32 & .10 & -.15 & -.01 & -.02 \\
\hline 9 & & & & & & & & & 1.00 & .11 & .03 & -.07 & .11 & $.15^{*}$ & .03 & $.28 * *$ & $.16^{*}$ & .03 \\
\hline 10 & & & & & & & & & & 1.00 & $-.48^{* *}$ & $-.27 * *$ & $-.15^{*}$ & .94 & $.25^{* *}$ & .09 & -.03 & $-.2 \mathrm{~J} * *$ \\
\hline II & & & & & & & & & & & 1.00 & $-.24 * *$ & -.13 & .48 & .03 & .00 & .12 & $.17^{*}$ \\
\hline 12 & & & & & & & & & & & & 1.00 & -.07 & -.23 & .08 & -.19 & -.05 & .06 \\
\hline 13 & & & & & & & & & & & & & 1.00 & -09 & -.01 & .07 & .07 & -.05 \\
\hline 14 & & & & & & & & & & & & & & 1.00 & $-.26 * *$ & .08 & .04 & $-.19 *$ \\
\hline 15 & & & & & & & & & & & & & & & 1.00 & -.11 & .00 & $.22^{* *}$ \\
\hline 16 & & & & & & & & & & & & & & & & 1.00 & $.21 *$ & -.10 \\
\hline 17 & & & & & & & & & & & & & & & & & 1.00 & -.00 \\
\hline 18 & & & & & & & & & & & & & & & & & & 1.00 \\
\hline
\end{tabular}

\begin{tabular}{|c|c|c|c|}
\hline 1 & CCTST Pre Evaluation & 10 & Social Work major ${ }^{104}$ \\
\hline 2 & Length of time & 11 & Psychology major ${ }^{105}$ \\
\hline 3 & Maleness (Female is reference category) & 12 & Sociology major ${ }^{106}$ \\
\hline 4 & White Ethnicity (Non-white is reference category) & 13 & Other helping major ${ }^{\text {Tot }}$ \\
\hline 5 & Age at Pretest & 14 & Type of Program ${ }^{108}$ \\
\hline 6 & Undergrad GPA & 15 & Cumulative GPA \\
\hline 7 & > A Year Between Undergrad and Grad School ${ }^{109}$ & 16 & Employment Hours \\
\hline 8 & Undergrad Research Institution. ${ }^{\text {"10 }}$ & 17 & CT Subscale \\
\hline 9 & SW Experience ${ }^{I I T}$ & 18 & CCTST Post Evaluation \\
\hline
\end{tabular}

${ }^{*} p \leq 0.05 ;{ }^{* *} p \leq 0.01$

104 Non-helping other majors is reference category

105 Non-helping other majors is reference category

106 Non-helping other majors is reference category

107 Non-helping other majors is reference category

10860 hour program is reference category

109 Less than a year between undergraduate and entry into graduate school is the reference category

110 Undergraduate Teaching Institution is reference category

11 No experience is reference category 
The researcher then conducted partial correlations controlling for the strongest correlations as noted in the correlation matrix in Table 73. The first partial correlation controlled for CCTST posttest evaluation and the second controlled for both CCTST posttest evaluation and cumulative GPA. See Table 74 for a summary of the results. In the first partial correlation, having a social work major $r(110)=-.20, p=.03$ and the 60 hour program $r(110)=-.22, p=.02$ both continued as a weak significant negative correlation. Having a psychology major $r(110)=.21, p=.02$ and White Ethnicity $r(110)$ $=.25, p=.01$ continued as with weak positive correlations. The second partial correlation indicated a continued a significant weak positive correlation with White ethnicity $r(109)$ $=.24, p=.01$. The significant weak negative correlation with 60 hour program $r(109)=$ $.19, p=.04$ continued. There was a transition from a significant correlation to a trend for having a social work major $r(109)=-.17, p=.07$. As a result of these preliminary analyses, the following variables were eliminated from the posttest evaluation predictor model: (a) maleness, (b) age at pretest, (c) undergraduate GPA, (d) more than a year between undergraduate school and entry into graduate school, (e) undergraduate research school, (f) social work experience, (g) mean hours worked at posttest, (h) critical thinking subscale of self-efficacy pretest. 


\section{Table 74}

Partial Correlations Between CCTST Posttest Evaluation Scores and Predictor Variables Controlling for CCTST Evaluation Pretest and Cumulative GPA

\begin{tabular}{|c|c|c|c|}
\hline Variable & $\begin{array}{l}\text { First Order } \\
\text { Correlation }\end{array}$ & $\begin{array}{l}\text { Partial Correlation } \\
\text { Controlling for } \\
\text { CCTST Inference } \\
\text { Pretest }\end{array}$ & $\begin{array}{l}\text { Partial Correlation } \\
\text { Controlling for } \\
\text { CCTST Inference } \\
\text { Pretest and } \\
\text { Cumulative GPA }\end{array}$ \\
\hline $\begin{array}{l}\text { CCTST Inference } \\
\text { Pretest }\end{array}$ & $.60^{*}$ & & \\
\hline $\begin{array}{l}\text { Length of time in } \\
\text { program at pretest }\end{array}$ & $.14 * *$ & .15 & .14 \\
\hline Maleness & .03 & .09 & .10 \\
\hline White Ethnicity & $.20^{*}$ & $.25 *$ & $.24 *$ \\
\hline Age at Pretest & -.09 & -.01 & -.03 \\
\hline Undergraduate GPA & .03 & .04 & -.01 \\
\hline $\begin{array}{l}\text { More than a year } \\
\text { between } \\
\text { undergraduate and } \\
\text { entry into graduate }\end{array}$ & .09 & .00 & -.04 \\
\hline $\begin{array}{l}\text { Undergraduate } \\
\text { Research Institution }\end{array}$ & -.02 & -.01 & -.02 \\
\hline $\begin{array}{l}\text { Social work } \\
\text { experience }\end{array}$ & .03 & -.08 & -.08 \\
\hline Social Work major & -.21 & -.20 & $-.17 * *$ \\
\hline Psychology major & .17 & .21 & .20 \\
\hline Sociology major & .06 & .09 & .09 \\
\hline Other helping major & -.05 & -.08 & -.06 \\
\hline 60 Hour Program & -.19 & -.22 & $-.19^{*}$ \\
\hline Cumulative GPA & $.22^{*}$ & .14 & \\
\hline $\begin{array}{l}\text { Mean hours worked } \\
\text { at pretest }\end{array}$ & -.10 & -.08 & -.07 \\
\hline $\begin{array}{l}\text { Critical Thinking } \\
\text { subscale of self- } \\
\text { efficacy scale }\end{array}$ & -.00 & -.09 & -.10 \\
\hline
\end{tabular}

$* \mathrm{p}<.05 ; * * \mathrm{p}<.1$

The initial hierarchical regression analysis was used to explore which of the remaining variables were the best predictors of CCTST posttest evaluation scores and resulted in retaining seven variables from the predictor model. The final hierarchical regression analysis revealed the control variables entered in Block 1with the following 
variables: CCTST pretest analytic and length of time in program when pretest was administered, was significant predictor of CCTST posttest analytic, $\left(R^{2}=.37, F(2,178)=\right.$ $51.15, p=.00$ ). Block 2 a trend was noted with the following variables: social work major, psychology major, sociology major, and other helping major $\left(\Delta R^{2}=.03, p=.06\right)$. Additionally, Block 3, which included cumulative GPA, also significantly contributed $\left(\Delta R^{2}=.02, p=.02\right)$. The predictor model indicated students with a psychology or sociology major and high cumulative GPA have higher CCTST posttest analytic scores. Having a psychology major was the strongest predictor and having a social work major was the weakest predictor. Note the control variables were not included in the reporting of the strongest and weakest predictors. This model accounted for $42 \%$ of the variability in CCTST posttest analytic scores $\left(R^{2}=.42, F(7,178)=17.52, p=.00\right)$. The demographic variables did not contribute to the model. See Table 75 for a summary of the regression results. 
Table 75

Hierarchical Regression Analysis of CCTST Posttest Evaluation Scores (N=179)

\begin{tabular}{lccc}
\hline Variables & B & SE B & B \\
\hline Step 1 & & & \\
$\quad$ Control Variables: & & & \\
$\quad$ CCTST Pretest Analytic & 0.61 & 0.61 & $0.59^{*}$ \\
$\quad$ Length of Time in Program & 0.02 & 0.01 & $0.13^{* *}$ \\
Step 2 & & & \\
$\quad$ Control Variables: & & & \\
$\quad$ CCTST Pretest Analytic & 0.61 & 0.06 & $0.59^{* *}$ \\
$\quad$ Length of Time in Program & 0.01 & 0.01 & 0.06 \\
$\quad$ Prior to Entry Variables: & & & \\
$\quad$ Social Work major & -0.20 & 0.36 & -0.05 \\
$\quad$ Psychology major & 0.62 & 0.34 & $0.14^{\mathrm{a}}$ \\
$\quad$ Sociology major & 0.67 & 0.44 & 0.11 \\
$\quad$ Helping major & 0.09 & 0.65 & 0.01 \\
Step 3 & & & \\
$\quad$ Control Variables: & & & \\
$\quad$ CCTST Pretest Analytic & 0.59 & 0.06 & $0.58^{* *}$ \\
$\quad$ Length of Time in Program & 0.01 & 0.01 & 0.06 \\
$\quad$ Prior to Entry Variables: & & & \\
$\quad$ Social Work major & .01 & .37 & .00 \\
$\quad$ Psychology major & .73 & .34 & $.17^{*}$ \\
$\quad$ Sociology major & .72 & .43 & $.12^{\mathrm{a}}$ \\
$\quad$ Other helping major & .20 & .65 & .02 \\
$\quad$ While in Program Variables: & & & \\
$\quad$ Cumulative GPA & 1.21 & .53 & $.14^{*}$ \\
& & & \\
&
\end{tabular}

Note: $R^{2}=0.37$ for Step 1.; $\Delta R^{2}=0.03$ for Step $2(p=0.00) ; ; \Delta R^{2}=0.02$ for Step3 $(p=0.00) .{ }^{*} p<0.05,{ }^{* *} p<.01,{ }^{\mathrm{a}} p \leq .10$

\section{Posttest CCTST Deductive Analysis Score}

Analysis of variance was conducted on undergraduate majors and posttest CCTST deductive posttest scores with no significant differences between groups. Individual independent $t$ tests were conducted on CCTST posttest deductive scores and gender, type of undergraduate, more than a year between undergraduate and entry into graduate school, social work experience and type of program indicated no significant difference. However, independent $t$ tests on CCTST posttest deductive scores and ethnicity $t(178)=$ 
$-3.38, p=.00$ indicated significant differences. Also note, in regards to the results for ethnicity, the Levene's test for equality of variance was significant at $F=7.1, p=.01$; therefore the equal variance not assumed portion of the independent $t$ test results was interpreted. The initial analysis indicated the potentiality of the categorical variables where the different groupings did not show significant differences between the groups on the CCTST posttest deductive; however, bivariate correlations on the dummy coded categorical variables as well as the other continuous variables were conducted to further investigate this decision making process.

Point biserial correlations were conducted on the binary dummy variables and Pearson product-moment correlations were conducted on all remaining variables in the posttest predictor model and are summarized in a correlation matrix in Table 76. There was a strong and significant positive correlation between CCTST posttest deductive and CCTST pretest deductive scores $r(175)=.63, p=.00$ and a weak and positive correlation between CCTST posttest analytic scores and White ethnicity $r(178)=.20, p=.01$; having a psychology major $r(178)=.16, p=.04$ and cumulative GPA $r(176)=.19, p=.01$. A weak negative correlation was noted with age at pretest $r(178)=-.19, p=.01$. A trend was noted in students in undergraduate GPA $r(174)=.13, p=.09$. The correlations did not indicate any further evidence of multicollinearity between the independent variables, aside from the previous correlation noted between social work major and type of program. 


\section{Table 76}

\section{Correlations between CCTST Posttest Deductive Score and Predictor Variables}

\begin{tabular}{|c|c|c|c|c|c|c|c|c|c|c|c|c|c|c|c|c|c|c|}
\hline & 1 & 2 & 3 & 4 & 5 & 6 & 7 & 8 & 9 & 10 & 11 & 12 & 13 & 14 & 15 & 16 & 17 & 18 \\
\hline 1 & 1.00 & .00 & .10 & .07 & -.13 & .07 & .01 & -.11 & .03 & .01 & .04 & .05 & -.10 & -.02 & $20^{* *}$ & -.08 & -.02 & $63^{* *}$ \\
\hline 2 & & 1.00 & -.01 & -.06 & $.37^{* *}$ & $-.26 * *$ & $32^{* *}$ & .03 & .08 & $-.51^{* *}$ & $.19 *$ & .15 & $.16^{*}$ &. $.52^{* *}$ & .12 & $.20^{*}$ & $.29 * *$ & .00 \\
\hline 3 & & & 1.00 & .07 & $19 *$ & -.03 & .07 & $-18^{*}$ & .04 & -.01 & .01 & .03 & -.01 & -.01 & .08 & -.044 & .08 & .08 \\
\hline 4 & & & & 1.00 & -.08 & .07 & .03 & .12 & .14 & .05 & .02 & .10 & .03 & .02 & .14 & -.12 & .08 & $20^{* *}$ \\
\hline 5 & & & & & 1.00 & -.06 & $30 * *$ & -.09 & .14 & -.14 & -.12 & $16^{*}$ & .04 & -.08 & .01 & .02 & $.16 *$ & $-19 * *$ \\
\hline 6 & & & & & & 1.00 & $-.24 * *$ & -.12 & .09 & $.33 * *$ & -.14 & -.10 & -.07 & $32 * *$ & $.27 * *$ & .07 & -.02 & $.13 * * *$ \\
\hline 7 & & & & & & & 1.00 & $.27^{* *}$ & $.29^{* *}$ & .08 & -.03 & -.07 & .04 & -.07 & $.20 * *$ & 17 & .10 & -.04 \\
\hline 8 & & & & & & & & 1.00 & -.09 & $-.33^{* *}$ & .17 & .09 & .13 & .32 & .10 & -.15 & -.01 & -.03 \\
\hline 9 & & & & & & & & & 1.00 & .11 & .03 & -.07 & .11 & $.15^{*}$ & .03 & $.28 * *$ & $.16^{*}$ & -.02 \\
\hline 10 & & & & & & & & & & 1.00 & $-.48 * *$ & $.27 * *$ & $-.15 *$ & .94 & $-.25 * *$ & .09 & -.03 & $-.11 *$ \\
\hline 11 & & & & & & & & & & & 1.00 & $.24 * *$ & -.13 & -.48 & .03 & .00 & .12 & $16^{*}$ \\
\hline 12 & & & & & & & & & & & & 1.00 & .07 & -.23 & .08 & -.19 & -.05 & .01 \\
\hline 13 & & & & & & & & & & & & & 1.00 & .09 & -.01 & .07 & .07 & -.07 \\
\hline 14 & & & & & & & & & & & & & & 1.00 & $-26 * *$ & .08 & .04 & -.09 \\
\hline 15 & & & & & & & & & & & & & & & 1.00 & -.11 & .00 & $.19 *$ \\
\hline 16 & & & & & & & & & & & & & & & & 1.00 & $.21 *$ & -.06 \\
\hline 17 & & & & & & & & & & & & & & & & & 1.00 & -.02 \\
\hline 18 & & & & & & & & & & & & & & & & & & 1.00 \\
\hline
\end{tabular}

\begin{tabular}{|c|c|c|}
\hline 1 & CCTST Pre Deductive & \begin{tabular}{|l|l|}
10 & Social Work major \\
\end{tabular} \\
\hline 2 & Length of time & \begin{tabular}{|l|l|l}
11 & Psychology major \\
\end{tabular} \\
\hline 3 & Maleness (Female is reference category) & 12 Sociology major 114 \\
\hline 4 & White Ethnicity (Non-white is reference category) & \begin{tabular}{|l|l}
13 & Other helping major \\
\end{tabular} \\
\hline 5 & Age at Pretest & 14 Type of Program ${ }^{16}$ \\
\hline 6 & Undergrad GPA & \begin{tabular}{|l|l|}
15 & Cumulative GPA \\
\end{tabular} \\
\hline 7 & $>$ A Year Between Undergrad and Grad School ${ }^{\text {IIT }}$ & 16 Employment Hours \\
\hline 8 & Undergrad Research Institution. $^{118}$ & 17 CT Subscale \\
\hline 9 & SW Experience ${ }^{119}$ & \begin{tabular}{|l|l|}
18 & CCTST Post Deductive \\
\end{tabular} \\
\hline
\end{tabular}

${ }^{*} p \leq 0.05 ;{ }^{* *} p \leq 0.01$

The researcher then conducted partial correlations controlling for the strongest correlations as noted in the correlation matrix in Table 76. The first partial correlation controlled for CCTST pretest deductive and the second controlled for both CCTST pretest deductive and age at pretest. See Table 77 for a summary of the results. In the first partial correlation, White ethnicity $r(110)=.18, p=.06$ and age at pretest $r(110)=-.19$,

\footnotetext{
112 Non-helping other majors is reference category

113 Non-helping other majors is reference category

114 Non-helping other majors is reference category

115 Non-helping other majors is reference category

11660 hour program is reference category

117 Less than a year between undergraduate and entry into graduate school is the reference category

118 Undergraduate Teaching Institution is reference category

119 No experience is reference category
} 
$p=.05$ transitioned to trends. In the second partial correlation, the trend in White ethnicity $r(109)=.18, p=.07$ continued. Having a social work major $r(109)=-.20, p=.04$ became a significant weak negative correlation. The 60 hour program $r(109)=.17, p=.07$ became a trend. As a result of these preliminary analyses, the following variables were eliminated from the posttest deductive predictor model: (a) maleness, (b) more than a year between undergraduate school and entry into graduate school, (c) undergraduate research school, (d) social work experience, (e) mean hours employed at posttest, (f) critical thinking subscale of self-efficacy pretest. 
Table 77

Partial Correlations Between CCTST Posttest Deductive Scores and Predictor
Variables Controlling for CCTST Deductive Pretest and Age at Pretest

\begin{tabular}{|l|l|l|l|}
\hline Variable & $\begin{array}{l}\text { First Order } \\
\text { Correlation }\end{array}$ & $\begin{array}{l}\text { Partial Correlation } \\
\text { Controlling for } \\
\text { CCTST Inference } \\
\text { Pretest }\end{array}$ & $\begin{array}{l}\text { Partial Correlation } \\
\text { Controlling for } \\
\text { CCTST Inference } \\
\text { Pretest and Age at } \\
\text { Pretest }\end{array}$ \\
\hline $\begin{array}{l}\text { CCTST Inference } \\
\text { Pretest }\end{array}$ & $.63^{*}$ & & \\
\hline $\begin{array}{l}\text { Length of time in } \\
\text { program at pretest }\end{array}$ & -.00 & -.03 & .05 \\
\hline Maleness & .08 & .04 & .08 \\
\hline White Ethnicity & $.20^{*}$ & $.18^{* *}$ & $.18^{* *}$ \\
\hline Age at Pretest & $-.19^{*}$ & $-.19^{*}$ & \\
\hline Undergraduate GPA & $.13^{* *}$ & .12 & .09 \\
\hline $\begin{array}{l}\text { More than a year } \\
\text { between } \\
\text { undergraduate and } \\
\text { entry into graduate }\end{array}$ & -.04 & -.13 & -.06 \\
\hline $\begin{array}{l}\text { Undergraduate } \\
\text { Research Institution }\end{array}$ & -.03 & .05 & .04 \\
\hline $\begin{array}{l}\text { Social work } \\
\text { experience }\end{array}$ & -.02 & .05 & -.07 \\
\hline Social Work major & -.11 & -.11 & $-.20^{*}$ \\
\hline Psychology major & $.16^{*}$ & .06 & .13 \\
\hline Sociology major & .01 & .14 & .08 \\
\hline Other helping major & -.07 & .06 & .07 \\
\hline 60 Hour Program & -.09 & .03 & -.17 \\
\hline Cumulative GPA & $.19^{*}$ & -.14 & .09 \\
\hline $\begin{array}{l}\text { Mean hours worked } \\
\text { at pretest }\end{array}$ & -.06 & -.01 & .00 \\
\hline $\begin{array}{l}\text { Critical Thinking } \\
\text { subscale of self- } \\
\text { efficacy scale }\end{array}$ & .02 & .10 \\
\hline pr.05; * & & & \\
\hline
\end{tabular}

${ }^{*} \mathrm{p}<.05 ;{ }^{* *} \mathrm{p}<.1$

The initial hierarchical regression analysis was used to explore which of the remaining variables were the best predictors of CCTST posttest deductive scores and resulted in retaining four of the original predictor variables. The final hierarchical regression analysis revealed the control variables entered in Block 1with the following 
variables: CCTST pretest deductive and length of time in program when pretest was administered, was a significant predictor of CCTST posttest deductive, $\left(R^{2}=.39, F(2\right.$, $178)=55.84, p=.00)$. Block 2 with the following variables: White Ethnicity and Age at Pretest, also significantly improved the model, $\left(\Delta R^{2}=.04, p=.00\right)$. The predictor model indicated younger students of White ethnicity have higher CCTST posttest deductive scores. White ethnicity was the strongest predictor and age at pretest was the weakest predictor. Note the control variables were not included in the reporting of the strongest and weakest predictors. This model accounted for $43 \%$ of the variability in CCTST posttest deductive scores $\left(R^{2}=.43, F(4,178)=32.20, p=.00\right)$. Block 3 (prior to entry) and Block 4 (while in program) did not contribute to the model. See Table 78 for a summary of the regression results.

\section{Table 78}

Hierarchical Regression Analysis of CCTST Posttest Deduction Scores (N=179)

\begin{tabular}{|c|c|c|c|}
\hline Variables & B & $\overline{S E ~ B ~}$ & B \\
\hline \multicolumn{4}{|l|}{ Step 1} \\
\hline \multicolumn{4}{|l|}{ Control Variables: } \\
\hline CCTST Pretest Deduction & 0.66 & 0.06 & $0.62 * *$ \\
\hline Length of Time in Program & 0.00 & 0.01 & 0.00 \\
\hline \multicolumn{4}{|l|}{ Step 2} \\
\hline \multicolumn{4}{|l|}{ Control Variables: } \\
\hline CCTST Pretest Deduction & 0.64 & 0.06 & $0.60 * *$ \\
\hline Length of Time in Program & 0.01 & 0.01 & 0.05 \\
\hline \multicolumn{4}{|l|}{ Demographic Variables: } \\
\hline White Ethnicity & 1.09 & 0.40 & $0.16^{* *}$ \\
\hline Age at Pretest & -0.04 & 0.02 & $-0.11^{\mathrm{a}}$ \\
\hline
\end{tabular}




\section{Posttest CCTST Inductive Score Analysis}

Analysis of variance was conducted on undergraduate majors and CCTST posttest inductive scores with no significant differences between groups. Individual independent $t$ tests were conducted on CCTST posttest inductive scores and gender, type of undergraduate and social work experience indicated no significant difference. However, an independent $\mathrm{t}$ test on CCTST posttest inductive scores ethnicity $t(178)=-3.28, p=.00$ and type of program $t(178)=2.80, p=.01$ indicated significant differences. Also note, in regards to the results for type of program, the Levene's test for equality of variance was significant at $F=6.31, p=.01$; therefore the equal variance not assumed portion of the independent $t$ test results was interpreted. The initial analysis indicated the potentiality of eliminating the categorical variables where the different groupings did not show significant differences between the groups on the CCTST posttest inductive scores; however, bivariate correlations on the dummy coded categorical variables as well as the other continuous variables was conducted to further investigate this decision making process.

Point biserial correlations were conducted on the binary dummy variables and Pearson product-moment correlations were conducted on all remaining variables in the posttest predictor model and are summarized in a correlation matrix in Table 79. There was a strong and significant positive correlation between CCTST posttest inductive and CCTST pretest inductive scores $r(175)=.65, p=.00$ and a moderate positive correlation with cumulative GPA $r(176)=.29, p=.00$. There was a weak positive correlation between CCTST posttest inductive scores and White ethnicity $r(178)=.24, p=.00$. A weak negative correlation was noted with having a social work major $r(178)=-.18$, 
$p=.02$ and being enrolled in the 60 hour program $r(178)=-.19, p=.01$. A trend was noted

with age at pretest $r(178)=-.14, p=.06$, length of time in program when pretest was

administered $r(174)=.15, p=.05$, and having a psychology major $r(174)=.13, p=.09$. The

correlations did not indicate any further evidence of multicollinearity between the

independent variables, aside from the previous correlation noted between social work

major and type of program.

Table 79

Correlations Between CCTST Posttest Inductive Score and Predictor Variables

\begin{tabular}{|c|c|c|c|c|c|c|c|c|c|c|c|c|c|c|c|c|c|c|}
\hline & 1 & 2 & 3 & 4 & 5 & 6 & 7 & 8 & 9 & 10 & 11 & 12 & 13 & 14 & 15 & 16 & 17 & 18 \\
\hline 1 & 1.00 & -.01 & .03 & $.18^{*}$ & -.14 & .05 & $.15^{*}$ & -.00 & .12 & .08 & .08 & .02 & -.09 & -.08 & $25^{* *}$ & -.10 & -.02 & $65^{6 * *}$ \\
\hline 2 & & 1.00 & -.01 & .06 & $.37^{* * *}$ & $-.26^{* *}$ & $.32^{* *}$ & .03 & .08 & $-.51^{* *}$ & $.19 *$ & .15 & $16^{*}$ & $-.52^{* *}$ & 12 & $.20^{*}$ & $29^{* *}$ & $15 * * *$ \\
\hline 3 & & & 1.00 & .07 & $.19^{*}$ & .03 & .07 & $-.18^{*}$ & .04 & .01 & .01 & .03 & -.01 & -.01 & -.08 & -.04 & .08 & -.01 \\
\hline 4 & & & & 1.00 & -.08 & .07 & .03 & .12 & .14 & .05 & .02 & 10 & .03 & .02 & .14 & -.12 & .08 & $24 * *$ \\
\hline 5 & & & & & 1.00 & -.06 & $.30^{* *}$ & -.09 & .14 & -.14 & -.12 & $.16^{*}$ & .04 & -.08 & .01 & .02 & $.16^{*}$ & $14^{* * *}$ \\
\hline 6 & & & & & & 1.00 & $.24 * *$ & -.12 & .09 & $.33^{* *}$ & -.14 & -.10 & .07 & $.32^{* *}$ & $.27^{* *}$ & -.07 & -.02 & .02 \\
\hline 7 & & & & & & & 1.00 & $-.27^{* *}$ & $29 * *$ & .08 & -.03 & -.07 & .04 & -.07 & $.20 * *$ & .17 & .10 & .10 \\
\hline 8 & & & & & & & & 1.00 & -.09 & $-.33^{* *}$ & .17 & .09 & 13 & -.32 & .10 & -.15 & -.01 & -.01 \\
\hline 9 & & & & & & & & & 1.00 & .11 & .03 & -.07 & 11 & $.15^{*}$ & .03 & $.28 * *$ & $16^{*}$ & .02 \\
\hline 10 & & & & & & & & & & 1.00 & $-.48 * *$ & $-.27 * *$ & $.15 *$ & .94 & $-.25^{* *}$ & .09 & -.03 & $-.18 *$ \\
\hline 11 & & & & & & & & & & & 1.00 & $-.24^{* *}$ & -.13 & -.48 & .03 & .00 & .12 & $13^{* * *}$ \\
\hline 12 & & & & & & & & & & & & 1.00 & -.07 & -.23 & .08 & -.19 & -.05 & .04 \\
\hline 13 & & & & & & & & & & & & & 1.00 & -09 & .01 & .07 & .07 & -.02 \\
\hline 14 & & & & & & & & & & & & & & 1.00 & $-.26^{* *}$ & .08 & .04 & $-19 * *$ \\
\hline 15 & & & & & & & & & & & & & & & 1.00 & -.11 & .00 & $29 * *$ \\
\hline 16 & & & & & & & & & & & & & & & & 1.00 & $.21^{*}$ & -.07 \\
\hline 17 & & & & & & & & & & & & & & & & & 1.00 & -.05 \\
\hline 18 & & & & & & & & & & & & & & & & & & 1.00 \\
\hline
\end{tabular}

\begin{tabular}{|c|c|c|}
\hline 1 & CCTST Pre Inductive & 10 Social Work major ${ }^{120}$ \\
\hline 2 & Length of time & \begin{tabular}{|l|l|}
11 & Psychology major \\
\end{tabular} \\
\hline 3 & Maleness (Female is reference category) & 12 Sociology major ${ }^{122}$ \\
\hline 4 & White Ethnicity (Non-white is reference category) & 13 Other helping major ${ }^{123}$ \\
\hline 5 & Age at Pretest & 14 Type of Program ${ }^{124}$ \\
\hline 6 & Undergrad GPA & \begin{tabular}{|l|l|}
15 & Cumulative GPA \\
\end{tabular} \\
\hline 7 & $>$ A Year Between Undergrad and Grad School ${ }^{125}$ & \begin{tabular}{|l|l}
16 & Employment Hours \\
\end{tabular} \\
\hline 8 & Undergrad Research Institution. ${ }^{126}$ & \begin{tabular}{|l|l|}
17 & CT Subscale \\
\end{tabular} \\
\hline 9 & SW Experience ${ }^{127}$ & \begin{tabular}{|l|l|}
18 & CCTST Post Deductive \\
\end{tabular} \\
\hline
\end{tabular}

${ }^{*} p \leq 0.05 ;{ }^{* *} p \leq 0.01$

${ }^{120}$ Non-helping other majors is reference category

121 Non-helping other majors is reference category

122 Non-helping other majors is reference category

123 Non-helping other majors is reference category

12460 hour program is reference category

${ }^{125}$ Less than a year between undergraduate and entry into graduate school is the reference category

126 Undergraduate Teaching Institution is reference category

${ }^{127}$ No experience is reference category 
The researcher then conducted partial correlations controlling for the strongest correlations as noted in the correlation matrix in Table 79. The first partial correlation controlled for CCTST pretest deductive and the second controlled for both CCTST pretest deductive and cumulative GPA. See Table 80 for a summary of the results. In the first partial correlation, White ethnicity $r(110)=.29, p=.00$ became a moderate positive correlation. Being enrolled in the 60 hour program $r(110)=-.22, p=.02$ was a weak negative correlation. Length of time in program when pretest was administered $r(110)=$ $.18, p=.06$ and having a psychology major $r(110)=.16, p=.09$ continued as trends. Having a social work major $r(110)=-.19, p=.05$ transitioned to a trend. In the second partial correlation, having a social work major $r(109)=-17, p=.08$ and length of time in program when pretest was administered $r(109)=.16, p=.09$ continued as trends. White ethnicity remained a moderate positive correlation $r(109)=.29, p=.00$. Being enrolled in the 60 hour program $r(109)=-20, p=.04$ remained a weak negative correlation. As a result of these preliminary analyses, the following variables were eliminated from the posttest inductive predictor model: (a) maleness, (b) undergraduate GPA, (c) more than a year between undergraduate school and entry into graduate school, (d) undergraduate research school, (e) social work experience, (f) mean hours worked at posttest, (g) critical thinking subscale of self-efficacy pretest total 
Table 80

Partial Correlations Between CCTST Posttest Inductive Scores and Predictor Variables Controlling for CCTST Inductive Pretest and Cumulative GPA

\begin{tabular}{|l|l|l|l|}
\hline Variable & $\begin{array}{l}\text { First Order } \\
\text { Correlation }\end{array}$ & $\begin{array}{l}\text { Partial Correlation } \\
\text { Controlling for } \\
\text { CCTST Inference } \\
\text { Pretest }\end{array}$ & $\begin{array}{l}\text { Partial Correlation } \\
\text { Controlling for } \\
\text { CCTST Inference } \\
\text { Pretest and } \\
\text { Cumulative GPA }\end{array}$ \\
\hline $\begin{array}{l}\text { CCTST Inference } \\
\text { Pretest }\end{array}$ & $.65^{*}$ & & \\
\hline $\begin{array}{l}\text { Length of time in } \\
\text { program at pretest }\end{array}$ & $.15^{*}$ & $.18^{* *}$ & $.16^{* *}$ \\
\hline Maleness & -.01 & .06 & .07 \\
\hline White Ethnicity & $.24^{*}$ & $.29^{*}$ & $.28^{*}$ \\
\hline Age at Pretest & $-.14^{* *}$ & -.03 & -.04 \\
\hline Undergraduate GPA & .02 & -.03 & -.07 \\
\hline $\begin{array}{l}\text { More than a year } \\
\text { between } \\
\text { undergraduate and } \\
\text { entry into graduate }\end{array}$ & .10 & -.10 & -.13 \\
\hline $\begin{array}{l}\text { Undergraduate } \\
\text { Research Institution }\end{array}$ & -.01 & -.10 & -.02 \\
\hline $\begin{array}{l}\text { Social work } \\
\text { experience }\end{array}$ & .02 & -.11 & -.01 \\
\hline Social Work major & $-.18^{*}$ & $-.19^{* *}$ & -.11 \\
\hline Psychology major & $.13^{* *}$ & $.16^{* *}$ & $-.17^{* *}$ \\
\hline Sociology major & .04 & .02 & .02 \\
\hline Other helping major & -.02 & -.09 & -.02 \\
\hline 60 Hour Program & $-.19^{*}$ & .12 & $-.20^{*}$ \\
\hline Cumulative GPA & $.29^{*}$ & .01 & .02 \\
\hline $\begin{array}{l}\text { Mean hours worked } \\
\text { at pretest }\end{array}$ & .07 & -01 & \\
\hline $\begin{array}{l}\text { Critical Thinking } \\
\text { subscale of self- } \\
\text { efficacy scale }\end{array}$ & -.05 & & \\
\hline
\end{tabular}

${ }^{*} \mathrm{p}<.05 ;{ }^{* *} \mathrm{p}<.1$

The initial hierarchical regression analysis was used to explore which of the remaining variables were the best predictors of CCTST posttest inductive scores and resulted in retaining four variables from the predictor model. The final hierarchical regression analysis revealed the control variables entered in Block 1with the following 
variables of CCTST pretest inductive and length of time in program when pretest was administered, was a significant predictor of CCTST posttest inductive, $\left(R^{2}=.43, F(2\right.$, $178)=67.39, p=.00$ ). Block 2 , which included White Ethnicity and younger age at pretest, also significantly improved the model, $\left(\Delta R^{2}=.03, p=.01\right)$. Block 3 , which included Cumulative GPA, also significantly improved the model, $\left(\Delta R^{2}=.01, p=.06\right)$. The predictor model indicated younger White students with higher cumulative GPAs have higher CCTST posttest inductive scores. White ethnicity was the strongest predictor and cumulative GPA was the weakest predictor. Note the control variables were not included in the reporting of the strongest and weakest predictors. This model accounted for $47.4 \%$ of the variability in CCTST posttest inductive scores $\left(R^{2}=.47, F(5,178)=31.19, p=.00\right)$. Block 4 (at entry block of variables did not contribute to the model. See Table 81 for a summary of the regression results. 


\section{Table 81}

Hierarchical Regression Analysis of CCTST Posttest Inductive Scores (N=179)

\begin{tabular}{|c|c|c|c|}
\hline Variables & B & SE B & B \\
\hline \multicolumn{4}{|l|}{ Step 1} \\
\hline \multicolumn{4}{|l|}{ Control Variables: } \\
\hline CCTST Pretest Inductive & 0.62 & 0.06 & $0.64 *$ \\
\hline Length of Time in Program & 0.03 & 0.01 & $0.15^{*}$ \\
\hline \multicolumn{4}{|l|}{ Step 2} \\
\hline \multicolumn{4}{|l|}{ Control Variables: } \\
\hline CCTST Pretest Inductive & 0.58 & 0.06 & $0.62 *$ \\
\hline Length of Time in Program & 0.03 & 0.01 & $0.16^{*}$ \\
\hline \multicolumn{4}{|l|}{ Demographic Variables: } \\
\hline White Ethnicity & 0.84 & 0.35 & $0.14 * *$ \\
\hline Age at Pretest & -0.04 & 0.02 & $-0.12 * *$ \\
\hline \multicolumn{4}{|l|}{ Step 3} \\
\hline \multicolumn{4}{|l|}{ Control Variables: } \\
\hline CCTST Pretest Inductive & 0.57 & 0.06 & $0.59 *$ \\
\hline Length of Time in Program & 0.03 & 0.01 & $0.15^{*}$ \\
\hline \multicolumn{4}{|l|}{ Demographic Variables: } \\
\hline White Ethnicity & 0.78 & 0.35 & $0.13 * *$ \\
\hline Age at Pretest & -0.04 & 0.02 & $-0.12 * *$ \\
\hline \multicolumn{4}{|l|}{ While in Program: } \\
\hline Cumulative GPA & 1.17 & 0.62 & $0.11^{\mathrm{a}}$ \\
\hline
\end{tabular}

Note: $R^{2}=0.43$ for Step $1 ; \Delta R^{2}=0.03$ for Step $2(p=0.01) .{ }^{*} p<0.05, * * p<.01$ ${ }^{\mathrm{a}} p \leq .10$

\section{Summary}

A summary of the hierarchical regression analyses results for the posttest prior to and while in program models are provided in Table 82 . The table provides the total variance explained by each model, all variables in the final model, the strongest predictor, as well as those predictors that were at the trend level. Note the control variables were not identified by strength or weakness, but only as variables included in the final model. 
Table 82

Posttest Model Summary of $R$ Square Change and Significant Predictors for Prior to While In Model

\begin{tabular}{|l|l|l|l|l|l|l|}
\hline CCTST Posttest & Total & Inference & Analytic & Evaluation & Deductive & Inductive \\
\hline$\Delta R^{2}$ & 3.6 & 3.9 & 5.0 & 5.0 & 3.7 & 2.9 \\
\hline Pretest & .71 & .53 & .37 & .58 & .60 & .58 \\
\hline $\begin{array}{l}\text { Length of time } \\
\text { in program }\end{array}$ & .13 & .04 & .11 & .06 & .05 & .19 \\
\hline Age & -.11 & & $-.23^{*}$ & & $-.11^{* *}$ & $-.12^{* *}$ \\
\hline White Ethnicity & $.16^{*}$ & $.20^{*}$ & & & $.16^{*}$ & $.12^{*}$ \\
\hline $\begin{array}{l}\text { Cumulative } \\
\text { GPA }\end{array}$ & & & & .14 & & $.11^{* *}$ \\
\hline $\begin{array}{l}\text { Social Work } \\
\text { major }\end{array}$ & & & & .00 & & \\
\hline $\begin{array}{l}\text { Psychology } \\
\text { major }\end{array}$ & & & $.17^{*}$ & & \\
\hline Sociology major & & & $.12^{* *}$ & & \\
\hline $\begin{array}{l}\text { Other helping } \\
\text { major }\end{array}$ & & & .02 & & \\
\hline
\end{tabular}

Note: The control variables of length of time in program and corresponding pretest were not included in determining the strongest and weakest. * Strongest predictor, ** Trend

\section{Conclusion}

This chapter provided an in depth explanation of the statistical results of this study. In particular, the appropriate descriptives for each sample and each of the four research questions were provided, as well as detailed results of each hierarchical regression analysis. The following chapter will build upon these results and explore potential reasons as well as the implications for future research and social work education. 


\section{CHAPTER FIVE}

\section{Discussion}

This chapter will build on the previous review of the statistical analyses, by exploring the meaning of the results through clear and specific linkages to the previously cited research, as well as the guiding theoretical underpinning. In addition, the implications for social work education, limitations of the study and suggestions for future research are also explicated. The discussion will follow the previous outline in that each research question will be discussed as ordered in the previous chapters.

\section{Research Question 1}

The discussion of the results of Research Question 1 will begin with differences between pretest and posttest administrations (hypotheses 1a through $1 \mathrm{f}$ ), then will proceed to group differences between pretest and posttest administrations, to the group differences on pretest and posttest scores separately, and conclude with an overall summary of the analyses conducted to address this question.

The analysis which specifically addressed Research Question 1 indicated there were significant differences only between the pretest and posttest inference subscales. These findings indicate students are improving in their ability to develop hypotheses, deliberate and question relevant information from a variety of sources, consider alternatives and potential consequences, and draw conclusions (Facione, 1990b). Within social work practice, inference skills are consistent with assessment skills in that the 
practitioner must ascertain the most appropriate services for a client by considering input from a variety of sources and not just relying on one or traditional sources. For example, the social worker would consider not only the client's self report, but also reports from family members, service providers, and other support systems, exploring alternative sources unique to the situation, such as cultural specific resources. In addition, the social worker would also have the ability to consider potential consequences of treatment choices and explore these with the client in making decisions. Assessment skills are emphasized throughout the social work curriculum and thus the increase in this particular skill set is consistent with expected outcomes of a social work education.

A review of the pretest and posttest scores revealed an interesting perspective of the students' skills, specifically on the subscales in regards to the points possible column (See Table 11). Students were most skilled at analysis, which requires the ability to dissect arguments and identify assumptions (Facione, 1990b). Secondly, students were more skilled at inductive (10.02 out of 17) than deductive ( 7.47 out of 17). Inductive skills are consistent with the social work values of starting where the client is, client's self-determination, gathering data from multiple sources, and acknowledging ones biases. Inductive reasoning begins with the observation (where the client is), looks for patterns (assessment process), develops a tentative hypothesis (develops a treatment plan) and suggests strategies to address the presenting problem (specific tasks to accomplish the treatment goal). Some researchers would argue that inductive is the more difficult skills of the two in that induction "as people must possess more expert knowledge and add more information to consider the probability of conclusions and assess the strength of inductive arguments" (Yuan, Kunawiktikul, Klunkin, \& Williams, 2008, p. 73). 
Interestingly, whereas the increase between pretest and post inductive scores was minimal (.01), it was larger between the pretest and posttest deductive (.28) scores. This suggests students do gain deductive skills, consistent with the problem solving and evidence based perspectives emphasized in Kent School's curriculum. Students were least skilled with evaluation. Although evaluation skills are essential to social work practice, these skills may contradict the social work values of self-determination, nonjudgmental and strengths perspective, thus making it more difficult of a skill for social work student to learn and integrate into their skill set.

Another interesting perspective with which to view the trends in students' scores, is in comparison to the trends in faculty scores. Research indicated faculty tend to teach according to their learning styles and it is suggested faculty teach to their specific strengths as well (Cornett, 1983; Entwistle, 1981). During the outcomes assessment process, Kent faculty were provided the opportunity to take the CCTST to acclimate themselves to the process students would be going through and to provide an opportunity for faculty to understand their personal strengths and weaknesses in critical thinking as well. Interestingly, faculty demonstrated much the same trends in scores as did the students (although they scored higher than students on the total as well as each sub scale as would be expected). Faculty members were most skilled at analytic skills. In addition, faculty were more skilled at inductive than deductive reasoning. However, where students were least skilled at evaluation skills, faculty members were least skilled in deductive skills as assessed by the CCTST. Although there are noted limitations to faculty members' scores (i.e. low number of participants, more part time faculty participated than full time faculty, and instruments were completed independently), the 
similarities in students' and faculty members' scores indicate a pattern in social workers' critical thinking skills. It may be that the constructs utilized by the Delphi group or the value assigned to each subscale in CCTST may not accurately reflect critical thinking within a social work context. As indicated in Jones' (2007) previously cited research regarding discipline specific definitions for critical thinking, it is suggested a social work specific definition of critical thinking and/or a social work specific critical thinking assessment instrument may more accurately assess Kent School students' critical thinking skills.

Research which provided detailed pretest and posttest analysis results to make comparisons with the current study was generally limited to those involving a critical thinking specific course. Facione (1990b) reported results of a study using a different set of students at pretest and posttest, the mean improvement ranged from .8473 to .6339 . In another study which used a paired sample of students the mean improvement was 1.45 (Facione, 1990b). Facione further reported: "with a confidence interval of $95 \%$ we can expect the mean improvement on the CCTST from pretest to post test to be bounded by 1.9071 and .9861 in the population of general education college students at a public comprehensive university. Note, Facione's research included undergraduate level students after a single critical thinking specific course. Yuan, Kunawiktikul, Klunklin, and Williams (2008) report a mean difference of 1.11 after utilizing specific instructional strategies with undergraduate nursing students. Wheeler and Collins (2003) report a mean difference on 1.04 for the experimental group and .29 for the control group after a semester long course utilizing a specific instructional strategy. 
Obviously, the current study did not reflect an overall improvement on critical thinking, as would be expected based on the previous literature; however, there were situational factors which may have impacted the results. The decrease between pretest and posttest scores for the analytic and evaluation scores, as well as the minimal increase between pretest and posttest may be explained by the students' lack of motivation.

Facione (1990b) cited similar issues in his research in that the pretest was administered at the beginning of the semester in which students were more motivated to cooperate and put forth effort compared to the end of the semester when students are under significant pressure to finish a variety of major assignments. Facione (1990b) argued this is particularly the case when students' grades are not impacted by participation as was the case with the current study. In addition to timing of the administration of the posttest, the lack of feedback to students on pretest scores may also have contributed to the lack of overall significant improvement in scores. Students were not notified about their pretest scores prior to taking the posttest; therefore, were unaware of their strengths and areas in need of improvement. It has been well established that feedback is an essential component in the assessment process (Banta, 2001; Banta, Lund, Black, \& Oblander, 1996; Grunwald \& Peterson, 2003; Palomba \& Banta, 1999) and the lack thereof may have negatively influenced students' motivation on the post tests. Ensuring students understand the assessment of critical thinking skills in the context of their individual scores and how they can improve, as well as the bigger context of improving the curriculum may help promote students' motivation to enhance their critical thinking skills. Providing individual test scores, improvement strategies specific to the areas in 
need of improvement, as well as explanations of the outcomes process are potential strategies to address this issue.

To further explore pretest and posttest differences, the researcher also examined differences in pretest and posttest scores based on gender, ethnicity, type of program, undergraduate major, months between undergraduate and entry into graduate school, social work experience and percentile ranking groups. There was a significant difference on the analytic subscale based on gender, but not in the expected direction. Specifically, males scored significantly lower on analytic posttest than on the pretest. In, fact males scored lower on all posttest scales except for inference. In contrast, although females' mean scores were lower than males on all pretest scales, they improved each of their mean scores at posttest. It may be that males were more susceptible to the motivational factor as discussed previously, as they demonstrated higher skill ability at pretest and it is not likely these stills were "lost" at completion of the program.

In addition, White students scored statistically higher on the inference posttest scores than on pretest with a similar trend indicated on deductive posttest. A visual inspection of the mean scores indicated White students scored higher than Non white students on both the pretest and posttest scales and of particular concern is that Non white students' critical thinking skills decreased after completing the program on all scales except for evaluation where there was a slight increase. Again, it is not suggested these skills were somehow "lost", but that Non-white students may have been more sensitive to the motivational issues discussed previously than White students. The literature recognizes the gap in research regarding influential factors to the development of critical thinking skills specific to minority groups, arguing "it suffers from the exclusion of issues 
germane to racial/ethnic minority populations" (Baranchik, 2002; Fleming, Garcia, \& Morning, 1995, p. 438). Fleming, Garcia and Morning (1995) indicate their exploratory study of minority engineering students' critical thinking skills suggest that improving students' interactions with faculty and institutional support can improve academic performance. Cokley (2002) examined the impact of college racial composition on African American students' academic self concept and reports students at historically Black colleges and universities report more positive experiences and more positive perceptions of their environment than students from predominantly White colleges and universities. He further reported that higher levels of academic self concept was positively correlated with higher GPAs $(r=.33)$, quality of interaction with faculty $(r=$ $.40)$ and encouragement to pursue further education $(r=.16)$ (Cokley, 2002). It is suggested as Kent School consists of mostly White students, that minority students may not feel as supported by the faculty, program or university as White students, thus negatively impacting critical thinking scores.

To further explore the lack of change in students' pretest and posttest scores, the grouping variable which reflected the percentile ranking of pretest scores was used to explore how the scores of students who scored low, middle and high on the pretest performed on the posttest. The results provided remarkable insight into pretest and posttest differences. Students who scored low on the pretest scored significantly higher on total critical thinking posttest, as well as all five of the subscales. The mean differences ranged from -.66 to -1.78 . However, of more concern is the fact that students with high levels of critical thinking, as measured by the CCTST, scored significantly lower on the total, analytic, evaluation and inductive at posttest. These findings 
demonstrated the critical thinking infused curriculum does well in improving deficits in critical thinking; however, does not fair well in improving the scores of students' with more advanced higher order levels of thinking.

Although these findings do reveal more significant differences between pretest and posttest scores, it suggests that the curriculum is still evolving in the goal to promote and develop advanced levels of higher order thinking. Those students with lower levels of critical thinking are learning the basic skills of critical thinking and improving their analytic, inference, evaluation, inductive and deductive skills, which does provides evidence the curriculum does promote critical thinking skills. However, with the posttest scores of students in the higher levels of critical thinking decreasing, it suggests the curriculum has not reached its full potential. Although it may again be an issue of motivation for those students with higher levels of critical thinking, it may also be the lack of critical thinking learning strategies to adequately challenged advanced students. As the critical thinking curriculum is still new, the learning strategies may be more geared towards the more basic critical thinking skill development and not towards promoting the more advanced level of skill development thus adequately challenge all students. It may also be that faculty members are continuing to use existing assignments without making revisions to reflect the critical thinking component of the curriculum. As the curriculum continues to solidify the advancement higher order levels of thinking through the continued emphasis of critical thinking throughout the curriculum, the more sophisticated levels of thinking will be achieved, thus assisting those with more advanced skills in critical thinking to progress even further. 
To further explore pretest and posttest differences, the researcher also examined pretest and posttest scores separately based on gender, ethnicity, type of program, undergraduate major, months between undergraduate and entry into graduate school, and social work experience. In most cases, if there were group differences at pretest, the curriculum overall did a good job of eliminating those differences while promoting critical thinking skills. For example, initially there was a trend for males scoring higher than females on the deductive pretest; however, there were no gender differences on the deductive, nor any other subscale at posttest. Again this demonstrates if there were gender differences in critical thinking skills initially, the curriculum did a good job of eliminating those differences. These findings contradicted Facione's (1990d) research which found males scored significantly higher on posttest scores than female students, but it is consistent with Ingle (2007) and Loken (2005) findings of no gender differences. However, caution should be exercised in interpreting these results too strongly. Recall when looking at gender differences between pretest and posttests differences, male students' scores decreased at posttest, lessening the gap between males and females. Therefore, the current findings may provide a false sense of security in that if the suggested lack of motivation is addressed and male students become more engaged in the posttest assessment process, the change in their scores could alter these findings.

The differences due to ethnicity had the opposite effect, in that there were no significant differences at pretest; however, White students scored significantly higher at posttest on the total, inference, inductive, with a trend noted in deductive. This indicated the curriculum was more sensitized towards growth in critical thinking for White students. These findings are consistent with Facione (1990d) who also found significant 
differences at posttest but not at pretest based on ethnicity. These results support the previous discussion of potential explanations of issues impacting ethnic difference in critical thinking skill development.

The lack of overall significant findings between pretest and posttest scores does provide insight into the outcomes of the revised curriculum. Even though Kent School's goal was to infuse critical thinking throughout the curriculum, the results may indicate this process has not fully developed thus potentially explaining the minimal change in students' pretest and posttest scores. The vertical and horizontal integration of critical thinking across the curriculum is a lofty and intensive process, which goes far beyond the visual linkages between the courses' goals and objectives. Critical thinking skills are not the result of merely rewording goals and objectives, but of explicit attention to skill development in each individual course and session through the creation of purposeful learning activities (Facione, 1990b; Plath et al., 1999; Rane-Szostak \& Robertson, 1996; Williams et al., 2003). This is a time consuming process not only in the revision of the curriculum, but in the amount of time for faculty to infuse critical thinking within specific courses and class sessions while also learning new strategies to develop and enhance higher order skill development in students. As Kurfiss (1988) explains, it is essential for faculty to work together to "cultivate thinking skills deliberately throughout the curriculum" (p. 91).

Critical thinking can be viewed as an ill-structured domain as defined within Cognitive Flexibility Theory. It is complex and involves a variety interactions of skills (analytic, inference, evaluation, deductive, and inductive) within multiple contexts and although individually the skills may be not identified as "critical thinking" together they 
form the concept of critical thinking as defined by the Delphi Group. As illustrated in previous discussions of critical thinking, different professions' definition of critical thinking vary somewhat, in that the definition is not necessarily incorrect, but insufficient to encompass all professions. As a result of the ill-structured nature of critical thinking, it then becomes necessary for students to utilize cognitive flexibility to utilize and demonstrate critical thinking skills within a variety of contexts in the social work profession. This type of flexibility requires specific teaching/learning strategies to promote the advanced knowledge acquisition of critical thinking, similar to those discussed in the theoretical underpinning section of this study. It is thus suggested that the different courses that make up the curriculum are compartmentalized, inhibiting the development of critical thinking among students. Compartmentalization as explained by Spiro, Feltovich, Jacobson and Coulson (1991b) occurs when information/ideas are presented as separable and self-reliant as individual containers or compartments, when in fact they are highly interrelated to other ideas/concepts. It is further suggested, due to the significant revisions in the curriculum in a relatively brief period of time, the vertical and horizontal alignment and integration between courses has not occurred, leading to a compartmentalization of the curriculum, thus inhibiting the development of critical thinking.

Additionally, it may be that motivation is not only an issue with students, but with faculty members as well. Recall, the emphasis on the development of critical thinking began as a result of the development of an outcomes assessment process at Kent School. Although this study focused on the development of critical thinking, it is a component of the overarching assessment process. As the engagement of faculty is cited as the most 
essential component to a successful outcomes process, overcoming potential barriers to faculty engagement, such as lack of understanding and resistance to the top down approach is essential (Allen, 2004; Banta, 2001, 2005; Bresciani, 2005; Burke \& Minassians, 2002; Meier \& Thannert, 2006; Neuman, 2003). At a time when faculty are under increasing pressure to generate funded research, while also maintaining publication standards, assuming additional responsibilities can be overwhelming. Faculty are often initially resistant to the assessment process due to fear of the data being used for promotion and tenure processes, the amount of time required to implement the assessment process, and the perception of assessment as an infringement upon academic freedom. Although the investment of time is often heavy on the front end of the process as faculty became acclimated to the process and gain a better understanding of how it can improve student learning kinks are worked out.

It is suggested that these issues exist within the critical thinking infusion process as well. Faculty members were initially overwhelmed in that the school's program goals and objectives had to be revised to reflect the critical thinking emphasis and completed within a limited amount of time due to the impending reaccreditation process. This discussion required several meetings and extensive collaboration for an agreement to be achieved. Next, the goals and objectives of each course had to be revised to reflect the infusion of critical thinking, assignments had to be developed/revised to assess the obtainment of the new goals, and course level assessment instruments, i.e. rubrics, were developed to measure the obtainment of the course level goals. This required a considerable investment for faculty to complete each of these steps and minimal time for faculty to evaluate specific learning strategies and/or activities to promote critical 
thinking skills development. It is expected as the foundation has been laid, i.e. revision of goals and objectives at the program and course level has been completed, as well as the development of grading rubrics that faculty will now have more time to focus on the infusion of critical thinking more specifically within their individual courses. This could include the exploration of literature regarding specific strategies or methods designed to help engage students in the development of critical thinking skills.

As when any significant change occurs within academia, there was a degree of resistance to the process. Palomba \& Banta (1999) identified the "three Rs" of responsibility, resources and rewards to overcome the "fourth R" of resistance. Exploring this within the context of curriculum revisions, providing opportunities for faculty to learn more about critical thinking in regards to innovative instructional strategies and techniques would be the primary strategies to engage faculty participation. Inviting critical thinking instructional experts to campus and/or sending faculty to seminars or conferences such those offered by the Center of Critical Thinking help faculty become more knowledgeable about critical thinking, how to redesign existing assignments and create new ones to reflect the critical thinking component of the course and to gain a deeper understanding of the skills related to critical thinking. Faculty members were given responsibility for the curriculum reform and implementation of the critical thinking infusion in the curriculum; however, their continued involvement in the assessment and feedback processes are also important. The rewards component can be as simple as a recognition of a faculty member who has developed learning activities and shared with the group or as large as financial rewards of campus wide recognition. Specifically, Kent School won the Paul Weber Award for Department Excellence in Teaching presented by 
the University of Louisville and was awarded a financial reward for their efforts. This money could potentially be used to fund the previously mentioned strategies to continue to increase faculty motivation and participation in the process.

The infusion curriculum structure may not in and of itself be sufficient enough to promote the development of student's critical thinking skills. Ennis (1989) recommended using a combination of the three curriculum structures, i.e. general, infusion, and immersion to minimize the weakness of any single approach. In particular, it is suggested a critical thinking specific course may improve students' critical thinking skills as explicit instruction was identified as the most influential factor in critical thinking skill development (Bangert-Drowns \& Bankert, 1990). There are consistent findings which indicate significant improvement in pretest and posttest assessment of students' critical thinking skills after a critical thinking specific course (Facione, 1990b; Plath et al., 1999; Rane-Szostak \& Robertson, 1996; Williams et al., 2003). Providing a critical thinking specific course with specific attention to the application within social work practice would lay the foundation for the development of critical thinking skills. Faculty would then not be faced with teaching the basics skills of critical thinking to students at a variety of skill levels (low/middle/high). These findings may suggest faculty spent so much time with the basics of critical thinking that there was insufficient time to address the more advanced knowledge components of critical thinking. Providing a critical thinking specific course would then put students at a more level playing field as they progress through the curriculum.

Lastly, it may be that the curriculm itself was just not effective in promoting the development of students' critical thinking skills. However, before further curriculum 
revisions are made, it is recommended that the student and faculty motivational issues be addressed first, as well as the implementation of teaching and learning strategies associated with optimal critical thinking development. These recommendations may specifically address the decrease in scores at posttest and thus provide a more accurate assessment of the effectiveness of the curriculum.

\section{Research Question Two}

Research Question Two attempted to identify predictors for pretest critical thinking scores on the total and all five subscales utilizing the Pretest Sample. This model utilized three different predictor blocks of demographics, generic and discipline specific variables to predict pretest scores. The discussion of the results will be organized according to these blocks.

The demographic block was a significant predictor for the total as well as five of the subscales; however, the significance of the variables within the block varied slightly. White ethnicity was a consistent predictor across all six scores, which is consistent with the significant group results indicated in Research Question One. Maleness was a predictor for the total score, as well as the inference, evaluation, and deductive subscales. Younger age was also a significant predictor for the total score, as well as for the subscales of inference, evaluation, and deductive. These findings contradict the majority of research on age which found it to be an insignificant predictor of critical thinking (Facione, 1990a; Ingle, 2007). However, as noted in the literature review the previous studies were conducted on undergraduate students, whereas the current research involves graduate level students indicating a potential difference in predictors for undergraduate critical thinking skills versus graduate level critical thinking skills. 
The generic block also yielded consistently significant results for all six models; however, type of undergraduate school (research versus teaching) was not a significant predictor of any of them. Undergraduate GPA was the strongest predictor across total and all subscales, except for inductive (still a significant predictor), which is consistent with research conducted by Wilson (2002), Gadzella, Baloglu and Stephens (2002), Facione (1990a). More than a year between undergraduate school and entry into graduate school was also a predictor for the total score, inference, analytic and inductive subscales. These results tend to support the idea critical thinking skills develop naturally with time in that students who entered graduate school more than a year after completing undergraduate school scored higher on total, inference, analytic and inductive. Previous research utilizing a time component was limited; however, these findings did contradict Facione's (1990b) research which yielded insignificant results utilizing the number of college units completed as a predictor of critical thinking.

In contrast to the other two predictor blocks, the discipline specific block only contributed significantly to the pretest analytic model and then only for a trend on the other helping major variable and the self-efficacy pretest. The years of social work experience and the other dummy coded major variables of social work, psychology, and sociology were not significant. Although significant, this block explained the least amount of variance of the three blocks. The overall results indicate the selected discipline specific variables were not significant predictors for five of the six models, suggesting either critical thinking does not have discipline specific components or alternative discipline specific variables should be explored. As a result of these analyses, the predictive model was amended to illustrate the significant predictors, as well as trends for 
each model, omitting those variables and/or blocks that did not significantly contribute.

See Figure 7 for the final conceptual model for entry level critical thinking.

\section{BLOCK 1}

DEMOGRAPHIC VARIABLES

Gender (total, inference,

evaluation and deductive)

Ethnicity*

Age (total, inference, evaluation and

deductive)

\section{GENERIC VARIABLES}

BLOCK 2

Undergraduate GPA*

Months between undergraduate

degree and entry into graduate

program (total, inference, analytic and inductive)

\section{BLOCK 3}

DISCIPLINE SPECIFIC VARIABLES

Pretest Foundation Practice Self-Efficacy

Total (analytic)

Undergraduate degree *

DEPENDENT VARIABLES*

Entry Level Total Critical Thinking

Entry Level Deductive Reasoning

Entry Level Inductive Reasoning

Entry Level Analysis

Entry Level Evaluation

Entry Level Inference

Note: * Indicates the predictor is present in all six models.

Figure 7: Final Conceptual Model to explain predictors of students' entry level critical thinking skills using generic and discipline specific blocks

\section{Research Question Three}

Research Question Three attempted to identify predictors for posttest critical thinking scores on the total and all five subscales utilizing the Not So Pure Posttest Sample. This model utilized the same predictor variables utilized in Research Question 
Two of demographics, generic and discipline specific variables to predict posttest scores; however, it also included the control variables of pretest scores appropriate to the specific model and the length of time in the program. The discussion of the results will be organized according to these blocks and will conclude with a discussion of the differences between the pretest and posttest models.

The demographic block was a significant predictor for the total as well as all five of the subscales; however, gender was not a significant predictor for any of the models. White ethnicity continued as a significant predictor for total critical thinking, inference, inductive, deductive and a trend for evaluation. Younger age was also a significant predictor for the total score and analytic and a trend for inductive and deductive. The generic block and the discipline specific block did not significantly contribute to any of the six predictor variables, nor were trends noted for these blocks. See Figure 8 for the final predictive model for the generic versus discipline specific blocks.

The most significant differences between the pretest and posttest generic and discipline specific models existed within the generic predictors. The discipline specific pretest predictors contributed only minimally to the analytic model and only at the trend level; whereas the generic block predictor of undergraduate GPA was a significant predictor across all six pretest models. In addition, time between undergraduate and graduate school was also a consistently significant predictor across four of the six pretest models. The strength of these predictors disappeared altogether in the posttest models. These findings are consistent with the analysis in Research Question One which found the significant differences at pretest for time between undergraduate and graduate school disappeared at posttest (aside from a trend in the inductive subscale). 


\section{BLOCK 1}

CONTROL VARIABLE

*Pretest scores on the appropriate dependent variable (total critical thinking, deductive reasoning, inductive reasoning, analysis, evaluation and inference)

*Length of time in the program when pretest was administered

\begin{tabular}{|l|l|l}
\hline BLOCK 2 \\
DEMOGRAPHIC VARIABLES \\
Ethnicity \\
Age
\end{tabular}

Note: The generic and discipline specific blocks were not significant for any of the six models.

\section{Figure 8: Final Conceptual Model to explain predictors of students' acquired level critical thinking skills using generic and discipline specific blocks}

\section{Research Question Four}

Research Question Four attempted to identify predictors for posttest critical thinking scores on the total and all five subscales utilizing the Not So Pure Posttest Sample. This model utilized continued to use the demographic block and control variables, it also included the new predictor blocks of student characteristics prior to entry into graduate school and student characteristics while in graduate school. The discussion of the results will be organized according to these blocks and will conclude with a comparison of this posttest model to the two previous predictor models (both pretest and posttest). 
The demographic block continued as a significant predictor for this group of models as well with significant results for the total as well as inference, analytic, deductive and inductive; however, gender was not a significant predictor for any of the models. White ethnicity continued as a significant predictor for total critical thinking, inference, deductive and inductive. Younger age was also a significant predictor for the total score and analytic and a trend for deductive and inductive.

The student characteristics at entry block was only significant for the evaluation subscale but only for the dummy coded major variable of psychology with a trend noted on sociology major. The other predictor variables of undergraduate GPA, months between undergraduate and graduate school, years of experience as well as type of undergraduate school were not significant predictors for any of these posttest models.

The student characteristics while in the program block was only significant for the evaluation subscale and then only for cumulative GPA. The other predictor variables in this block (type of program, mean hours worked per week and the critical thinking subscale) were not significant for any of these posttest models. The insignificant finding for the cumulative GPA predictor contradicts existing literature which indicates GPA at a variety of levels (high school, undergraduate and graduate) is a significant predictor of critical thinking skills (Facione, 1990a; Gadzella et al., 2002; Pascarella et al., 1993; Wilson, 2002). As a result of these analyses, the predictive model was amended to illustrate the significant predictors, as well as trends for each model, omitting those variables and/or blocks that did not significantly contribute. See Figure 9 for the final conceptual model for entry level critical thinking. 
The pretest and both posttest predictive models demonstrated significance or trends with the demographic block predictors of younger age and White ethnicity. Gender appears to be a predictor of four of the six pretest critical thinking models; however, it does not contribute to any of the posttest models. Of particular interest in the comparisons of these models is the significance of undergraduate GPA for the pretest models, yet both GPA variables in both posttest models are largely insignificant (aside from the posttest evaluation model for the prior to while in program model). It was expected based on the significance of GPA in the pretest models, as well as the previous literature supporting it as a significant predictor, that GPA would continue as a significant variable, at least with the cumulative GPA; however, this assumption did not hold true. This may be due to the lack of variability in graduate GPAs compared to undergraduate GPAs. See Table 56 for the descriptive for the Not So Pure Post Test model. The mean undergraduate GPA was $3.26(\mathrm{SD}=.41)$ and a range of 2.05 to 4.0 compared to the mean cumulative GPA of $3.70(\mathrm{SD}=.23)$ with a range of 3.03 to 4.0 . 


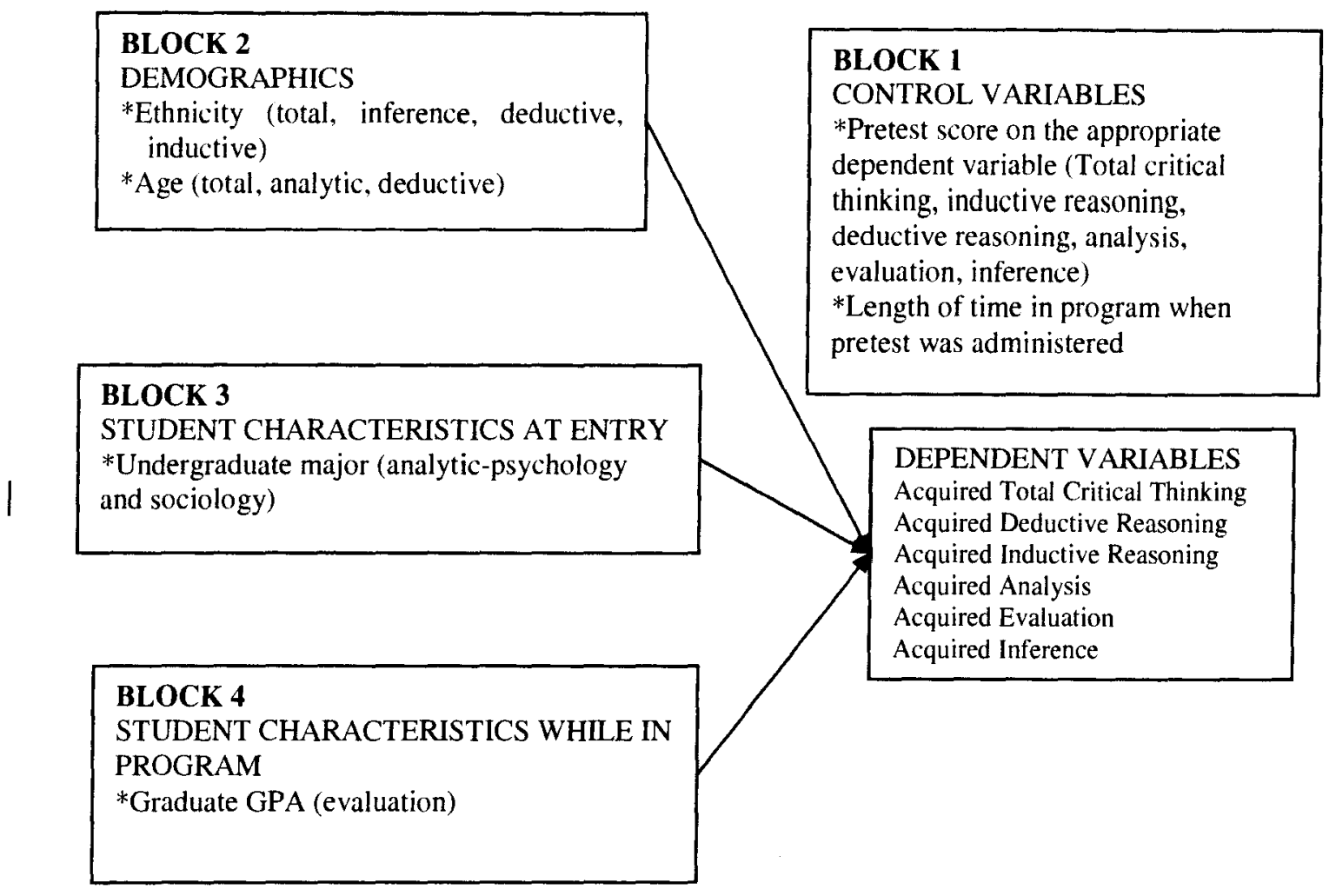

Figure 9: Final conceptual model to explain predictors of students' acquired critical thinking scores using prior to entry and while in program blocks

\section{Limitations}

This research was specifically designed to assess the obtainment of critical thinking skills for social work students who had completed a critical thinking infused curriculum, as well as test predictor models for entry level and acquired critical thinking skills for these students. Generalizability is a key limitation of this study in that researchers did not take a random sample of all graduate level social work students, utilizing instead students from Kent School of Social Work. These students may vary significantly from students attending smaller, private, and/or teaching focused schools from other geographical regions. 
The use of a generic critical thinking instrument was another potential limitation on two levels. One being that this instrument may have missed the social work specific components of critical thinking of particular interest in the current study and social work educators. The CCTST was designed to measure critical thinking skills without necessarily considering the discipline specific component of the concept. In addition, the generic quality of the CCTST may also have deterred students' participation in the assessment process, as they did not see the value of answering questions that did not have a social work foundation.

Lack of a comparison group was also a limitation of this study. Ideally, students' pretest and posttest critical thinking skills should have been assessed prior to reforming the curriculum to allow a comparison group after the curriculum changes were implemented. This comparison group would have allowed the researcher to make stronger claims as to how the critical thinking infused curriculum promoted change in students' critical thinking.

\section{Future Research}

There are a variety of suggestions for future research in regards to critical thinking skills of social work students/graduates. The ill-structured domain of critical thinking may be better served with predictor models which have variables specific to each subscale. In the current study, the researcher utilized the same predictor variables for the subscales as was used for the total critical thinking model; however, future research may want to review the literature and explore potential predictors' specific to the applicable subscale. In addition, this literature review may also provide insight for faculty in developing strategies to enhance students' critical thinking skills by learning more 
about each of the components to critical thinking as conceptualized by the CCTST (evaluation, analytic, inference, inductive and deductive), such as Leighton's (2006) article on how to teach and assess deductive reasoning skills or Watters and English's (1995) research on implications for developing scientific reasoning skills or Duroy's (Duroy, 1987) dissertation on the development of inductive and deductive reasoning for students in a nursing program.

Future research may also include the development and testing of a social work specific critical thinking instrument. There appears to be a trend in developing instruments custom designed to the needs of the particular discipline. Insight Assessment, the administrators of the CCTST, developed such discipline specific critical thinking instruments for health sciences and business. Previous research, which guided the selection of the discipline specific blocks, highlighted previous attempts to measure discipline specific critical thinking skills (Rane-Szostak \& Robertson, 1996; Staib, 2003; Williams et al., 2003). This research should be continued in social work with particular attention given to how critical thinking is operationalized within the profession. Considering CSWEs increased attention to the development of students' critical thinking skills in the new EPAS, it may even be beneficial to consider creating a group of social work experts to discuss and define critical thinking, within a social work context, similar to the process used by the Delphi group when the generic critical thinking definition was constructed.

Further research is needed to explore teaching strategies which optimize critical thinking development, specifically those geared to addressing the needs of a culturally diverse student population. This study did not have any variables which described 
specific learning strategies utilized in the courses and how this may have impacted critical thinking development. For example, the nursing profession has identified problem-based learning and concept mapping as effective strategies to promote critical thinking (Wheeler \& Collins, 2003; Yuan et al., 2008). Future research may want to explore these and others in regards to their effectiveness within social work practice. A qualitative study may also be beneficial by providing students with low and high pretest scores, the opportunity to describe their views on what teaching/learning strategies most impacted their critical thinking skill development, what were barriers to their critical thinking development, and what steps could be taken to enhance critical thinking skills. Additionally, a qualitative study regarding faculty members' experiences and suggestions for promoting the vertical and horizontal as well as potential instructional strategies.

There are additional variables that should also be explored that were not addressed in the current study. Specifically, previous research regarding predictors of students' critical thinking skills measured students' activities inside and outside of the classroom, i.e. number of hours spent studying, participation in professional clubs/organizations, volunteer hours (outside of practicum), engagement with other students, and faculty contacts (number of face to face meetings, email, etc.)(Gellin, 2003a; Terenzini et al., 1993).

\section{Social Work Implications}

The key findings that students with lower scores improve and higher scores decrease as well as ethnic differences occurring on posttests but not on pretests have implications for social work. The findings indicate the critical thinking infused curriculum does well at improving the critical thinking skills of students' with lower 
scores on the CCTST; however, does not adequately challenge those students who enter with high critical thinking skills. These findings support the previous argument that the infusion of critical thinking in a social work curriculum involves more than just the alignment and rewording of goals and objectives, but also requires the active participation of faculty to develop and enhance explicit critical thinking learning strategies across not only the curriculum as a whole, but also through each individual course. The fact that students with lower scores improved but those with higher scores did not further supports the idea that the curriculum has not reached full maturity in promoting the more complex levels of critical thinking. The findings are not sufficient enough to claim the curriculum is not effective, but that explicit learning strategies which target the more advanced skill development and application are needed. Cognitive Flexibility Theory could provide the framework for these learning activities as discussed in the literature review. Not only did the theory provide part of the underlying theoretical framework for the revision of the curriculum but it could also provide a theoretical framework for specific learning strategies aimed at providing students multiple opportunities to practice and develop the ill-structured domain of critical thinking skills providing diverse courses and settings.

As a profession that prides itself on the value of cultural diversity and equality for all groups, the differences between ethnic groups is quite concerning. Facione (1990c) found a similar pattern with gender in that there were no differences in pretest, but males scored higher at posttest. He hypothesized men and women gain critical thinking skills differently, which may also be applicable to the ethnic differences noted in the current study. There are similar implications for ethnicity in regards to all three of the predictor 
models in that ethnicity continued to be a consistently significant predictor of critical thinking skills at entry level, as well as upon completion of the critical thinking infused curriculum. This reiterates the importance of developing learning strategies that are not only geared towards improving critical thinking skills, but are also culturally sensitive and meet the educational needs of a diverse student body. Although challenging, it is still imperative that ethnic differences are minimized albeit eliminated in interfering with the obtainment of educational outcomes.

The predictor models in this study only explained a minimal amount of variance, aside from contribution of pretest scores and the length of time in program when pretest was administered. However, the implications of those social work specific variables that did not contribute: type of program (30 versus 60 hour program), undergraduate major, years of social work experience, graduate GPA, mean hours worked, social work selfefficacy as well as the critical thinking subscale of the self-efficacy instrument, is quite interesting. The lack of contribution made by these social work specific predictors may indicate the profession's novelty in cultivating critical thinking skills in students. It is not to say the profession does not have critical thinkers, but that there are still gains to be made in the development of this skill in students. This struggle is not isolated to social work, but in fact numerous professions, as well as colleges and universities are still working to develop innovative learning strategies to promote and enhance students' critical thinking skills.

\section{Conclusion}

Developing comprehensive educational assessment plans is a daunting process for institutions of higher education, particularly when administrators and faculty view it as a 
process solely for the purpose of the accreditation process. This project highlighted how the data gathered by Kent School of Social Work to address accreditation requirements can also be used to assess curriculum decisions and improve student learning. This study provided feedback regarding the influence of curriculum changes on the improvement of students' critical thinking and their confidence to perform social work skills and provided insight to factors that can predict student's critical thinking skills.

Although sizeable significant differences or percentage of variance explained are the primary goals of researchers, it is often the absence of these substantial findings which provides the most valuable insight into knowledge development, particularly in an exploratory research study such as this one. The knowledge gained from this study can serve as a basis for future research as social work educators and researchers strive to promote strong well-equipped critical thinkers for the social work profession. 


\section{REFERENCES}

Abu-Bader, S. H. (2006). Using Statistical Methods in Social Work Practice: A Complete SPSS Guide. Chicago, Ill.: Lyceum Books, Inc.

Adams, M. H., Whitlow, J. F., Stover, L. M., \& Johnson, K. W. (1996). Critical thinking as an educational outcome: an evaluation of current tools of measurement. Nurse Educator, 21(3), 23-32.

Adelman, C. (1987). War and peace among the words. The Journal of Higher Education, $58,371-403$.

Alexander, L. (1986). Time for results: an overview. Phi Delta Kapan, 68, 202-204.

Alexander, L. (1987). National Governors' Association report on education reform. The Education Digest, 52, 2-5.

Allen, M. J. (2004). Assessing Academic Programs in Higher Education. Bolston: Anker Publishing Company, Inc.

Angelo, T. (1999). Doing assessment as if learning matters most. American Association for Higher Education (AAHE).

Answers.com. (2007). Higher education curriculum: National reports on the undergraduate curriculum.

Austin, D. M. (1983). The Flexner myth and the history of social work. Social Service Review, 57(3), 357-377. 
Bangert-Drowns, R. L., \& Bankert, E. (1990). Meta-analysis of effects of explicit instruction for critical thinking. Paper presented at the Annual Meeting of the American Educational Research Association.

Banta, T. W. (2001). Making Difference. San Francisco: Jossey-Bass.

Banta, T. W. (2002). Building a Scholarship of Assessment. San Francisco: Jossey-Bass.

Banta, T. W. (2005). How much have we learned? BiEd, 35-38.

Banta, T. W., Lund, J. P., Black, K. E., \& Oblander, F. W. (1996). Assessment in Practice. San Francisco: Jossey-Bass.

Baranchik, A. C., B. (2002). Identifying gaps in mathematics preparation that contribute to ethnic, gender, and American/foreign differences in precalculus performance. The Journal of Negro Education, 71(4), 253-268.

Bloom, B. S. (Ed.). (1956). Taxonomy of Educational Objectives: Handbook 1: Cognitive Domain. New York: David McKay Company, Inc.

Boehm, W. M. (1959). Social Work Curriculum Study. New York: Council on Social Work Education.

Boger-Mehall, S. R. (1997). Cognitive flexibility theory: Implications for teaching and teacher education. Retrieved 05-15-07, from http://www.kdassem.dk/didaktik/14-16.htm

Bohr, L., Pascarella, E., Nora, A., Zusman, B., \& Jacobs, M. (1992). Cognitive effects of two-year and four-year colleges: a preliminary study (No. ERIC Document Reproduction Service No. ED357707). Washington, DC: Office of Educational Research and Improvement. 
Bresciani, M. J. (2005). Outcomes-Based Academic and Co-Curricular Program Review. Virginia: Stylus Publishing, LLC.

Burke, J. C., \& Minassians, H. P. (2002). The new accountability: From regulations to results. New Directions for Institutional Research, 2002(116), 5-19.

CAAP Technical Handbook 2007-2008, Assessing academic achievement in reading, writing, mathematics, science and critical thinking Available from http://www.act.org/caap/materials.html

Calgary, U. o. (2007). Evolution of Social Work.

Chaffee, J. (1994). Teaching for critical thinking. In D. Rane-Szostak \& J. F. Robertson (Eds.), Issues in measuring critical thinking: Meeting the challenge (Vol. 35, pp. 5-11). Journal of Nursing Education.

Cohen, J., Cohen, P., West, S. G., \& Aiken, L. S. (2003). Applied Multiple Regression/Correlation Analysis for the Behavioral Sciences (3rd ed.). Mahwah: Lawerence Erlbaum Associates.

Cokley, K. (2002). The impact of college racial composition on African American students' academic self-concept: A replication and extension. The Journal of Negro Education, 71(4), 288-296.

Collegiate Assessment of Academic Proficiency (2000). CAAP User's Guide. Iowa City: American Collegiate Testing.

Cornett, C. E. (1983). What you should know about teaching and learning styles. Phi Delta Kappa, Cook Inlet, AK (BBB21162). (ERIC Document Reproduction Service No. ED 228235) 
Cournoyer, B. R. (2001). Assessment of student learning in social work education: The Indiana model. Advances in Social Work, 2(2), 128-151.

Dewey, J. (1933). How We Think (2nd ed.). Lexington, MA: Heath Publishing.

Duroy, F. (1987). Determining the extent to which inductive and deductive reasoning skills are present at critical intervals in nursing programs. ProQuest Digital Dissertations, AAT: 8626943.

Ennis, R. H. (1989). Critical thinking and subject specificity: Clarification and needed research. Educational Research, 18(3), 4-10.

Ennis, R. H., Millman, J., \& Tomko, T. (1985). Cornell Critical Thinking Skills Tests Level $X$ and Level Z Manual (3rd ed.). Pacific Grove, CA: Midwest Publications.

Entwistle, N. (1981). Styles of Learning and Teaching. New York: John Wiley and Sons.

Erwin, T. D. (2000). The NPEC Sourcebook on Assessment, Volume 1: Definitions and Assessment Methods for Critical Thinking, Problem Solving, and Writing. Retrieved January 6, 2007. from http://nces.ed.gov/pubs2000/2000195.pdf.

Evans, C. J., Kirby, J. R., \& Fabriger, L. R. (2003). Approaches to learning, need of cognition, and strategic flexibility among university students. British Journal of Educational Psychology, 73, 507-528.

Ewell, P. T. (2002). Perpetual movement: Assessment after twenty uears. Paper presented at the National Assessment Institute.

Ewell, P. T. (2004). Can assessment serve accountability? In J. C. A. Burke (Ed.), Achieving Accountability in Higher Education: Balancing Public, Academic and Market Demands. San Francisco Jossey-Bass. 
Facione, P. A. (1990a). The California Critical Thinking Skills Test: College Level Technical Report \#2, Factors Predictive of CT Skills. Millbrae: The California Academic Press.

Facione, P. A. (1990b). The California Critical Thinking Skills Test: College Level, Technical Report \#1, Experimental validation and content validity Millbrae: The California Academic Press.

Facione, P. A. (1990c). The California Critical Thinking Skills Test: College Level, Technical Report \#4, Interpreting the CCTST, Group Norms and Sub-Scores. Millbrae: The California Academic Press.

Facione, P. A. (1990d). The California Critical Thinking Skills Test: College Level, Technical Report \#3, Gender, Ethnicity, Major, Self-Esteem and the CCTST. Millbrae: The California Academic Press.

Facione, P. A. (1990e). Critical Thinking: A Statement of Expert Concensus for Purposes of Educational Assessment and Instruction. Research Findings and Recommendations. Retrieved. from.

Facione, P. A. (2007). CCTST Form 2000 Compared to CCTST Form A Insight Assessment

Facione, P. A., Facione, N. C., \& Giancarlo, C. A. (2000). The disposition toward critical thinking: Its character, measurement, and relationship to critical thinking skill. Informal Logic, 20(1), 61-84.

Ficklen, E. (1986). Governors to school boards. The American School Board Journal, $173,31-32$. 
Field, A. (2005). Discovering Statistics Using SPSS (2nd ed.). Thousand Oaks: SAGE Publications, Inc.

Fisher, E. A. (2005). Facing challenges of outcomes measurement: The role of transformational leadership. Administration in Social Work, 29(4), 35-49.

Fitzgerald, G. E., Wilson, B., \& Semrau, L. P. (1997). An interactive multimedia program to enhance teacher problem-solving skills based on cognitive flexibility theory: Design and outcomes. Journal of educational Multimedia and Hypermedia, 6(1), $47-76$.

Fleming, J., Garcia, N., \& Morning, C. (1995). The critical thinking skills of minotiry engineering students: An exploratory study. The Journal of Negro Education, 64(4), 437-453.

Flexner, A. (2001). Is social work a profession. Research on Social Work Practice, 11(2), $151-165$.

Flynn, P. (1995). Global competition and education: another Sputnik? The Social Studies, 86(March/April 1995), 53-55.

Forest, K., \& Kinser, K. (2002). Higher Education in the United States: An Encyclopedia Frans, D. J. (1993). A scale for measuring social worker empowerment. Research on Social Work Practice, 3, 312-328.

Frumkin, M., \& Lloyd, G. L. (1995). Social work education. In R. L. Edwards (Ed.), Encyclopedia of Social Work (Vol. Vol. III, pp. 2238-2247). Washington, D.C.: NASW Press. 
Gadzella, B. M., Baloglu, M., \& Stephens, R. (2001). Validity and reliability of the Watson-Glaser Critical Thinking Appraisal for teachers. Paper presented at the Southwestern Psychological Association.

Gadzella, B. M., Baloglu, M., \& Stephens, R. (2002). Prediction of GPA with educational psychology grades and critical thinking scores. Education, 122(3), 618-623.

Gadzella, B. M., Hogan, L., Masten, W., Stacks, J., Stephens, R., \& Zascavage. (2006). Reliability and validity of the Watson-Glaser Critical Thinking Appraisal-forms for different academic groups. Journal of Instructional Psyhology, 33(2), 141143.

Gadzella, B. M., \& Masten, W. (1998). Critical thinking and learning processes for students in two major fields. Journal of Instructional Psyhology, 25(4), 256-261.

Gambrill, E. (2001). Evaluating the quality of social work education: Options galore. Journal of Social Work Education, 37(3), 418-429.

Garcia, J. A., \& Floyd, C. E. (2002). Addressing evaluative standards related to program assessment: How do we respond? Journal of Social Work Education, 38(3), 369382.

Gellin, A. (2003a). The effect of undergraduate student involvement on critical thinking: A meta-analysis of the literature 1991-2000. Journal of College Student Development, 44(6), 746-762.

Gellin, A. (2003b). The effect of undergraduate student involvement on critical thinking: A meta-analysis of the literature 1991-2000. Journal of College Student Sevelopment, 44(6), 746-762. 
Gibbons, J., \& Gray, M. (2004). Critical thinking as integral to social work practice. Journal of Teaching Social Work, 24(1/2), 19-38.

Godshalk, V. M., Harvey, D. M., \& Moller, L. (2004). The role of learning tasks on attitude change during cognitive flexibility hypertext systems. The Journal of the Learning Sciences, 13(4), 507-526.

Graddy, D. B. (2001). Cognitive Flexibility Theory as a Pedagogy for Web-Based Course Design. Paper presented at the Teaching Online in Higher Education Online Conference.

Greene, R. (2005). Redefining social work for the new millennium: Serring a context. Journal of Human Behavior in the Social Environment, 11(1), 37-54.

Grunwald, H., \& Peterson, M. W. (2003). Factors that promote faculty involvement in and satisfaction with institutional and classroom student assessment Research in Higher Education, 44(2), 173-205.

Guthrie, J. (Ed.). (2002). Encyclopedia of Education (2nd ed.). New York: Macmillan Reference USA.

Hadden, C., \& Davies, T. G. (2002). From innovation to institutionalization: the role of administrative leadership in the assessment process. Community College journal of Research and Practice, 26, 243-160.

Handbook of Accreditation Standards and Procedures. (2003). Alexandria: Council on Social Work Education.

Hanna, W. (2007). The new Bloom's taxonomy: Implications for music education. Arts Education Policy Review, 108(4), 7-16. 
Harden, R. M., \& Stamper, N. (1999). What is spiral curriculum? Medical Teacher, $21(2), 141-143$.

Hebel, S. (2006). Report card on colleges finds U.S. is slipping. The Chronicle of Higher Education, 53(4), A22-23.

Hoffman, K., \& Godenzi, A. (2007). Increasing our impact through unification. Journal of Social Work Education, 43(2), 181-185.

Holden, G., Anastas, J., \& Meenaghan, T. (2003). Determining attainment of the EPAS foundation program objectives: Evidence for the use of self-efficacy as an outcome. Journal of Education for Social Work, 39(3), 425-440.

Holden, G., Anastas, J., Meenaghan, T., \& Metrey, G. (2002). Outcomes of social work education: The case for social work self-efficacy. Journal of Education for Social Work, 38(1), 115-133.

Holden, G., Meenaghan, T., \& Anastas, J. (2005). EPAS objectives and foundation practice self-efficacy: A replication. Journal of Education for Social Work, 4l(3), $559-570$.

Hollis, E. V., \& Taylor, A. L. (1951). Forward, Preface and Chapters 1, 2, \& 3. In Social work education in the United States: The report of a study made for the National COuncil on Social Work Education

(pp. vii-152). Wesport, CT: Greenwood Press.

Holloway, S. (2005). Some suggestions on educational program assessment and continuous improvement: Council on Social Work Education, Commission on Accreditation. 
Holloway, S., \& Detlaff, A. (2006). A conversation about plans for revisions of the EPAS. Paper presented at the 52nd Annual Program Meeting of CSWE, Chicago, Illinois.

Holosko, M. J. (2003). The history of the working definition of practice Research on Social Work Practice, 13, 271-285.

Holstein, B., Zangrilli, B. F., \& Taboas, P. (2006). Standardized testing tools to support quality educational outcomes. Quality Management in Health Care, 15(4), 300308.

Hoyt, J. E. (1999). Performance funding in higher education. Retrieved May 2, 2007

Huba, M. E., \& Freed, J. E. (2000). Learner-Centered Assessment on College Campuses. Boston: Allyn and Bacon.

Ingle, C. I. (2007). Predictors of critical thinking ability among college students. ProQuest Digital Dissertations, UMI No: 3263681.

Jones, A. (2007). Multiplicities or manna from heaven? Critical thinking and the disciplinary context. Australian Journal of Education, 51(1), 84-103.

Jones, E. (1992). Is a core curriculum best for everybody? In J. Ratcliff (Ed.), Assessment and curriculum reform. Minneapolis: University of Minnesota Press.

Kearsley, G. (2006a). Cognitive Flexibility Theory. Retrieved November 13, 2006, from http://tip.psychology.org/spiro.html

Kearsley, G. (2006b). Constructivist Theory (J. Bruner). Retrieved June 5, 2007, from http://tip.psychology.org/bruner.html

Kearsley, G. (2006c). Genetic Epistemology (J. Piaget). Retrieved June 5, 2007, from http://tip.psychology.org/piaget.html 
Kearsley, G. (2006d). Subsumption Theory (D. Ausubel) Retrieved June 5, 2007, from http://tip.psychology.org/ausubel.html

Kearsley, G. (2006e). Symbol System (G. Salomon). Retrieved June 5, 2007, from http://tip.psychology.org/salomon.html

Kurfiss, J. G. (1988). Critical Thinking: Theory, Research, Practice \& Possibilities. Washington, D.C.: Association for the Study of Higher Education.

Lee, G. A. A. (2004). Cognitive Flexibility: The Theoretical Framework for Investigating the Effectiveness of Constructivist-Pedagogically-DesingedHypertext on Text Comprehension Learning Outcomes. Unpublished Dissertation, University of Louisville, Louisville.

Lee, M. J., \& Tedder, M. C. (2003). The effects of three different computer texts on readers' recall: based on working memory capacity. Computers in Human Behavior, 19(6), 767-783.

Leighton, J. P. (2006). Teaching and assessing deductive reasoning skills. Journal of Experimental Education, 74(3).

Lewis, C. (2004). The 1970s and American's Crisis of Confidence. In A. S. H. Page (Ed.): University of Colorado at Boulder.

Li, Q., \& Johnson, B. (2004). Diverse populations and cognitive flexibility theory: An instructional model. Educational Technology, 44(5), 55-58.

Loken, L. M. (2005). Critical thinking abilities of undergraduate entry-level athletic training students. ProQuest Digital Dissertations, UMI No. 3206235. 
Loo, R., \& Thorpe, K. (1999). A psychometric investigation of scores on the Watson-

Glaser Critical Thinking Appraisal new Form S. [watson-glaser]. Educational and Psychological Measurement, 59(6), 995-1003.

Lord, T., \& Baviskar, S. (2007). Moving students from informaiton recitation to informtion understanding: Exploiting Bloom's taxonomy in creating science questions. Journal of College Science Teaching, 36(5), 40-44.

Matthiesen, V., \& Wilhelm, C. (2006). Quality outcomes and program evaluation in nursing education. Quality Management in Health Care, 15(4), 279-284.

McPeck, J. E. (1990). Critical thinking and subject specificity: A reply to Ennis. Educational Researcher, 19(4), 10-12.

Meier, G., \& Thannert, N. (2006). Assessment results: How can the lead to curriculum changes? Paper presented at the National Assessment Institute, Indianapolis, Indiana.

Meyers, L. S., Gamst, G., \& Guarina, A. J. (2006). Applied Multivariate Research. Thousand Oaks, California: Sage Publications, Inc.

Mulcahy, K. V. (1986). The humanities and the failure of American. The Journal of Aesthetic Education, 20, 98-102.

NASW. (1996). NASW Code of Ethics, Washington, D.C.

A Nation At Risk. (1983). National Commission on Excellence in Education.

Neuman, K. M. (2003). Developing a comprehensive outcomes management program. Administration in Social Work, 27(1), 5-23.

Norris, S. P., \& Phillips, L. M. (1987). Explanations of reading comprehension: Schema theory and critical thinking theory. Teachers College Record, 89(2), 281-306. 
Osborne, J. W., \& Overbay, A. (2004). The power of outliers (and why researchers should always check for them). Practical Assessment, Research \& Evaluation, $9(6)$.

Palomba, C. A., \& Banta, T. W. (1999). Assessment Essentials. San Francisco: JosseyBass.

Palomba, C. A., \& Banta, T. W. (2001). Assessing Student Competence: In Accredited Disciplines. Virginia: Stylus Publishing, LLC.

Pascarella, E. T. (1989). The development of critical thinking: Does college make a difference? Journal of College Development, 30, 19-26.

Pascarella, E. T., Bohr, L., \& Nora, A. (1994). Cognitive effects of two-year and fouryear colleges: Some new evidence. Washington, DC: Office of Educational Research and Improvement.

Pascarella, E. T., Bohr, L., Nora, A., Zusman, B., Inman, P., \& Desler, M. (1993). Cognitive impacts of living on campus versus commuting to college. Journal of College Student Development, 34, 216-220.

Pascarella, E. T., \& Terenzini, P. T. (1991). How College Affects Students: Findings and Insights from Twenty Years of Research. San Francisco: Jossey-Bass.

Paul, R. (1992). Critical thinking: What every person needs to survive in a rapidly changing world (2nd ed.). Santa Rosa, CA: The Foundation for Critical Thinking.

Pearson, C. V. (1991). Barrier to success: Community college students critical thinking skills Santa Ana, CA. (ERIC Document Reproduction Service No. ED 340-415). 
Peebles-Wilkins, W., \& Shank, B. W. (2003). A response to Charles Cowger: Shaping the future of social work as an institutional response to standards. Journal of Social Work Education, 39(1), 49-56.

Phillips, C. R., Chestnust, R. J., \& Rospond, R. M. (2004). The California critical thinking instrument for benchmarking, program assessment and directing cirrucular change. American Journal of Pharmaceutical Education, 68(4), 1-8.

Pichert, J. W., \& Anderson, R. C. (1977). Taking different perspectives on a story. Journal of Educational Psychology, 69(4), 309-315.

Pinar, W. F. (2007, May 2007). Crisis, Reconceputalization, Internalization: U.S. curriculum theory since 1950, East China Normal University, Shanghai.

Plath, D., English, B., Connors, L., \& Beveridge, A. (1999). Evaluating the outcomes of intensive critical thinking instruction for social work students. Social Work Education, 18(2), 207-217.

Prawat, R. S. (1991). The value of ideas: The immersion approach to the development of thinking. Educational Researcher, 20(2), 3-10.

Principals of Accreditation: Foundations for Quality Enhancement. (2001). Southern Association of Colleges and Schools.

Puzon, B. (1994). Integrity in the College Curriculum. Liberal Education, 80(3), 14-21.

Rane-Szostak, D., \& Robertson, J. F. (1996). Issues in measuring critical thinking: Meeting the challenge. Journal of Nursing Education, 35, 5-11.

Rhodes, L. A. (1987). A tale of two reports. Educational Leadership, 44, 86-88. 
Rodriguez, G. (2000). Demographics and disposition as predictors of the application of critical thinking skills in nursing practice. ProQuest Digital Dissertations, UMI No. 3002095 .

Rubin, A., \& Babbie, E. R. (2008). Research Methods for Social Work (6th ed.). Belmont, CA: Thomson Higher Education.

Salomon, G. (1977). Interaction of Media, Cognition, and Learning. San Francisco: Jossey-Bass.

Schoenfield, A. H. (1987). What's all the fuss about metacognition? In A. H. Schoenfield (Ed.), Cognitive science and mathematics education. Hillsdale, New Jersey: Lawrence Erlbaum.

Scriven, M., \& Paul, R. (1992). Critical thinking defined Paper presented at the Critical Thinking Conference.

Seelig, J. M. (1991). Social work and the critical thinking movement. Journal of Teaching Social Work, 5(1), 21-34.

Singleton, J., R.A., \& Straits, B. C. (2005). Approaches to Social Research (4th ed.). New York: Oxford University Press.

Sisung, J. (2005). Relationship Between Standardized Critical Thinking Test Scores and Earned Grades in Coures Purported to Teach Critical Thinking at Kellogg Community College. University of Nebraska, Lincoln, NE.

Spiro, R. J., Collins, B. P., \& Ramchandran, A. (2006). Reflections on a post-gutenberg epistemology for video use in ill-structured domains: Fostering complex learning and cognitive flexibility. In R. Goldman, R. D. Pea, B. Barron \& S. Derry (Eds.), 
Video Research in the Learning Sciences. Mahwah, New Jersey: Lawrence Erlbaum Associates.

Spiro, R. J., Collins, B. P., Thota, J. J., \& Feltovich, P. J. (2003). Cognitive flexibility theory: Hypermedia for complex learning, adaptive knowledge application, and experience acceleration. Educational Technology, 43(5), 5-10.

Spiro, R. J., Coulson, R. L., Feltovich, P. J., \& Anderson. (1988). Cognitive Flexibility Theory: Advanced Knowledge Acquisition in Ill-Structured Domains. Paper presented at the Tenth Annual Conference of the Cognitive Science Society, Hillsdale, NJ.

Spiro, R. J., Feltovich, P. J., \& Coulson, R. L. (1991). Cognitive Flexibility Theory. Journal. Retrieved from http://www.personal.psu.edu/faculty/l/x/lxz135/INSYS525/cognitive.htm

Spiro, R. J., Feltovich, P. J., Jacobson, M. J., \& Coulson, R. L. (1991a). Cognitive flexibility, constructivism, and hypertext: Random access instruction for advanced knowledge acquisition in ill-structured domains. Educational Technology, 24-33.

Spiro, R. J., Feltovich, P. J., Jacobson, M. J., \& Coulson, R. L. (1991b). Knowledge representation, content specification, and the development of skill in situationspecific knoweldge assembly: Some constructivist issues as they relate to cognitive flexibility theory and hypertext. Educational Technology, 22-25.

Spiro, R. J., \& Jehng, J. C. (1990). Cognitive flexibility and hypertext: Theory and technology for the nonlinear and multidimensional traversal of complex subject matter. In D. Nix \& R. Spiro (Eds.), Cognition, Education, Multimedia: 
Exploring Ideas in High Technology. Hillsdale, New Jersey: Lawrence Erlbaum Associates, Inc.

Staib, S. (2003). Teaching and measuring critical thinking. Journal of Nursing Education, $42(11), 498-508$.

Tabachnick, B. G., \& Fidell, L. S. (2001). Using Multivariate Statistics (4th ed.). Boston: Allyn and Bacon.

Terenzini, P. T., Springer, L., Pascarella, E. T., \& Nora, A. (1993). Influences affecting the development of students' critical thinking skills. Paper presented at the Association for Institutional Research.

A Test of Leadership: Charting the Future of U.S. Higher Education. (2006). (Report of the Commission Appointed by Secretary of Education Margaret Spellings).

Trimbur, J. (1986). To reclaim a legacy, cultural literacy, and the discourse. Liberal Education, 72, 109-119.

Watson-Glaser Critical Thinking Appraisal. (2007). In I. Harcourt Assessment (Ed.), Harcourt Assessment, Inc. San Antonio, TX: Pearson Education, Inc.

Watson, G. B., \& Glaser, E. M. (1980). Watson-Glaser Critical Thinking Appraisal Manual. In B. M. Gadzella, M. Baloglu \& R. Stephens (Eds.), Prediction of GPA with educational psychology sgrades and critical thinking scores. San Antonio, TX: Psychological Corporation.

Watson, G. B., \& Glaser, E. M. (1994). Watson-Glaser critical thinking appraisal Form $S$ manual. San Antonio, TX.

Watters, J. J., \& English, L. D. (1995). Children's application of simultaneous and successive processing in inductive and deductive reasoning problems: 
Implicaitons for developing scientific skills. Journal of Research in Science Teaching, 32(7), 699-714.

Wheeler, L. A., \& Collins, S. K. (2003). The influence of concept mapping on critical thinking in baccalaureate nursing students. Journal of Professional Nursing, 19(6), 339-346.

Williams, R. L., Oliver, R., Allin, J. L., Winn, B., \& Booher, C. S. (2003). Psychological critical thinking as a course predictor and outcome variable. Teaching of Psychology, 30(3), 220-223.

Williams, R. L., Oliver, R., \& Stockdale, S. (2004). Psychological versus generic critical thinking as predictors and outcome measures in a large undergraduate human development course. The Journal of General Education, 53(1), 37-58.

Wilson, K. W. (2002). The relationship of the critical thinking skills of college students in selected southern baptist colleges to a specified set of variables. ProQuest Digital Dissertations, UMI No. 3070753.

Wolanin, T. R. (2003). Reauthorizing the Higher Education Act. Retrieved. from http://eric.ed.gov/ERICDocs/data/ericdocs2/content storage 01/0000000b/80/27/ dc/71.pdf.

Yorke, M., \& Knight, P. T. (2006). Curriculua for economic and social gain. Higher Education, 51, 565-588.

Yuan, H., Kunawiktikul, W., Klunkin, A., \& Williams, B. A. (2008). Improvement of nursing students' critical thinking skills through problem-based learning in the People's Republic of China: A quasi-experimental study. Nursing and Health Sciences, 10, 70-76. 
Zygmont, D. M., \& Schaefer, K. M. (2006). Assessing the critical thinking skills of faculty: What do the findings mean for nursing education. Nursing Education Perspectives, 27(5), 260-268. 


\section{APPENDIX A \\ Kent School Curriculum Description}

The main premise of the curriculum is to provide strategies for students to learn challenging materials, to encourage flexibility in the use of knowledge, and to change the underlying ways of thinking. At the end of their studies students will achieve a deeper, more complex understanding of social work, they will be able to critically evaluate and contemplate the material while experimenting with the flexible application of the knowledge in a variety of contexts. This higher order of thinking that will be developed and promoted with the curriculum is referred to as critical thinking.

This curriculum philosophy responds well to social work as an ever changing and evolving profession that responds to new knowledge on the radically changing needs and demands of society. It is impossible for any curriculum to address each problem or case example that social work graduates may face in their practice.

Development of cognitive flexibility provides avenues and rolls for students to integrate their learning experiences in such a way as to maximize their potential to meet the demands of the profession upon graduation. The curriculum is designed to enhance students' ability to enable diverse client systems to make decisions that contribute to the quality and health of their clients. The focus will also be on decisions that promote social justice. The curriculum is designed to graduate professional social workers who think critically about what they do, why they do it, and what outcomes they hope will result from their social work practices. 
Critical thinking is defined as "the intellectual disciplined process of actively and skillfully conceptualizing, applying, analyzing, synthesizing, and/or evaluating information gathered from, or generated by, observation, experience, reflection, reasoning, or communication, as a guide to belief or action" (Scriven \& Paul, 2004).

Critical thinking includes specific skills such as problem-solving and the ability to integrate knowledge from multiple disciplines and theories of human behavior. Throughout the curriculum, there is an emphasis on critical reflection, or appraisal of various points of view no matter what the source. The curriculum draws heavily on social science knowledge and integrates this with problem-solving phases such as assessment, intervention and evaluation. In this respect, the curriculum is designed to teach students to access, integrate, and assess practice and policy related research to solve social problems and to work towards social justice. When critical thinking skills are used effectively, it leads to transparency and promotes social change, particularly with and on behalf of vulnerable and oppressed individuals and groups of people.

Bruner's spiral curriculum format (1991) is used to implement the above mentioned cognitive flexibility philosophy in the development of higher order critical thinking skills. With this format, topics are revisited throughout the curriculum, while increasing the level of difficulty, complexity and depth of the area and linking new knowledge or information to previous levels of learning on this same topic to increase the competency of the students. Students will be introduced in the foundation curriculum to different strategies for developing critical thinking. In the advanced curriculum they will move towards a higher level of complexity in their thinking in that will be required to analyze problems from multiple perspectives (clients, practice, wisdom, and research), 
evaluate multiple sources of evidence, and address complex issues and problems incorporating multiple level forces on client systems.

The undergraduate BSW and MSSW foundation curricula promote a generalist perspective in which the simultaneous impact of many systemic levels (individuals, families, groups, organizations, and communities) on clients' lives is critically analyzed and recognized. The foundation builds upon a liberal arts base that fosters an understanding of society as a complex organization of diverse people and ideas. Social problems are understood as occurring within the nexus of cultural, conflictual, developmental, ecological, and systems' forces and as such, efforts to help or intervene must include consideration of these forces. Students will be able to critically identify and assess social problems, specifically attending to (a) how such problems are maintained, (b) how they impact the quality of peoples' lives, (c) a cultural sensitivity and appreciation of marginalized people, (d) how to actively promote social and economic justice. In the foundation year, the focus is on the development of critical thinking skills in all of these areas.

The advanced curriculum seeks to develop the utilization and application of critical thinking on all levels--in reading professional writing and research, in students' practicum, in the classroom, and in the students' own thinking. Consistently monitoring the ethics of their practice, evaluating theoretical principles and epistemologies, and utilizing technological advances become basic practice patterns. Specific skill sets developed include:

1) Creating, organizing and integrating ideas and action for engaging diverse client systems effectively in change; 
2) Assessing, conceptualizing and analyzing theoretical, practice and research problems from multiple perspectives and utilizing critical thinking skills to formulate impressions based upon the data;

3) Analyzing, synthesizing and evaluating the evidence available to guide advanced social work practice;

4) Synthesizing, formulating and implementing a plan of action for social work practice that addresses complex issues and problems, builds consensus and incorporates multiple-level forces on client systems;

5) Analyzing and evaluating data of client progress and outcomes and assessing implications and consequences of this progress and outcomes;

6) Synthesizing, creating, and organizing ideas from theory, research and practice for social justice; and

7) Demonstrating the ability to integrate culturally competent skills into all aspects of social work practice.

These skills will be used to actively pursue social change, particularly with and on behalf of vulnerable and oppressed client systems. Students will learn how to become leaders in social change efforts focused primarily on issues of health, poverty, discrimination, interpersonal conflict, and other forms of human suffering and social injustice.

To assist graduates in their future professional careers, these skills are organized around three practice foci: a) children and families, b) health and mental health, and c) community and international practice. These domains provide opportunities for students to focus on clustered learning within the context of these fields of practice. Recognizing 
that the employment of students after graduation is often a function of geography and personal circumstances, the school allows students the programmatic option of combining interests and focus areas.

While curricular options exist for students to develop a certain subject-matter expertise, the recognition of the School that it needs to prepare students more broadly places the principal focus of the concentration work on (a) high-level critical thinking about social work engagement and (b) the translational knowledge and skills that support the graduates' movement from one field of practice to another. Once students learn how to learn and how to think about social work practices, and understand the components of ethical practice and the responsibility to increase specific field-to-practice expertise, they will be better equipped to practice in a world where knowledge changes and transforms what we do on a rapidly accelerating course ("Approved Curriculum Design", 2007, p. 1$3)$. 


\title{
APPENDIX B
}

\author{
Kent School of Social Work \\ Master of Science in Social Work \\ Pretest Assessment
}

\section{Critical Thinking Skills and Self-Etficacy}

As part of our accreditation requirements and to meet our interest in continuous quality improvement, we need to measure student leaming outcomes. Kent School decided to locus on critical thinking and self-efficacy as two of our outcomes we want to measure with a prepost test design

We are inviting you to participate in this pretest about your critical thinking skills with a standardized critical thinking skills test. We also want to explore your perceived self efficacy as thelates to core social work tasks.

In order to compare different groups of students. we meed some basic demographic information about vou. The test is anonymous and the analysis will orly be done on the grotup lovel. We do however request that you use your University iD as your identification number. so that we can compare pre and posttest restits. We also request that you use the following group numbers: if you are a 60 hour student, use the group number oot. If you are a 30 hour student, use the group number oo?

As you participate we ask that you first read the instructions for the critical thinking test very carefully, then complete the timed test, and when you are done, complete the selt-efficacy questionnaire. The knowledge ganed trom this survey will help Kent School to improve our surrculum. Thank you for your time!!

Sincerely

Office of the Dean

Kent School of Social Work

Instructions for the Critical Thinking Test

Please read the instructions very carefully:

1. Use the pencif provided to you by the instructor. DO NOT USE A PEN

2. Do NOT put your name on the test

3. Your identification number is your sfudent ID.

4. Your group number is 001 if you are in the 60 hour program and 002 if you are in the 30 hour program.

Complete tha demographic questions.

Do not open the booklet or begin the test until you are told to

7. You have 45 minutes to complete the 34 questions in the booklet.

8. Do not write in the booklets. Blank paper is available in the test booklet.

9. Whon done, return the booklet and the response form to your instructor and complete the self-efticacy sumey. 


\section{Social Work Selt-Efficacy Scale (Gary Holden, DSW)}

We want to know how confident you are in your ablity to peiform specific sochal work tasks. After you consider tach ask bedse rate you confidence in your abiity to pertom that task successtuly, by arding the number from 0 to 100 that best describes your level of confidence. What we mean here by sucesstuly, is trat you wouct be able to pertorm the soccific task in a manner that a social work superisor would consider excollent. The phrases above the mumbers [0 Can not do at all: 50 Moderately certain can do and 100 - Centain can dol are only guides. You can use these nimpers or any of the rumbers a beween to describe your level of contidence. We want to know how confident you are that you could successfully perform these tasks today.

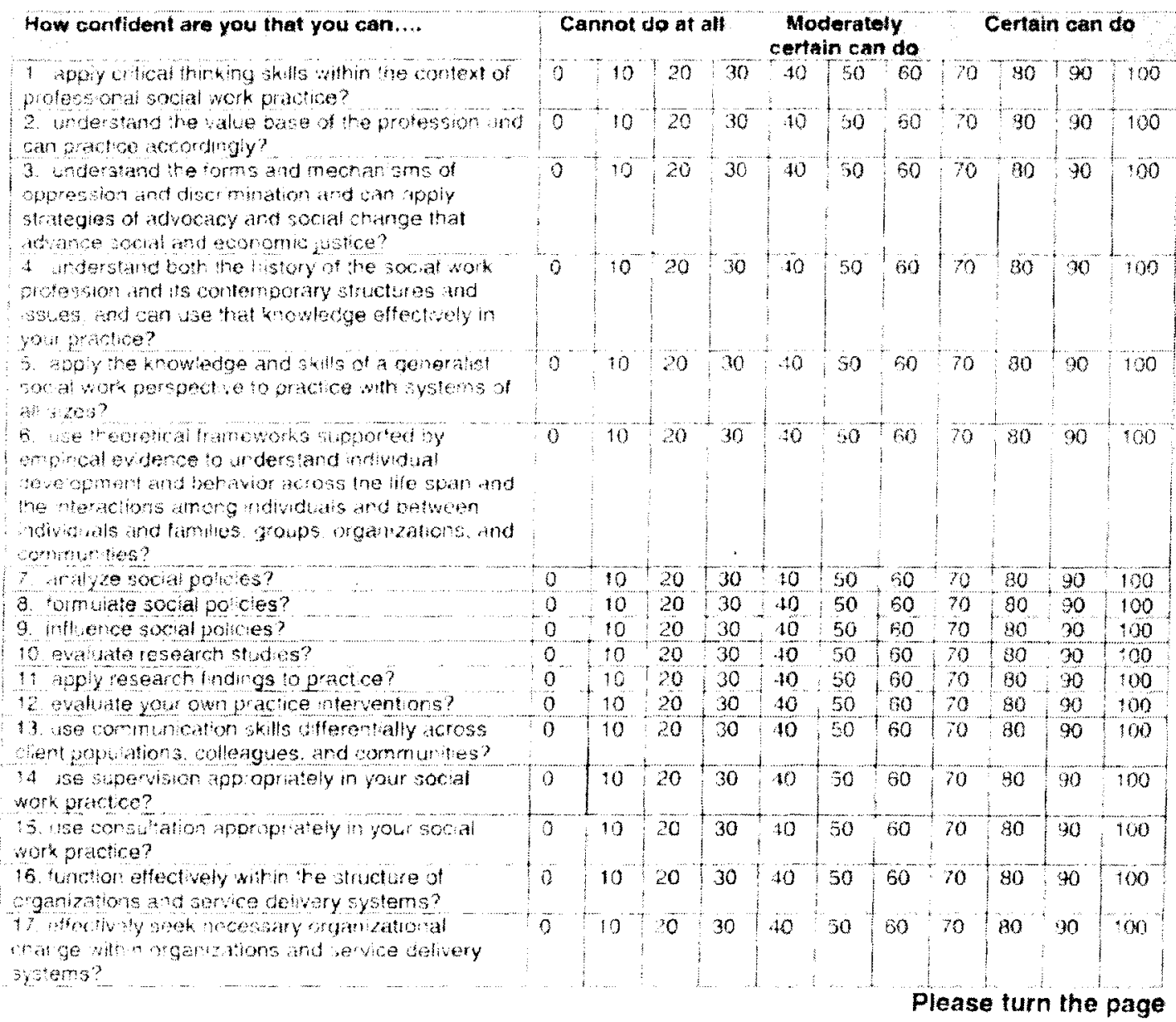




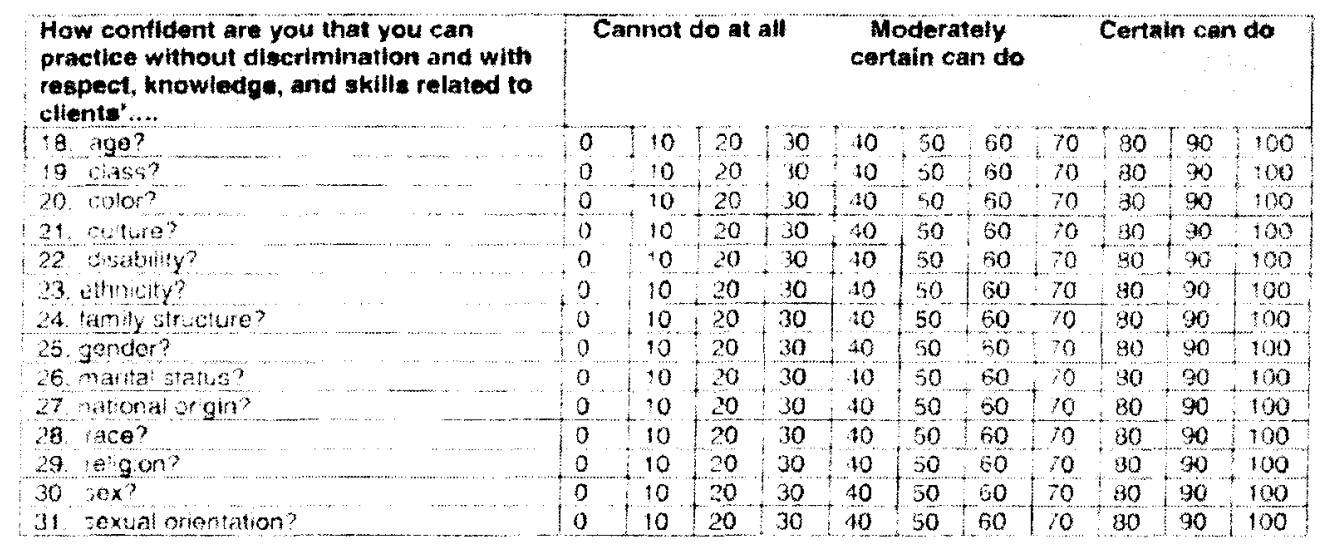

Please tell us about yourself:

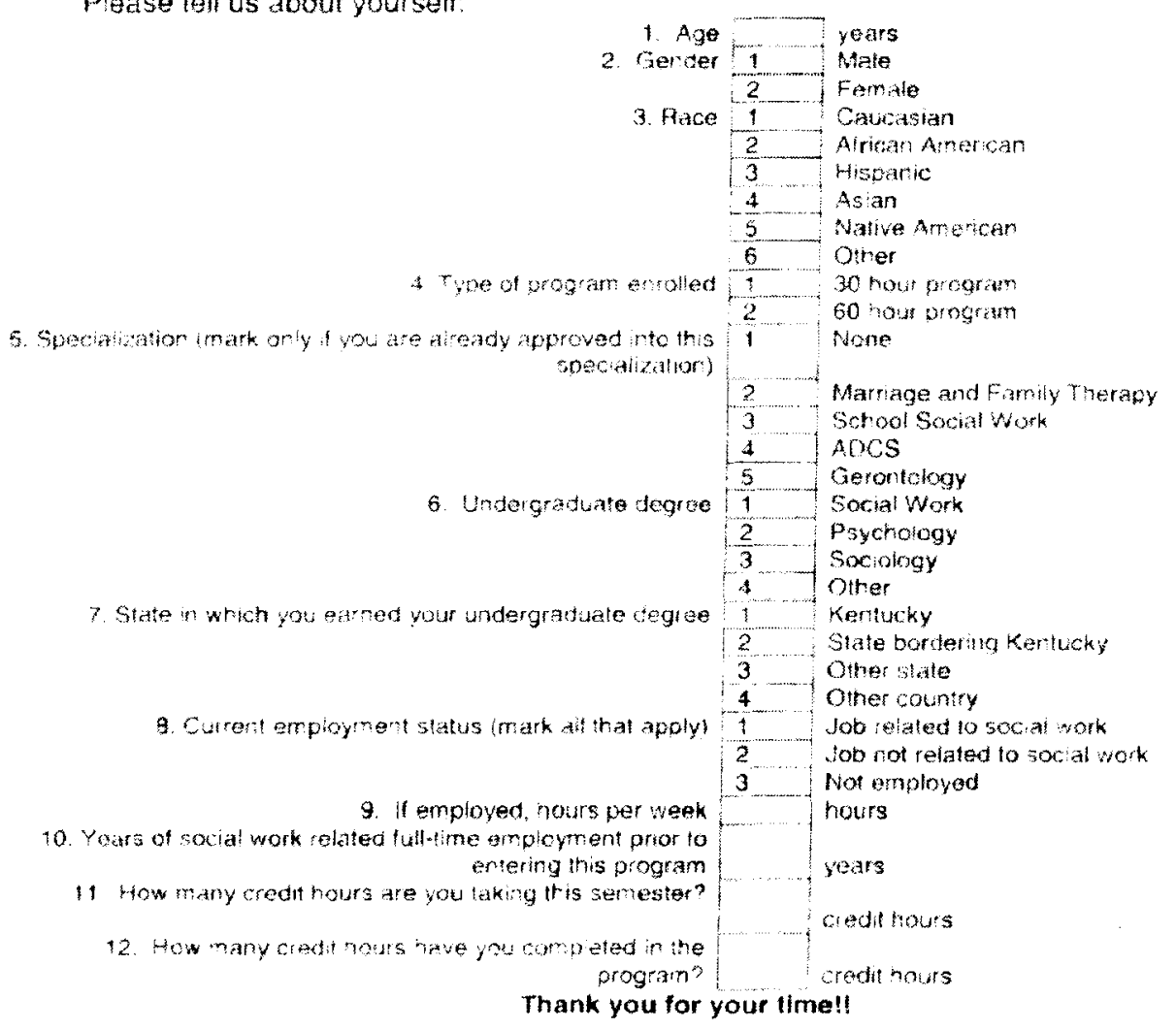




\title{
APPENDIX C
}

\author{
Kent School of Social Work \\ Master of Science in Social Work \\ Posttest Assessment
}

\section{Critical Thlnking Skills and Self-Efficacy}

\begin{abstract}
As part of our accreditation requirements and to meet our interest in continuous quality improvement, we need to measure student laming outcomes. Kent School decicted to focus on critical thinking and self-efficacy as wo of our outcomes we want to measure with a prepost test design
\end{abstract}

We are inviting you to participate in this posttest about your critical thinking skills with a stardardized critical thinking skills test. We also want to explore your perceved self-ellicacy as it relates to core social work tasks both retrospectively the way you perceive your sell.etticacy was at the beginning of the progtam) and at the end of your education kent.

In order to compare diferent groups of students, we need some basic demographic intormation about you. The test is anonymous and the analysis will only be done on the group level. We tequest that you use five zeros and the last four dights of your Social Security Number as your dentitication number, so that we can compare pre and postlest results. We also request that you use the following group number: 002.

As you participate. we ask that you first read the instructions for the critical thinking test very carefully, then complete the timed test, return the packet to your instructor when you are done. and then pick up the self elficacy packet and complete. The knowedge gained from this survey will help Kent School to improve our curriculum. Thank you for your time!!

Sincoraly

Office of the Dean

Kent School of Social Work

\section{Instructions for the Critical Thinking Test}

Please read the instructions very carefully:

1. Use the pencil provided to you by the instructor. DO NOT USE A PEN.

2. DO NOT put your name on the test.

3. Your identification number is five zeros followed by the last four digits of your SSN

4. Vour group number is coe.

5. Complete the dermographic questions.

6. Do not open the booklet or begin the test until your instructor tells you to.

7. You have 45 minutes to complete the 34 questions in the booklet.

8. Do not write in the booklets. Blank paper is available upon request from your instructor.

9. When tone return the booklet and the response fom to your instrictor and complete the second packet on self africacy. 


\section{Social Work Self-Efficacy Scale (Gary Holden, DSW) RETROSPECTIVE ASSESSMENT}

We wat to know how confiden you too va were at the start of your graduate studles at kent in



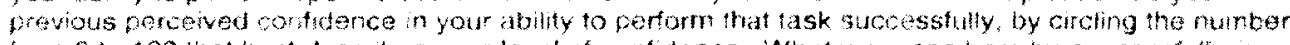
from 0 to 100 that best describes your lovel of confidence. What we maan here by successhuly, is that you wouto be whe to perform the spewtic fask in a manner that a sotal work superwisor would consider excellent. The phrases above me rumbers 10.6 an not do at all: 50 -Moderately centain an rio: and $100=$ Coman can dol are only gudes. You can use these mumbers or any of the numbars in bistween to descrbe your sevel of confidonce. We want to know how confident you were that you could successfully perform these tasks at the start of your graduate studies.

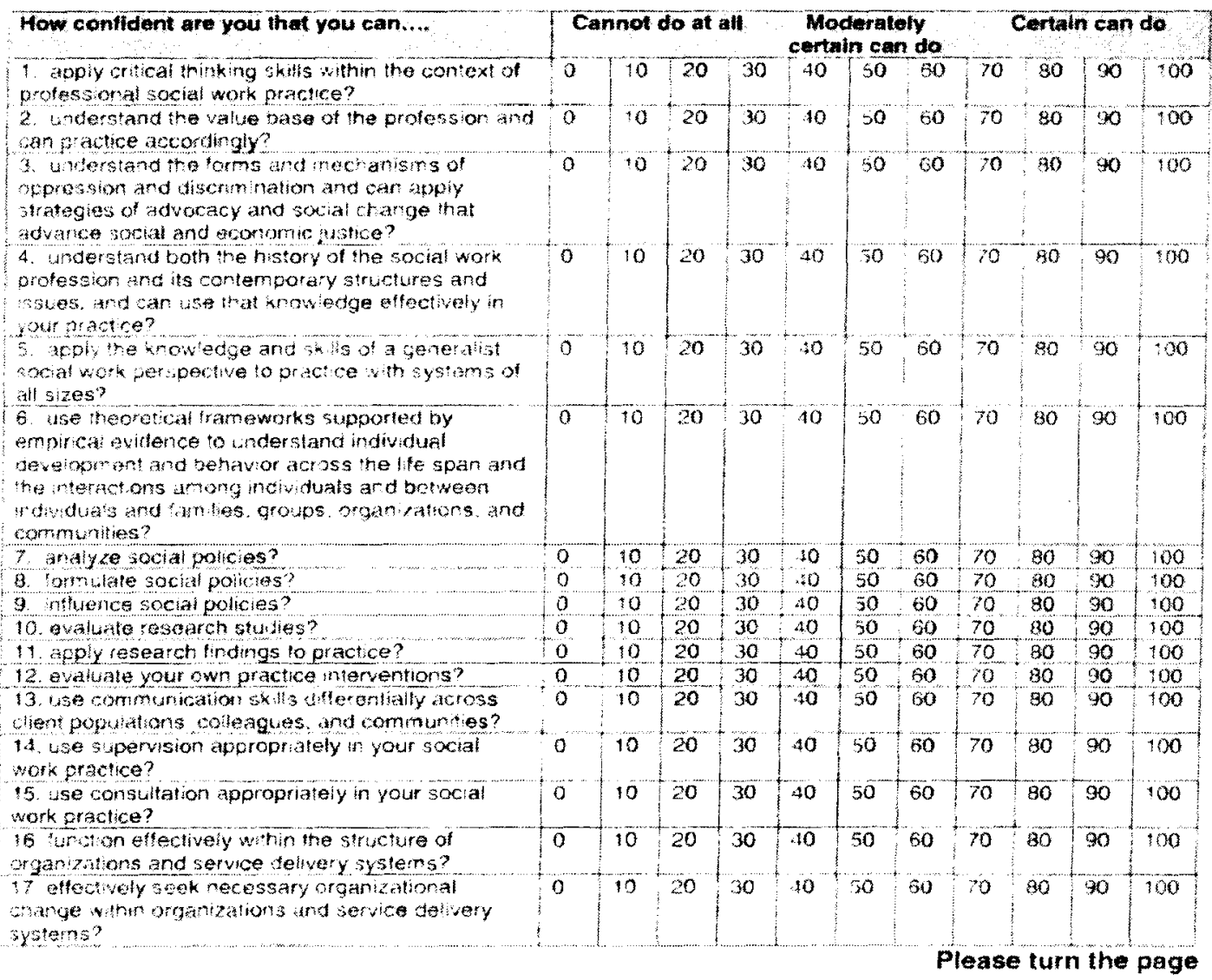




\begin{tabular}{|c|c|c|c|c|c|c|c|c|c|c|c|}
\hline $\begin{array}{l}\text { How contident are you that you can } \\
\text { practice without dlecrimination and with } \\
\text { respect, knowledge, and skills related to } \\
\text { cllents... }\end{array}$ & \multicolumn{4}{|c|}{ Cannot do at all } & \multicolumn{3}{|c|}{$\begin{array}{l}\text { Moderately } \\
\text { certain can do }\end{array}$} & \multicolumn{4}{|c|}{ Certain can do } \\
\hline ig age? & 0 & 10 & 20 & 30 & 10 & 50 & $n 0$ & 70 & 80 & 90 & 100 \\
\hline 19. ltss? & 0 & 10 & 20 & 30 & .10 & 30 & 60 & 70 & 80 & 90 & $\$ 00$ \\
\hline 20 agor? & 0 & 10 & 20 & 30 & 40 & 50 & 50 & 70 & 80 & 90 & 100 \\
\hline 21 ruture? & 0 & 10 & 20 & 30 & 10 & 50 & 60 & 70 & $B O$ & 30 & 100 \\
\hline 22. Tsabiry? & 0 & 10 & 20 & 30 & 10 & 80 & 50 & 70 & 80 & 30 & 10 \\
\hline 23. othncity? & 9 & 10 & 20 & 30 & 10 & 50 & 60 & 70 & 80 & 30 & 100 \\
\hline 24 tamly stucture? & 0 & 10 & 20 & 30 & 10 & 50 & 60 & 70 & 30 & 90 & 100 \\
\hline 25 gantar? & 0 & 10 & 20 & 30 & 10 & 50 & 60 & 70 & 80 & 30 & 100 \\
\hline as nartal status? & 0 & 10 & 20 & 30 & 40 & 50 & 60 & 70 & 90 & 90 & 100 \\
\hline 27 nationalorgin? & 0 & 10 & 20 & 30 & 10 & 50 & 60 & 10 & 30 & $\$$ & $\$ \infty$ \\
\hline 28 race? & 0 & 10 & 20 & 30 & 10 & 50 & 60 & 70 & 30 & 90 & 100 \\
\hline 29. religlon? & 0 & 10 & 20 & 30 & 10 & 50 & 60 & 70 & 80 & 90 & 100 \\
\hline 30 sex? & 0 & 10 & 20 & 30 & 40 & 50 & 60 & 20 & 90 & 90 & 100 \\
\hline 31. Sxual rientrion? & 0 & 10 & 20 & 30 & 40 & 50 & 60 & 70 & 80 & 90 & 100 \\
\hline
\end{tabular}




\section{Soclal Work Self-Efficacy Scale (Gary Holden, DSW) POST ASSESSMENT}

We want to know how confident you are at the end of your graduate studies in your ablity to pertorm specific social work lasks. After you consider aach task, ploase rate your confidence in your atwity to pertom that task successfully. by circling the number from 0 to 100 that best describes your tevel of contuence. What we mean here by successfully, is that you would be able to perfonn the soectic lask in a mamer that a social work supervisor would consinter exedtent. The phrases above

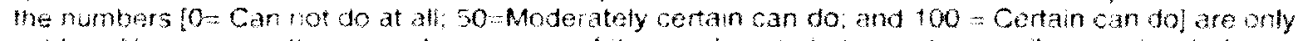
guides. You can use these numbers or any of the numbers in betmeen to describe you level of confidence. We want to know how confident you are that you could successfully perform these tasks today.

\begin{tabular}{|c|c|c|c|c|c|c|c|c|c|c|c|}
\hline \multirow{2}{*}{ 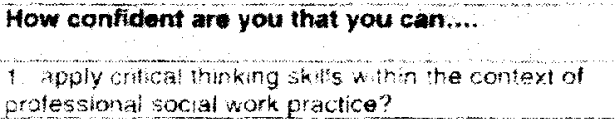 } & \multicolumn{4}{|c|}{ Cannot do at all } & \multicolumn{3}{|c|}{$\begin{array}{l}\text { Moderately } \\
\text { certain can do }\end{array}$} & \multicolumn{4}{|c|}{ Certain can do } \\
\hline & 0 & 10 & 20 & 30 & 10 & 50 & 60 & 70 & 80 & 190 & 100 \\
\hline $\begin{array}{l}\text { 2. inferstand the value base of the protession and } \\
\text { car practce acoordingly? }\end{array}$ & 0 & 10 & 20 & 30 & 40 & 50 & 60 & 70 & 80 & 90 & 100 \\
\hline  & 0 & 10 & 20 & 30 & 40 & 30 & 50 & 70 & 90 & 90 & 100 \\
\hline 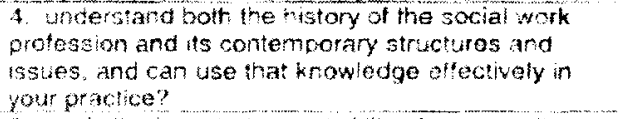 & 0 & 10 & 20 & 30 & 40 & $50^{\circ}$ & 60 & 70 & 30 & 90 & 400 \\
\hline 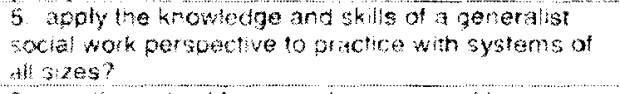 & 0 & 10 & 20 & 30 & 40 & 50 & 90 & 70 & 30 & 30 & 100 \\
\hline 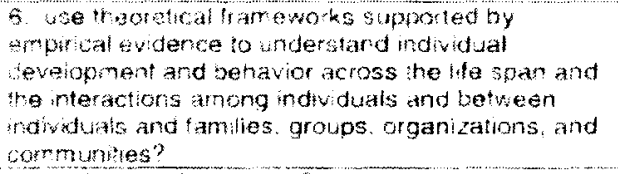 & 0 & 10 & 20 & 30 & 40 & 30 & 60 & 70 & 90 & 30 & 100 \\
\hline 7 andyes social polcos? & 0 & 10 & 20 & 30 & 10 & 50 & 60 & 70 & 80 & 90 & 100 \\
\hline a monvate sociat policles? & 0 & 10 & 20 & 30 & 40 & 50 & 60 & 70 & 80 & 30 & 100 \\
\hline 9 mbence socal poicies? & 0 & 10 & 20 & $30^{\circ}$ & $\$ 0$ & 90 & 60 & 70 & 80 & 90 & 100 \\
\hline 13 waluale sesarch zludes? & 0 & 10 & 20 & 30 & 40 & $60^{\circ}$ & 60 & 70 & 90 & 90 & 100 \\
\hline 11 apply research findings to praclice? & 0 & 10 & 20 & 30 & 40 & 50 & 60 & 70 & 20 & 30 & 100 \\
\hline 12. evaluate your own practice interyentions? & 0 & 10 & 20 & 30 & 40 & 50 & 60 & 70 & 90 & 90 & 100 \\
\hline 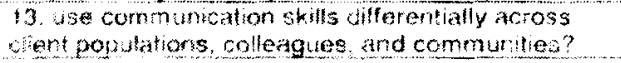 & $\theta$ & 10 & 20 & 30 & 40 & 50 & 60 & 79 & 80 & 90 & 100 \\
\hline $\begin{array}{l}\text { T4. use auperision approplately in you social } \\
\text { woth pracuco? }\end{array}$ & 0 & 10 & 20 & 30 & 40 & 50 & 60 & 70 & 180 & 90 & 100 \\
\hline $\begin{array}{l}15 \text { use corsultation appropriately in y ut social } \\
\text { work praftce? }\end{array}$ & 0 & 10 & 20 & 30 & 10 & 50 & 60 & 70 & $B O$ & 90 & 100 \\
\hline $\begin{array}{l}\text { 6. tumction effectively whin the structure of } \\
\text { organizations and service de very systems? }\end{array}$ & 0 & 10 & 20 & 30 & .10 & 50 & 60 & 70 & 80 & 90 & 100 \\
\hline $\begin{array}{l}\text { 7 eftectively seek necessary organizational } \\
\text { ohange whin organizations and service delivery } \\
\text { systems? }\end{array}$ & 0 & 10 & 20 & 30 & 10 & 50 & 60 & 70 & 80 & $90^{\circ}$ & 100 \\
\hline
\end{tabular}




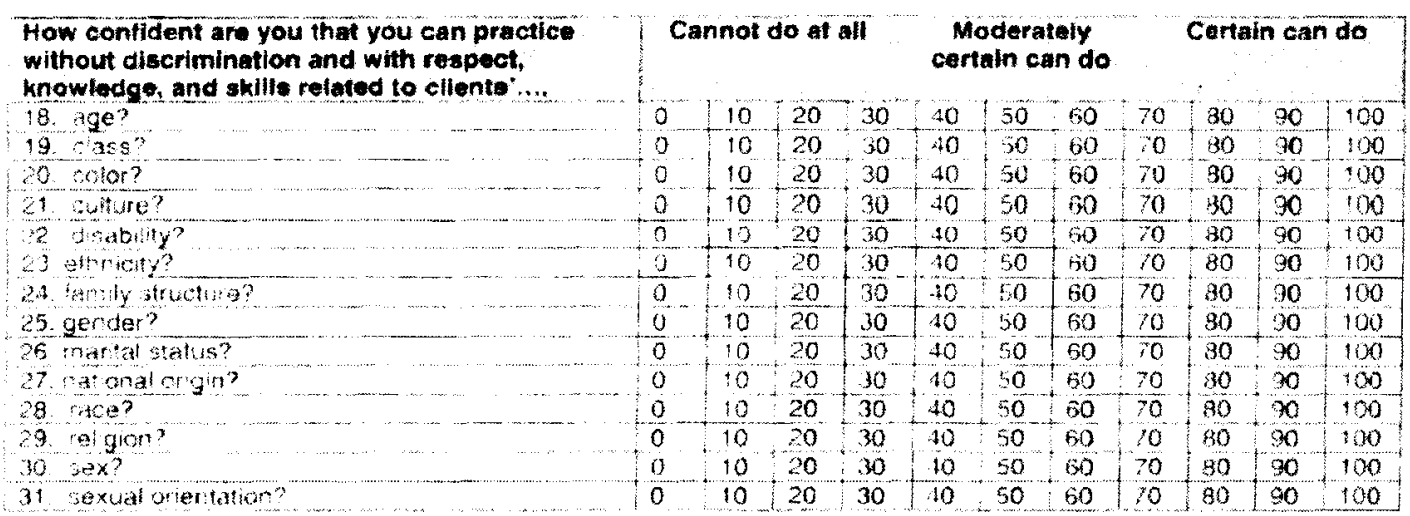

Please tell us about yourself:

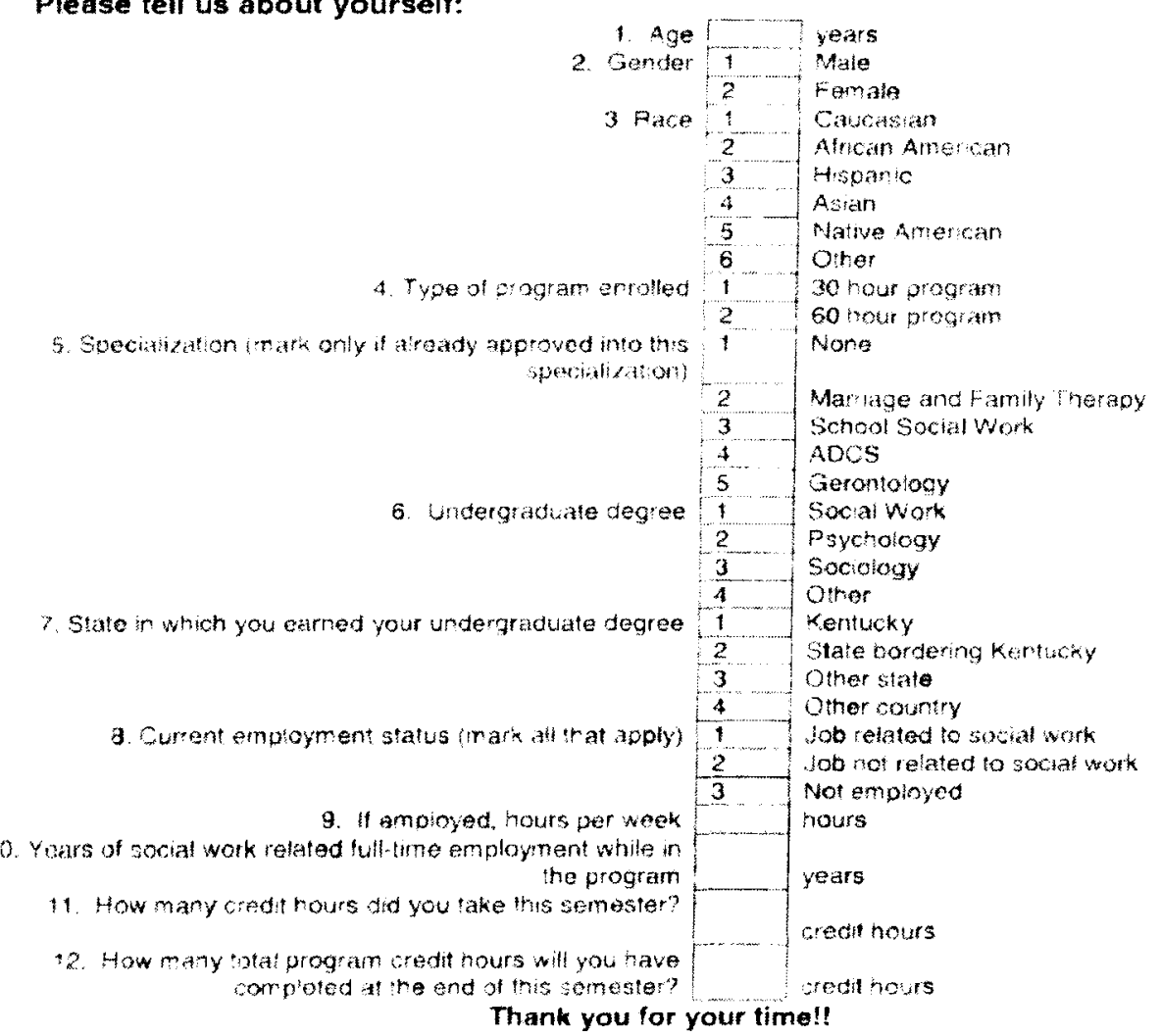




\section{CURRICULUM VITA}

Tonya Michelle Tucker

112 Mayfield Drive, Campbellsville, KY 42718

270-789-4104

michelle.tucker@louisville.edu

\section{EDUCATION}

Kent School of Social Work

University of Louisville, Louisville, $K Y$

Ph.D. in Social Work

2008.

Dissertation: "Predictors of Critical Thinking as a Component of an Outcomes Assessment in a Graduate level School of Social Work"

Kent School of Social Work

University of Louisville, Louisville, $K Y$

MSSW

Campbellsville University, Camplellsville, $K Y$

BSW

\section{AWARDS}

- Staff Person of the Year by Lake Cumberland Foster Parent Assoc.

\section{TEACHING EXPERIENCE}

Carver School of Social Work

Camphellsville University, Campbellsville, $K Y$

\section{Associate Professor}

Kent School of Social Work

University of Louisville, Louisville, $K Y$

Instructor - SW 604 Social Work Practice I

Kent School of Social Work

University of Louisille. Louisville, $K Y$

Teaching Practicum- SW 766 Doctoral Preparation

\section{RELATED EXPERIENCE}

Kent School of Social Work

University of Louisville, Louisville, KY

Research Assistant

Assisted the Associate Dean of Academic Atfairs in preparation for CSWE reaccreditation process, to include attendance at Outcomes and Curriculum Committee meetings, gathered research to support and guide curriculum reform process and data analysis. 
Kent School of Social Work

University of Louisville, Louisille, $K Y$

IRB Research Assistant

2005-2006

Assisted Kent faculty in processing research proposals through the university's IRB by writing proposals, editing submissions, completing the necessary forms and providing feedback to facilitate prompt approval.

Cabinet for Health and Family Services, Camphellsville. $K Y$

Social Service Clinician I

1999.2005

Provided professional social work services to individuals/families through the assessment of allegations of abuse/neglect of children, spouses and/or adults. Prepared District and Circuit Court reports, expert testimony at court hearings and monitored the conditions set by the court. Member of interdisciplinary team and conducted guardianship assessments. Data entry, records maintenance, conducted home visits, assessed the need for services and provided ongoing family based services. Served as Chief for approximately two years which included supervisory responsibilities when FSOS was out of the office. Also served as Interim FSOS for a period of approximately 8 months.

\section{Practicum Supervisor}

2003-current

Served as a practicum supervisor for students from the BSW program at Campbellsville University and Western Kentucky University, as well as the MSW programs from University of Kentucky and University of Louisville during their placement at the Cabinet for Health and Family Services. Responsibilities included assisting students develop goals and objectives for their learning agreements, monitoring progress at the placement to ensure optimal learning opportunities, conducted midterm and final evaluation of students' performance, assisted student in overcoming barriers to learning.

\section{COMMUNITY INVOLVEMENT}

- Chairman for the Lake Cumberland Region Foster Care Review Board

* Board member for Taylor County Federal Emergency Management Agency (FEMA)

\section{PROFESSIONAL PRESENTATIONS}

" Singer, T., Faul, A. \& Tucker, M. (2008). Critical Thinking in Social Work Education: Model of Rigorous Application and Assessment. Council for Social Work Education Annual Program Meeting in Philadelphia, PA.

\section{MEMBERSHIPS}

* Council on Social Work Education

* Society for Social Work and Research

\section{REFERENCES}

Dr. Annatjie Faul

Associate Dean of Academic Affairs

Kent School of Social Work

University of Louisville

Oppenheimer Hall Room 114

Louisville, KY 40242

502-852-1981 (work)

actanlof whouisville.edu

\section{Dr. Ruth Huber}

Director of Doctoral Program

Kent School of Social Work

University of Louisville

Patterson Hall

Louisville, KY 40242

502-852-0435 (work)

ruth hubur(a)louisville edu 
Dr. Seana Golder

Kent School of Social Work

University of Louisville

Patterson Hall

Louisville. Kentucky 40252

502-852-0432

sogoldo2 a louisville.edu 